\title{
Risk for psychosis : a life span perspective
}

\author{
Citation for published version (APA):
}

van der Werf, M. (2011). Risk for psychosis : a life span perspective. [Doctoral Thesis, Maastricht University]. Maastricht University. https://doi.org/10.26481/dis.20110513mw

Document status and date:

Published: 01/01/2011

DOI:

10.26481/dis.20110513mw

Document Version:

Publisher's PDF, also known as Version of record

\section{Please check the document version of this publication:}

- A submitted manuscript is the version of the article upon submission and before peer-review. There can be important differences between the submitted version and the official published version of record.

People interested in the research are advised to contact the author for the final version of the publication, or visit the DOI to the publisher's website.

- The final author version and the galley proof are versions of the publication after peer review.

- The final published version features the final layout of the paper including the volume, issue and page numbers.

Link to publication

\footnotetext{
General rights rights.

- You may freely distribute the URL identifying the publication in the public portal. please follow below link for the End User Agreement:

www.umlib.nl/taverne-license

Take down policy

If you believe that this document breaches copyright please contact us at:

repository@maastrichtuniversity.nl

providing details and we will investigate your claim.
}

Copyright and moral rights for the publications made accessible in the public portal are retained by the authors and/or other copyright owners and it is a condition of accessing publications that users recognise and abide by the legal requirements associated with these

- Users may download and print one copy of any publication from the public portal for the purpose of private study or research.

- You may not further distribute the material or use it for any profit-making activity or commercial gain

If the publication is distributed under the terms of Article $25 \mathrm{fa}$ of the Dutch Copyright Act, indicated by the "Taverne" license above, 


\section{Colophon}

ISBN | 978-90-5335-392-9

Graphic Design | Marinus van der Werf

Print and production| Ridderprint (Ridderkerk)

Copyright | Margriet van der Werf, Maastricht 2011

All rights reserved. No part of this thesis may be reproduced, stored or transmitted in any way or by any means without the prior permission of the author or, when appropriate, from the publishers of the publications. 


\section{RISK FOR PSYCHOSIS}

\section{A Life Span Perspective}

PROEFSCHRIFT

Ter verkrijging van de graad van doctor aan de Universiteit Maastricht, op gezag van de Rector Magnificus, Prof. Mr. G.P.M.F. Mols, volgens het besluit van het College van Decanen, in het openbaar te verdedigen op 13 mei 2011 om 14:00

door

Margriet van der Werf

Geboren op 6 mei 1981 te Arnhem 


\section{PROMOTORES}

Prof. dr. J.J. van Os

Prof. dr. F.R.J. Verhey

\section{CO-PROMOTOR}

Dr. R. van Winkel

\section{BEOORDELINGSCOMMISSIE}

Dr. Ph. A.E. G. Delespaul

Prof. dr. M.W. de Vries (voorzitter)

Prof. dr. D.H. Linszen (Universiteit van Amsterdam)

Prof. dr. I. Myin-Germeys

Prof. dr. M. Vandenbulcke (UZ Leuven)

South Limburg Mental Health and Teaching Network, PhD series. The research described in this thesis was performed in the School for Mental Health and Neurosciences (MHeNS), and the department of Psychiatry and Neuropsychology, Maastricht University Medical Centre, Maastricht, the Netherlands.

Publication of this thesis was financially supported by : Lundbeck B.V., Servier Nederland Farma B.V., Astra Zeneca and Janssen-Cilag B.V.
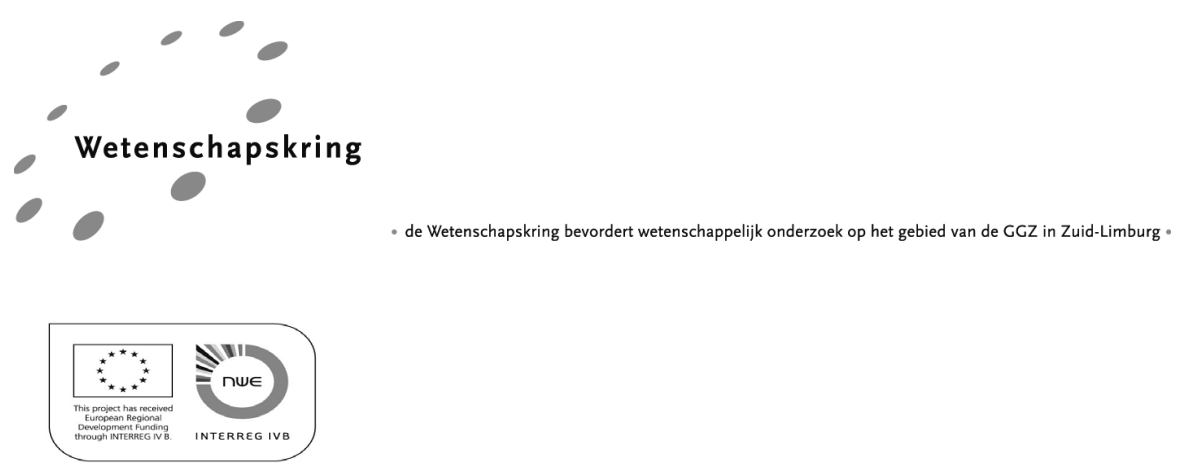
Links en rechts het donker

van de gekte en de dood

onder je en voor een

net nog zichtbaar spoor van licht

waarop je balanceren moet

Je voeten voet voor voet;

Je spreidt je armen wijd;

Je lichaam richt zich op in wankel evenwicht

En als ik val neem ik een sprong

Ik sla mijn armen heftig wijd

En schreeuw mijn schreeuw door het heelal

Misschien dat ik nog vleugels krijg

Maar liever heb ik iemand

Heb ik iemand om mij

lemand om mij op te vangen als ik val

de Koorddanser - Marinus van der Werf

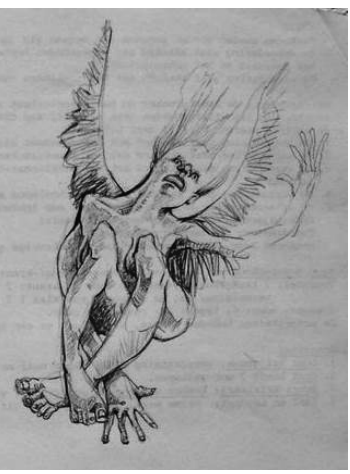




\section{PARANIMFEN}

Mart Bles

Petra Habets 


\title{
CONTENTS
}

\author{
Page \\ 9 \\ CHAPTER 1 \\ General introduction \\ 23 \\ CHAPTER 2 \\ Sex differences in schizophrenia risk across the age span: an individual participant \\ meta-analysis of 117,000 cases. \\ 67 \\ CHAPTER 3 \\ Cognitive functioning and age at onset in non-affective psychotic disorder. \\ 87 \\ CHAPTER 4 \\ Mild hearing impairment and psychotic experiences in a normal aging population. \\ 103 CHAPTER 5 \\ Adolescent psychosis as an outcome of hearing impairment in a 10-year \\ longitudinal study. \\ 125 CHAPTER 6 \\ Evidence that the impact of hearing impairment on psychosis risk is moderated by \\ the level of complexity of the social environment. \\ 143 CHAPTER 7 \\ General discussion \\ 169 \\ Summary • Samenvatting \\ 179 \\ Dankwoord \\ 183 \\ Curriculum Vitae \\ 185 \\ List of publications
}



Psychotic disorders, such as schizophrenia, are severe and often debilitating mental conditions characterized by a marked distortion in the perception of reality. The most salient features include positive psychotic symptoms (hallucinations and delusions) and negative symptoms (e.g. affective flattening or blunting, alogia, avolition and anhedonia). Besides these traditionally acknowledged symptoms, affective symptoms and neurocognitive impairments have been increasingly acknowledged as prominent characteristics of psychotic disorder. However, schizophrenia is a heterogeneous condition, with striking variability in phenomenology, course and outcome among affected individuals.

All or nothing? - Schizophrenia afflicts approximately $0.4 \%$ of the population throughout the world (Saha et al., 2005). However, symptoms that characterize patients with psychosis, such as delusional thinking and hallucinations are relatively common in apparently healthy people (van Os et al., 2009). The majority of these psychotic phenomena are transitory and do not lead to need for care. However, there is also evidence that in some people they may precede a diagnosis of psychotic disorder and hospital admission for schizophrenia by many years (Cougnard et al., 2007, Dominguez et al., 2009). In addition, most of the risk factors for clinical psychosis also correlate with the risk for such psychotic symptoms in the general population (Johns et al., 2004). Taken together, this suggests that psychosis is expressed on a continuum of increasing severity, rather than being a dichotomous or "all or nothing" phenomenon. Hence, to increase our understanding of the mechanisms underlying risk for schizophrenia, research should extent its scope well beyond the clinical expressions of psychosis. 
The fascinating phenomenology of psychosis has always drawn the attention of researchers, yet the pathophysiology and etiology of psychosis remains largely unknown. Variations in rate of occurrence of a disorder over time, place and in person may provide important clues to the origin and nature of a given disorder. Incidence, i.e. the estimated annual number of first-onset cases in a defined population at risk, is of great importance for risk-factor epidemiology. Incidence estimates can be interpreted in terms of probability of disease occurrence in a given population. Further, incidence rates are temporally close to the antecedents or precipitants of the disease (Jablensky, 1997). In a recent systematic review that pooled estimates from all suitable studies, the incidence of schizophrenia was estimated to be 15.2 per 100.000 persons per year (McGrath et al., 2004). More interestingly, this review demonstrated considerable variation between lowest and highest incidence rates among studies. Part of this variation in risk can probably be attributed to systematic bias, methodological differences and insufficient accounting for confounding factors. However, real variation across populations is undoubtedly present. The most consistent observation in schizophrenia epidemiology, however, is the striking variation in risk by age and sex.

Risk by age - The incidence for psychosis typically peaks during late adolescence or early adulthood and declines with increasing age (Hafner et al., 1993a, Verdoux et al., 1998). Hence, it has been postulated that adolescence constitutes a critical period of vulnerability for the expression of psychosis (Weinberger, 1987). However, the expression of subclinical psychotic symptoms or even psychotic disorder is not confined to early in life and first manifestations later in life may be more common than previously thought (Castle et al., 1997, Kohler et al., 2007). Schizophrenia and related psychotic disorders can emerge at any time between childhood and old age, from childhood schizophrenia up to the first presentation of schizophrenia at age 100 (Cervantes et al., 2006). However, the 
classification of psychotic disorders with late-onset has been fuzzy and inconsistent over time leading to a great variety of definitions, constituting symptoms and age cut-offs. To stimulate research and to ameliorate the consistency of used definitions for late-onset psychosis over studies, a consensus was reached on how to classify psychotic disorders across the age of onset span (Howard et al., 2000). The following three different onset groups were distinguished: (i) early-onset schizophrenia with age of onset before 40 years (ii) late-onset schizophrenia with onset between 40 years and 60 years and (iii) very-late-onset-schizophrenia like psychosis with onset at 60 years and older. Despite this consensus, few studies have specifically examined risk for psychotic disorders at the extreme ends of the life cycle. Consequently, valid estimates of the age-specific risk well beyond the early critical period of psychosis vulnerability are lacking.

Risk by sex - Risk for psychosis does not only vary by age, there is also considerable variation by sex. In fact, sex differences in schizophrenia risk are one of the most well established findings in schizophrenia epidemiology. Men typically have a four to five years earlier age of onset than women (Angermeyer and Kuhn, 1988). Further, the age of onset distribution curves for schizophrenia are not isomorphic, i.e. men and women have different age of onset distributions. Risk for schizophrenia in men typically peaks in early adulthood and then shows a steady decline by age. In contrast, the incidence peak in women is slightly delayed compared to men and the decline in risk by age is less pronounced. Finally, there is evidence for a female overrepresentation of psychosis with first manifestation in late life. The age of onset distribution by sex is presented in figure 1. Sex differences in age of onset are often regarded as an indicator of an underlying sex-linked biological mechanism of schizophrenia (DeLisi, 1992). However, there is evidence that sex differences may be influenced by environmental factors. For example, some studies have failed to replicate the sex difference in age onset 
(Folnegovic-Smalc et al., 1990, Folnegovic and Folnegovic-Smalc, 1994, Murthy et al., 1998). Moreover there is evidence for a reversed gender effect in parts of the population in India, thus women showing an earlier age of onset than men (Gangadhar et al., 2002). Further, sex differences in age of onset are absent in patients with a positive family history (Esterberg et al., 2010) and are attenuated when controlling for marital status and premorbid personality, suggesting that inadequate controlling for confounding factors may partly underlie the observed gender differences in age of onset (Jablensky and Cole, 1997).

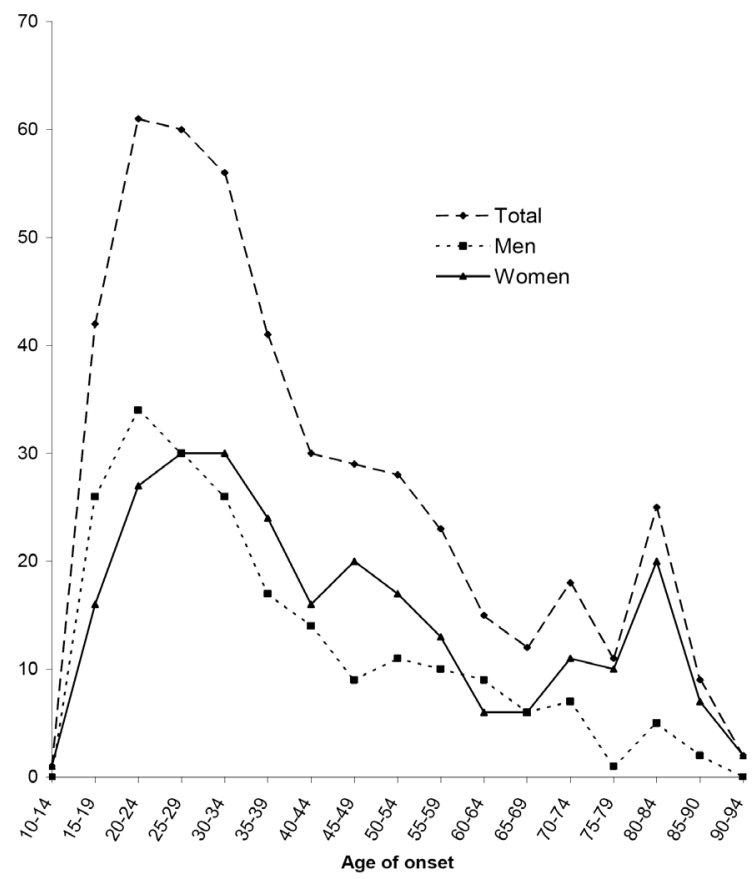

Figure 1. Age of onset distribution for non-affective psychotic disorder by sex (Kohler et al (2009), pp 226-32). 


\section{AETIOLOGY OF PSYCHOSIS ACROSS THE LIFE SPAN}

The aetiology of psychosis is complex and heterogeneous. Understanding the origins of these variations in risk by age may yield important clues about the etiological underpinnings of schizophrenia and related disorders (DeLisi, 1992). Genetic factors and environmental exposures, and most likely the combination of both, will modulate the timing of psychosis onset (van Os et al., 2008). Some of the factors that have been found to precipitate an earlier age of onset include family history of schizophrenia (Suvisaari et al., 1998, Esterberg et al., 2010), male gender (Angermeyer and Kuhn, 1988), obstetric complications (Verdoux et al., 1997), cannabis abuse and poor premorbid social and occupational adjustment (Vourdas et al., 2003). These factors may act at different periods of life to increase the vulnerability for psychosis. Overall, the onset of psychosis probably represents the convergence of multiple pathogenetic paths.

Genes or environment? - Family and twin studies have consistently shown a high degree of heritability of schizophrenia, suggestive of an important genetic component (Cannon et al., 1998, Cardno et al., 1999). However, the concordance rate for schizophrenia in monozygotic twins is no greater than $50 \%$ although they share $100 \%$ of their genes, and about $60 \%$ of all persons with schizophrenia have neither a first- nor second-degree relative with psychotic disorder (Gottesman and Erlenmeyer-Kimling, 2001). The expression of vulnerability for psychosis may become overt when exposures to environmental factors trigger the expression of psychosis (van Os et al., 2008). The combination of genetic liability and exposure to environmental hazards, or gene-environment interactions, may partly explain the observed heterogeneity in age of onset. When genetic vulnerability for psychosis is high, few environmental influences may be necessary to trigger the onset of psychosis. However, when 
vulnerability is low, multiple or prolonged exposure to risk factors may be needed to develop psychosis. Thus, the accumulation of exposure to environmental risk factors across the age span in combination with low or absent genetic liability may delay the onset of psychosis to later in life. This view is supported by studies showing that the relatives of patients with late-onset schizophrenia do not have an increased risk of developing schizophrenia (Pearlson et al., 1989, Howard et al., 1997).

Disorder of neurodevelopment? • It is generally believed that schizophrenia is a neurodevelopmental disorder. Different conceptualizations exist, but basically this model posits that schizophrenia is the behavioral outcome of neurodevelopmental aberration that begins long before the first onset of symptoms (Feinberg, 1982, Weinberger, 1987, Murray et al., 1992). Evidence stems from many lines, including the observation that individuals who later develop schizophrenia are more likely than healthy comparison subjects to have experienced pre- or perinatal adverse events (i.e. hypoxia and infection) or to have been exposed to potentially harmful stressors (i.e. maternal stress) (Rapoport et al., 2005). Further, early developmental delays in several social, neurological and cognitive domains have been found in young people who later develop schizophrenia (Cannon et al., 2002). Finally, post mortem studies of patients' brains have failed to show typical signs of neurodegenerative disorder (Bertolino et al., 1998). Taken together, there is considerable evidence to support a neurodevelopmental origin of schizophrenia, at least for early-onset schizophrenia.

Disorder of neurodegeneration? - Whereas schizophrenia with onset early in life may be the consequence of aberrant brain development during fetal and neonatal life, considerable debate exists about the origins of schizophrenia and other non-affective psychotic disorders with first onset in late life. Generally, the argument goes that the later the onset of psychosis, the less likely a neurodevelopmental etiology, and it is assumed 
that psychotic symptoms observed in the elderly are early manifestations of neurodegenerative disorder (van Os et al., 1993, Riecher-Rossler et al., 2003). Indeed, late-life psychotic phenomena can be the result of underlying neurodegenerative pathology. For example, approximately $50 \%$ of the patients presenting with dementia of the Lewy Body type (Borroni et al., 2008) and 30\% of patients with Alzheimer's disease (Bassiony and Lyketsos, 2003) show psychotic symptoms. Although neurocognitive decline can trigger the onset of psychotic symptoms, previous work that studied the risk of developing dementia in late-onset psychoses yielded inconclusive results (Brodaty et al., 2003, Laks et al., 2006). Along the same line, it remains unclear whether age of onset impacts on the nature and severity of the cognitive impairment in psychotic disorders. Although it is widely accepted that schizophrenia and related psychotic disorders are characterized by a generalized cognitive deficit (Heinrichs and Zakzanis, 1998), considerable variation in severity and pattern of impairments between patients has been shown (Joyce et al., 2005). It has hence been suggested that age of onset may also contribute to this observed cognitive heterogeneity, yet previous work has yielded inconclusive results. Some studies reported more severe learning and memory impairments in patients with an earlier age of onset (Tuulio-Henriksson et al., 2004), whereas others suggested equal levels of cognitive impairment over the age span (Heaton et al., 1994, Jeste et al., 1995, Sachdev et al., 1999). The latter observation suggests neurobiological continuity of the cognitive deficit in psychosis by age of onset and would thus argue against pure neurodegenerative etiology of late-life psychosis. Therefore, other potential causes for the onset of psychosis in late life should be considered.

Specific risk factors in late life? - As has been outlined above, one of the most salient features of late-onset psychosis is the marked overrepresentation of women. The excess of women with late-onset 
psychotic disorder has often been ascribed to the protective effects of estrogen (Hafner et al., 1993b, Seeman, 1996). The estrogen hypothesis postulates that the anti-psychotic properties of estrogen on dopamine- $D_{2}$ receptors delay the expression of psychosis vulnerability (Kulkarni et al., 2008). When the production of estrogen is reduced during menopause, the loss of this protective effect may lead the expression of psychosis. However, the decrease in protection by estrogen will be expected to have the most forceful effect on psychosis expression close to the timing of the menopause and not well beyond this period. Thus, it seems unlikely that the estrogen hypothesis can account for the relative high proportion of women with very-late-onset schizophrenia-like psychosis, but suggests that other risk factors might be at work. Among such putative risk factors are social isolation (Rodriguez-Ferrera et al., 2004) and sensory deprivation, especially hearing impairment (Cooper and Curry, 1976, Stein and Thienhaus, 1993). Both conditions are highly prevalent among the elderly. Yet, whereas much of the older work has focussed on hearing impairment as risk factor in the elderly (Cooper, 1976, Cooper and Curry, 1976), more recent work has suggested that hearing impairment is associated with increased risk for psychosis in young rather than in old people (Thewissen et al., 2005, Stefanis et al., 2006). Overall, late-onset psychosis may represent a final common pathway of various disease processes of different etiology including hormonal changes, differential exposure to risk factors, neurodegenerative conditions and gender-linked genetic effects (Barta et al., 1997).

\section{GAPS IN KNOWLEDGE}

The importance of studying variation in risk for psychosis by age has generally been acknowledged. However, only very few studies have specifically addressed this issue by examining the possible sources of heterogeneity by age of onset in samples covering the whole age span. 
Further, most of the previous studies have been small and comparability between studies has greatly been hampered due to methodological and clinical differences. Consequently, little is known about (1) the age and sex-specific incidence for schizophrenia well beyond the early critial period of disease expression; (2) the effect modification of environmental (e.g. time and place) and methodological factors (e.g. sampling frame, case ascertainment and diagnostic confirmation) on the sex differences in age of onset; (3) the variation by age of onset in nature and severity of the cognitive deficits as a proxy measure of underlying neurobiological changes; (4) the contribution of demographic and clinical variables to the association between age of onset and cognition, and (5) the specificity and causes of hearing impairment as risk factor for psychosis in young and old people.

\section{AIMS AND OUTLINE OF THE THESIS}

In order to address these gaps in knowledge, this thesis was set out to examine risk and risk correlates for psychosis across the life span. More specifically the aim of the thesis was to answer the following questions:

How does risk for schizophrenia vary by age and sex? $\vee$ In Chapter 2 we establish age- and sex-specific incidence rates for schizophrenia by conducting a systematic review and individual participant meta-analysis of incidence studies of schizophrenia. Additionally, we assess the impact of methodological and population characteristics on risk by age and sex.

What is the effect of age at onset on cognitive functioning? - Chapter 3 examines the association between age of onset and cognitive functioning in a large sample of patients presenting with non-affective psychotic disorder across the whole age of onset span. First, the effect of age at onset cognitive test scores is assessed. Second, mediation by illness and demographic factors in this association is formally tested. Subjects were recruited from two ongoing 


\section{Chapter 1}

and related studies, both conducted in the Netherlands and the Flemish part of Belgium. Participants aged 50 years and younger were recruited in the Genetic Risk and Outcome in Psychosis (GROUP) study, and participants aged 45 years and older were recruited for the parallel Psychosis in the Elderly (PSITE) study. Is hearing impairment a risk factor for psychosis in young and old individuals? Both chapter 4 and chapter 5 address the effect of age on the association between hearing impairment and psychosis. The aim of chapter 4 is to replicate the association between hearing impairment and psychotic experiences and to clarify the effect modification by age in this association using data from a nonclinical, normal aging general population sample conducted in the Maastricht Region, Netherlands (Maastricht Ageing Study; MAAS). In chapter 5 we examine the hypothesis that adolescent hearing impairment, particularly in the phase of early adolescence, is associated with an increased risk for psychotic symptoms. This hypothesis is tested in a prospective cohort study of a population sample of adolescents and young adults aged 14-24 years at baseline, in Munich, Germany (Early Developmental Stages of Psychopathology Study; EDSP). What is the underlying mechanism linking hearing impairment to psychosis? Finally, in Chapter 6 we test the assumption that the association between hearing impairment and psychosis risk is sensitive to environmental variables representing higher level of social complexity, such as urbanicity. Results pertain to subjects seen within the previous described MAAS study. 
Angermeyer, MC \& Kuhn, L (1988). Gender differences in age at onset of schizophrenia. An overview. Eur Arch Psychiatry Neurol Sci 237, 351-64.

Barta, PE, Powers, RE, Aylward, EH, Chase, GA, Harris, GJ, Rabins, PV, Tune, LE \& Pearlson, GD (1997). Quantitative MRI volume changes in late onset schizophrenia and Alzheimer's disease compared to normal controls. Psychiatry Res 68, 65-75.

Bassiony, MM \& Lyketsos, CG (2003). Delusions and hallucinations in Alzheimer's disease: review of the brain decade. Psychosomatics 44, 388-401.

Bertolino, A, Callicott, JH, Elman, I, Mattay, VS, Tedeschi, G, Frank, JA, Breier, A \& Weinberger, DR (1998). Regionally specific neuronal pathology in untreated patients with schizophrenia: a proton magnetic resonance spectroscopic imaging study. Biol Psychiatry 43, 641-8.

Borroni, B, Agosti, C \& Padovani, A (2008). Behavioral and psychological symptoms in dementia with Lewy-bodies (DLB): frequency and relationship with disease severity and motor impairment. Arch Gerontol Geriatr 46, 101-6.

Brodaty, H, Sachdev, P, Koschera, A, Monk, D \& Cullen, B (2003). Long-term outcome of late-onset schizophrenia: 5-year follow-up study. Br J Psychiatry 183, 213-9.

Cannon, M, Caspi, A, Moffitt, TE, Harrington, H, Taylor, A, Murray, RM \& Poulton, R (2002). Evidence for early-childhood, pan-developmental impairment specific to schizophreniform disorder: results from a longitudinal birth cohort. Archives of General Psychiatry 59, 449-56.

Cannon, TD, Kaprio, J, Lonnqvist, J, Huttunen, M \& Koskenvuo, M (1998). The genetic epidemiology of schizophrenia in a Finnish twin cohort. A population-based modeling study. Arch Gen Psychiatry 55, 67-74.

Cardno, AG, Marshall, EJ, Coid, B, Macdonald, AM, Ribchester, TR, Davies, NJ, Venturi, P, Jones, LA, Lewis, SW, Sham, PC, Gottesman, II, Farmer, AE, McGuffin, P, Reveley, AM \& Murray, RM (1999). Heritability Estimates for Psychotic Disorders: The Maudsley Twin Psychosis Series. Arch Gen Psychiatry $56,162-168$.

Castle, DJ, Wessely, S, Howard, R \& Murray, RM (1997). Schizophrenia with onset at the extremes of adult life. Int J Geriatr Psychiatry 12, 712-7.

Cervantes, AN, Rabins, PV \& Slavney, PR (2006). Onset of Schizophrenia at Age 100. Psychosomatics 47, 356-359.

Cooper, AF (1976). Deafness and psychiatric illness. Br J Psychiatry 129, 216-26.

Cooper, AF \& Curry, AR (1976). The pathology of deafness in the paranoid and affective psychoses of later life. Journal of Psychosomatic Research 20, 97-105.

Cougnard, A, Marcelis, M, Myin-Germeys, I, De Graaf, R, Vollebergh, W, Krabbendam, L, Lieb, R, Wittchen, HU, Henquet, C, Spauwen, J \& Van Os, J (2007). Does normal developmental expression of psychosis combine with environmental risk to cause persistence of psychosis? A psychosis pronenesspersistence model. Psychol Med 37, 513-27.

DeLisi, LE (1992). The significance of age of onset for schizophrenia. Schizophrenia Bulletin 18, 209 15.

Dominguez, MD, Wichers, M, Lieb, R, Wittchen, HU \& van Os, J (2009). Evidence That Onset of Clinical Psychosis Is an Outcome of Progressively More Persistent Subclinical Psychotic Experiences: An 8-Year Cohort Study. Schizophrenia Bulletin.

Esterberg, ML, Trotman, HD, Holtzman, C, Compton, MT \& Walker, EF (2010). The impact of a family history of psychosis on age-at-onset and positive and negative symptoms of schizophrenia: A metaanalysis. Schizophr Res In Press, Corrected Proof.

Feinberg, I (1982). Schizophrenia: caused by a fault in programmed synaptic elimination during adolescence? J Psychiatr Res 17, 319-34.

Folnegovic-Smalc, V, Folnegovic, Z \& Kulcar, Z (1990). Age of disease onset in Croatia's hospitalised schizophrenics. BrJ Psychiatry 156, 368-72.

Folnegovic, Z \& Folnegovic-Smalc, V (1994). Schizophrenia in Croatia: age of onset differences between males and females. Schizophr Res 14, 83-91. 


\section{Chapter 1}

Gangadhar, BN, Selvan, CP, Subbakrishna, DK \& Janakiramaiah, N (2002). Age-at-onset and schizophrenia: reversed gender effect. Acta Psychiatr Scand 105, 317-319.

Gottesman, II \& Erlenmeyer-Kimling, L (2001). Family and twin strategies as a head start in defining prodromes and endophenotypes for hypothetical early-interventions in schizophrenia. Schizophr Res 51, 93-102.

Hafner, H, Maurer, K, Loffler, W \& Riecher-Rossler, A (1993a). The influence of age and sex on the onset and early course of schizophrenia. Br J Psychiatry 162, 80-6.

Hafner, H, Riecher-Rossler, A, An Der Heiden, W, Maurer, K, Fatkenheuer, B \& Loffler, W (1993b).

Generating and testing a causal explanation of the gender difference in age at first onset of schizophrenia. Psychol Med 23, 925-40.

Heaton, R, Paulsen, JS, McAdams, LA, Kuck, J, Zisook, S, Braff, D, Harris, J \& Jeste, DV (1994). Neuropsychological deficits in schizophrenics. Relationship to age, chronicity, and dementia. Arch Gen Psychiatry 51, 469-76.

Heinrichs, RW \& Zakzanis, KK (1998). Neurocognitive deficit in schizophrenia: a quantitative review of the evidence. Neuropsychology 12, 426-45.

Howard, R, Rabins, PV, Seeman, MV \& Jeste, DV (2000). Late-onset schizophrenia and very-late-onset schizophrenia-like psychosis: an international consensus. The International Late-Onset Schizophrenia Group. Am J Psychiatry 157, 172-8.

Howard, RJ, Graham, C, Sham, P, Dennehey, J, Castle, DJ, Levy, R \& Murray, R (1997). A controlled family study of late-onset non-affective psychosis (late paraphrenia). Br J Psychiatry 170, 511-4.

Jablensky, A (1997). The 100-year epidemiology of schizophrenia. Schizophr Res 28, 111-25.

Jablensky, A \& Cole, SW (1997). Is the earlier age at onset of schizophrenia in males a confounded finding? Results from a cross-cultural investigation. Br J Psychiatry 170, 234-40.

Jeste, DV, Harris, MJ, Krull, A, Kuck, J, McAdams, LA \& Heaton, R (1995). Clinical and neuropsychological characteristics of patients with late-onset schizophrenia. Am J Psychiatry 152, 722-30.

Johns, LC, Cannon, M, Singleton, N, Murray, RM, Farrell, M, Brugha, T, Bebbington, P, Jenkins, R \& Meltzer, H (2004). Prevalence and correlates of self-reported psychotic symptoms in the British population. BrJ Psychiatry 185, 298-305.

Joyce, EM, Hutton, SB, Mutsatsa, SH \& Barnes, TRE (2005). Cognitive heterogeneity in first-episode schizophrenia. British Journal of Psychiatry. Supplement 187, 516-522.

Kohler, S, van Os, J, de Graaf, R, Vollebergh, W, Verhey, F \& Krabbendam, L (2007). Psychosis risk as a function of age at onset: a comparison between early- and late-onset psychosis in a general population sample. Soc Psychiatry Psychiatr Epidemio/ 42, 288-94.

Kulkarni, J, de Castella, A, Fitzgerald, PB, Gurvich, CT, Bailey, M, Bartholomeusz, C \& Burger, H (2008). Estrogen in Severe Mental IIIness: A Potential New Treatment Approach. Arch Gen Psychiatry 65, 955960.

Laks, J, Fontenelle, LF, Chalita, A \& Mendlowicz, MV (2006). Absence of dementia in late-onset schizophrenia: a one year follow-up of a Brazilian case series. Arq Neuropsiquiatr 64, 946-9.

McGrath, J, Saha, S, Welham, J, El Saadi, O, MacCauley, C \& Chant, D (2004). A systematic review of the incidence of schizophrenia: the distribution of rates and the influence of sex, urbanicity, migrant status and methodology. BMC Med 2, 13.

Murray, RM, O'Callaghan, E, Castle, DJ \& Lewis, SW (1992). A neurodevelopmental approach to the classification of schizophrenia. Schizophr Bull 18, 319-32.

Murthy, GV, Janakiramaiah, N, Gangadhar, BN \& Subbakrishna, DK (1998). Sex difference in age at onset of schizophrenia: discrepant findings from India. Acta Psychiatr Scand 97, 321-5.

Pearlson, GD, Kreger, L, Rabins, PV, Chase, GA, Cohen, B, Wirth, JB, Schlaepfer, TB \& Tune, LE (1989). A chart review study of late-onset and early-onset schizophrenia. Am J Psychiatry 146, 1568-74. Rapoport, JL, Addington, AM, Frangou, S \& Psych, MRC (2005). The neurodevelopmental model of schizophrenia: update 2005. Mol Psychiatry 10, 434-449.

Riecher-Rossler, A, Hafner, H, Hafner-Ranabauer, W, Loffler, W \& Reinhard, I (2003). Late-onset schizophrenia versus paranoid psychoses: a valid diagnostic distinction? Am J Geriatr Psychiatry 11 , 595-604. 


\section{Risk for Psychosis: A Life Span Perspective}

Rodriguez-Ferrera, S, Vassilas, CA \& Haque, S (2004). Older people with schizophrenia: a community study in a rural catchment area. International Journal of Geriatric Psychiatry 19, 1181-7.

Sachdev, P, Brodaty, H, Rose, N \& Cathcart, S (1999). Schizophrenia with onset after age 50 years. 2: Neurological, neuropsychological and MRI investigation. BrJ Psychiatry 175, 416-21.

Saha, S, Chant, D, Welham, J \& McGrath, J (2005). A systematic review of the prevalence of schizophrenia. PLoS Med 2, e141.

Seeman, MV (1996). The role of estrogen in schizophrenia. J Psychiatry Neurosci 21, 123-7.

Stefanis, NC, Thewissen, V, Bakoula, C, van Os, J \& Myin-Germeys, I (2006). Hearing impairment and psychosis: a replication in a cohort of young adults. Schizophrenia Research 85, 266-72.

Stein, LM \& Thienhaus, OJ (1993). Hearing impairment and psychosis. International Psychogeriatrics 5, 49-56.

Suvisaari, JM, Haukka, J, Tanskanen, A \& Lonnqvist, JK (1998). Age at onset and outcome in schizophrenia are related to the degree of familial loading. BrJ Psychiatry 173, 494-500.

Thewissen, V, Myin-Germeys, I, Bentall, R, de Graaf, R, Vollebergh, W \& van Os, J (2005). Hearing impairment and psychosis revisited. Schizophrenia Research 76, 99-103.

Tuulio-Henriksson, A, Partonen, T, Suvisaari, J, Haukka, J \& Lonnqvist, J (2004). Age at onset and cognitive functioning in schizophrenia. BrJ Psychiatry 185, 215-9.

van Os, J, Galdos, P, Lewis, G, Bourgeois, M \& Mann, A (1993). Schizophrenia sans frontieres: concepts of schizophrenia among French and British psychiatrists. Bmj 307, 489-92.

van Os, J, Linscott, RJ, Myin-Germeys, I, Delespaul, P \& Krabbendam, L (2009). A systematic review and meta-analysis of the psychosis continuum: evidence for a psychosis proneness-persistenceimpairment model of psychotic disorder. Psychol Med 39, 179-95.

van Os, J, Rutten, BP \& Poulton, R (2008). Gene-environment interactions in schizophrenia: review of epidemiological findings and future directions. Schizophrenia Bulletin 34, 1066-82.

Verdoux, H, Geddes, J, Takei, N, Lawrie, S, Bovet, P, Eagles, J, Heun, R, McCreadie, R, McNeil, T, O'Callaghan, E, Stober, G, Willinger, M, Wright, P \& Murray, R (1997). Obstetric complications and age at onset in schizophrenia: an international collaborative meta-analysis of individual patient data. $A m J$

Psychiatry 154, 1220-1227.

Verdoux, H, van Os, J, Maurice-Tison, S, Gay, B, Salamon, R \& Bourgeois, M (1998). Is early adulthood a critical developmental stage for psychosis proneness? A survey of delusional ideation in normal subjects. Schizophrenia Research 29, 247-54.

Vourdas, A, Pipe, R, Corrigall, R \& Frangou, S (2003). Increased developmental deviance and premorbid dysfunction in early onset schizophrenia. Schizophr Res 62, 13-22.

Weinberger, DR (1987). Implications of normal brain development for the pathogenesis of schizophrenia. Arch Gen Psychiatry 44, 660-9. 


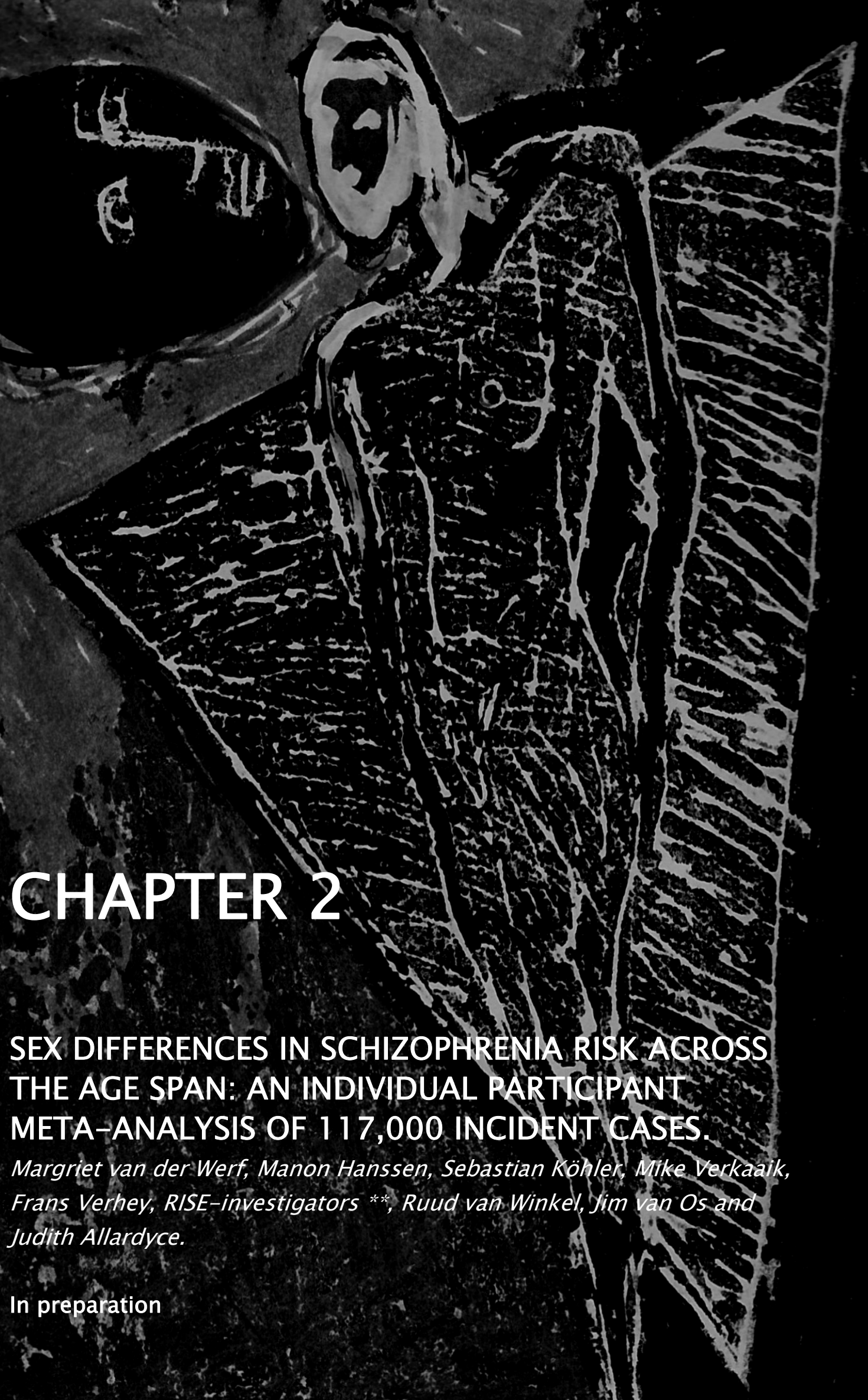




\section{ABSTRACT}

Context • Understanding the developmental timing of schizophrenia onset and its window of sex disparity may help to characterize underlying processes of vulnerability. Objective - To quantify schizophrenia incidence by age and sex using a comprehensive systematic review and individual participant meta-analysis.

Data sources and study selection - PUBMED, EMBASE and PsychINFO databases were searched between January 1950 and December 2009. Schizophrenia incidence studies that covered a broad age span were included. Data extraction - Numerator and population data were extracted by age, sex and, if possible, study period. Original data was requested from the authors in case of insufficient availability of data to calculate age- and sex-specific incidence rates. Forty-three independent samples met inclusion criteria, yielding 117,645 incident cases of schizophrenia for analysis. Data synthesis - Incidence rate ratios (IRR) with their 95\% confidence intervals $(\mathrm{Cl})$ were computed by age and sex from negative binomial regression models. Men had a 1.2-fold $(95 \% \mathrm{Cl}$ : 1.02-1.35) greater risk of schizophrenia than women. Incidence peaked at age 20-29 years in men (IRR: 2.37, 95\% Cl: 1.65-3.40), and at age 20-29 years (IRR: 2.08, 95\% Cl: 1.52-2.84) and 30-39 years (IRR: 2.01, 95\% Cl: 1.42-2.85) in women. This peak was followed by an age-incidence decline up to age 60 that was stronger in men than in women $\left(X^{2}=50.8 ; P<.001\right)$. Consequently, the relative risk of schizophrenia was greater in men up to age 39 years and this reversed to a greater relative risk in women over the age groups 5070 years. Contrary to expectations, no evidence for a second incidence peak in middle-aged women was found. Conclusions - Robust sex-differences exist in the distribution of risk for schizophrenia across the age span, suggesting that men and women have different susceptibility to schizophrenia at different stages of life. The findings question the possible involvement of estrogen in explaining late- and very-late-onset schizophrenia in women. 


\section{INTRODUCTION}

The incidence of schizophrenia peaks in early adulthood 1,2. However, risk extends well beyond that period, and the age-incidence pattern varies with sex ${ }^{3}$. In men, the age-incidence curve is characterized by a single pronounced peak in the late teens/early twenties, followed by a gradual decline. The female distribution shows an initial later and broader peak, a second smaller peak at age 45 to 49 years ${ }^{1}$ and possibly a third peak at the age of 65 years 4 . Although sex differences in age of onset for schizophrenia are well replicated 45,6 , their origin remains to be elucidated. Understanding the timing and the window of sex disparity in illness onset may help pinpoint the underlying process of vulnerability.

Risk differences by age and sex may indicate that men and women are differentially vulnerable to develop schizophrenia at different stages of life. The extent to which sex differences in timing of schizophrenia onset are inherent to the disorder itself, however, remains unclear. Differences in timing of onset between men and women have traditionally been interpreted in the light of possible neuroprotective effects of estrogen in women ${ }^{7}$, sex-linked genetic effects 8 or differential susceptibility to subtypes of schizophrenia with different timing of onset ${ }^{9}$. However, sex differences in age of onset are attenuated when controlling for family history ${ }^{10}$, paternal age 11 and marital status ${ }^{12}$, and appear to be absent in developing countries ${ }^{13}$. Hence, sex differences may be strongly influenced by environmental influences and biological variables. Finally, sex differences in age of onset may be secondary to methodological artifact such as criterion or sample bias. For example, differences in the age and sex distribution depend on the stringency of the applied diagnostic classification systems and on arbitrary age criteria 14 .

A systematic review and meta-analysis is a transparent approach to critically appraise and integrate quantitative evidence from a 
comprehensive pool of related studies. Individual participant meta-analysis has numerous clinical and statistical advantages over the aggregate metaanalytic approach ${ }^{15}$ and is considered the gold standard for meta-analysis 16. No such approach has been undertaken to examine the incidence for schizophrenia by age and sex. Hence, a comprehensive individual participant meta-analysis of schizophrenia incidence studies was conducted, with the primary aim to (i) examine risk estimates for schizophrenia by age and sex across the entire age range and (ii) investigate the contribution of population and methodological characteristics to variation in incidence by age and sex.

\section{METHODS}

\section{Study selection}

The methodology of the systematic review and meta-analysis was based on the recommendations of the Meta-Analysis of Observational Studies in Epidemiology (MOOSE) group. 17 The search was conducted by two investigators (M.W. and M.H.) using PUBMED, EMBASE and PsychINFO databases between January 1950 and December 2009. The broad key words epidemiology and schizophrenia OR psychosis were chosen in order to locate as many studies as possible. Additionally, studies were located by manually tracking references from relevant papers, review papers and book chapters, including a previous extensive systematic review of schizophrenia incidence studies ${ }^{18}$. Web of Science was used for forward and backward citation tracking. Finally, experts in the field of psychosis epidemiology were contacted for missing publications and unpublished data. Studies were selected using the following inclusion criteria: (1) schizophrenia incidence study; (2) presence of age- and sex-specific incidence data in the paper or data that could be obtained by contacting the author; (3) published as original research no earlier than 1950; (4) publication in English, Dutch or German language. Inclusion of studies with low age- 
cutoffs will introduce age bias in the estimated risk ratios by sex. Hence, studies that imposed strict age restrictions (age groups $<45$ years or $\geq 30$ years only) were excluded. All retrieved citations were screened independently by two reviewers in a three-stage screening approach $(\mathrm{MW} / \mathrm{MH})$. In the first stage, all citations were inspected for relevance. In the second stage, all studies that clearly did not meet the specified inclusion criteria were excluded. Finally, full-text articles were scrutinized to assess inclusion criteria in detail.

\section{Data extraction}

Data was extracted by one researcher (M.W.) and was validated by two independent investigators (M.H./S.K.). Consensus was reached by discussion. For each independent sample, numerator and population data (in person-years) were extracted by age, sex and, if possible, study period. Incidence data was first extracted according to the consensus statement made by Howard and collegues 19, using early (age $<40$ years: EOS), late (age 40-59 years: LOS) and very-late onset (age $\geq 60$ years: VLOS) schizophrenia age groups. Data presented in different age formats were manually assigned to one of the age groups. This approach has the advantage of including all studies and additionally provides rates based on consensus statement thereby increasing comparability across studies. In the second approach numerator and population data were extracted by ten-year age groups, yielding a more restricted pool of samples. This approach enables the more gradual examination of effect modification by sample characteristics on variation in incidence by age and sex. Information about the source population and methodological characteristics were extracted at the sample level. Each sample was classified as rural or mixed/urban, based on combined information about population density estimates and the proportion of people living in urbanized areas 20 . Samples were further categorized into developing or developed countries according to the World Health Organization Human 
Development Index of countries ${ }^{21}$. Methodological characteristics included, among others, sampling frame (hospital-admission or first-contact with psychiatric service), case ascertainment (clinical, systematic or interview) and type of diagnostic classification system used (DSM 22-24, ICD 25, 26, RDC 27 and other). When multiple classification systems were used in one study, the one applying the broadest schizophrenia definition was selected(e.g. ICD instead of DSM). Schizophreniform disorder was included when studies published results based on DSM criteria. Authors were contacted to ensure accuracy and to provide original data in case of insufficient available data to calculate age- and sex-specific incidence rates (author list available upon request).

\section{STATISTICAL ANALYSES}

First, a descriptive synthesis of incidence rates was completed using information from all studies with data stratified by EOS, LOS and VLOS age groups (analysis 1). The distribution of incidence rates was presented by age, sex and female to male incidence rate ratios (IRR) showing mean, median (better indicator of incidence in case of non-normality) and 25\%$75 \%$ interquartile quartile range (IQR) values. Additionally, the distribution of incidence rates by population and methodological characteristics was explored. Second, analyses were conducted on the subset of samples with data stratified by ten-year age bands (analysis 2). The Poisson models showed significant overdispersion. Hence, the effect of age and sex on schizophrenia risk was modeled by fitting negative binomial regression models, yielding IRR and corresponding 95\% confidence intervals $(\mathrm{Cl})$. The cluster robust option, with sample as cluster, was used to correct standard errors for hierarchical clustering of observations within samples. Main effects on incidence were calculated with age, sex and population and methodological characteristics as predictors, followed by adding an age $x$ sex interaction term to assess risk modification of age by sex. Stratified effects were then calculated by applying the appropriate linear 
combinations, derived from the model containing the interaction, using the STATA LINCOM routine. Confounding in these models was examined by adjusting for sample characteristics. To examine potential effects of age bias and small sample size on risk estimates, the final analyses were repeated on (i) samples without age restriction and (ii) those that included at least 100 cases of schizophrenia. Finally, availability bias across the different selection stages was explored by contrasting included and excluded samples on salient sample characteristics. All analyses were conducted using Stata, version 1128 .

\section{RESULTS}

The initial search yielded 11,307 citations of which 329 articles were inspected for inclusion in the second screen. Ninety-one studies 4, 29-118 derived from 44 non-overlapping samples met inclusion criteria for the initial analyses. One study 39 contributed significantly to methodological heterogeneity due to its study design that was incomparable to all other included studies. This study was excluded from further analysis, leaving a risk set of 43 independent samples for the analyses. Table 7 shows the characteristics of the included studies organized by sample. A list of excluded articles and their justification for exclusion is presented in Appendix $A$. The included and those excluded due to insufficient data were similar with regard to sample characteristics, total number of cases and population size (results available upon request). 


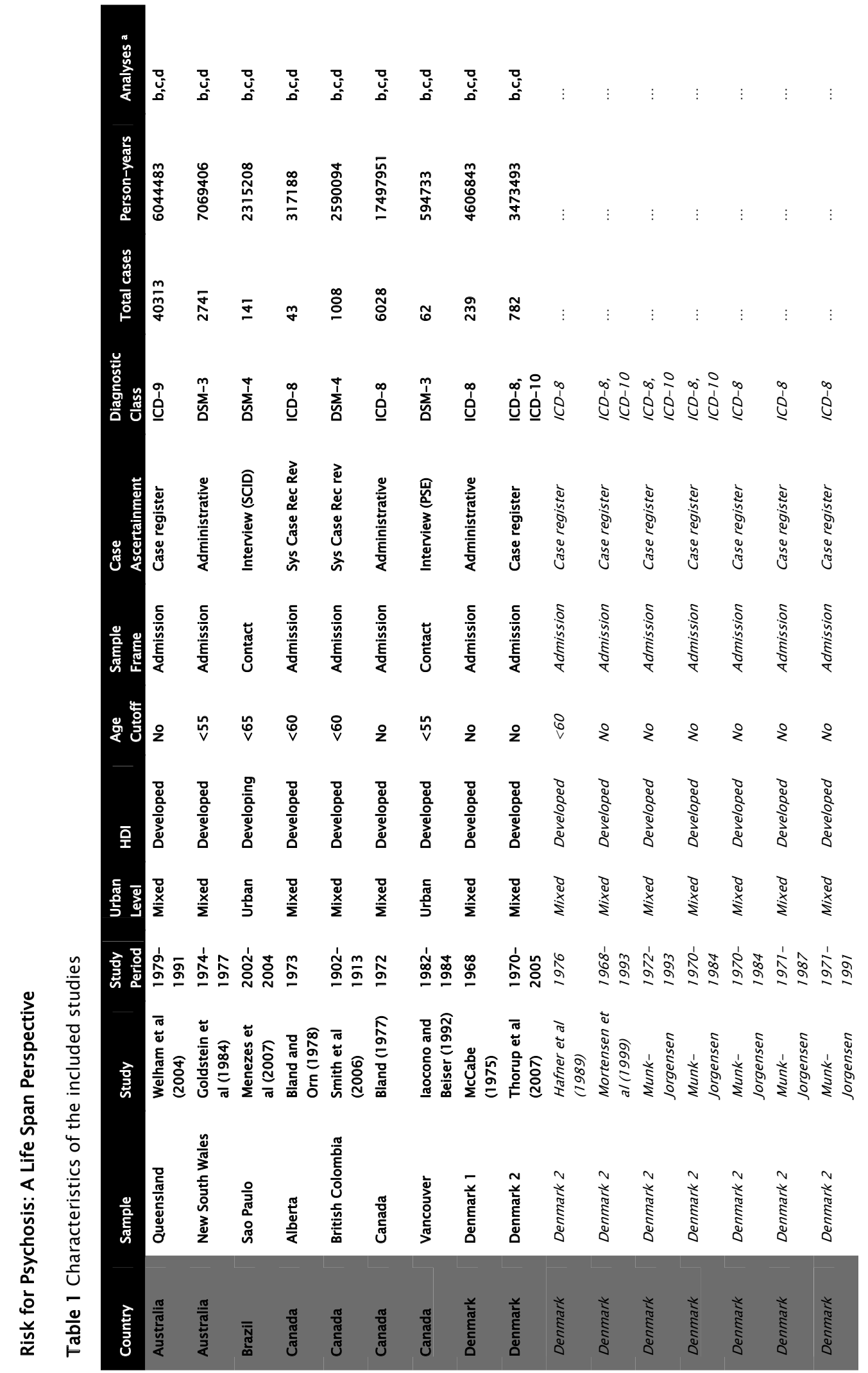




$$
\begin{aligned}
& \frac{3}{\mathscr{B}}
\end{aligned}
$$

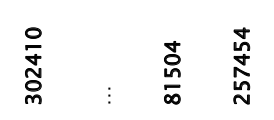

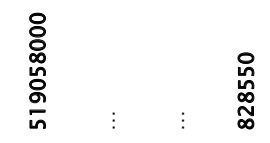

$$
\begin{aligned}
& m \quad \vdots \quad \hat{\sim}
\end{aligned}
$$

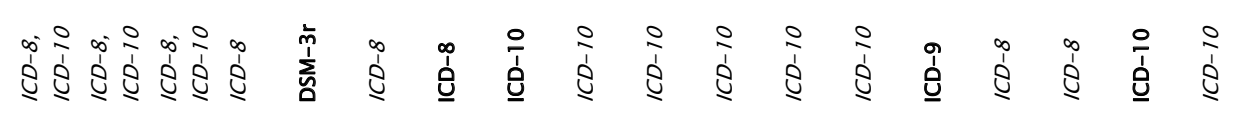

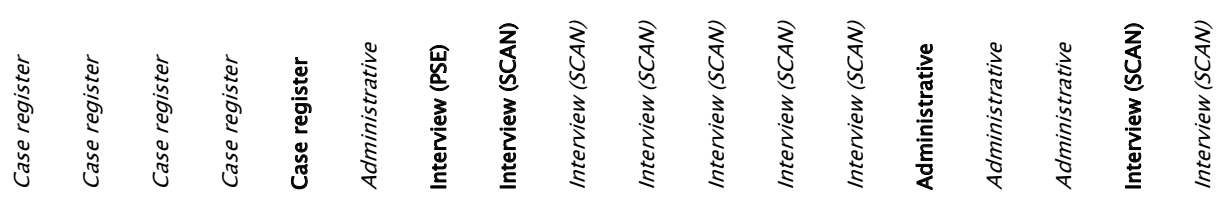

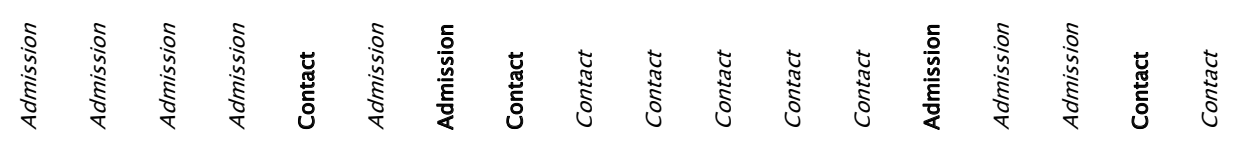

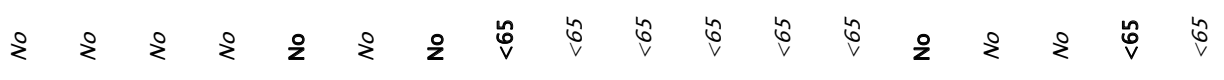

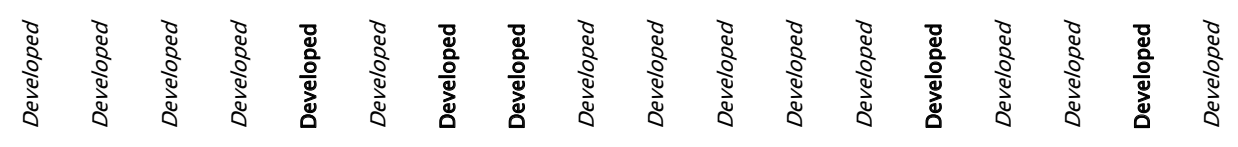

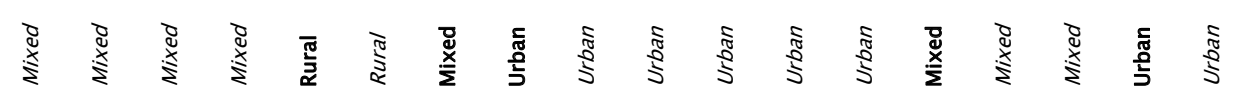

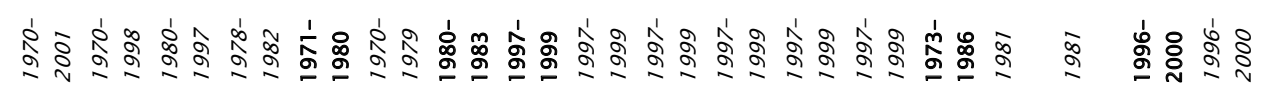

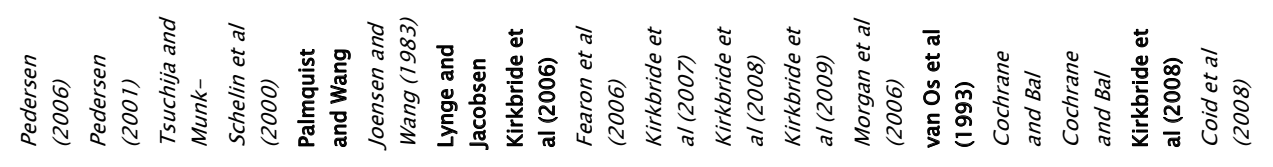

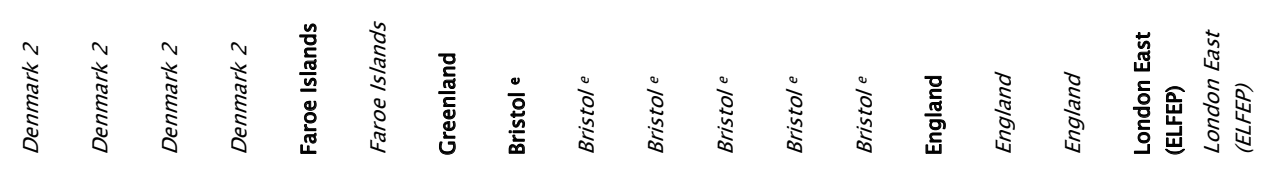

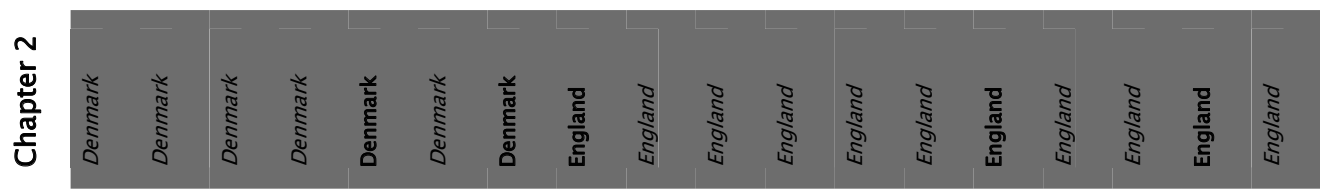


$\stackrel{\square}{\stackrel{\square}{S}}$

$$
\stackrel{\square}{\square}
$$

总

$$
\text { 厗 }
$$

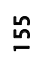

$\frac{n}{6}$

in

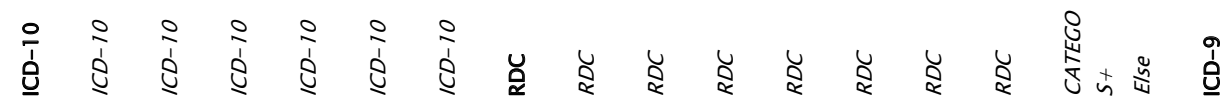

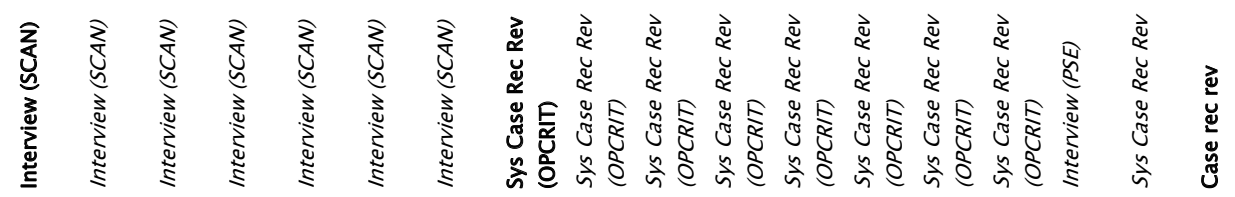

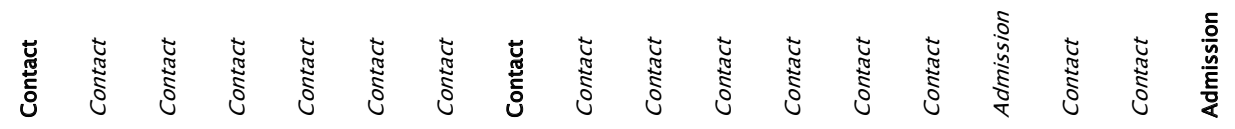

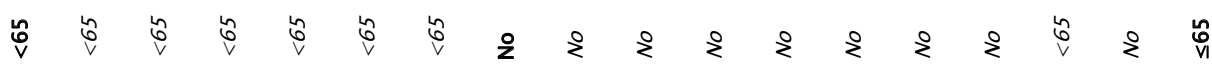

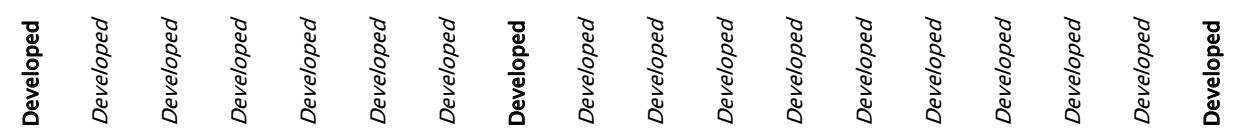

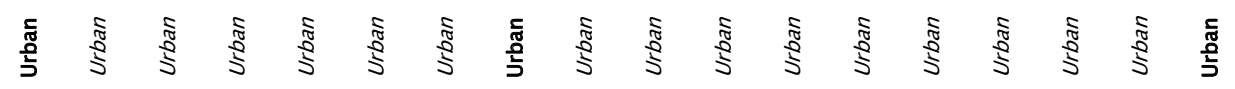

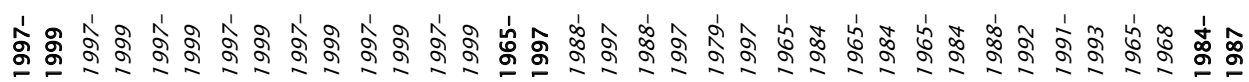

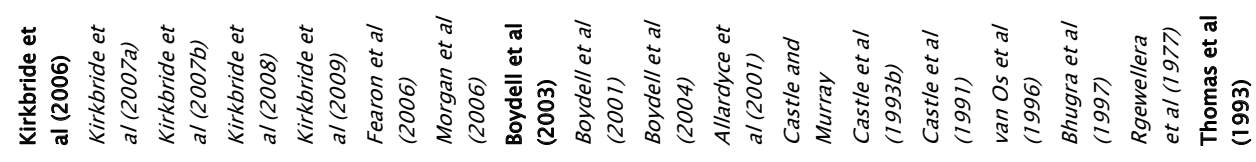

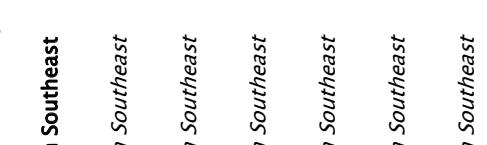

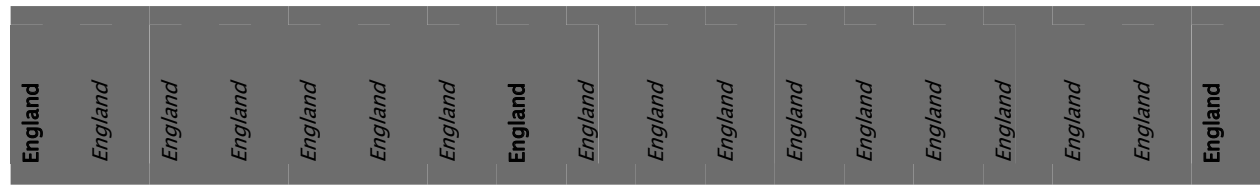




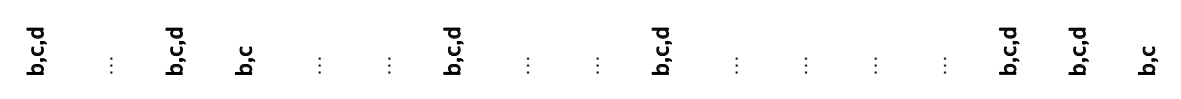

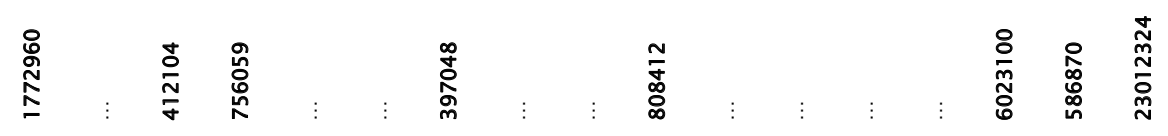

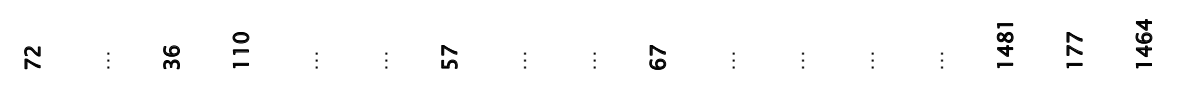

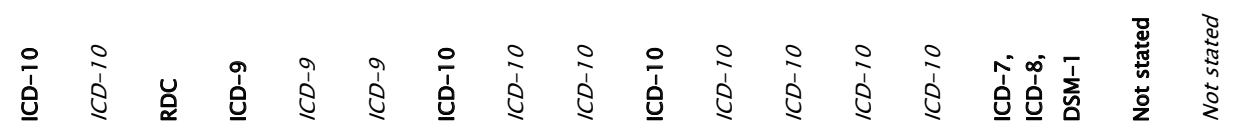

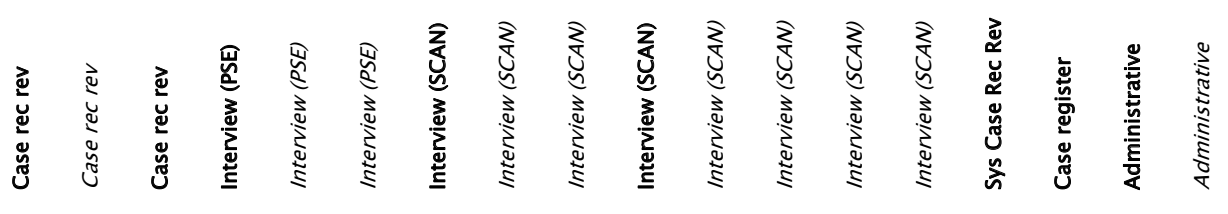

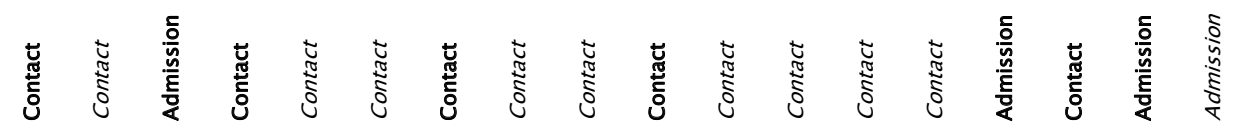

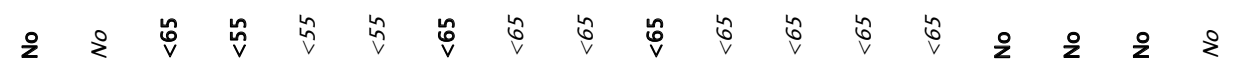

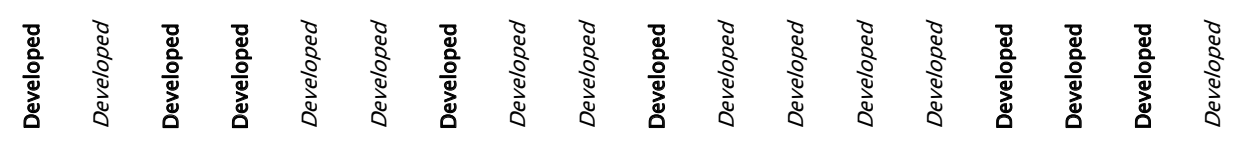

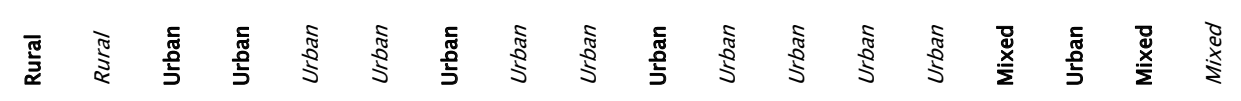

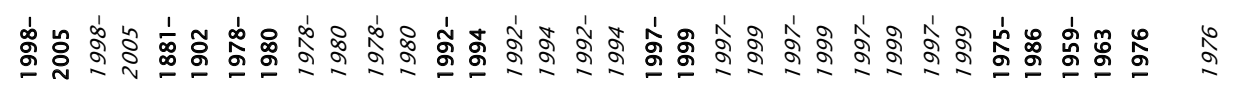

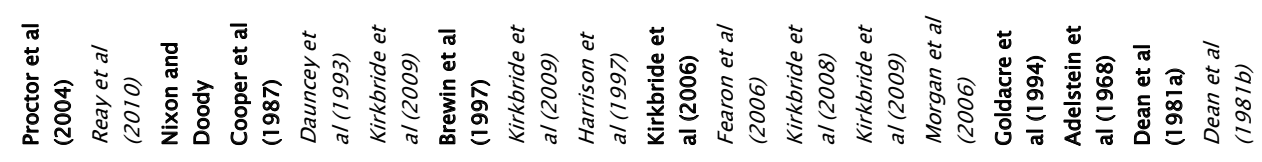
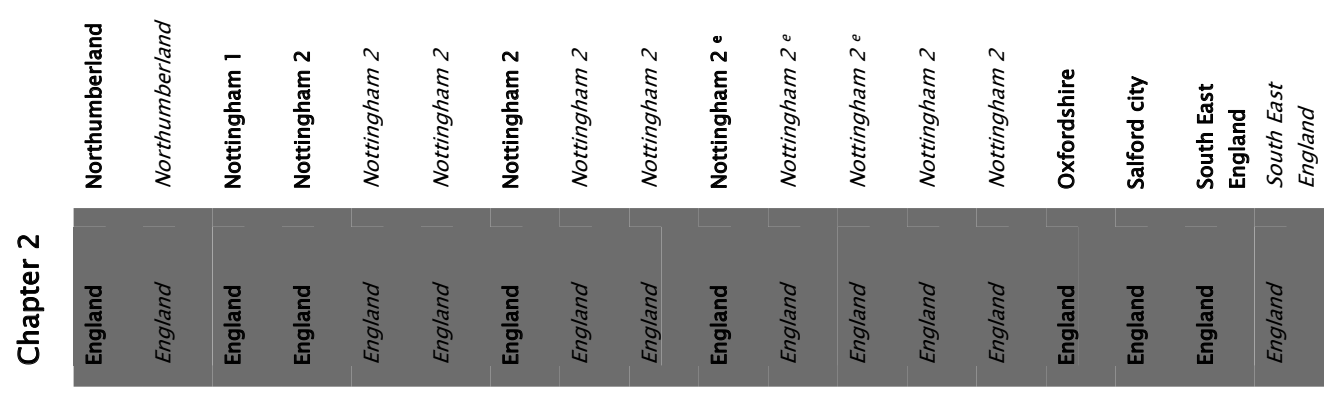


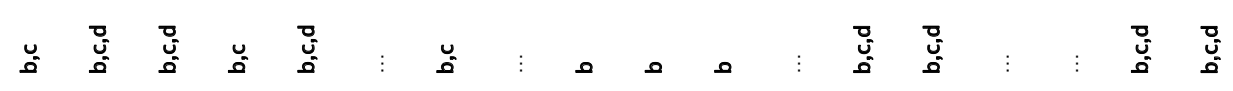

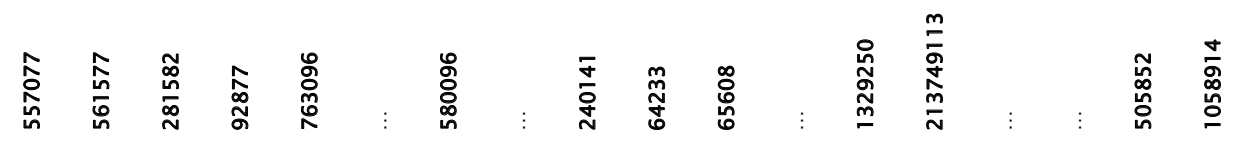

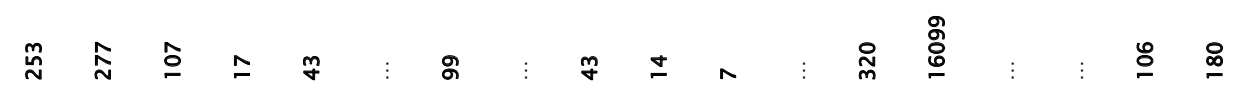

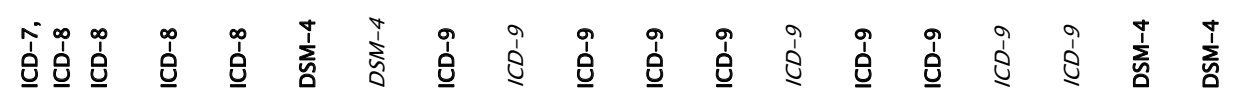

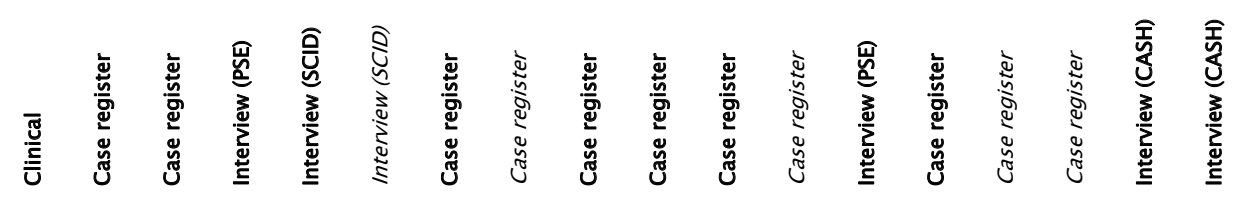

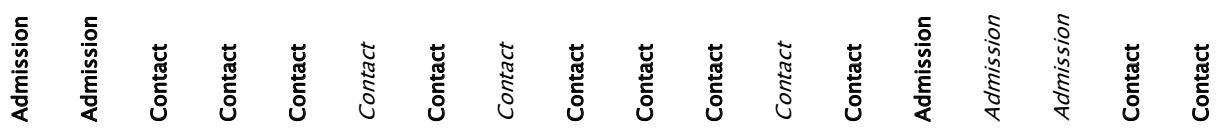

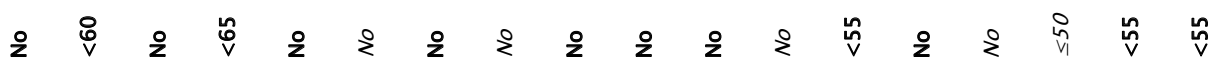

!I!I!I!I!I!IIIII!I!

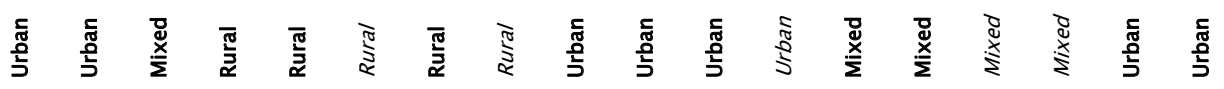

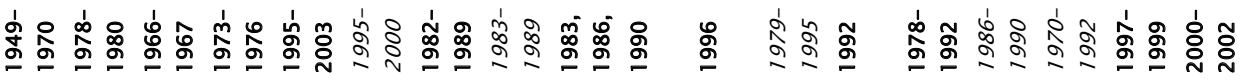

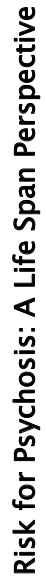

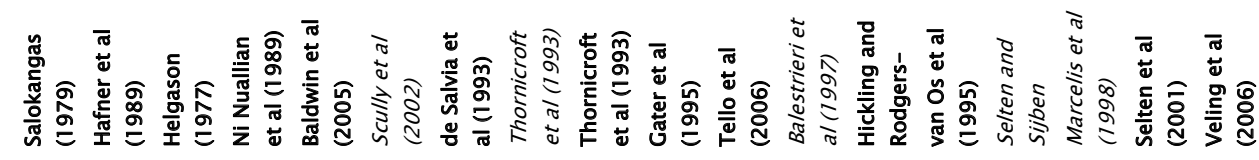

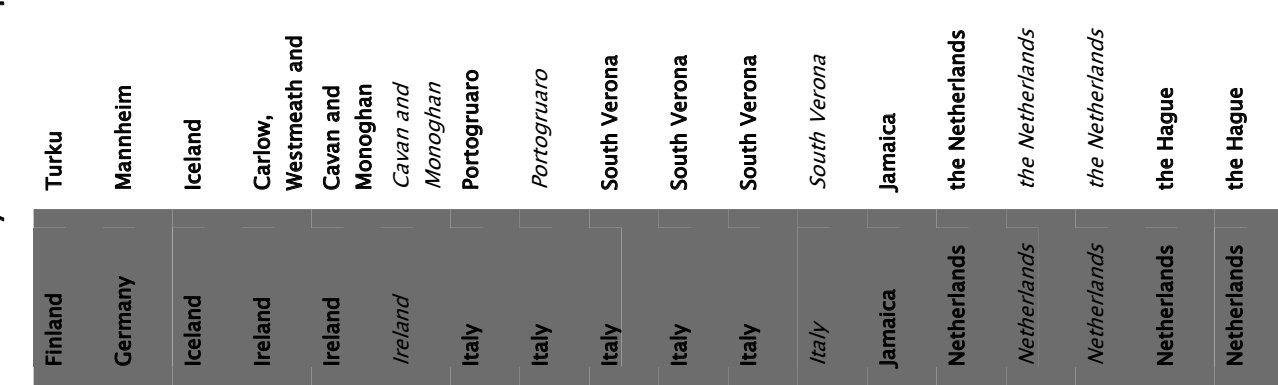




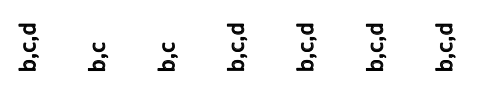

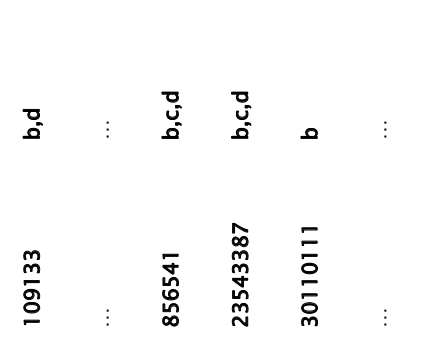

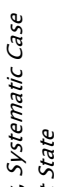

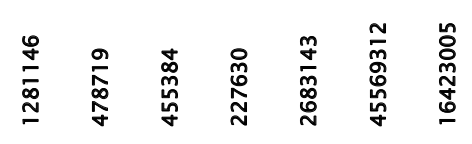

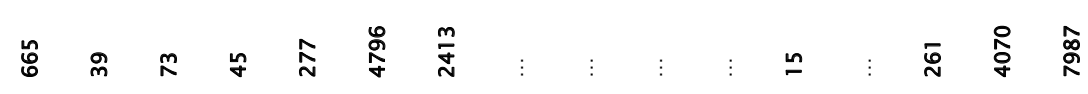

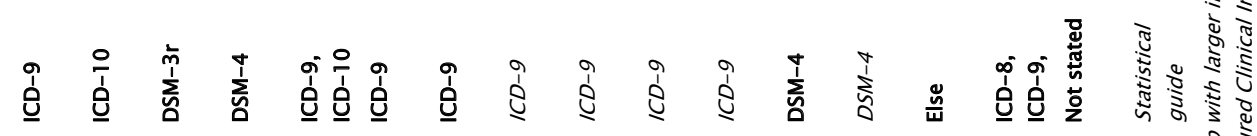

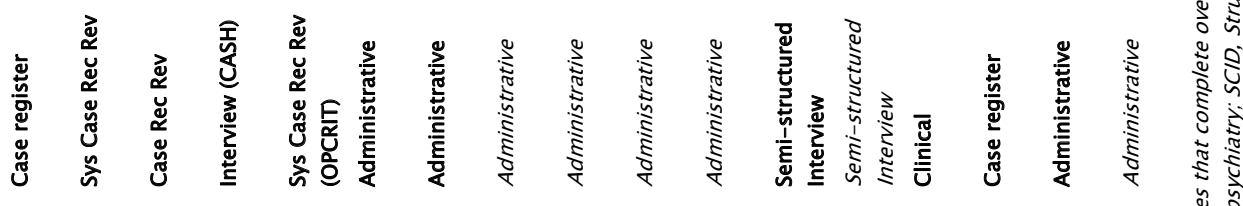
\|\|\|\|\|\|\|\|\|\|

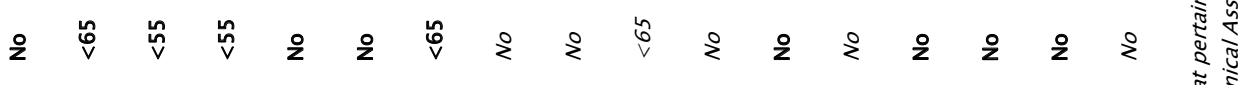

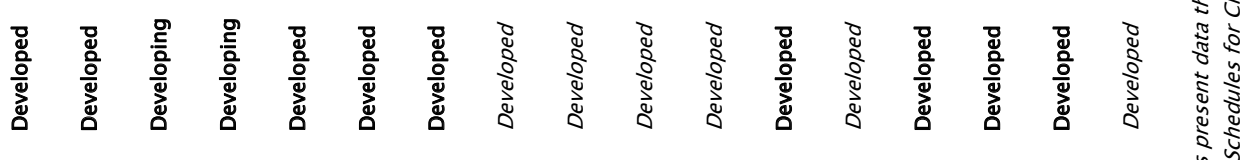

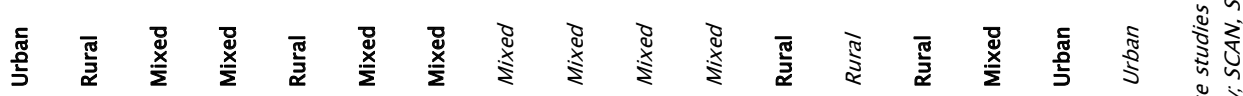

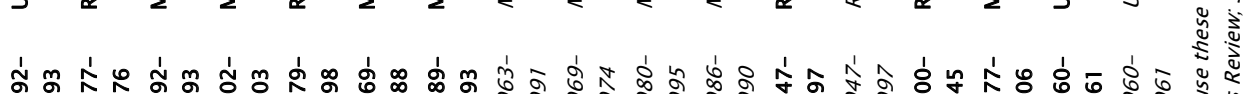

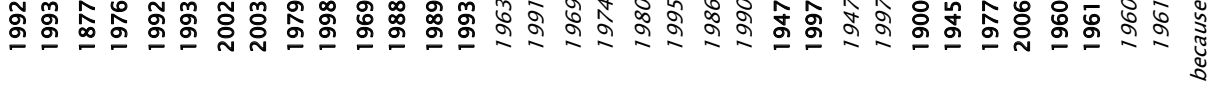

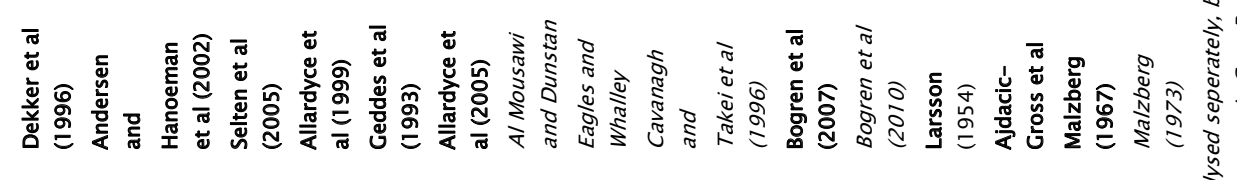

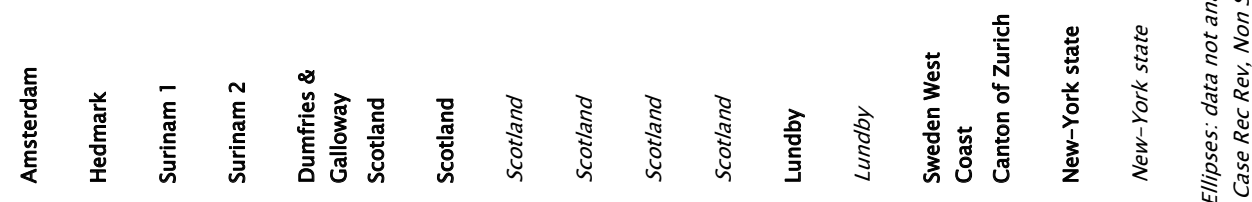

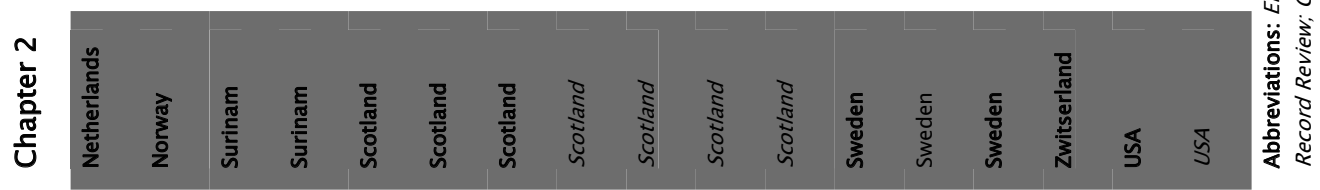


Risk for Psychosis: A Life Span Perspective

\section{Descriptive synthesis (analysis 1)}

The first set of analyses was based on all 43 samples, yielding 1037 effect sizes and 117,645 cases of schizophrenia. The pooled median incidence rate for schizophrenia over these samples was 18.3 per 100,000 personyears, with an almost three-fold difference between samples with $25 \%$ of the lowest and highest reported rates (IQR, 10.9-30.2). Incidence rates declined strongly with increasing age (Table 2). The overall incidence rate was higher in men than in women. However, the initial male preponderance in the EOS group (IRR: 0.54, IQR: 0.44-0.76) leveled of to a similar female to male risk ratio in the LOS group (IRR: 1.15, IQR: 0.92-1.55), and resulted in a higher relative risk in women in the VLOS group (IRR: 1.27, IQR: 0.921.92). Table 3 presents the distribution of incidence rates by sample characteristics over the EOS, LOS and VLOS groups. Rates tended to be low in samples based on diagnostic interview methods and first contacts, and in samples conducted after 1980, in rural areas and in developing countries. However, the age-incidence decline was manifest regardless of differences in population characteristics or applied methodology.

\section{Systematic recalculation (analysis 2)}

The second set of analyses was based on the subset of 33 non-overlapping samples with data stratified by sex and ten years age bands, providing 598 effect sizes and 47,661 incident cases of schizophrenia. For all models, the negative binomial analyses fitted the data better than the zero-inflated negative binomial model (Vuong test $=0.70 ; P=0.24$ ).

In the fully adjusted models, urbanicity (IRR: $1.80,95 \% \mathrm{Cl}: 1.18-$ 2.73), younger age (IRR: $1.25,95 \% \mathrm{Cl}: 1.18-1.33$ ) and male sex (IRR: 1.17, 95\% Cl: 1.02-1.35) were significantly associated with higher incidence rates, whereas study period after 2000 (IRR: $0.30,95 \% \mathrm{Cl}$ : 0.17-0.54) was associated with lower incidence rates. Figure $l$ shows the crude age- and sex-specific incidence rates. A strong negative interaction between sex and age was apparent in the crude $\left(\mathrm{X}^{2}=71.4 ; \mathrm{P}<.001\right)$ and fully adjusted model 
$\left(X^{2}=50.8 ; P<.001\right)$. Stratified analyses in this fully adjusted model revealed a significantly stronger overall age-incidence decline in men (IRR: 0.72, 95\%Cl: $0.67-0.77$ ) than in women (IRR: $0.89,95 \% \mathrm{Cl}: 0.83-0.95$ ). Table 4 presents the unadjusted and adjusted IRRs by age and sex with the youngest age group as reference ( $<20$ years). Male incidence peaked at age 20-29 years (IRR: $2.37,95 \% \mathrm{Cl}: 1.65-3.40$ ). The incidence peak in women was less sharp and spread out over age bands $20-29$ (IRR: $2.08,95 \% \mathrm{Cl}$ : 1.52-2.84) and 30-39 years (IRR: $2.01,95 \% \mathrm{Cl}: 1.42-2.85$ ). After this initial peak, incidence rates declined continuously up to old age and leveled off to a non-significant risk difference by age 60 . Finally, the relative risk of schizophrenia remained greater in men up to age 39 years, equalled for men and women between 40-49 and reversed to a greater female risk over age groups $50-70$ years (Table 5).

Restricting the analyses to samples without age restriction $(n=20)$ or a minimum sample size of 100 cases $(n=22)$ yielded similar patterns of risk by age and sex. Finally, the subset used for analysis 2 yielded similar incidence rates by age and sex as those used for analysis 1, rendering availability bias unlikely (results available upon request). 
Risk for Psychosis: A Life Span Perspective

Table 2 Distribution of incidence rates for schizophrenia by age and sex a

\begin{tabular}{|c|c|c|c|c|c|}
\hline & & & & & Interquartile Range \\
\hline \multirow[t]{4}{*}{ Totals } & & Ns & Mean & Median & $(25 \% ;-75 \%)$ \\
\hline & All ages & 43 & 22.3 & 18.3 & $10.9 ; 30.2$ \\
\hline & Men & 37 & 24.9 & 17.0 & $13.0 ; 35.0$ \\
\hline & Women & 37 & 18.0 & 13.0 & $7.1 ; 25.8$ \\
\hline \multicolumn{6}{|l|}{ Age groups } \\
\hline \multirow[t]{3}{*}{ EOS (<40 yrs) } & Total & 43 & 28.8 & 18.3 & $10.9 ; 30.2$ \\
\hline & Men & 37 & 33.1 & 26.2 & $16.6 ; 46.4$ \\
\hline & Women & 37 & 20.3 & 15.5 & $8.1 ; 30.9$ \\
\hline \multirow[t]{3}{*}{ LOS (40-59 yrs) } & Total & 42 & 16.9 & 12.3 & $7.0 ; 26.1$ \\
\hline & Men & 36 & 15.4 & 8.5 & $5.8 ; 22.4$ \\
\hline & Women & 36 & 17.2 & 9.9 & $6.9 ; 25.7$ \\
\hline \multirow[t]{3}{*}{ VLOS (>60 yrs) } & Total & 31 & 9.1 & 5.9 & $2.6 ; 13.0$ \\
\hline & Men & 26 & 8.1 & 4.6 & $2.2 ; 9.0$ \\
\hline & Women & 27 & 10.5 & 8.5 & $2.7 ; 14.4$ \\
\hline
\end{tabular}

Abbreviations: $n_{s}$, number of samples; EOS, early-onset schizophrenia; LOS, late-onset schizophrenia; VLOS, very-late-onset schizophrenia. a All rates are presented as number of cases per 100000 person-years. 


\section{Chapter 2}

Table 3. Distribution of incidence rates stratified by age and sample characteristics a

\begin{tabular}{|c|c|c|c|c|c|c|c|c|c|}
\hline & & \multicolumn{2}{|r|}{ All ages } & \multicolumn{2}{|r|}{ EOS } & \multicolumn{2}{|r|}{ LOS } & \multicolumn{2}{|r|}{ VLOS } \\
\hline \multicolumn{2}{|c|}{ Sample characteristic } & ns & median (IQR) & ns & median (IQR) & ns & median (IQR) & ns & median (IQR) \\
\hline \multirow[t]{3}{*}{ Period } & Period < 1970 & 13 & $15.7(8.2-33.0)$ & 13 & $36.4(16.0-46.3)$ & 13 & $13.6(8.6-26.1)$ & 10 & $9.4(4.2-15.3)$ \\
\hline & $1970-1980$ & 18 & $15.1(8.0-27.8)$ & 18 & $20.4(14.1-34.2)$ & 18 & $14.0(8.3-27.1)$ & 12 & $7.6(4.0-12.1)$ \\
\hline & $\geq 1990$ & 19 & $9.1(4.6-20.8)$ & 19 & $20.2(10.9-27.2)$ & 19 & $7.7(3.5-13.3)$ & 16 & $4.1(2.3-8.8)$ \\
\hline \multirow{2}{*}{$\begin{array}{l}\text { Diagnostic } \\
\text { classification }\end{array}$} & DSM & 10 & $16.7(6.5-26.6)$ & 10 & $22.2(16.3-36.4)$ & 10 & $15.2(3.5-26.1)$ & 4 & $5.0(2.7-10.6)$ \\
\hline & ICD & 27 & $15.5(7.1-30.6)$ & 27 & $27.1(15.6-43.1)$ & 27 & $12.5(7.1-30.6)$ & 22 & $6.1(3.5-13.0)$ \\
\hline \multirow{3}{*}{$\begin{array}{l}\text { Case } \\
\text { ascertainment }\end{array}$} & Clinical & 27 & $15.4(7.3-31.8)$ & 27 & $24.7(15.3-46.3)$ & 27 & $12.7(8.5-29.9)$ & 21 & $7.5(4.5-15.3)$ \\
\hline & Systematic & 5 & $12.5(7.1-30.6)$ & 5 & $30.3(16.6-35.7)$ & 5 & $7.9(7.1-30.6)$ & 4 & $4.7(2.8-9.2)$ \\
\hline & Interview & 12 & $12.4(2.5-19.3)$ & 12 & $20.3(14.5-27.4)$ & 12 & $7.1(2.0-14.4)$ & 8 & $2.3(1.4-5.9)$ \\
\hline \multirow[t]{2}{*}{ Sample frame } & First admission & 20 & $15.4(7.2-36.0)$ & 20 & $34.9(13.9-50.6)$ & 20 & $12.3(8.6-33.7)$ & 14 & $6.1(4.5-13.0)$ \\
\hline & First contact & 23 & $13.9(5.6-21.4)$ & 23 & $21.4(16.3-30.3)$ & 23 & $11.4(3.5-17.0)$ & 18 & $5.4(2.3-12.5)$ \\
\hline \multirow[t]{2}{*}{ Urban level } & Rural & 8 & $8.7(2.6-19.0)$ & 8 & $19.2(10.7-33.0)$ & 8 & $11.7(4.5-17.2)$ & 7 & $2.6(1.4-6.0)$ \\
\hline & Mixed/Urban & 35 & $15.4(7.1-27.6)$ & 35 & $24.7(15.6-43.1)$ & 35 & $12.3(7.0-27.1)$ & 25 & $6.8(4.3-16.8)$ \\
\hline \multirow{2}{*}{$\begin{array}{l}\text { Human } \\
\text { Development }\end{array}$} & Developing & 4 & $13.3(8.9-21.4)$ & 4 & $18.3(12.1-24.3)$ & 4 & $12.4(7.0-17.5)$ & 1 & $1.5(\ldots)$. \\
\hline & Developed & 39 & $15.3(6.6-29.9)$ & 39 & $24.7(15.6-43.1)$ & 39 & $12.3(7.0-27.1)$ & 31 & $5.9(3.5-13.0)$ \\
\hline
\end{tabular}

Abbreviations: Ellipses, not applicable; n, =number of samples; EOS, early-onset schizophrenia; LOS, late-onset schizophrenia; VLOS-very late onset schizophrenia; IQR, Interquartile Range; a All rates are presented as number of cases per 100000 person-years. 
Risk for Psychosis: A Life Span Perspective

Figure 1. Estimated age- and sex-specific median incidence rates (per 100000 person-years) (-口- women; - - men)

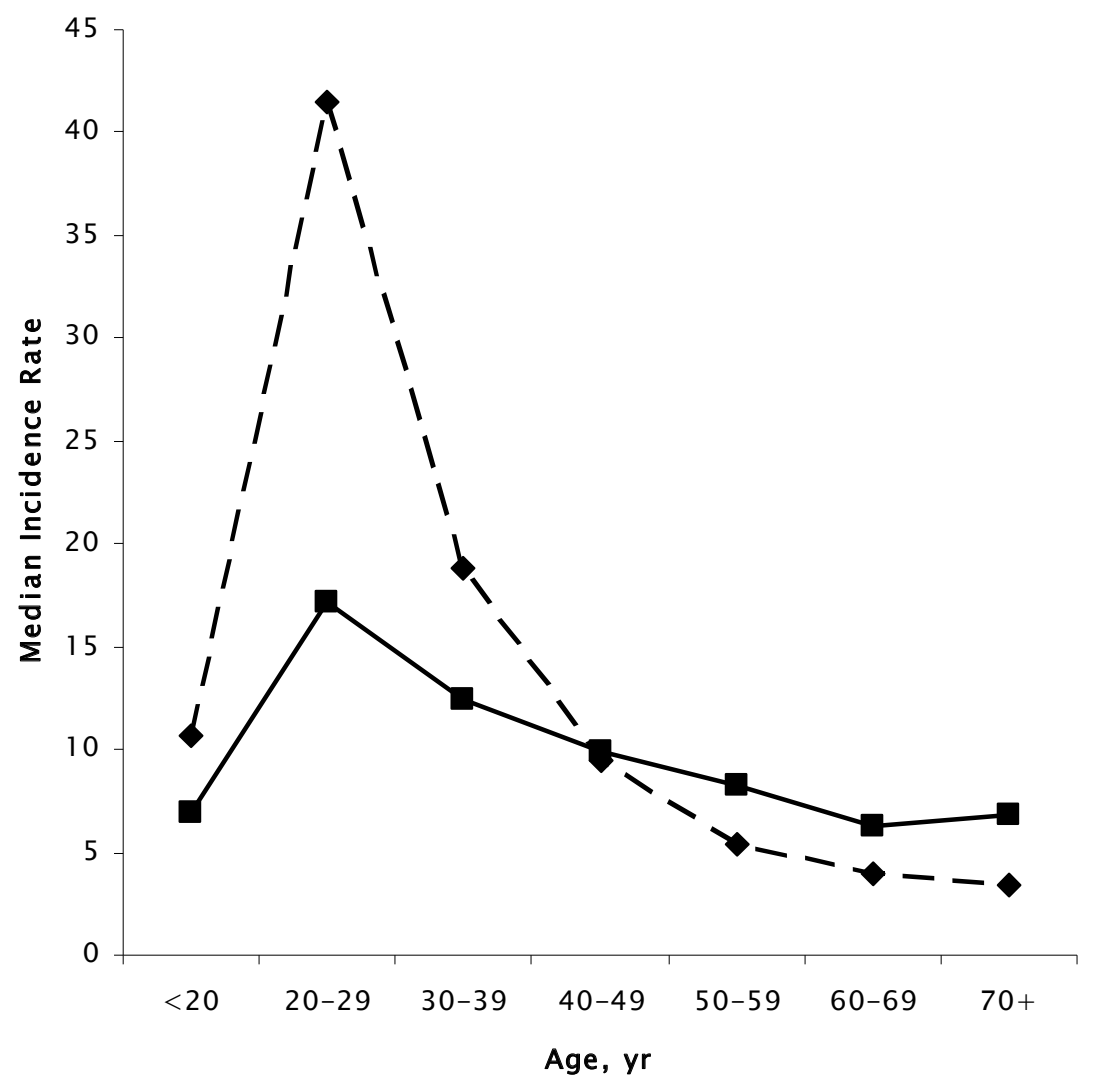




\section{Chapter 2}

Table 4 Age- and sex-specific incidence rates of schizophrenia (per 100000 person-years)

\begin{tabular}{|lccc|}
\hline Age, yr & $\begin{array}{c}\text { Crude rate } \\
\text { Median }\end{array}$ & $\begin{array}{l}\text { Crude IRR } \\
(95 \% \mathrm{Cl})\end{array}$ & $\begin{array}{l}\text { Adjusted IRR a } \\
(95 \% \mathrm{Cl})\end{array}$ \\
\hline Men & & & \\
$<20$ & 10.4 & {$[1]$ reference } & {$[1]$ reference } \\
$20-29$ & 41.4 & $2.47(1.79-3.41)$ & $2.37(1.65-3.40)$ \\
$30-39$ & 18.8 & $1.47(1.01-2.13)$ & $1.32(0.86-2.02)$ \\
$40-49$ & 9.4 & $0.84(0.53-1.32)$ & $0.72(0.43-1.20)$ \\
$50-59$ & 5.4 & $0.58(0.35-0.94)$ & $0.49(0.28-0.82)$ \\
$60-69$ & 4.0 & $0.33(0.22-0.49)$ & $0.29(0.18-0.47)$ \\
$70+$ & 3.4 & $0.37(0.22-0.61)$ & $0.36(0.20-0.63)$ \\
\hline Women & & & \\
$<20$ & 6.9 & {$[1]$ reference } & {$[1]$ reference } \\
$20-29$ & 17.1 & $2.11(1.59-2.81)$ & $2.08(1.52-2.84)$ \\
$30-39$ & 12.4 & $2.11(1.54-2.90)$ & $2.01(1.42-2.85)$ \\
$40-49$ & 9.9 & $1.72(1.20-2.47)$ & $1.60(1.08-2.35)$ \\
$50-59$ & 8.2 & $1.36(0.94-1.98)$ & $1.25(0.83-1.90)$ \\
$60-69$ & 6.3 & $0.83(0.56-1.24)$ & $0.80(0.50-1.26)$ \\
$70+$ & 6.8 & $0.86(0.52-1.43)$ & $0.88(0.49-1.55)$ \\
\hline
\end{tabular}

Abbreviations: $\mathrm{Cl}$, confidence interval; IRR, Incidence Rate Ratio.

a Adjusted for period, population and methodological characteristics.

Table 5 Female to male incidence risk ratios over the age groups

\begin{tabular}{|c|c|c|}
\hline & Crude model & Adjusted model * \\
\hline Age group, yr & IRR $(95 \% \mathrm{Cl})^{\text {a }}$ & IRR $(95 \% \mathrm{Cl})$ b \\
\hline$<20$ & $0.57(0.46-0.72)$ & $0.53(0.41-0.68)$ \\
\hline $20-29$ & $0.49(0.43-0.55)$ & $0.47(0.40-0.54)$ \\
\hline $30-39$ & $0.82(0.73-0.92)$ & $0.81(0.72-0.91)$ \\
\hline $40-49$ & $1.17(0.98-1.40)$ & $1.18(0.99-1.41)$ \\
\hline $50-59$ & $1.35(1.09-1.68)$ & $1.39(1.14-1.70)$ \\
\hline $60-69$ & $1.46(1.09-1.96)$ & $1.45(1.06-1.97)$ \\
\hline $70+$ & $1.35(0.94-1.94)$ & $1.30(0.84-2.00)$ \\
\hline
\end{tabular}

Abbreviations: $\mathrm{Cl}$, confidence interval; IRR, Incidence Rate Ratio; a IRR $<1$ indicates higher relative risk in men and IRR $>1$ indicates higher relative risk in women b adjusted for period, population and methodological characteristics 


\section{COMMENT}

This meta-analysis demonstrated marked risk-differences of schizophrenia by age and sex that were not explained by differences in the underlying population distribution or by sample characteristics. As expected, schizophrenia risk rose steeply from (pre-) adolescence to reach its summit in early adulthood. This initial peak was followed by a rapid decline up to age 60 years, the point where age incidence rates levelled off to a low stable risk state. Marked sex differences in risk were apparent over the age span. Lifetime risk of developing schizophrenia was 1.2 times greater in men than in women, a figure only slightly smaller than those previously reported in the meta-analysis of Aleman and collegues 119. The initial high peak in men was followed by a dramatic drop in incidence rates starting at 30. Women, on the contrary, showed a much broader and lower incidence peak which was followed by a slower decline in risk over the age span. The slower decline of incidence rates in women with increasing age resulted in a small but significant female excess in middle and old age. Finally, and most surprisingly, the meta-analytic data could not support the generally accepted second incidence peak in middle aged women. Instead, women showed the same continuous incidence decline by age up to age 60 year.

The results support the prevailing notion that schizophrenia is primarily a disorder of early adulthood of probable neurodevelopmental origin 2 that is more prevalent in men ${ }^{9}$. The neurodevelopmental model posits that schizophrenia is the behavioral outcome of alterations in neurodevelopment that begin long before the onset of clinical symptoms 120. Early genetic and environmental risk factors, and most likely their combination ${ }^{121}$, may confer schizophrenia vulnerability by derailing normal developmental processes resulting in subtle pathologic alterations of specific neurons and their brain circuits. The timing of formal illness onset may further be determined by late maturational processes and 
environmental risks that 'unmask' the neurobiologically defined latent vulnerability 122 . Adolescence constitutes a particularly critical developmental phase for the emergence of psychotic symptoms, because of the extraordinary neural, hormonal, biochemical and interpersonal transitions that take place during this period 123 .

How to explain the marked sex disparity in the timing of illness onset? The greater male disposition for schizophrenia early in life is thought to arise from a slower pace of early developmental and later maturational processes and a differential exposure to gonodal hormones 7 , resulting in a greater male vulnerability and worse response to early developmental alterations 124 . The female brain develops more rapidly and is considered to be more resilient to these early environmental insults, yielding partial protection for early onset of schizophrenia. The onset of psychosis in women may further be delayed by the neuroprotective effects of estrogen during the critical adolescent phase 7,125 . Estrogen exerts antipsychotic effects on dopamine-D2 receptors which may temporarily delay the expression of psychosis vulnerability in women until estrogen levels wane during menopause 126 . The often reported second incidence peak around menopause is quoted in favour of the estrogen hypothesis 1 48. As mentioned previously, the current study failed to support a period of increased risk in middle-aged women 125 127. Although it may be argued that a brief rise in incidence rates around menopause may not have been picked up due to the application of ten year instead of five year age bands, this explanation seems unlikely due to the large number of total participants included. Hence, the oft reported second risk period in middle-aged women may be the result of artifact or chance, questioning the dominating view on the role of estrogen in the pathofysiology of sexdifferences in later life. Any reduction in estrogen-mediated protective effects would further be expected to impact psychosis expression in close proximity to menopause rather than well beyond this period. Whereas estrogen may impart important sex differences throughout life, especially 
during the critical phases of early development and later maturation, it is unlikely that the estrogen hypothesis accounts for the overrepresentation of women with onset of schizophrenia in late life. The delayed expression of schizophrenia vulnerability is most likely shaped by the additive and interactive exposure to psychosocial, neural or hormonal protective factors (or lack of risk factors) and normal or pathological age-related processes that impact on a milder or absent neurodevelopmental vulnerability 128 .

Finally, although not the primary aim of this meta-analysis, schizophrenia risk was lower in the more recently conducted studies and in rural areas. It must be emphasized that no causal inference can be drawn from these results since the included studies were not specifically designed to estimate risk differences over time and place. Nevertheless, the observed heterogeneity in schizophrenia risk over time and in urban versus rural areas supports previous work 129 108. Moreover, the finding that the heterogeneity could not be attributed to differences in the underlying age and sex distribution or sampling strategies add to the prevailing notion that exposure to socio-environmental risk factors over time and in place may modulate schizophrenia risk ${ }^{130}$.

To the best of our knowledge, this study is the first to systematically examine variations in risk for schizophrenia by age and sex covering the whole age span. Moreoever, we used an individual participant meta-analytic approach which yields many advantages over the mostly adopted aggregate meta-analytic approach ${ }^{15}$. The establishment of ageand sex-specific incidence rates for schizophrenia is of great importance for policy makers, mental health service development and service planning. Delineating the timing of schizophrenia onset reveals the window of opportunity for possible early detection and preventive strategies. The results further highlight that a small, but not negligible, proportion of individuals develop schizophrenia after age 65 years. These numbers will rise significantly when the first of the post-war "baby boom" generation will reach the age of 65 years by the end of 2010131 . Hence, the number of 
individuals in the community with late-onset psychotic disorder is expected to rise as well. The concept of prevention should therefore not be restricted to adolescents only and should be applied to elderly persons as well ${ }^{132}$. Finally, future research must go beyond identifying risk factors for schizophrenia, but should instead target at finding possible biological and psychosocial protective factors that delay onset.

While individual participant meta-analysis is considered the gold standard for meta-analyses, some methodological concerns remain. First, although publication and reporting biases are less likely to occur in incidence studies, other factors (i.e. lack of time, unwillingness or unavailabity of data) may still put constraints on the comprehensiveness of the included studies. The studies available for the analyses may thus constitute a biased subset of all existing studies, introducing availability bias. Although this possibility cannot not be refuted, the finding of similarities in sample characteristics among the different subsets of samples in this meta-analysis suggests otherwise. Second, although data was available at the individual level for age, sex and study period, this was not the case for other sample characteristics, such as urbanicity, developmental level and methodology. Using these aggregated data to explore additional sources of heterogeneity in the age and sex distribution of schizophrenia would introduce ecological bias. Hence, no further subgroup testing was conducted. This may not be a limitation per se since sub-group analysis is considered potentially misleading as it introduces the possibility of both systematic error (bias) and random error (chance) 133. Further, independent of which type of meta-analysis is applied, poor study design and conduct have the power to distort risk estimates. However, using such an extensive dataset will likely mimimize the influence exerted by poorly conducted studies. Besides limitations inherent to methodology, bias may occur at the level of patient identification. Estimations of risk for schizophrenia in the elderly are likely underestimations of true risk due to an apparent reluctance in clinicians to 
Risk for Psychosis: A Life Span Perspective

diagnose schizophrenia in the elderly 115, 134. Finally, limited data is available from developing countries. Only nine (of which four included and five excluded because of limited data availability) samples were collected in developing countries. The findings therefore may not be generalisable to developing countries, especially since sex differences may show a different distribution by age in these countries 135 . 


\section{Chapter 2}

** Research Initiative into Schizophrenia Epidemiology (RISE) Investigators:

Margriet van der Werf, Judith Allardyce, Manon Hanssen, Sebastian Köhler, Jim van Os, Frans Verhey, Inge Lynge, Jim van Os, Jean-Paul Selten, Jan-Dirk-Blom, Natalie Veen, Caroline Verheyde-Zeyl, John Geddes, Michael Goldacre, David GR Yeates, Neil Nixon, Vladeta Adjacic, Wulf Rössler, Trizia Baldwin, John Waddington, James Kirkbride, Craig Morgan, Paola Dazzan, Robin Murray, Peter B Jones, Gillian Doody, Glynn Harrison, Julian Leff, Jeremy W Coid, Paul Fearon, JE Andersen, Torfinn Hynnekleiv, Robin McCreadie, Harper Gilmour, Paolo Menezes, Geoffrey Smith, William Iacono, Anne Thorup, Carsten Pedersen, Heinz Häfner, Wolfram an der Heiden, Frederick Hickling, Jaap Peen, Jack Dekker, Ron de Graaf, Wim Veling, Wijbrand Hoek, Mats Bogren, Wulf Rössler, Jane Boydell, David Castle, Emma Mitford, Neil Nixon, John Brewin, Michael Goldacre, John Geddes, Nori Takei and Francesco Ammaddeo. 
1. Hafner H, Maurer K, Loffler W, Riecher-Rossler A. The influence of age and sex on the onset and early course of schizophrenia. Br J Psychiatry. Jan 1993;162:80-86.

2. Weinberger DR. Implications of normal brain development for the pathogenesis of schizophrenia. Arch Gen Psychiatry. Jul 1987;44(7):660-669.

3. Angermeyer MC, Kuhn L. Gender differences in age at onset of schizophrenia. An overview. Eur Arch Psychiatry Neurol Sci. Sep 1988;237(6):351-364.

4. Hafner H, Riecher A, Maurer K, Loffler W, Munk-Jorgensen P, Stromgren E. How does gender influence age at first hospitalization for schizophrenia? A transnational case register study. Psychol Med. Nov 1989;19(4):903-918.

5. Hambrecht M, Maurer K, Hafner H, Sartorius N. Transnational stability of gender differences in schizophrenia? An analysis based on the WHO study on determinants of outcome of severe mental disorders. Eur Arch Psychiatry Clin Neurosci. 1992;242(1):6-12.

6. Jablensky A, Sartorius N, Ernberg G, et al. Schizophrenia: manifestations, incidence and course in different cultures. A World Health Organization ten-country study. Psychol Med Monogr Suppl. 1992;20:1-97.

7. Seeman MV. The role of estrogen in schizophrenia. J Psychiatry Neurosci. Mar 1996;21(2):123-127.

8. DeLisi LE, Devoto M, Lofthouse R, et al. Search for linkage to schizophrenia on the $X$ and $Y$ chromosomes. Am J Med Genet. Jun 15 1994;54(2):113-121.

9. Murray RM, O'Callaghan E, Castle DJ, Lewis SW. A neurodevelopmental approach to the classification of schizophrenia. Schizophr Bull. 1992;18(2):319-332.

10. Esterberg ML, Trotman HD, Holtzman C, Compton MT, Walker EF. The impact of a family history of psychosis on age-at-onset and positive and negative symptoms of schizophrenia: A meta-analysis. Schizophr Res. 2010; In Press, Corrected Proof.

11. Rosenfield PJ, Kleinhaus K, Opler M, et al. Later paternal age and sex differences in schizophrenia symptoms. Schizophr Res. Feb 2010;116(2-3):191-195.

12. Jablensky A, Cole SW. Is the earlier age at onset of schizophrenia in males a confounded finding? Results from a cross-cultural investigation. Br J Psychiatry. Mar 1997; 170:234-240.

13. Venkatesh BK, Thirthalli J, Naveen MN, et al. Sex difference in age of onset of schizophrenia: findings from a community-based study in India. World Psychiatry. Oct 2008;7(3):173-176.

14. Castle DJ, Wessely S, Murray RM. Sex and schizophrenia: effects of diagnostic stringency, and associations with and premorbid variables. BrJ Psychiatry. May 1993;162:658-664.

15. Riley RD, Lambert PC, Abo-Zaid G. Meta-analysis of individual participant data: rationale, conduct, and reporting. Bmj. 2010;340:c221.

16. Stewart LA, Parmar MK. Meta-analysis of the literature or of individual patient data: is there a difference? Lancet. Feb 13 1993;341(8842):418-422.

17. Stroup DF, Berlin JA, Morton SC, et al. Meta-analysis of observational studies in epidemiology: a proposal for reporting. Meta-analysis Of Observational Studies in Epidemiology (MOOSE) group. JAMA. Apr 19 2000;283(15):2008-2012.

18. McGrath J, Saha S, Welham J, El Saadi O, MacCauley C, Chant D. A systematic review of the incidence of schizophrenia: the distribution of rates and the influence of sex, urbanicity, migrant status and methodology. BMC Med. 2004;2(1):13.

19. Howard R, Rabins PV, Seeman MV, Jeste DV. Late-onset schizophrenia and very-late-onset schizophrenia-like psychosis: an international consensus. The International Late-Onset Schizophrenia Group. Am J Psychiatry. Feb 2000;1 57(2):172-178.

20. World Bank World Development Indicators. http://data.worldbank.org/data-catalog. Accessed 23/7/2010.

21. United Nations Human Development Report 2009. 2009. 


\section{Chapter 2}

22. American Psychiatric Association Diagnostic and Statistical Manual of Mental Disorders. Fourth edition ed. Washington, DC; 1994.

23. American Psychiatric Association. Diagnostic and Statistical Manual of Mental Disorders. Revised Third Edition ed. Washington, DC: American Psychiatric Association 1987.

24. Diagnostic and Statistical Manual of Mental Disorders (DSM-IV). Washington, DC: American Psychiatric Association; 1994.

25. World Health Organization International Classification of Diseases, Ninth Revision (ICD-9). . Geneva, Switzerland: World Health Organization; 1977.

26. World Health Organization International Classification of Diseases, 10th Revision (ICD-10). Geneva, Switzerland: World Health Organization; 1992.

27. Spitzer RL, Endicott J, Robins E. Research Diagnostic Criteria: Rationale and Reliability. Arch Gen Psychiatry. June 1, 1978 1978;35(6):773-782.

28. Stata Statistical Software [computer program]. Version Release 11.0. Texas; 2009.

29. Adelstein AM, Downham DY, Stein Z, Susser MW. The Epidemiology of Mental Illness in an English City. Inceptions Recognized by Salford Psychiatric Services. Social Psychiatry. 1968;3(2):47-59.

30. Ajdacic-Gross V, Lauber C, Warnke I, Haker H, Murray RM, Rossler W. Changing incidence of psychotic disorders among the young in Zurich. Schizophr Res. Sep 2007;95(1-3):9-18.

31. Al Mousawi AH, Dunstan FD. Changes in the risk of schizophrenia in Scotland: is there an environmental factor? Schizophr Bull. 1998;24(4):529-535.

32. Allardyce J, Boydell J, Van Os J, et al. Comparison of the incidence of schizophrenia in rural Dumfries and Galloway and urban Camberwell. BrJ Psychiatry Oct 2001;179:335-339.

33. Allardyce J, Gilmour H, Atkinson J, Rapson T, Bishop J, McCreadie RG. Social fragmentation, deprivation and urbanicity: relation to first-admission rates for psychoses. British Journal of Psychiatry. Nov 2005;187:401-406.

34. Allardyce J, Morrison G, Van Os J, Kelly J, Murray RM, McCreadie RG. Schizophrenia is not disappearing in south-west Scotland. BrJ Psychiatry. Jul 2000;1 77:38-41.

35. Andersen JE, Hynnekleiv T. Hospital-treated psychosis and suicide in a rural community (1877-2005). Part 2: Genetic founder effects. Acta Psychiatr Scand Suppl. 2007(436):20-32.

36. Baldwin P, Browne D, Scully PJ, et al. Epidemiology of first-episode psychosis: illustrating the challenges across diagnostic boundaries through the Cavan-Monaghan study at 8 years. Schizophr Bull. Jul 2005;31(3):624-638.

37. Balestrieri M, Rucci P, Nicolaou S. Gender-specific decline and seasonality of births in operationally defined schizophrenics in italy. Schizophrenia Research. 1997;27(1):73-81.

38. Bhugra D, Leff J, Mallett R, Der G, Corridan B, Rudge S. Incidence and outcome of schizophrenia in Whites, African-Caribbeans and Asians in London. Psychological Medicine. 1997;27(04):791-798.

39. Bijl RV, de Graaf R, Ravelli A, Smit F, Vollebergh WAM. Gender and age-specific first incidence of DSM-III-R psychiatric disorders in the general population Results from the Netherlands Mental Health Survey and Incidence Study (NEMESIS). Social Psychiatry and Psychiatric Epidemiology. 2002;37(8):372-379.

40. Bland RC. Demographic aspects of functional psychoses in Canada. Acta Psychiatr Scand. May 1977;55(5):369-380.

41. Bland RC, Orn H. 14-year outcome in early schizophrenia. Acta Psychiatr Scand. Oct 1978;58(4):327-338.

42. Bogren M, Mattisson C, Horstmann V, Bhugra D, Munk-Jorgensen P, Nettelbladt P. Lundby revisited: first incidence of mental disorders 1947-1997. Aust N Z J Psychiatry. Feb 2007;41(2):178-186.

43. Bogren M, Mattisson C, Isberg PE, Munk-Jorgensen P, Nettelbladt P. Incidence of psychotic disorders in the 50 year follow up of the Lundby population. Australian and New Zealand Journal of Psychiatry. Jan 2010;44(1):31-39. 


\section{Risk for Psychosis: A Life Span Perspective}

44. Boydell J, Van Os J, Lambri M, et al. Incidence of schizophrenia in south-east London between 1965 and 1997. BrJ Psychiatry. Jan 2003;182:45-49.

45. Boydell J, van Os J, McKenzie K, et al. Incidence of schizophrenia in ethnic minorities in London: ecological study into interactions with environment. Bmj. Dec 8 2001;323(7325):1336-1338.

46. Boydell J, van Os J, McKenzie K, Murray RM. The association of inequality with the incidence of schizophrenia--an ecological study. Social Psychiatry and Psychiatric Epidemiology. Aug 2004;39(8):597-599.

47. Brewin J, Cantwell R, Dalkin T, et al. Incidence of schizophrenia in Nottingham. A comparison of two cohorts, 1978-80 and 1992-94. BrJ Psychiatry. Aug 1997;171:140-144.

48. Castle D. Decline in the incidence of schizophrenia. The British Journal of Psychiatry. June 1, 1993 1993;162(6):847a-.

49. Castle D. Rates of schizophrenia among males and females. Am J Psychiatry. September 1, 1993 1993;150(9):1431b-1432.

50. Castle D, Wessely S, Der G, Murray RM. The incidence of operationally defined schizophrenia in Camberwell, 1965-84. BrJ Psychiatry. Dec 1991;159:790-794.

51. Cavanagh JT, Shajahan PM. Increasing rates of hospital admission for men with major mental illnesses: data from Scottish mental health units, 1980-1995. Acta Psychiatr Scand. May 1999;99(5):353-359.

52. Cochrane R, Bal SS. Migration and schizophrenia: an examination of five hypotheses. SoC Psychiatry. 1987;22(4):181-191.

53. Cochrane R, Bal SS. Mental hospital admission rates of immigrants to England: a comparison of 1971 and 1981. Soc Psychiatry Psychiatr Epidemiol. Jan 1989;24(1):2-11.

54. Coid JW, Kirkbride JB, Barker D, et al. Raised Incidence Rates of All Psychoses Among Migrant Groups Findings From the East London First Episode Psychosis Study. Arch Gen Psychiatry. Nov 2008;65(1 1):1250-1258.

55. Cooper JE, Goodhead D, Craig T, Harris M, Howat J, Korer J. The incidence of schizophrenia in Nottingham. BrJ Psychiatry. Nov 1987;151:619-626.

56. Dauncey K, Giggs J, Baker K, Harrison G. Schizophrenia in Nottingham: lifelong residential mobility of a cohort. BrJ Psychiatry. Nov 1993;163:613-619.

57. de Salvia D, Barbato A, Salvo P, Zadro F. Prevalence and incidence of schizophrenic disorders in Portogruaro. An Italian case register study. J Nerv Ment Dis. May 1993;181 (5):275-282.

58. Dean G, Downing H, Shelley E. First admissions to psychiatric hospitals in south-east England in 1976 among immigrants from Ireland. Br Med J (Clin Res Ed). Jun 6 1981;282(6279):1831-1833.

59. Dean G, Walsh D, Downing H, Shelley E. First admissions of native-born and immigrants to psychiatric hospitals in South-East England 1976. Br J Psychiatry. Dec 1981;139:506-512.

60. Dekker J, Peen J, Heijnen H, Kwakman H, Sanders H. [Psychiatric admissions in Amsterdam according to ethnic background and diagnosis]. Ned Tijdschr Geneeskd. Feb 17 1996;140(7):368-371.

61. Eagles JM, Whalley LJ. Decline in the diagnosis of schizophrenia among first admissions to Scottish mental hospitals from 1969-78. BrJ Psychiatry. Feb 1985;146:151-154.

62. Fearon P, Kirkbride JB, Morgan C, et al. Incidence of schizophrenia and other psychoses in ethnic minority groups: results from the MRC AESOP study. Psychological Medicine. Nov 2006;36(11):1541-1550.

63. Gater R, Amaddeo F, Tansella M, Jackson G, Goldberg D. A comparison of community-based care for schizophrenia in south Verona and south Manchester. BrJ Psychiatry. Mar 1995;166(3):344-352.

64. Geddes JR, Black RJ, Whalley LJ, Eagles JM. Persistence of the decline in the diagnosis of schizophrenia among first admissions to Scottish hospitals from 1969 to $1988 . \mathrm{Br} J$ Psychiatry. Nov 1993;163:620-626. 


\section{Chapter 2}

65. Goldacre M, Shiwach R, Yeates D. Estimating incidence and prevalence of treated psychiatric disorders from routine statistics: the example of schizophrenia in Oxfordshire. J Epidemiol Community Health. Jun 1994;48(3):318-322.

66. Goldstein G, Hall W, Andrews G. The incidence of schizophrenia in New South Wales, Australia. A psychiatric register study. Acta Psychiatrica Scandinavica. Sep 1984;70(3):220227.

67. Hanoeman M, Selten JP, Kahn RS. Incidence of schizophrenia in Surinam. Schizophr Res. Apr 1 2002;54(3):219-221.

68. Harrison G, Glazebrook C, Brewin J, et al. Increased incidence of psychotic disorders in migrants from the Caribbean to the United Kingdom. Psychol Med. Jul 1997;27(4):799-806.

69. Helgason L. Psychiatric services and mental illness in Iceland. Incidence study (1966-1967) with 6-7 year follow-up. Acta Psychiatr Scand Suppl. 1977(268):1-140.

70. Hickling FW, Rodgers-Johnson P. The incidence of first contact schizophrenia in Jamaica. $B r J$ Psychiatry. Aug 1995;167(2):193-196.

71. Iacono WG, Beiser M. Are males more likely than females to develop schizophrenia? $\mathrm{Am} J$ Psychiatry. Aug 1992;149(8):1070-1074.

72. Joensen S, Wang AG. First admissions for psychiatric disorders. A comparison between the Faroe Islands and Denmark. Acta Psychiatr Scand. Jul 1983;68(1):66-71.

73. Kirkbride JB, Barker D, Cowden F, et al. Psychoses, ethnicity and socio-economic status. BrJ Psychiatry. Jul 2008;193(1):18-24.

74. Kirkbride JB, Boydell J, Ploubidis GB, et al. Testing the association between the incidence of schizophrenia and social capital in an urban area. Psychological Medicine. Aug 2008;38(8):1083-1094.

75. Kirkbride JB, Croudace T, Brewin J, et al. Is the incidence of psychotic disorder in decline? Epidemiological evidence from two decades of research. International Journal of Epidemiology. Oct 2009;38(5):1255-1264.

76. Kirkbride JB, Fearon P, Morgan C, et al. Neighbourhood variation in the incidence of psychotic disorders in Southeast London. Soc Psychiatry Psychiatr Epidemiol. Jun 2007;42(6):438-445.

77. Kirkbride JB, Fearon P, Morgan C, et al. Heterogeneity in incidence rates of schizophrenia and other psychotic syndromes: findings from the 3-center AeSOP study. Arch Gen Psychiatry. Mar 2006;63(3):250-258.

78. Kirkbride JB, Morgan C, Fearon P, Dazzan P, Murray RM, Jones PB. Neighbourhood-level effects on psychoses: re-examining the role of context. Psychological Medicine. Oct 2007;37(10):1413-1425.

79. Larsson T, Sjogren T. A methodological, psychiatric and statistical study of a large Swedish rural population. Acta Psychiatr Neurol Scand Suppl. 1954;89:11-250.

80. Lynge I, Jacobsen J. Schizophrenia in Greenland - A follow-up-study. Acta Psychiatrica Scandinavica. Jun 1995;91(6):414-422.

81. Malzberg B. Internal migration and mental disease among the white population of New York state, 1960-1961. Int J Soc Psychiatry. Summer 1967;13(3):184-191.

82. Malzberg B. Mental disease among Jews in New York State, 1960-1961. A study of ethnic variation in incidence. Acta Psychiatr Scand. 1973;49(4):479-518.

83. Marcelis M, Navarro-Mateu F, Murray R, Selten JP, Van Os J. Urbanization and psychosis: a study of 1942-1978 birth cohorts in The Netherlands. Psychological Medicine. Jul 1998;28(4):871-879.

84. McCabe MS. Demographic differences in functional psychoses. BrJ Psychiatry. Oct 1975;127:320-323.

85. Menezes PR, Scazufca M, Busatto G, Coutinho LM, McGuire PK, Murray RM. Incidence of first-contact psychosis in Sao Paulo, Brazil. BrJ Psychiatry Suppl. Dec 2007;51:s102-106.

86. Morgan C, Dazzan P, Morgan K, et al. First episode psychosis and ethnicity: initial findings from the AESOP study. World Psychiatry. Feb 2006;5(1):40-46. 


\section{Risk for Psychosis: A Life Span Perspective}

87. Mortensen PB, Pedersen CB, Westergaard T, et al. Effects of family history and place and season of birth on the risk of schizophrenia. N Eng/J Med. Feb 25 1999;340(8):603-608.

88. Munk-Jorgensen P. Decreasing first-admission rates of schizophrenia among males in Denmark from 1970 to 1984. Changing diagnostic patterns? Acta Psychiatr Scand. Jun 1986;73(6):645-650.

89. Munk-Jorgensen P. Schizophrenia in Denmark. Incidence and utilization of psychiatric institutions. Acta Psychiatr Scand. Feb 1986;73(2):172-180.

90. Munk-Jorgensen P, Jorgensen P. Decreasing rates of first-admission diagnoses of schizophrenia among females in Denmark 1970-84. Acta Psychiatr Scand. Oct 1986;74(4):379-383.

91. Munk-Jørgensen P, Mortensen P. Is schizophrenia really on the decrease? European Archives of Psychiatry and Clinical Neuroscience. 1993;242(4):244-247.

92. Munk-Jorgensen P, Mortensen PB. Incidence and other aspects of the epidemiology of schizophrenia in Denmark, 1971-87. British Journal of Psychiatry. Oct 1992;161:489-495.

93. ni Nuallain M, O'Hare A, Walsh D, Blake B, Halpenny JN, O'Brien PF. The incidence of mental illness in Ireland - patients contacting psychiatric services in three Irish counties. IrJ Psychiatry. 1984;5:23-29.

94. Nixon NL, Doody GA. Official psychiatric morbidity and the incidence of schizophrenia 1881-1994. Psychol Med. Aug 2005;35(8):1145-1153.

95. Palmquist J, Wang AG. Schizophrenia in the Faroe Islands. Nordic Journal of Psychiatry. 1997;51(5):351-357.

96. Pedersen CB. No evidence of time trends in the urban-rural differences in schizophrenia risk among five million people born in Denmark from 1910 to 1986. Psychol Med. Feb 2006;36(2):211-219.

97. Pedersen CB, Mortensen PB. Family history, place and season of birth as risk factors for schizophrenia in Denmark: a replication and reanalysis. British Journal of Psychiatry. Jul $2001 ; 179: 46-52$.

98. Proctor SE, Mitford E, Paxton R. First episode psychosis: a novel methodology reveals higher than expected incidence; a reality-based population profile in Northumberland, UK. J Eval Clin Pract. Nov 2004;10(4):539-547.

99. Reay R, Mitford E, McCabe K, Paxton R, Turkington D. Incidence and diagnostic diversity in first-episode psychosis. Acta Psychiatrica Scandinavica. Apr 2010;121(4):315-319.

100. Rwegellera GGC. Psychiatric morbidity among West Africans and West Indians living in London. Psychological Medicine Monograph Supplement. 1977;7:317-329.

101. Salokangas RK. First admissions for psychosis in Turku. A time trend study. Acta Psychiatr Scand. Sep 1979;60(3):249-262.

102. Schelin EM, Munk-Jorgensen P, Olesen AV, Gerlach J. Regional differences in schizophrenia incidence in Denmark. Acta Psychiatrica Scandinavica. Apr 2000;101(4):293-299.

103. Scully PJ, Quinn JF, Morgan MG, et al. First-episode schizophrenia, bipolar disorder and other psychoses in a rural Irish catchment area: incidence and gender in the CavanMonaghan study at 5 years. BrJ Psychiatry Suppl. Sep 2002;43:s3-9.

104. Selten JP, Sijben N. First admission rates for schizophrenia in immigrants to The Netherlands. The Dutch National Register. Soc Psychiatry Psychiatr Epidemiol. Apr 1994;29(2):71-77.

105. Selten JP, Veen N, Feller W, et al. Incidence of psychotic disorders in immigrant groups to The Netherlands. BrJ Psychiatry. Apr 2001;178:367-372.

106. Selten JP, Zeyl C, Dwarkasing R, Lumsden V, Kahn RS, Van Harten PN. First-contact incidence of schizophrenia in Surinam. BrJ Psychiatry. Jan 2005;186:74-75.

107. Smith GN, Boydell J, Murray RM, et al. The incidence of schizophrenia in European immigrants to Canada. Schizophr Res. Oct 2006;87(1-3):205-211.

108. Takei N, Lewis G, Sham PC, Murray RM. Age-period-cohort analysis of the incidence of schizophrenia in Scotland. Psychol Med. Sep 1996;26(5):963-973. 


\section{Chapter 2}

109. Tello JE, Mazzi M, Tansella M, Bonizzato P, Jones J, Amaddeo F. Does socioeconomic status affect the use of community-based psychiatric services? A South Verona case register study. Acta Psychiatr Scand. Sep 2005;112(3):215-223.

110. Thomas CS, Stone K, Osborn M, Thomas PF, Fisher M. Psychiatric morbidity and compulsory admission among UK-born Europeans, Afro-Caribbeans and Asians in central Manchester. BrJ Psychiatry. Jul 1993;163:91-99.

111. Thornicroft G, Bisoffi G, De Salvia D, Tansella M. Urban-rural differences in the associations between social deprivation and psychiatric service utilization in schizophrenia and all diagnoses: a case-register study in Northern Italy. Psychol Med. May 1993;23(2):487-496.

112. Thorup A, Waltoft BL, Pedersen CB, Mortensen PB, Nordentoft M. Young males have a higher risk of developing schizophrenia: a Danish register study. Psychol Med. Apr 2007;37(4):479-484.

113. Tsuchiya KJ, Munk-Jorgensen P. First-admission rates of schizophrenia in Denmark, 19801997: have they been increasing? Schizophr Res. Apr 1 2002;54(3):187-191.

114. van Os J, Castle DJ, Takei N, Der G, Murray RM. Psychotic illness in ethnic minorities: clarification from the 1991 census. Psychol Med. Jan 1996;26(1):203-208.

115. van Os J, Galdos P, Lewis G, Bourgeois M, Mann A. Schizophrenia sans frontieres: concepts of schizophrenia among French and British psychiatrists. Bmj. Aug 21 1993;307(6902):489492.

116. van Os J, Howard R, Takei N, Murray R. Increasing age is a risk factor for psychosis in the elderly. Social Psychiatry and Psychiatric Epidemiology. Jul 1995;30(4):161-164.

117. Veling W, Selten JP, Veen N, Laan W, Blom JD, Hoek HW. Incidence of schizophrenia among ethnic minorities in the Netherlands: A four-year first-contact study. Schizophrenia Research. Sep 2006;86(1-3):189-193.

118. Welham JL, Thomis RJ, McGrath JJ. Age-at-first-registration for affective psychosis and schizophrenia. Schizophr Bull. 2004;30(4):849-853.

119. Aleman A, Kahn RS, Selten JP. Sex differences in the risk of schizophrenia: evidence from meta-analysis. Arch Gen Psychiatry. Jun 2003;60(6):565-571.

120. Rapoport JL, Addington AM, Frangou S, Psych MRC. The neurodevelopmental model of schizophrenia: update 2005. Mol Psychiatry. 2005;10(5):434-449.

121. van Os J, Rutten BP, Poulton R. Gene-environment interactions in schizophrenia: review of epidemiological findings and future directions. Schizophrenia Bulletin. Nov 2008;34(6):1066-1082.

122. Andersen SL. Trajectories of brain development: point of vulnerability or window of opportunity? Neurosci Biobehav Rev. Jan-Mar 2003;27(1-2):3-18.

123. Keshavan MS, Hogarty GE. Brain maturational processes and delayed onset in schizophrenia. Dev Psychopathol. Summer 1999;11(3):525-543.

124. Raz S, Goldstein R, Hopkins TL, Lauterbach MD, Shah F, Porter CL. Sex differences in early vulnerability to cerebral injury and their neurodevelopmental implications. Psychobiology. 1994;22(3):244-253.

125. Hafner H, Riecher-Rossler A, An Der Heiden W, Maurer K, Fatkenheuer B, Loffler W. Generating and testing a causal explanation of the gender difference in age at first onset of schizophrenia. Psychol Med. Nov 1993;23(4):925-940.

126. Kulkarni J, de Castella A, Fitzgerald PB, et al. Estrogen in Severe Mental Illness: A Potential New Treatment Approach. Arch Gen Psychiatry. August 1, 2008 2008;65(8):955-960.

127. Castle DJ, Abel K, Takei N, Murray RM. Gender Differences in Schizophrenia: Hormonal Effect or Subtypes? Schizophr Bull. 1995;21(1):1-12.

128. Vahia IV, Palmer BW, Depp C, et al. Is late-onset schizophrenia a subtype of schizophrenia? Acta Psychiatr ScandFeb 252010.

129. Krabbendam L, van Os J. Schizophrenia and urbanicity: a major environmental influence-conditional on genetic risk. Schizophr Bull. Oct 2005;31 (4):795-799.

130. Van Os J, Kenis G, Rutten PF. The Environment and schizophrenia. Nature. 2010; In press. 


\section{Risk for Psychosis: A Life Span Perspective}

131. Jeste DV, Alexopoulos GS, Bartels SJ, et al. Consensus statement on the upcoming crisis in geriatric mental health: research agenda for the next 2 decades. Arch Gen Psychiatry. Sep 1999;56(9):848-853.

132. Lebowitz BD, Pearson JL. Intervention research in psychosis: prevention trials. Schizophr Bull. 2000;26(3):543-549.

133. Oxman A, Clarke M, Stewart L. From Science to Practice: Meta-Analyses Using Individual Patient Data are Needed. JAMA. 1995;274:845 - 846.

134. Harris MJ, Jeste DV. Late-onset schizophrenia: an overview. Schizophr Bull. 1988;14(1):3955.

135. Gangadhar BN, Selvan CP, Subbakrishna DK, Janakiramaiah N. Age-at-onset and schizophrenia: reversed gender effect. Acta Psychiatr Scand. 2002;105(4):317-319. 


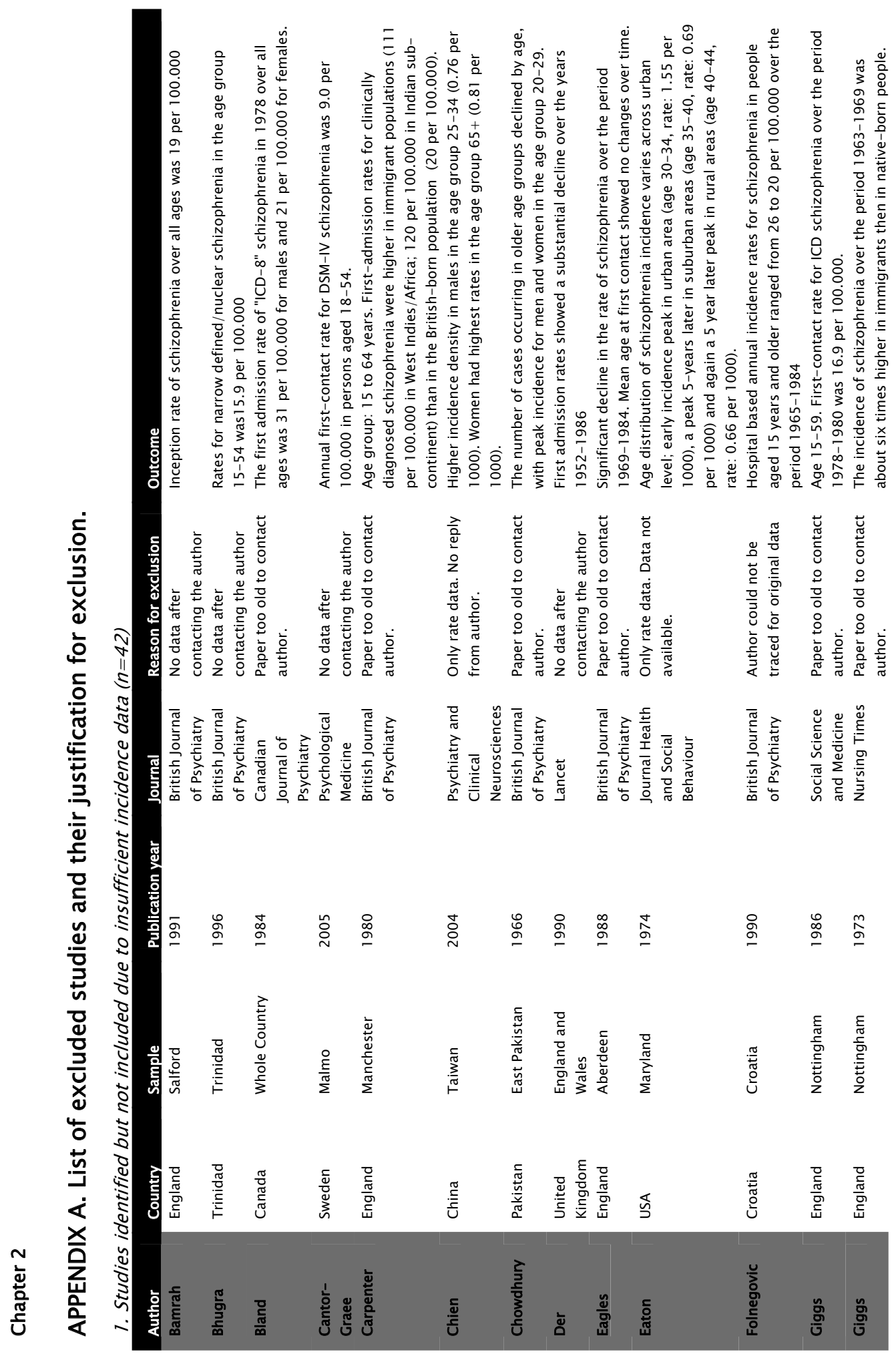




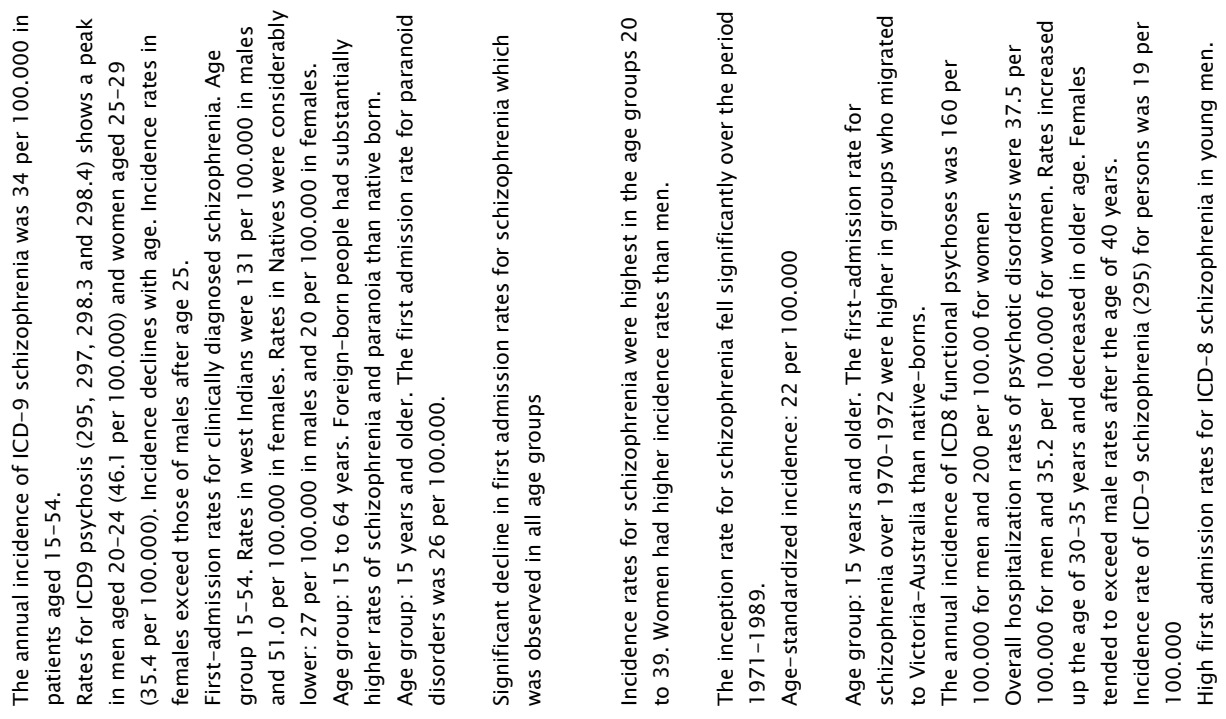

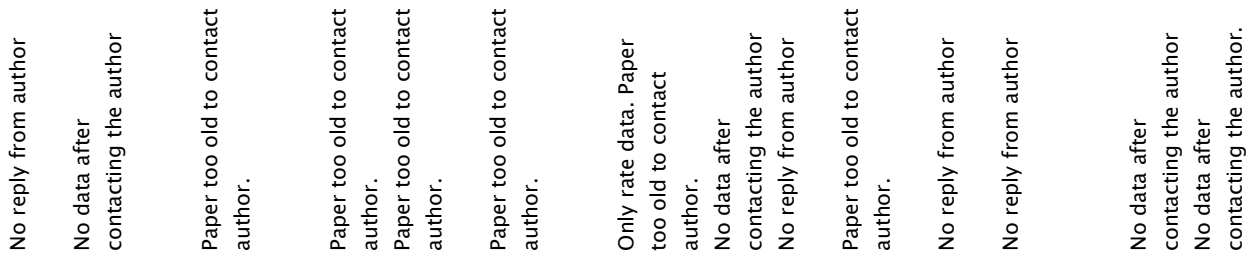

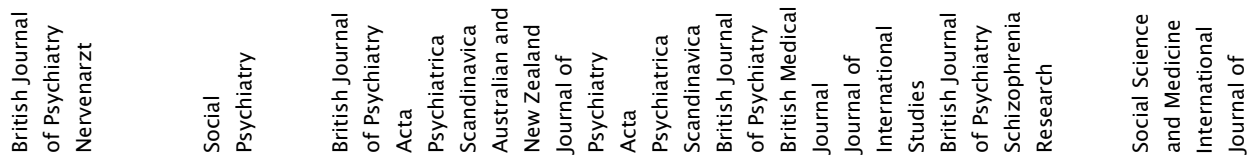

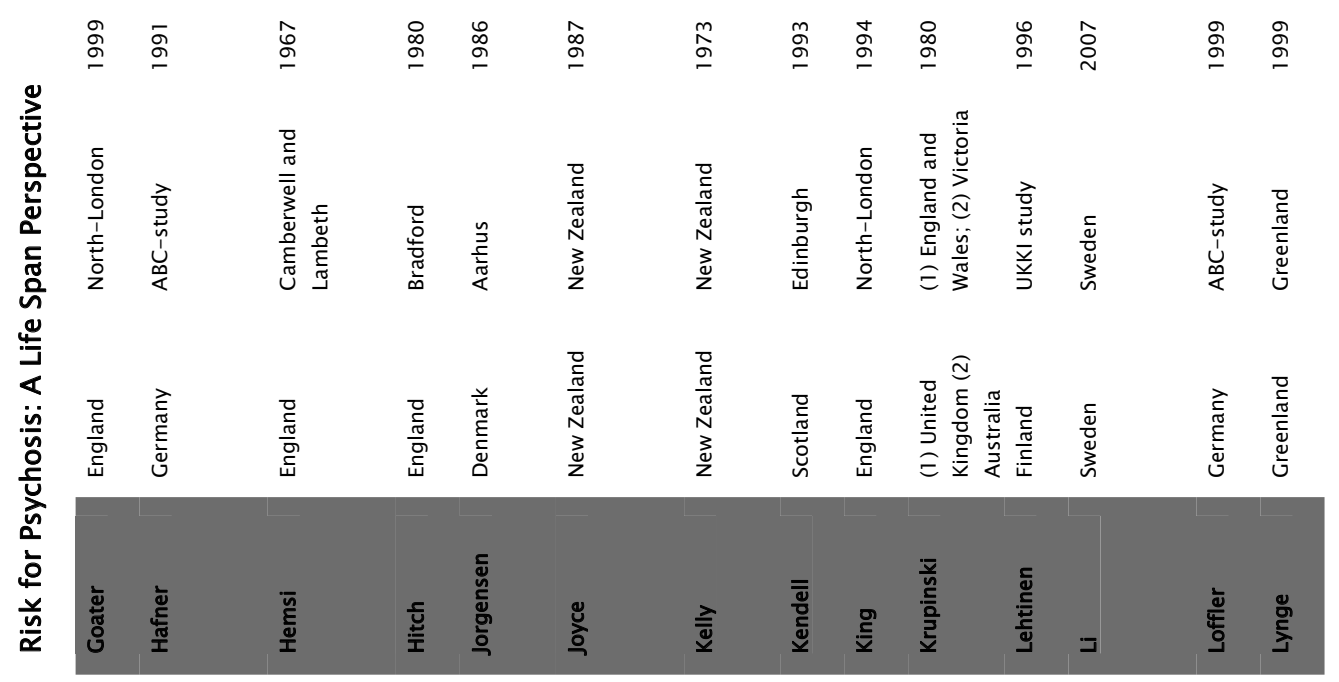




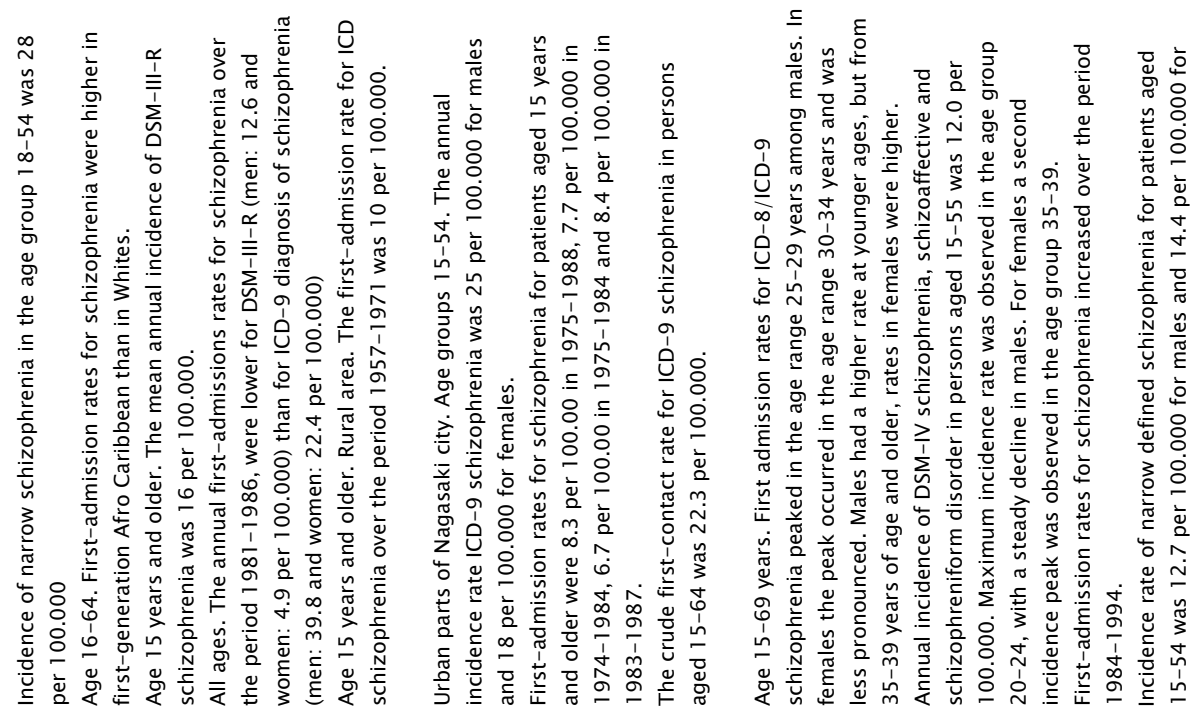

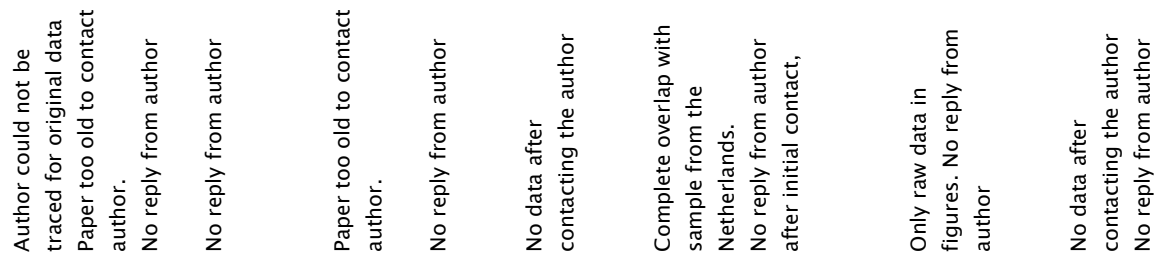

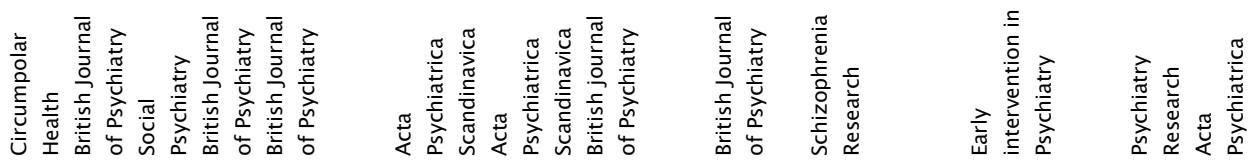

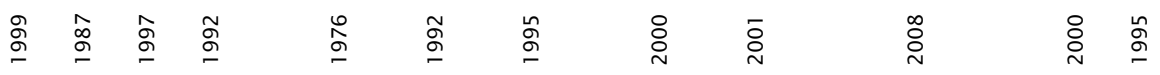

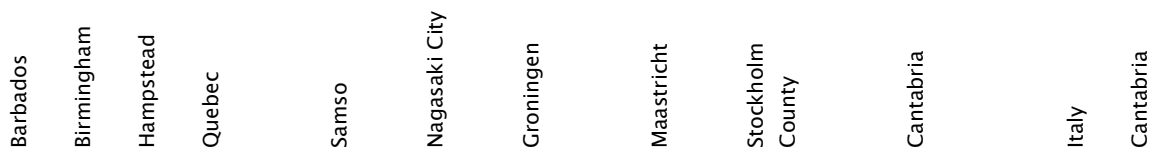

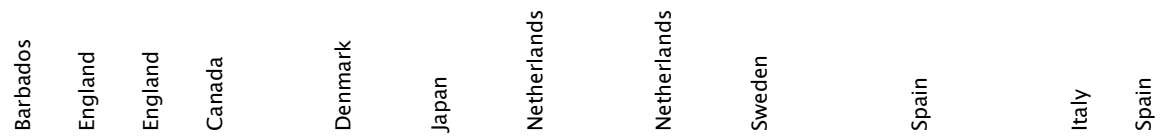

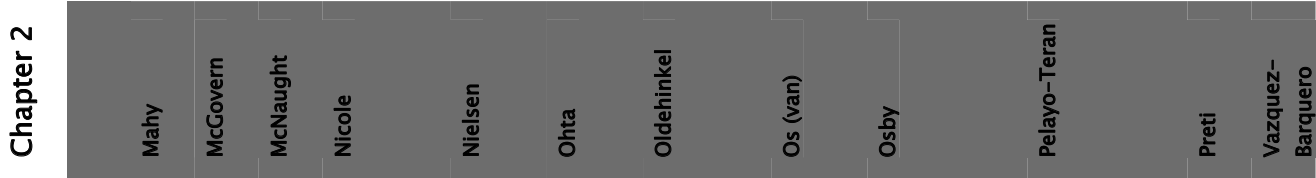




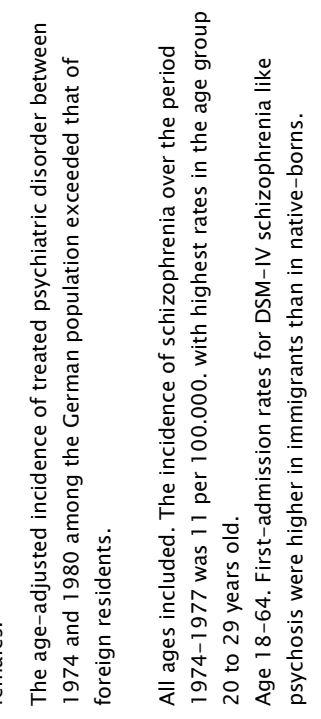

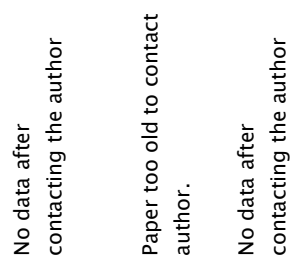

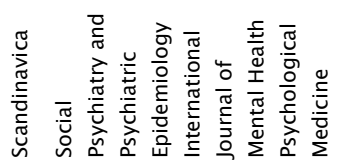

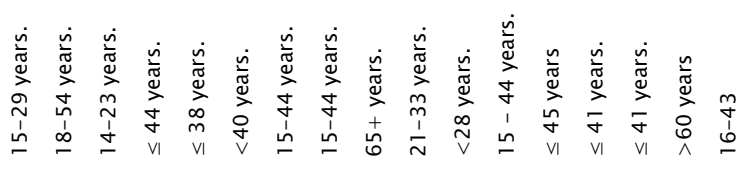
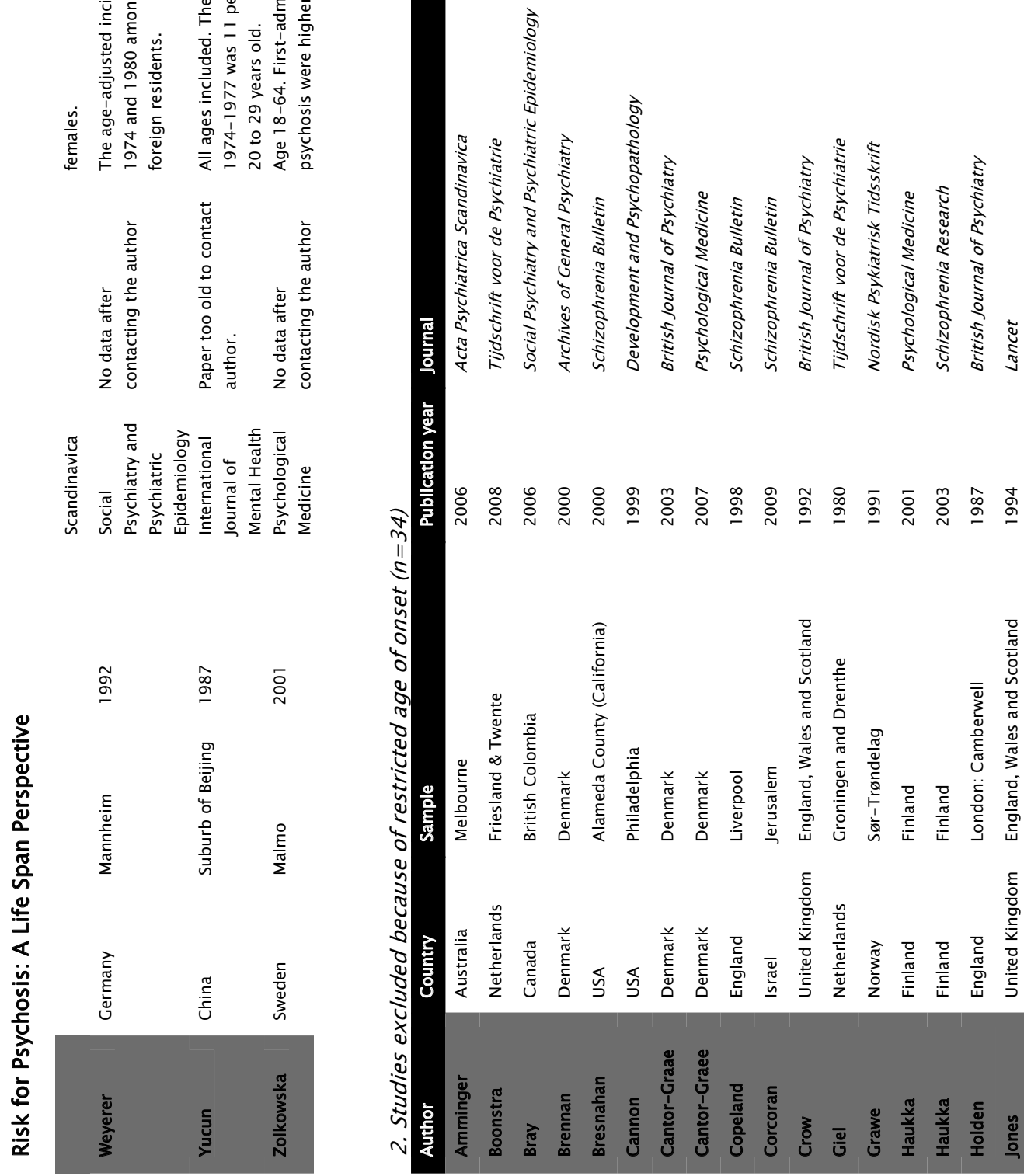

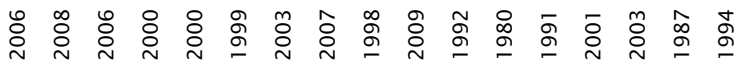

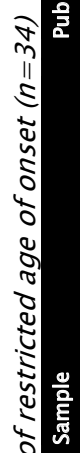

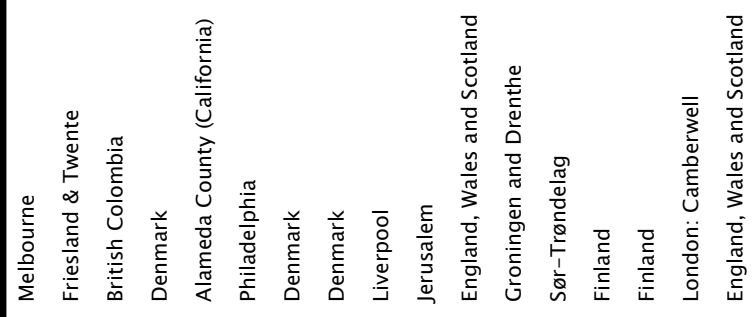

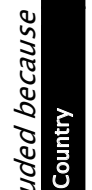

|n⿴囗十) 

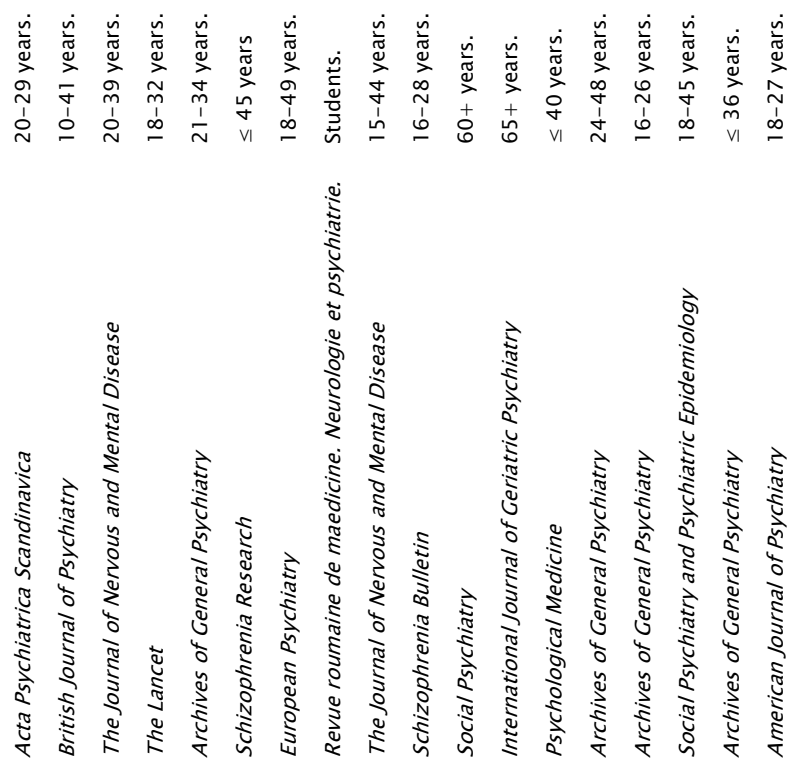

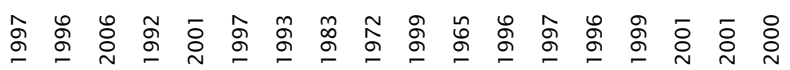

MnnnInIm!n

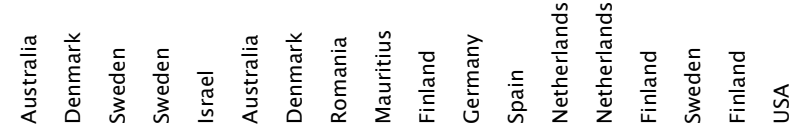
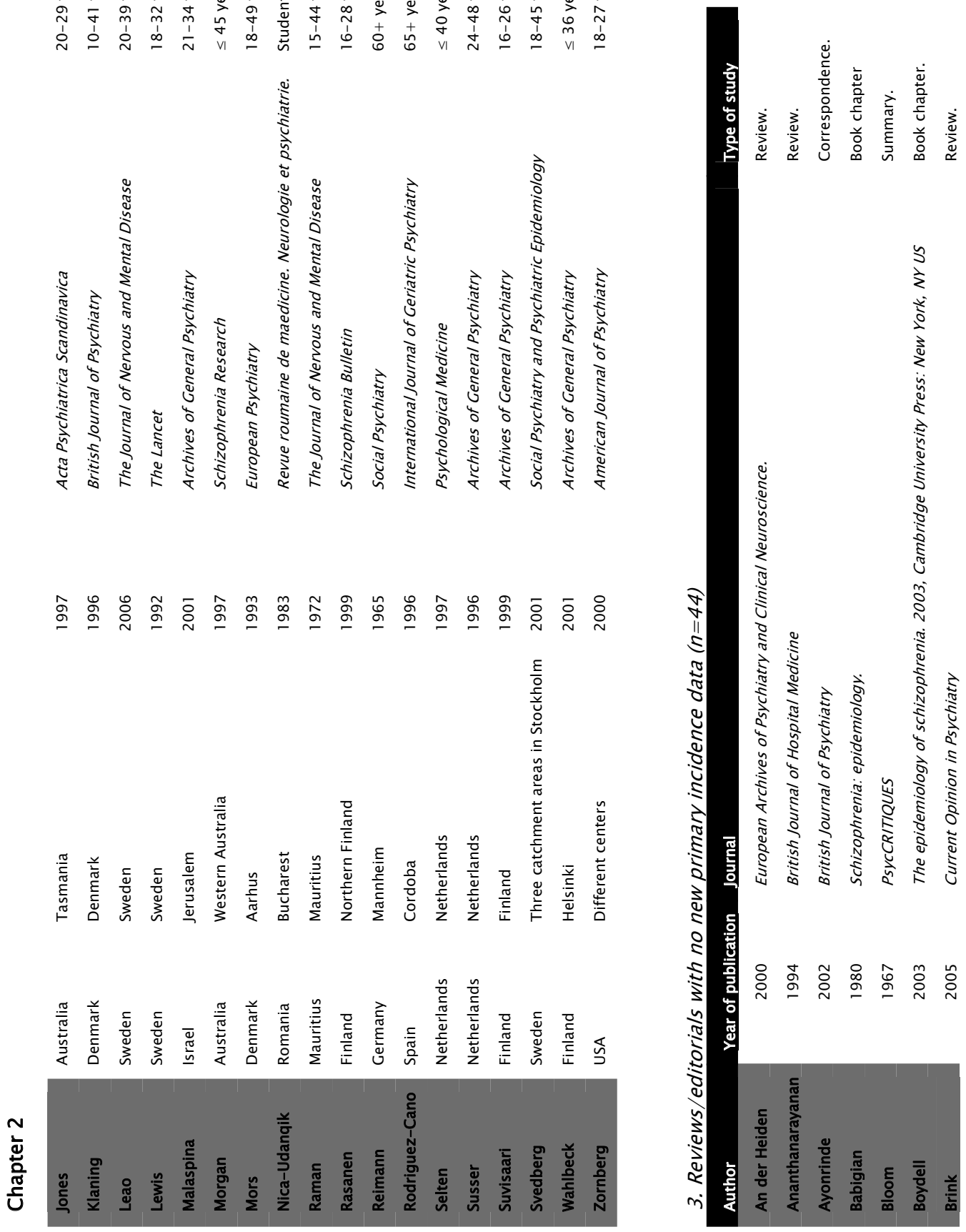


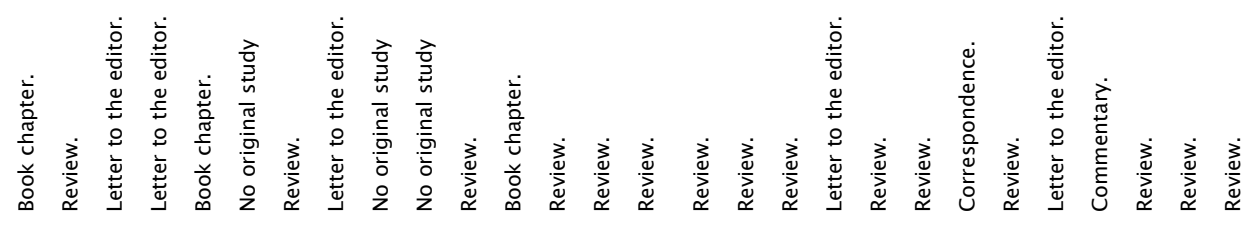
3
sis
s.

䁇

宊

章

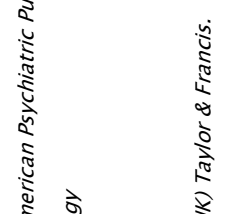

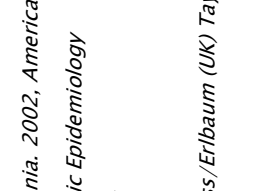

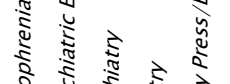

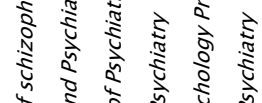

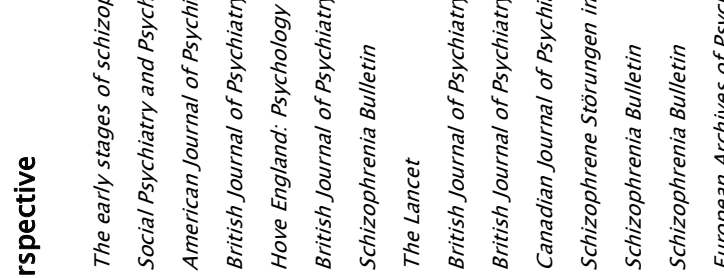

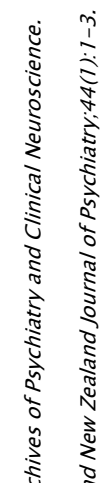

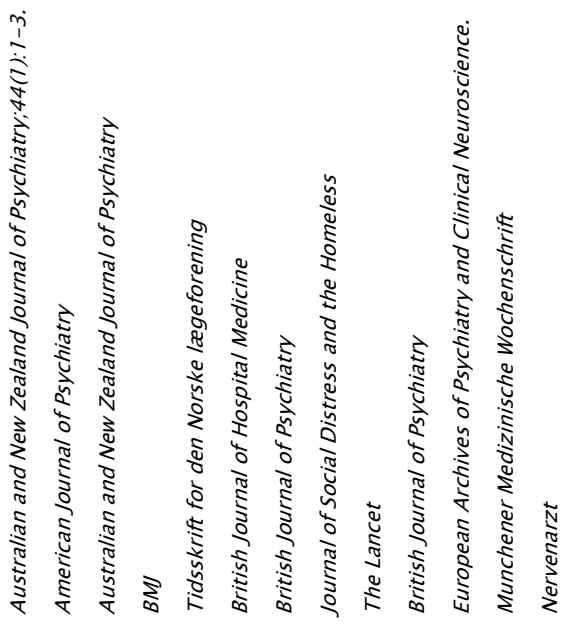

离

華

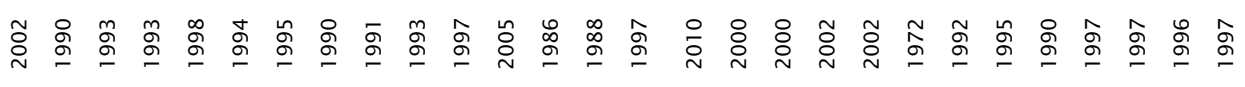

$\frac{\dddot{n}}{\frac{0}{n}}$

ธั่

$\frac{4}{\frac{1}{x}}$

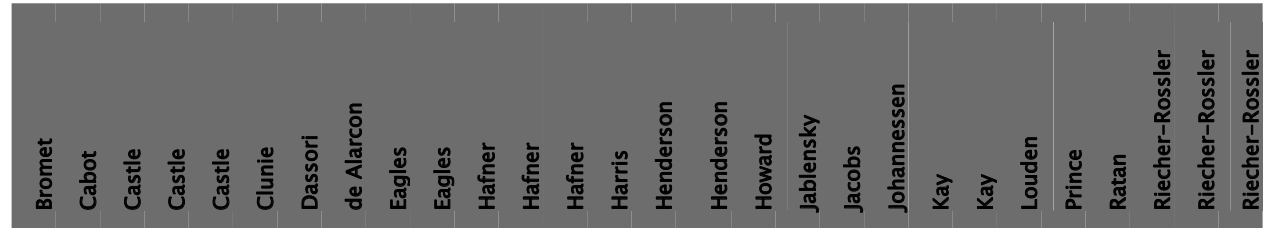




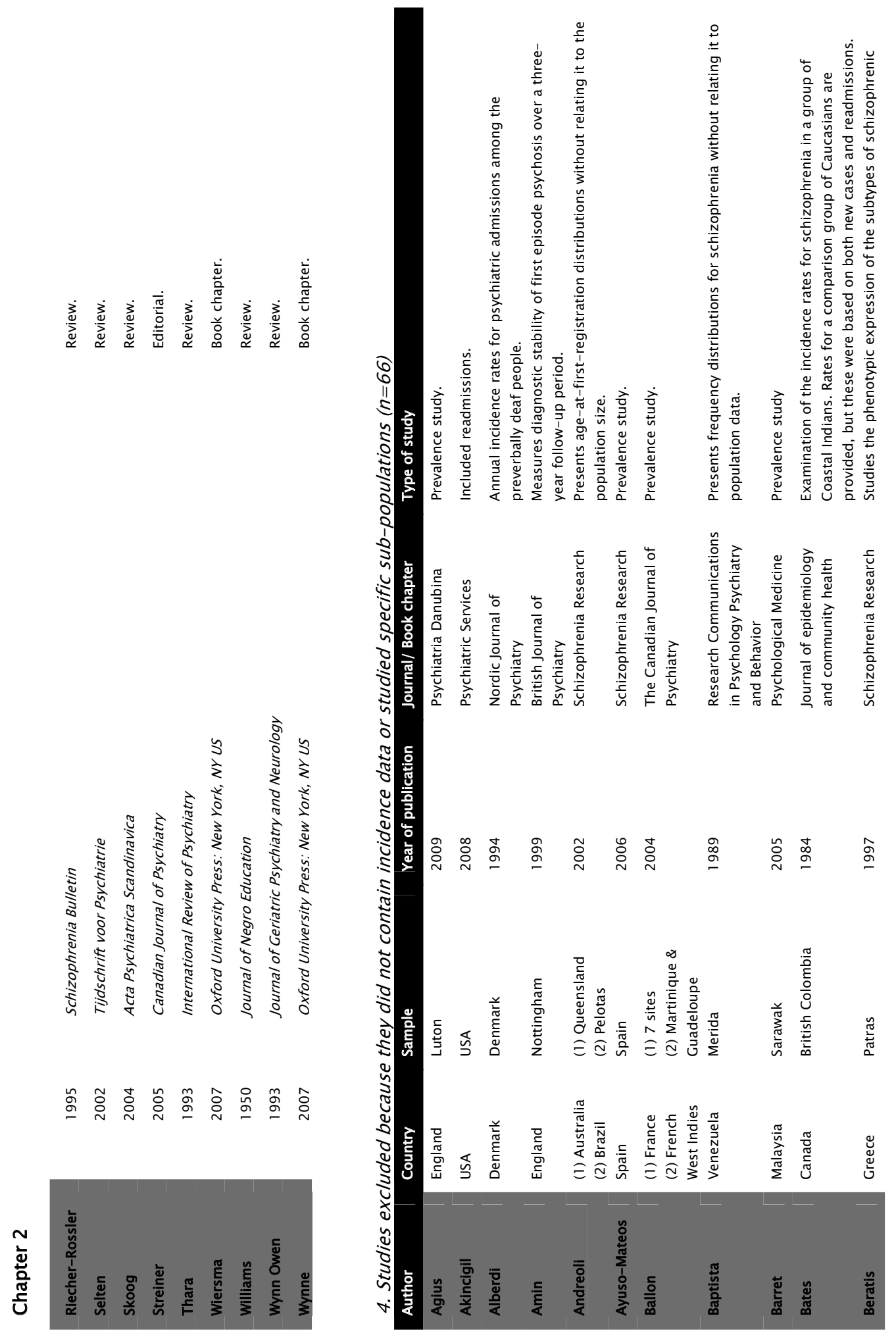



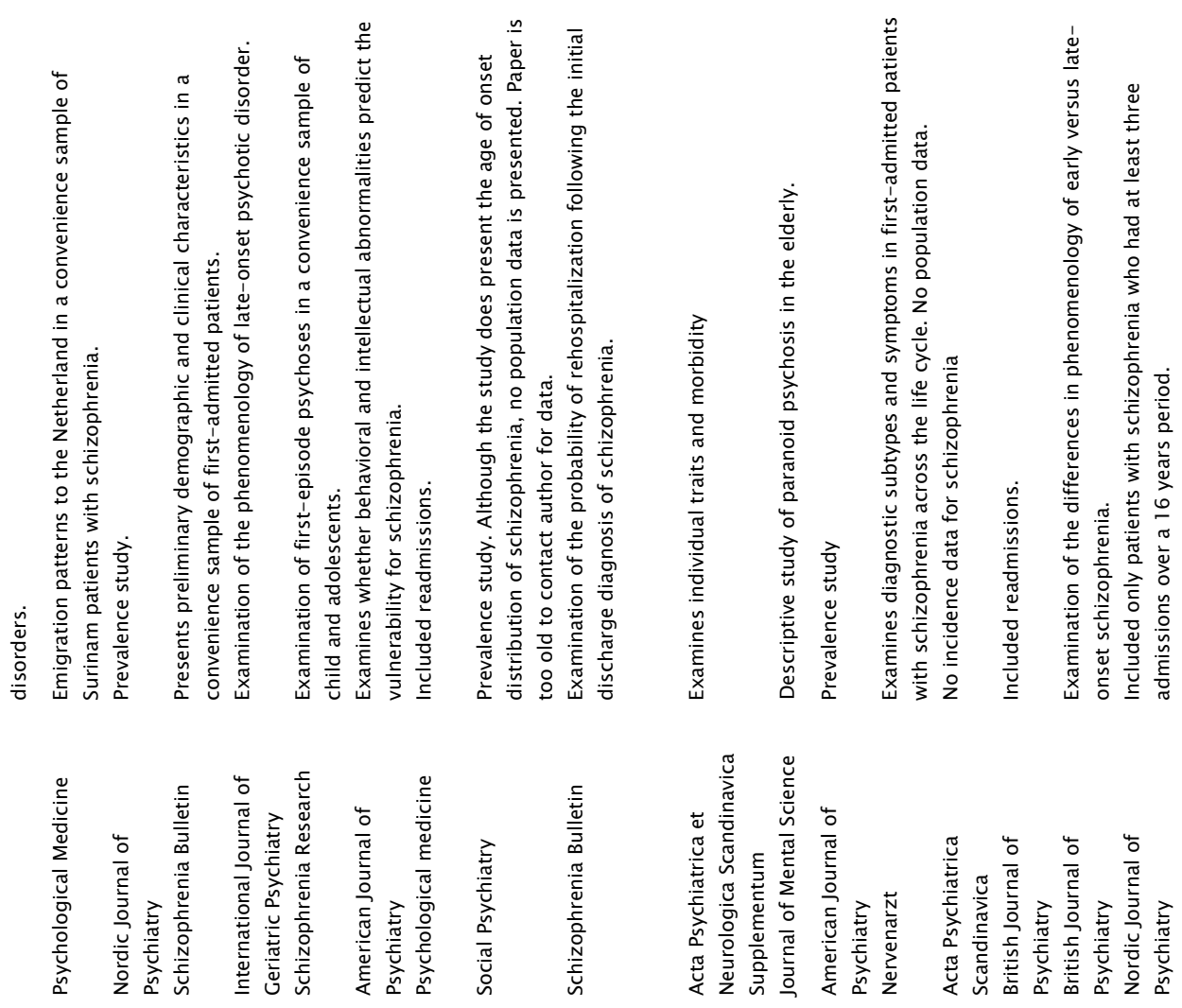

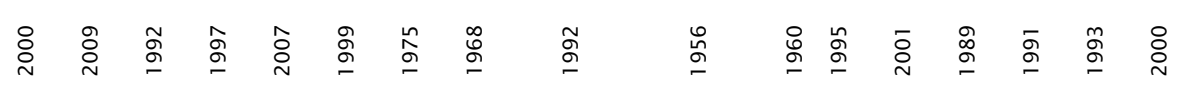

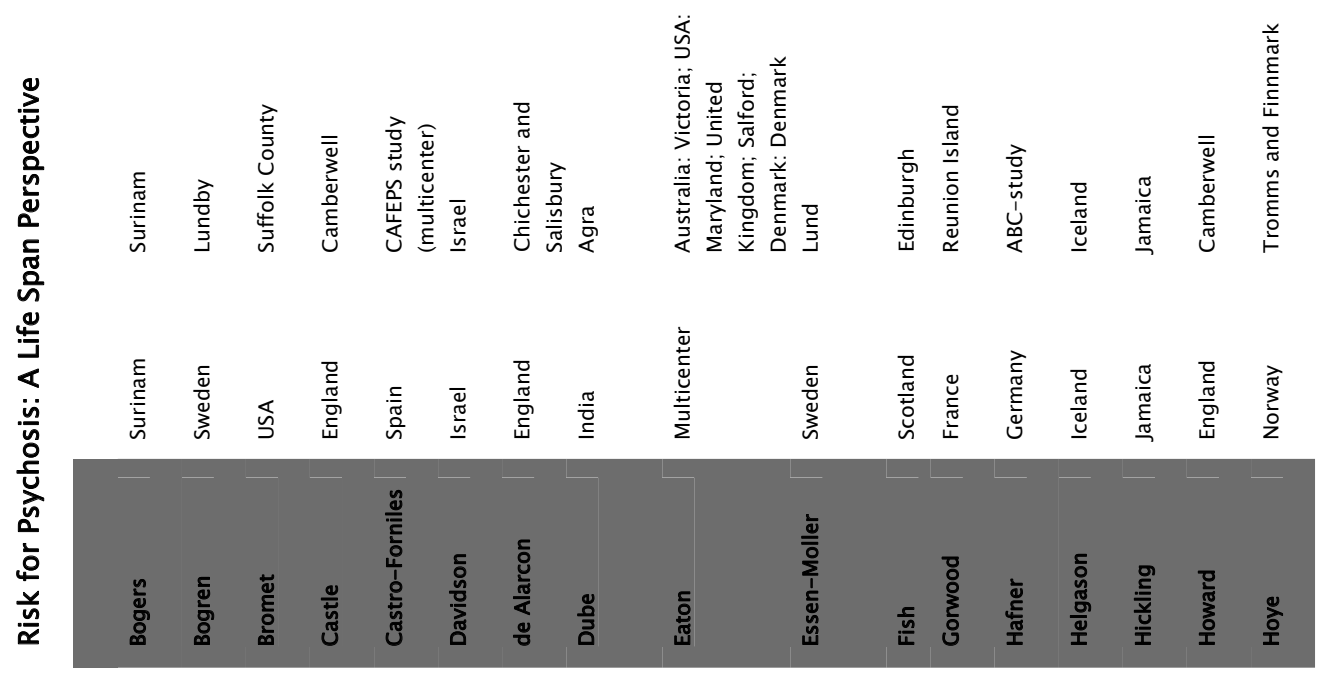



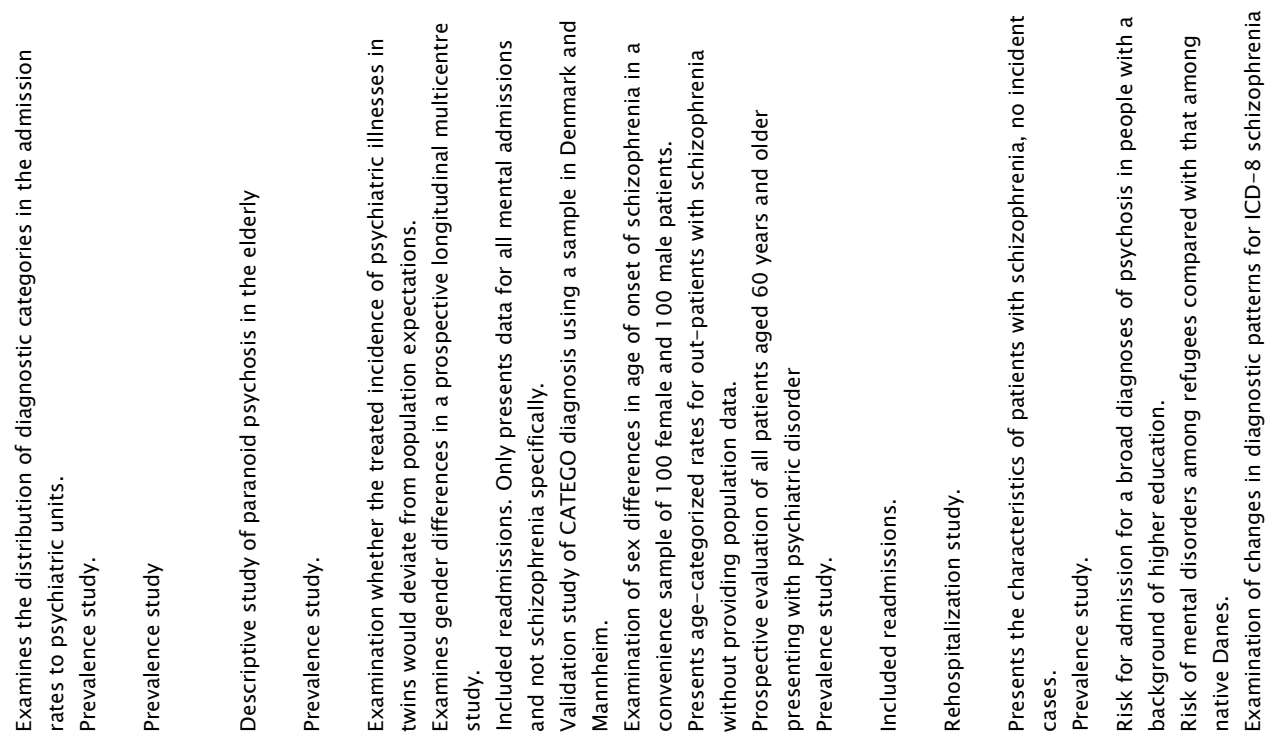

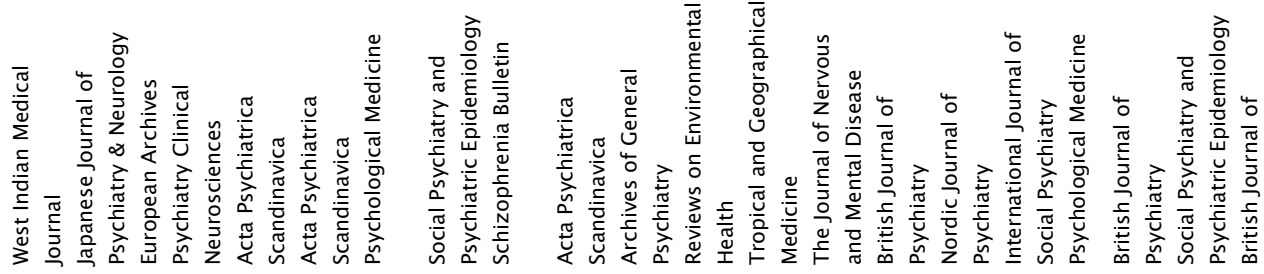

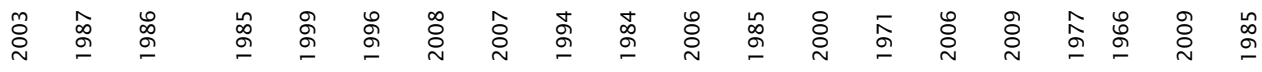<smiles>[AlH2]</smiles>

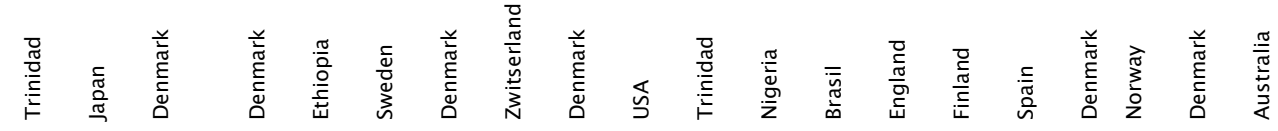

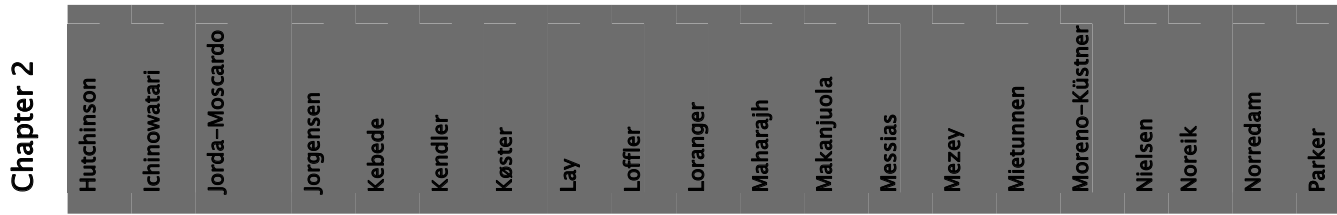




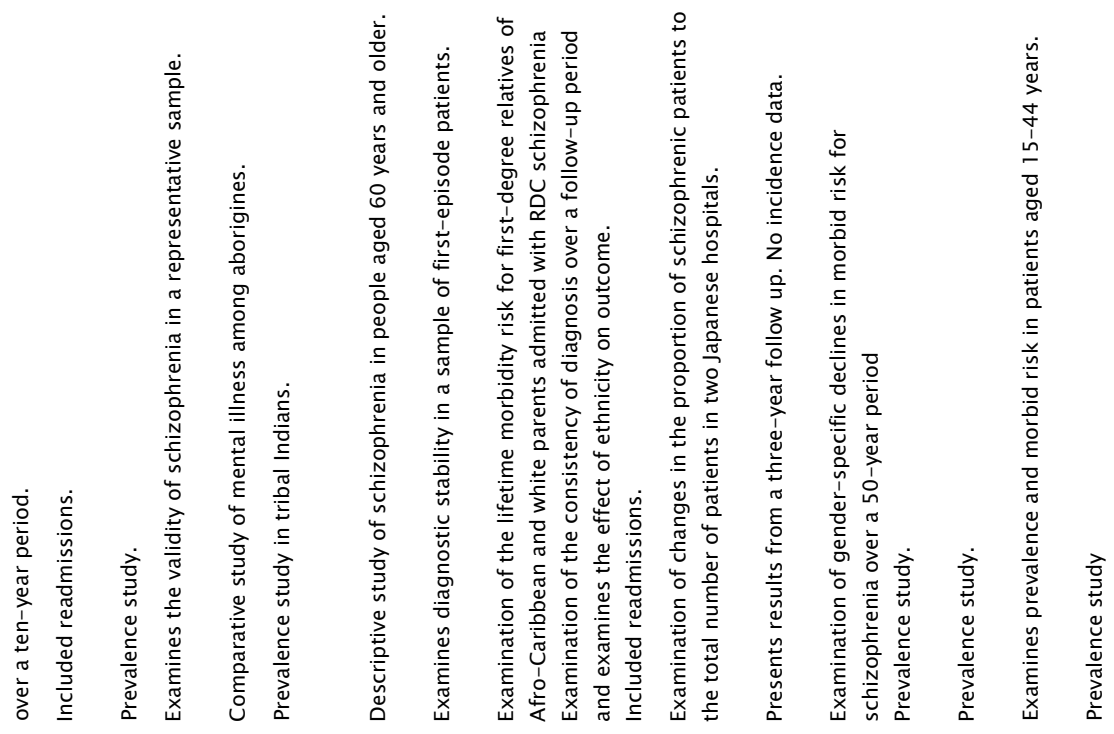

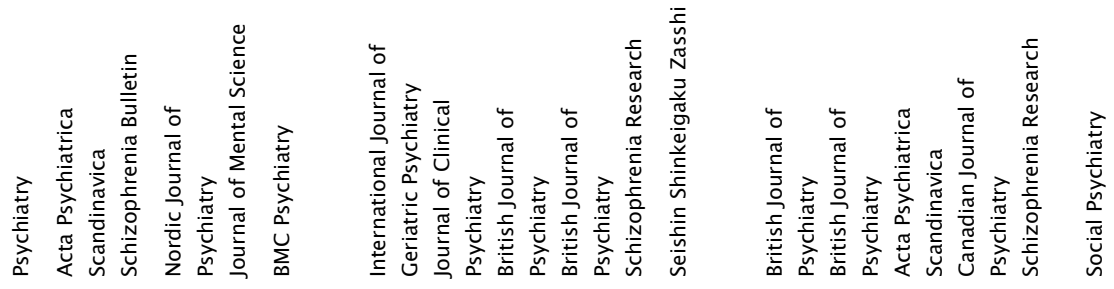

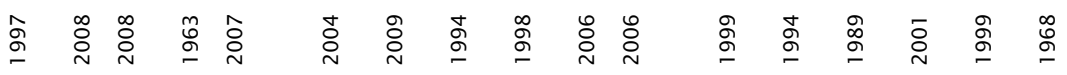

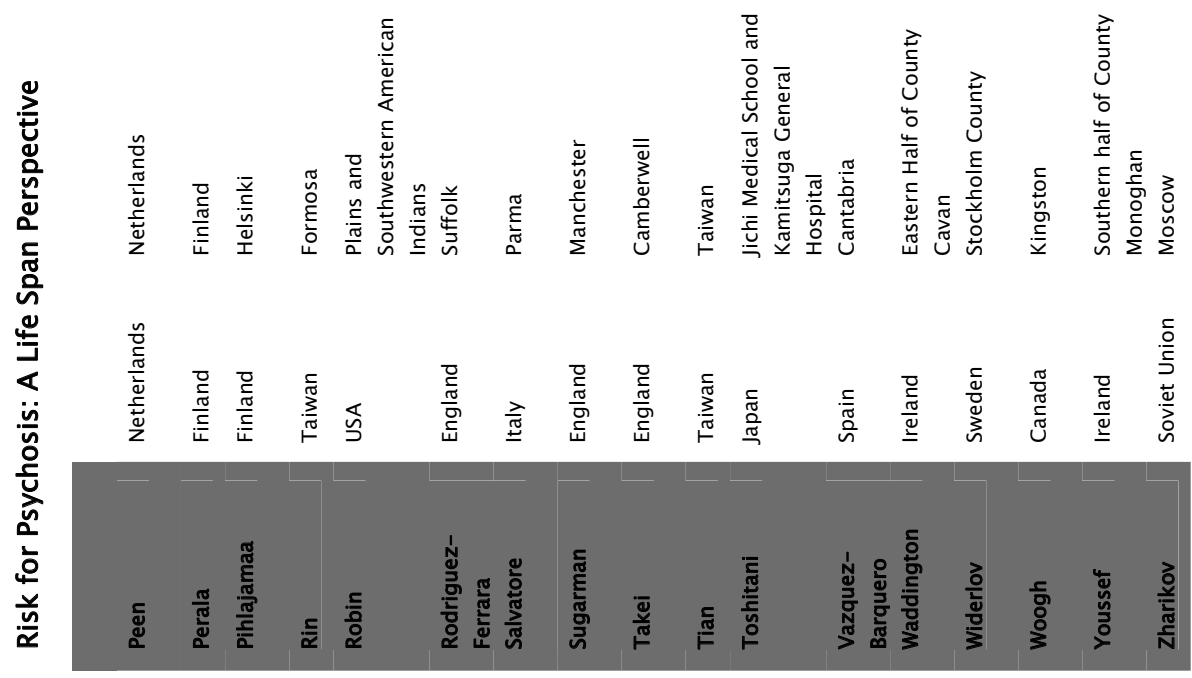




$$
\text { Ll }
$$




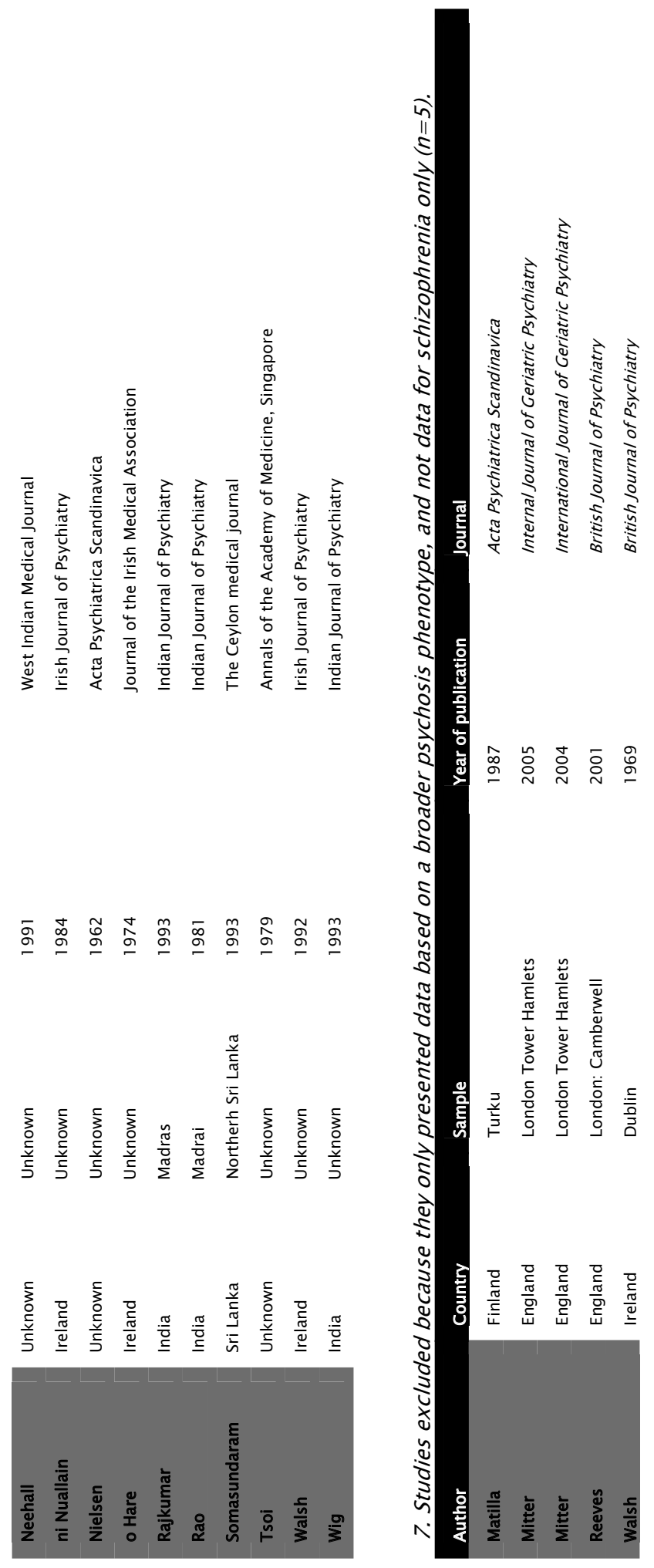




\section{ABSTRACT}

Background - Age of psychosis onset has been related to variability in cognitive functioning, but its effect might be mediated by related demographic and clinical factors.

Aims - To study the contribution of age at onset, demographic and illness characteristics to variation in cognitive functioning in patients with schizophrenia spectrum disorder.

Methods - Patients $(n=1053)$ and healthy controls $(n=631)$ underwent comprehensive neuropsychological and clinical assessments. The effect of age at onset on age-standardized cognitive test scores was assessed with multiple linear regression analyses, followed by formal mediation tests for illness and demographic characteristics.

Results - Earlier onset was associated with worse performance on immediate recall and sustained attention. However, male sex, more negative symptoms and higher antipsychotic dosage mediated the effects on memory, while negative symptoms explained the association between age at onset and CPT accuracy.

Conclusion - Greater impairment in memory and attention in early onset psychosis may be explained by features indicative of underlying neurodevelopmental vulnerability. 


\section{INTRODUCTION}

Cognitive impairment is considered a core and stable feature of schizophrenia (Heinrichs and Zakzanis, 1998), yet considerable variation in the pattern and severity of impairments is apparent (Joyce et al., 2005). This heterogeneity may reflect differences in underlying neurobiological vulnerability or may point to differences in the distribution of demographic and clinical characteristics, including age at onset (Goldstein and Shemansky, 1995). The expression of vulnerability for psychosis peaks in early adulthood (Hafner et al., 1993), but is not confined to this age range (Castle et al., 1997). An earlier onset of psychosis has been associated with differences in psychopathology (Castle et al., 1997), risk factor profile (Howard et al., 2000) and a less favorable outcome (Suvisaari et al., 1998). These findings suggest that age at onset indexes differences in the distribution of etiological factors, and possibly also reflect differences in underlying vulnerability. Hence, age at onset may contribute to the observed inter-individual variation in cognitive functioning in patients with schizophrenia spectrum disorder. Previous work in this area has yielded inconsistent results. Some studies suggest similar levels of cognitive impairment over the age-at-onset span (Heaton et al., 1994, Jeste et al., 1995) (Sachdev et al., 1999), whereas others report more severe learning and memory impairments in patients with an earlier age at onset (TuulioHenriksson et al., 2004). A recent meta-analysis suggested that individuals with early onset of disorder (i.e. onset $\leq 40$ years) were more impaired on measures of IQ, processing speed, verbal memory and executive functioning than patients with later onset (i.e. $>40$ years) (Rajji et al., 2009). Previous studies were restricted to younger samples and focused on patients with schizophrenia even though similar patterns and severity of cognitive impairments have been shown among different schizophrenia spectrum diagnostic groups (Addington and Addington, 2002). Finally, 
interpretations of the nature of the link between age at onset and cognitive impairment in psychosis are contingent on study differences in adjustment for demographic and clinical factors (Irani et al., 2010). Most of the variables associated with early onset of psychosis also relate to poor cognitive functioning, including male sex (Goldstein et al., 1998), and negative symptoms (Dominguez et al., 2009). In addition, more severe negative symptoms, earlier age at onset and male sex have been found to drive the greater cognitive impairment in schizophrenia compared with affective psychoses(Bora et al., 2009). Thus, the contribution of age at onset to variability in the nature and severity of cognitive functioning may be better understood by its associations with demographic and clinical risk factors. This study investigates (1) the effect of age at onset on cognitive functioning and (2) examines possible mediation of effects by demographic and clinical variables. These questions were addressed in a large and representative sample of patients with non-affective psychotic disorder across the entire age at onset range.

\section{METHODS}

\section{Subjects}

Subjects were recruited at baseline in the context of two ongoing and related studies. Participants aged 50 years and younger were recruited in the Genetic Risk and Outcome in Psychosis (GROUP) study, and participants aged 45 years and older were recruited for the parallel Psychosis in the Elderly (PSITE) study. GROUP is a large Dutch multi-centre study on genetic and environmental risk factors for onset and course of psychotic illness. The study design has been described in more detail elsewhere (Genetic Risk and Outcome in Psychosis (GROUP) Investigators., 2010). Briefly, inand outpatients living within selected representative geographical areas in the Netherlands and Belgium were recruited for study participation. Inclusion criteria for study entry were: (1) age 16 to 50 years, (2) diagnosis 
of non-affective psychotic disorder (295, 297, 298.8 and 298.9) according to the Diagnostic and Statistical Manual of Mental Disorder-IV (DSM-IV) criteria (American Psychiatric Association 1994) and (3) good mastery of Dutch language. DSM-IV diagnoses were assessed with the Comprehensive Assessment of Symptoms and History (CASH) interview (Andreasen et al., 1992) or Schedules for Clinical Assessment for Neuropsychiatry 2.1 (SCAN) (Wing et al., 1990). At baseline, 1120 patients were included.

PSITE was specifically designed to complement the GROUP sample in order to enable the comparison of risk and outcome of psychotic disorder across the whole age at onset span. Patients were recruited in close collaboration with mental health care institutes in the South Limburg Region of the Netherlands and Belgium. Patients were required to meet GROUP inclusion criteria (1) to (3), with additional criteria (4) age at onset of first psychotic symptoms at age 45 years or later and (5) no clinical diagnosis of dementia. To ensure the absence of dementia at inclusion, clinicians were contacted at approximately one year after baseline assessment (mean duration of follow-up: 66.3 weeks). At follow-up, five of the 51 included patients (9\%) had received a clinical diagnosis of dementia. These subjects were excluded from the analyses, leaving a risk set of 46 patients with late-onset psychotic disorder.

In both studies, unrelated controls, frequency-matched for age, were selected through a system of random mailings to addresses in the catchment areas. Exclusion criteria for the controls were (1) a first-degree relative with psychotic disorder (as assessed by FIGS interview (NIMH Genetics Initiative., 1992) with the control as informant) and (2) current or past DSM-IV diagnosis of schizotypal, borderline, psychotic or bipolar disorder as assessed by CASH or SCAN interview. The standing ethics committee approved both studies and all subjects signed informed consent.

Age at onset was defined as age at first contact with mental health services and was assessed retrospectively using combined information 
from patients and clinicians. Patients were excluded from the current analyses if they (1) had missing data on age at onset $(n=82),(2)$ had onset before the age of seven years $(n=6)$ or (3) fulfilled inclusion criteria at study entry, but had missing diagnostic information or had their diagnosis changed to affective, drug or medication-induced psychotic disorder $(n=32)$.

The final risk set comprised 1053 patients and 631 controls. Of these, 720 (68\%) received a diagnosis of schizophrenia, 57 (6\%) schizophreniform disorder, 124 (12\%) schizoaffective disorder, 24 (2\%) delusional disorder, 21(2\%) brief psychotic disorder and 106 (10\%) psychotic disorder not otherwise specified.

\section{Clinical Assessments}

At baseline, patients and controls were clinically evaluated with the CASH or SCAN, which were used to generate DSM-IV diagnoses of non-affective psychotic disorder. Current psychopathology was assessed with the Positive and Negative Syndrome Scale (PANSS) (Kay et al., 1987), and five symptom dimensions (positive symptoms, negative symptoms, disorganization, excitement, and emotional distress) were constructing using the algorithm provided by van der Gaag and co-workers (2006). The Global Assessment of Functioning Scale (GAF) (American Psychiatric Association 1994) was used as a global measure of symptoms and disability. Finally, dose of current daily antipsychotic medication was converted to milligram Haldol equivalents.

\section{Neuropsychological assessments}

All tests were administered by trained researchers and research assistants with a background in psychology or medicine. The rationale and description of the included tests has been described in more detail elsewhere (Meijer et al.). Briefly, the test battery was aimed at assessing the following cognitive abilities: 
(1) General intellectual ability Full IQ scores for the GROUP study were derived from the four-subtest version (Information, Block Design, Digit Symbol Coding and Arithmetic) of the Dutch version of the Wechsler Adult Intelligence Scale (WAIS) (Wechsler, 2000). Anticipating the limited ability to undergo prolonged testing in the older subjects, the Raven Standard Progressive Matrices (RAVEN) (Raven et al., 2003) was chosen to assess general intellectual ability in the PSITE study. In order to compare full IQ scores across the two studies, raw total scores of the WAIS and Raven were first standardized against their test group and later collapsed.

(2) Verbal memory and learning was measured with the Groningen Word Learning Task (WLT) (Brand and Jolles, 1985). Extracted variables were immediate recall (total number of words recalled over trial 1-3), learning (trial 3 minus trial 1), retention rate (proportion of words recalled over a 20-minute delay as a function of the maximum number of words learned over trial 1 to 3 ) and delayed recognition (proportion of total correct over the 20-minute delay).

(3) Attention/vigilance was assessed using a Continuous Performance Test (CPTHQ) with working memory load (Beck et al., 1956) (Jabben et al., 2010). The outcome measure was accuracy, which was defined as the total percentage of correct responses (correct detections and correct rejections).

(4) Speed of processing: Response latency in milliseconds of correct detections in the CPT-HQ test was used as a measure of processing speed.

(5) Reasoning and problem solving was assessed using the Response Shifting Task (RST), a modified version of the Competing Programs Task (Bilder et al., 1992). The RST is set-shifting ability task with working memory load and requires switching between two response rules. Participants have to deduce response rules from trial-by-trial feedback without explicit instruction. The variables used in the analyses were cost difference scores for proportion correct and for reaction time to measure the decrement in performance related to shifting in the response rules from imitation to reversal. 
The distribution of the cognitive test scores was inspected for outliers and observations with more than three standard deviations from the mean were replaced with the closest value within the same group. Co-varying age in the model with age at onset introduces bias in effect measures due to collinearity (Pearson $\mathrm{r}=0.94, \mathrm{p}<.001$ ) (Miller and Chapman, 2001). Therefore, raw test scores were standardized against the means and standard deviations of healthy controls using matched age groups, with each age stratum consisting of minimally thirty subjects against whom to standardize. Scores were reversed where necessary so that higher scores always reflected better performance. The age-standardized test $z$-scores were used as dependent variables in the subsequent analyses.

\section{Statistical Analyses}

All analyses were carried out in STATA version 11.1(StataCorp, 2009). Demographic differences between patient and controls were examined using one-way ANOVA for normally distributed variables, Mann-Whitney $U$-tests for non-normally distributed variables and Chi-square tests for categorical variables. Associations between demographic and clinical variables on the one hand and age at onset and cognitive variables on the other hand were investigated using Pearsons' correlation coefficient for two continuous variables and point-biserial correlation coefficients when comparing a nominal and a continuous variable. The association between age at onset and cognition was examined using linear regression analyses, first without covariates and second with adjustment for sex (' 0 ' men, ' 1 ' women) and ethnicity ( 0 'Caucasian', ' 1 ' non-Caucasian ethnicity), course of illness ('0' chronic, ' 1 ' episodic), negative symptom dimension (range 339) and antipsychotic dose in Haldol equivalents (range 0 - 52.4). Inclusion of a squared and a cubic age-at-onset-term accounted for possible nonlinear associations. For each cognitive domain that was associated with age at onset, a Sobel test, extended to account for multiple mediator variables (Preacher and Hayes, 2008), was conducted to examine potential effect 
Chapter 3

mediation by demographic and clinical variables. Risk of type 1 error was addressed by applying the Simes' modification of the Bonferroni correction (Simes, 1986).

\section{RESULTS}

The demographic and clinical characteristics of the sample are summarized in Table 1. Patients and controls differed substantially in distributions of sex, age, ethnicity and education. Mean age at onset of psychosis was 24.4 years ( $S D=11.4$; range $7-86$ ), with men displaying significantly earlier onset than women $(\mathrm{z}=-5.57, \mathrm{p}<.001)$. Table 2 presents the pair-wise correlations between age at onset, cognitive test scores and the demographic and clinical characteristics. A diagnosis of schizophrenia $(r=-$ $0.08, p=.013)$, higher antipsychotic dose $(r=-0.12, p<.001)$ and more negative symptoms $(r=-0.10, p=.001)$ were associated with earlier onset of illness, while female sex $(r=.29, p<.001)$ and a more chronic course were associated with later illness onset $(r=0.08, p=.017)$. 


\section{Risk for Psychosis: A Life Span Perspective}

Table 1. Demographic and clinical characteristics of patients and controls.

\begin{tabular}{|c|c|c|c|c|c|}
\hline & \multirow{2}{*}{$\begin{array}{l}\text { Patients } \\
n=1053\end{array}$} & \multirow{2}{*}{$\begin{array}{c}\text { Controls } \\
n=631\end{array}$} & \multicolumn{3}{|c|}{ Between group comparison } \\
\hline & & & $x^{2}$ & DF & $\mathbf{P}$ \\
\hline Age & $29.3(11.9)$ & $33.2(14.5)$ & 22.6 a & 1 & $<.001$ \\
\hline Age range & $15-93$ & $15-87$ & & & \\
\hline Male gender, n (\%) & 785 (74.6) & $283(44.9)$ & 150.0 & 1 & $<.001$ \\
\hline \multicolumn{6}{|l|}{ Education, n (\%) } \\
\hline Elementary & $152(14.6)$ & $25(4.0)$ & & & \\
\hline Secondary school & $584(56.2)$ & $290(46.3)$ & 93.5 & 2 & $<.001$ \\
\hline Higher education & $304(29.2)$ & $312(49.8)$ & & & \\
\hline Non-Caucasian ethnicity, n (\%) & $210(20.2)$ & $49(7.9)$ & 44.3 & 1 & $<.001$ \\
\hline Age at first contact (years) & $24.4(11.4)$ & NA & & & \\
\hline Men & $22.5(7.5)$ & NA & & & \\
\hline Women & $30.1(17.5)$ & NA & & & \\
\hline IIIness duration (years) & $4.4(4.1)$ & NA & & & \\
\hline Recent onset ( $<1$ years) & $207(19.7)$ & & & & \\
\hline \multicolumn{6}{|l|}{ Course of illness, $n(\%)$} \\
\hline Episodic & $853(84.0)$ & NA & & & \\
\hline Chronic & $162(16.0)$ & NA & & & \\
\hline PANNS positive & $14.2(6.8)$ & NA & & & \\
\hline PANNS negative & $14.9(6.6)$ & NA & & & \\
\hline PANNS general & $44.5(13.5)$ & NA & & & \\
\hline GAF symptom score & $55.5(15.9)$ & NA & & & \\
\hline GAF disability scores & $54.5(16.0)$ & NA & & & \\
\hline Current use antipsychotics, $n(\%)$ & $858(83.2)$ & NA & & & \\
\hline Current antipsychotic doseb & $2.8(3.5)$ & NA & & & \\
\hline
\end{tabular}

Note: Values presented as means (standard deviation) unless specified otherwise; DF = degrees of freedom. $\mathrm{NA}=$ not applicable. a based on Kruskal-Wallis rank test for non-normal distributed data; b Milligram per day haloperidol equivalents 


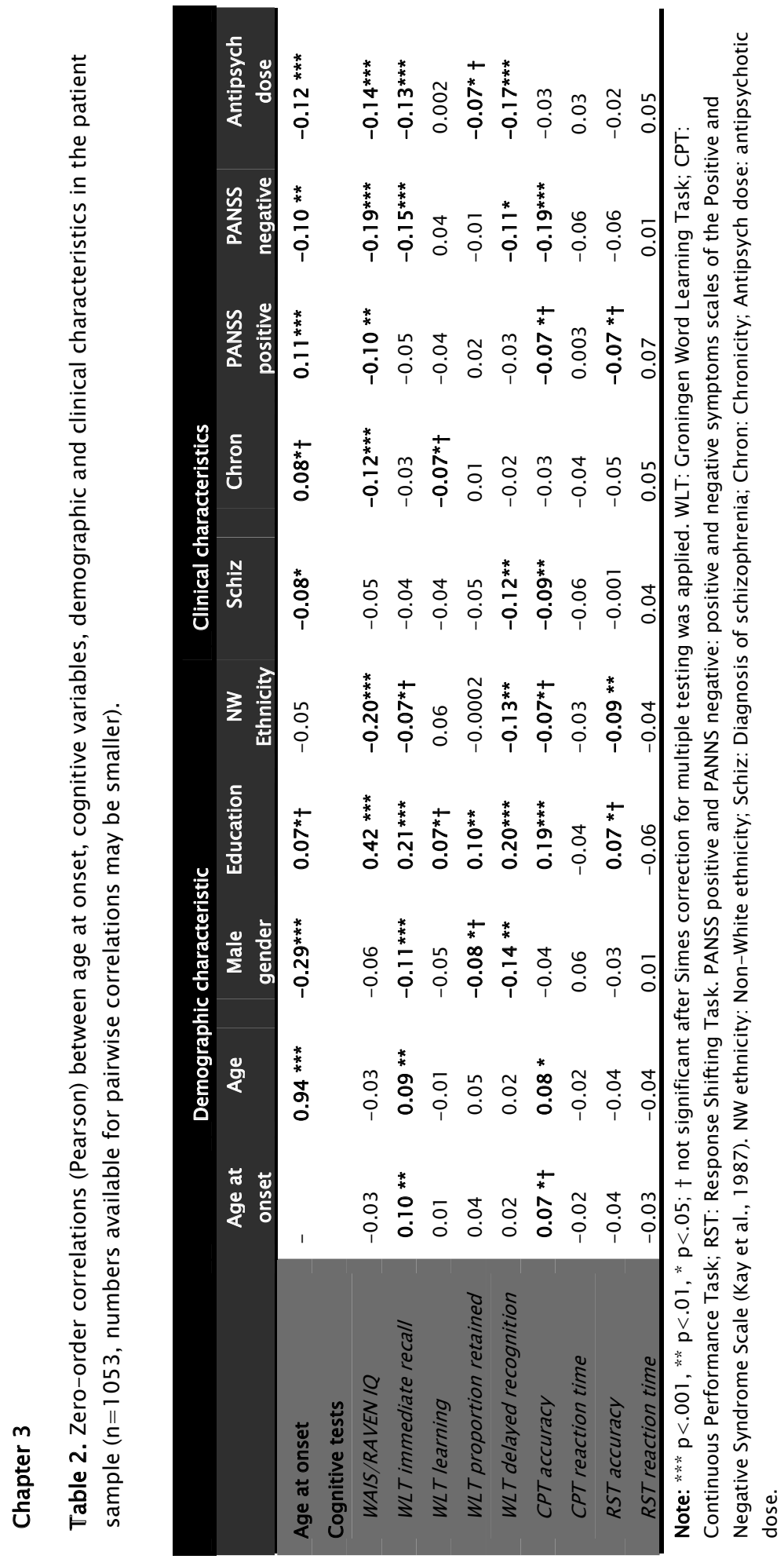




\section{Cognitive functioning and age at onset}

Table 3 shows the results from the linear regression analyses for the association between cognition and age at onset. In univariate models, earlier age at onset was associated with lower z-scores for WLT immediate recall $(b=0.011, p=.002)$ and CPT accuracy $(b=0.023, p=.003)$. The associations between age at onset and WLT immediate recall and CPT accuracy was reduced to non-significance once demographic and clinical variables were included in the model, suggesting significant mediation. Multiple mediation analyses revealed that the effect of age at onset on immediate recall was similarly mediated by male sex $(z=3.55, p<.001)$, more negative symptoms ( $z$ $=1.97, p=.05)$ and higher antipsychotic dosage $(z=2.19, p=.028)$. Likewise, Sobel test analysis revealed a trend-significant mediation effect for negative symptoms in the association between age at onset and CPT accuracy ( $z=1.86$, $\mathrm{p}=.06)$.

Table 3. Effect of age of onset on neurocognitive functioning in patients with nonaffective psychotic disorder $(\mathrm{n}=1053)$.

\begin{tabular}{|c|c|c|c|c|}
\hline \multirow[b]{2}{*}{ Cognitive test } & \multicolumn{2}{|c|}{ Unadjusted model } & \multicolumn{2}{|c|}{ Adjusted model } \\
\hline & Estimate & $95 \% \mathrm{Cl}$ & Estimate & $95 \% \mathrm{Cl}$ \\
\hline WAIS/RAVEN IQ & -0.003 & $-0.010 ; 0.003$ & -0.005 & $-0.013 ; 0.002$ \\
\hline WLT immediate recall & $0.011 * *$ & $0.004 ; 0.018$ & 0.004 & $-0.004 ; 0.012$ \\
\hline WLT learning & 0.001 & $-0.005 ; 0.007$ & 0.003 & $-0.004 ; 0.010$ \\
\hline WLT proportion retained & 0.005 & $-0.003 ; 0.013$ & 0.003 & $-0.006 ; 0.011$ \\
\hline WLT delayed recognition & 0.002 & $-0.007 ; 0.011$ & -0.008 & $-0.019 ; 0.003$ \\
\hline CPT accuracy & $0.023 * *$ & $0.008 ; 0.039$ & 0.005 & $-0.012 ; 0.021$ \\
\hline CPT reaction time & -0.002 & $-0.009 ; 0.005$ & -0.00002 & $-0.008 ; 0.008$ \\
\hline RST accuracy & -0.004 & $-0.012 ; 0.004$ & -0.006 & $-0.015 ; 0.003$ \\
\hline RST reaction time & -0.002 & $-0.014 ; 0.005$ & -0.002 & $-0.012 ; 0.009$ \\
\hline
\end{tabular}

Note: Regression coefficients are reported. WAIS = Wechsler Adult Intelligence Scale; WLT = Groningen Word Learning Task; CPT = Continuous Performance Test; RST = Response Shifting Task. *** $\mathrm{p}<.001, * * \mathrm{p}<.01 * \mathrm{p}<.01$ 


\section{DISCUSSION}

This study aimed to establish the nature of the effect of age at onset on the pattern and severity of cognitive impairments in patients with schizophrenia spectrum disorder. To the best of our knowledge, this has not been addressed before in such a large sample of patients presenting with schizophrenia spectrum disorder across the whole age at onset range.

\section{Age at onset and cognitive impairment}

Earlier onset of psychosis was associated with greater impairment in memory and attention, but not with other cognitive domains tested. This suggests that age at onset has a specific rather than a global effect on cognitive functioning. The current findings add to previous reports of more compromised verbal learning and memory (Tuulio-Henriksson et al., 2004, Rajji et al., 2009) (Vahia et al., 2010) and sustained attention (Bellino et al., 2004) in schizophrenia with earlier onset, but contradict others showing few or no differences with age at onset (Heaton et al., 1994, Jeste et al., 1998, Sachdev et al., 1999).

\section{Age at onset and demographic and clinical correlates}

In addition to its associations with cognitive functioning, earlier onset of psychosis was associated with male sex, a diagnosis of schizophrenia, more negative symptoms and higher antipsychotic dosage. These features are generally believed to be suggestive of neurodevelopmental alterations (Murray et al., 1992), and jointly suggest a more severe illness process (DeLisi, 1992). In contrast, a chronic course type did not relate to these features, which is in line with recent reports suggesting that chronicity increases with onset in later life (Köhler et al., 2009). 


\section{Independent sources of variations in cognitive functioning}

After taking into account the different distributions of demographic and clinical features, variation in cognitive functioning initially attributed to age at onset was removed. Instead, male sex, negative symptoms and higher antipsychotic dose contributed to the more profound impairments in immediate recall in patients with earlier onset of psychosis, and differences in sustained attention by age at onset were explained by negative symptoms. Whether this variation in cognitive functioning further diverges during the course of the illness is not known. However, there is evidence for two notably different cognitive trajectories with aging in patients with schizophrenia: while community-living schizophrenic patients tend to display normal cognitive aging, age-accelerated cognitive decline over time has been demonstrated for a smaller group of institutionalized patients (Harvey et al., 1999).

\section{A neurodevelopmental perspective on cognitive functioning in psychosis}

Male sex and a more severe clinical profile were important determinants of the more severe cognitive profile in patients with early onset psychosis. These findings are contingent with the view that early onset schizophrenia is the negative outcome of an underlying neurodevelopmental vulnerability, that is more prevalent in men (Murray et al., 1992). The neurodevelopmental model posits that schizophrenia is the behavioral outcome of alterations in neurodevelopment that begins long before the onset of clinical symptoms (Rapoport et al., 2005). Both early genetic and environmental risk factors may adversely affect the developing brain and predispose an individual towards an earlier age at onset (Hollis, 1995) and a more severe manifestation of the illness (Suvisaari et al., 1998). It has been suggested that sex differences in normal developmental and maturational processes and a worse response to early environmental insults results in a greater vulnerability to early developmental alterations in the male as compared to the female brain ( $R a z$ et al., 1994). For instance, boys born preterm display poorer cognitive outcome and reduced white matter volume at age six and eight respectively than girls 


\section{Chapter 3}

born preterm when compared to their age- and sex-matched peers (Reiss et al., 2004) (Marlow et al., 2005). Hence, early age at onset and illness severity may stem from the same underlying neurodevelopmental vulnerability that is more prevalent in men. Given that the pattern and degree of the cognitive impairment is shaped by features that are indicative of a neurodevelopmental origin, it may be hypothesised that part of the more profound cognitive impairments in patients with early onset schizophrenia may relate to the same underlying vulnerability. Although speculative, early age at onset, greater illness severity and more profound impairments in memory and sustained attention may be the outcome of a shared underlying vulnerability of neurodevelopmental origin.

\section{Strengths and limitations}

The results of the present study should be interpreted in the light of its strengths and limitations. By combining two complementary studies (GROUP and PSITE), a very large sample of patients presenting with schizophrenia spectrum disorder across the whole age at onset span ranging from 7 to 86 years was available for analysis. The study showed phenomenological discontinuity between patients with earlier and later age at onset and additionally demonstrated patterns of cognitive heterogeneity by age at onset that were comparable with previous studies that were restricted to younger patients. This suggests that most of the heterogeneity stems from patients presenting with psychosis early in life. Furthermore, instead of limiting the analyses to patients with a narrow diagnosis of schizophrenia, age at onset effects were studied across the schizophrenia disorder spectrum. Finally, since failure to control for multiple comparisons may lead to spurious associations (Binder et al., 2009), risk for type I error was minimized by adequate control for multiple testing.

Several limitations deserve closer inspection. First, not all patients had complete cognitive test scores. Patients with missing data on a given test may be more cognitively impaired than those who were able to participate. 
Particularly older patients ( $\geq 65$ years) were likely to have incomplete testing, due to the fact that most cognitive tests were computer-based. Systematic bias introduced by such differences would have led to an underestimation of the magnitude of the impairments on these tests with increasing age. However, older patients made up a relatively small group in this sample, so their impact on sample averaged effect sizes was likely minimal. Second, the use of standard deviations of the normal control group to generate $z$-scores for the patient group may spuriously inflate $z$-scores if the standard deviations in the control group are smaller than those in the patient groups (Cirillo and Seidman, 2003). Larger between- and within-subject variation on cognitive tests has often been observed in patient groups and in ageing people as well. Although this may have impacted on the magnitude of the impairments comparing patients with controls, it is hard to see how this could have affected differences in cognition by age at onset. Finally, none of the analyses were adjusted for differences in the distribution of education among patients. Whether to 'correct' for differences in educational attainment remains a controversial topic. However, since correcting for education might eliminate important effects of the illness itself (Resnick, 1992), it was decided not to enter education as a covariate in any of the models. Finally, standardizing the cognitive data by age attenuated possible age-cohorts effects on educational attainment. 
Addington, J \& Addington, D (2002). Cognitive functioning in first-episode schizophrenia. J Psychiatry Neurosci 27, 188-92.

American Psychiatric Association (1994). Diagnostic and Statistical Manual of Mental Disorders (DSM-IV). In American Psychiatric Association: Washington, DC.

Andreasen, NC, Flaum, M \& Arndt, S (1992). The Comprehensive Assessment of Symptoms and History (CASH). An instrument for assessing diagnosis and psychopathology. Arch Gen Psychiatry 49, 615-23.

Beck, LH, Bransome, ED, Jr., Mirsky, AF, Rosvold, HE \& Sarason, I (1956). A continuous performance test of brain damage. J Consult Psycho/20, 343-50.

Bellino, S, Rocca, P, Patria, L, Marchiaro, L, Rasetti, R, Di Lorenzo, R, Paradiso, E \& Bogetto, F (2004). Relationships of age at onset with clinical features and cognitive functions in a sample of schizophrenia patients. J Clin Psychiatry 65, 908-14.

Bilder, RM, Turkel, E, Lipschutz-Broch, L \& Lieberman, JA (1992). Antipsychotic medication effects on neuropsychological functions. Psychopharmacol Bul/ 28, 353-66.

Binder, LM, Iverson, GL \& Brooks, BL (2009). To err is human: "abnormal" neuropsychological scores and variability are common in healthy adults. Arch Clin Neuropsycho/ 24, 31-46.

Bora, E, Yucel, M \& Pantelis, C (2009). Cognitive functioning in schizophrenia, schizoaffective disorder and affective psychoses: meta-analytic study. BrJ Psychiatry 195, 475-82.

Brand, N \& Jolles, J (1985). Learning and retrieval rate of words presented auditorily and visually. Journal of General Psychology 112, 201-10.

Castle, DJ, Wessely, S, Howard, R \& Murray, RM (1997). Schizophrenia with onset at the extremes of adult life. Int J Geriatr Psychiatry 12, 712-7.

Cirillo, MA \& Seidman, LJ (2003). Verbal declarative memory dysfunction in schizophrenia: from clinical assessment to genetics and brain mechanisms. Neuropsychol Rev 13, 43-77.

DeLisi, LE (1992). The significance of age of onset for schizophrenia. Schiz Bull 18, 209-15.

Dominguez, MD, Wichers, M, Lieb, R, Wittchen, HU \& van Os, J (2009). Evidence that onset of clinical psychosis is an outcome of progressively more persistent subclinical psychotic experiences: an 8-year cohort study. Schizophr Bul/ 37, 84-93.

Genetic Risk and Outcome in Psychosis (GROUP) Investigators. (2010). Evidence That Familial Liability for Psychosis Is Expressed as Differential Sensitivity to Cannabis: An Analysis of Patient-Sibling and Sibling-Control Pairs. Arch Gen Psychiatry.

Goldstein, G \& Shemansky, WJ (1995). Influences on cognitive heterogeneity in schizophrenia. Schizophr Res 18, 59-69.

Goldstein, JM, Seidman, LJ, Goodman, JM, Koren, D, Lee, H, Weintraub, S \& Tsuang, MT (1998). Are there sex differences in neuropsychological functions among patients with schizophrenia? Am J Psychiatry 155, 1358-1364.

Hafner, H, Maurer, K, Loffler, W \& Riecher-Rossler, A (1993). The influence of age and sex on the onset and early course of schizophrenia. BrJ Psychiatry 162, 80-6.

Harvey, PD, Silverman, JM, Mohs, RC, Parrella, M, White, L, Powchik, P, Davidson, M \& Davis, KL (1999). Cognitive decline in late-life schizophrenia: a longitudinal study of geriatric chronically hospitalized patients. Biol Psychiatry 45, 32-40.

Heaton, R, Paulsen, JS, McAdams, LA, Kuck, J, Zisook, S, Braff, D, Harris, J \& Jeste, DV (1994). 


\section{Risk for Psychosis: A Life Span Perspective}

Neuropsychological deficits in schizophrenics. Relationship to age, chronicity, and dementia. Arch Gen Psychiatry 51, 469-76.

Heinrichs, RW \& Zakzanis, KK (1998). Neurocognitive deficit in schizophrenia: a quantitative review of the evidence. Neuropsychology 12, 426-45.

Hollis, C (1995). Child and adolescent (juvenile onset) schizophrenia. A case control study of premorbid developmental impairments. BrJ Psychiatry 166, 489-495.

Howard, R, Rabins, PV, Seeman, MV \& Jeste, DV (2000). Late-onset schizophrenia and verylate-onset schizophrenia-like psychosis: an international consensus. The International LateOnset Schizophrenia Group. Am J Psychiatry 157, 172-8.

Irani, F, Kalkstein, S, Moberg, EA \& Moberg, PJ (2010). Neuropsychological Performance in Older Patients With Schizophrenia: A Meta-Analysis of Cross-sectional and Longitudinal Studies. Schizophr Bull.

Jabben, N, Arts, B, van Os, J \& Krabbendam, L (2010). Neurocognitive functioning as intermediary phenotype and predictor of psychosocial functioning across the psychosis continuum: studies in schizophrenia and bipolar disorder. J Clin Psychiatry 71, 764-74. Jeste, DV, Harris, MJ, Krull, A, Kuck, J, McAdams, LA \& Heaton, R (1995). Clinical and neuropsychological characteristics of patients with late-onset schizophrenia. Am J Psychiatry $152,722-30$.

Jeste, DV, McAdams, LA, Palmer, BW, Braff, D, Jernigan, TL, Paulsen, JS, Stout, JC, Symonds, LL, Bailey, A \& Heaton, RK (1998). Relationship of neuropsychological and MRI measures to age of onset of schizophrenia. Acta Psychiatr Scand 98, 156-64.

Joyce, EM, Hutton, SB, Mutsatsa, SH \& Barnes, TRE (2005). Cognitive heterogeneity in firstepisode schizophrenia. British Journal of Psychiatry. Supplement 187, 516-522.

Kay, SR, Fiszbein, A \& Opler, LA (1987). The positive and negative syndrome scale (PANSS) for schizophrenia. Schizophr Bull 13, 261-76.

Köhler, S, van der Werf, M, Hart, B, Morrison, G, McCreadie, R, Kirkpatrick, B, Verkaaik, M, Krabbendam, L, Verhey, F, van Os, J \& Allardyce, J (2009). Evidence that better outcome of psychosis in women is reversed with increasing age of onset: A population-based 5-year follow-up study. Schizophrenia Research 113, 226-232.

Marlow, N, Wolke, D, Bracewell, MA \& Samara, M (2005). Neurologic and developmental disability at six years of age after extremely preterm birth. $N$ Eng/J Med 352, 9-19.

Meijer, J, Simons, CJP, Quee, P, Verweij, K \& G.R.O.U.P. Baseline neurocognition.

Miller, GA \& Chapman, JP (2001). Misunderstanding analysis of covariance. J Abnorm Psychol $110,40-8$.

Murray, RM, O'Callaghan, E, Castle, DJ \& Lewis, SW (1992). A neurodevelopmental approach to the classification of schizophrenia. Schizophr Bull 18, 319-32.

NIMH Genetics Initiative. (1992). Family Interview for Genetic Studies (FICS). National Institute of Mental Health.

Preacher, KJ \& Hayes, AF (2008). Asymptotic and resampling strategies for assessing and comparing indirect effects in multiple mediator models. Behav Res Methods 40, 879-91.

Rajji, TK, Ismail, Z \& Mulsant, BH (2009). Age at onset and cognition in schizophrenia: metaanalysis. BrJ Psychiatry 195, 286-93.

Rapoport, JL, Addington, AM, Frangou, S \& Psych, MRC (2005). The neurodevelopmental model of schizophrenia: update 2005. Mol Psychiatry 10, 434-449.

Raven, J, Raven, JC \& Court, JH (2003). Manual for Raven's Progressive Matrices and Vocabulary Scales. Section 1: General Overview. TX: Harcourt Assessment: San Antonio. 


\section{Chapter 3}

Raz, S, Goldstein, R, Hopkins, TL, Lauterbach, MD, Shah, F \& Porter, CL (1994). Sex differences in early vulnerability to cerebral injury and their neurodevelopmental implications.

Psychobiology 22, 244-253.

Reiss, AL, Kesler, SR, Vohr, B, Duncan, CC, Katz, KH, Pajot, S, Schneider, KC, Makuch, RW \& Ment, LR (2004). Sex differences in cerebral volumes of 8-year-olds born preterm. J Pediatr 145, 242-9.

Resnick, SM (1992). Matching for education in studies of schizophrenia. Arch Gen Psychiatry 49, 246.

Sachdev, P, Brodaty, H, Rose, N \& Cathcart, S (1999). Schizophrenia with onset after age 50 years. 2: Neurological, neuropsychological and MRI investigation. BrJ Psychiatry 175, 416-21. Simes, RJ (1986). An improved Bonferroni procedure for multiple tests of significance.

Biometrika 73, 751-754.

StataCorp (2009). Stata Statistical Software. College Station, TX: Texas.

Suvisaari, JM, Haukka, J, Tanskanen, A \& Lonnqvist, JK (1998). Age at onset and outcome in schizophrenia are related to the degree of familial loading. BrJ Psychiatry 173, 494-500.

Tuulio-Henriksson, A, Partonen, T, Suvisaari, J, Haukka, J \& Lonnqvist, J (2004). Age at onset and cognitive functioning in schizophrenia. BrJ Psychiatry 185, 21 5-9.

Vahia, IV, Palmer, BW, Depp, C, Fellows, I, Golshan, S, Kraemer, HC \& Jeste, DV (2010). Is lateonset schizophrenia a subtype of schizophrenia? Acta Psychiatr Scand 122, 414-26.

van der Gaag, M, Hoffman, T, Remijsen, M, Hijman, R, de Haan, L, van Meijel, B, van Harten, PN, Valmaggia, L, de Hert, M, Cuijpers, A \& Wiersma, D (2006). The five-factor model of the Positive and Negative Syndrome Scale II: a ten-fold cross-validation of a revised model.

Schizophr Res 85, 280-7.

Wechsler, D (2000). WAIS-III, Nederlandse bewerking: Afname en scoringshandleiding. Swets \& Zeitlinger B.V.: Lisse.

Wing, JK, Babor, T, Brugha, T, Burke, J, Cooper, JE, Giel, R, Jablenski, A, Regier, D \& Sartorius, N (1990). SCAN. Schedules for Clinical Assessment in Neuropsychiatry. Arch Gen Psychiatry 47, 589-93. 


\section{ABSTRACT}

Background - Hearing impairment $(\mathrm{HI})$ in the elderly may be a risk factor for psychosis, but associations between $\mathrm{HI}$ and psychotic disorder or psychotic experiences have been reported more consistently in younger than in older populations. The aims of this study were to replicate the positive association between hearing impairment and psychotic experiences and to clarify any differences between groups of young and old individuals in a non-clinical, normal aging general population sample.

Methods - $\mathrm{HI}$, assessed at baseline and at 3-year follow-up, and psychotic experiences, assessed at 3-year follow-up, were analyzed in a group of 848 individuals aged 33 to 89 years between 1999 and 2004. HI was determined on the basis of both self-report and audiometric examination. The "Psychoticism" and "Paranoid ideation" subscales from the SCL-90-R were used to assess level of psychotic experiences.

Results - Self-reported hearing problems expressed as conversational $\mathrm{HI}$ ( $\beta=0.08,95 \% \mathrm{Cl}: 0.23,7.90, p=0.04)$ and subjective $\mathrm{HI}(\beta=0.09,95 \% \mathrm{Cl}: 0.70$, $10.30, p=0.03$ ), but not audiometric objective $\mathrm{HI}$, were associated with psychotic experiences. In those with hearing aids, associations with psychotic experiences were only present if accompanied by self-reported hearing problems that persisted in spite of the hearing aid. In addition, $\mathrm{HI}$ increased the risk for psychotic experiences specifically in younger rather than older individuals.

Conclusions - Self-reported hearing problems rather than audiometric or remediated hearing loss may contribute to the development of psychotic experiences in younger rather than in older individuals. 


\section{INTRODUCTION}

Reviews of the literature show that approximately $10 \%$ to $18 \%$ of individuals in the general population report one or more psychotic experiences (Krabbendam et al., 2004; Laroi et al., 2006; Tien, 1991; van Os, 2003). Prevalent subclinical psychotic experiences likely have a degree of continuity with more severe psychotic states. For example, many of the factors that contribute to the risk of subclinical psychosis in the general population have been found to also predict the risk for clinical psychotic states such as schizophrenia (Johns and van Os, 2001; Peters et al., 1999) and individuals with subclinical psychotic experiences have a much higher probability of later making the transition to clinical psychotic disorder (Poulton et al., 2000).

It has been suggested that hearing impairment $(\mathrm{HI})$ increases the susceptibility to develop psychotic symptoms (Cooper, 1976; Cooper and Curry, 1976; Corbin and Eastwood, 1986; David et al., 1995; Livingston et al., 2001, Stefanis et al., 2006; Stein and Bienenfeld, 1992; Thewissen et al., 2005). Hearing-impaired people may have a tendency to withdraw from social interaction, which could lead to social isolation, oversensitivity or hostile reactions towards the environment (Corbin and Eastwood, 1986). Degenerative diseases of the ear impair responsiveness to the interpersonal and social environment may increase feelings of vulnerability and cause hallucinations in the affected sensory modality in some individuals (Sadock and Sadock, 2000). Misperception of auditory stimuli can occur and these may lead to apparently inappropriate associations that may constitute the basis of paranoid ideations (Cooper and Curry, 1976).

Although such associations between psychotic experiences and $\mathrm{HI}$ are widely hypothesised, evidence is scarce and results to date are contradictory. In addition, it remains unclear to what degree $\mathrm{HI}$ increases the risk for psychosis in people of different ages. While some studies suggest that $\mathrm{HI}$ associated psychotic disorder is particularly prevalent in older persons 
(Cooper and Curry, 1976; Howard et al., 1994; Rodriguez-Ferrera et al., 2004), others have reported that $\mathrm{HI}$ acts as a risk factor for psychotic experiences in samples of young people (Stefanis et al., 2006; Thewissen et al., 2005). In a comparison between 109 hearing-impaired and 137 nonhearing-impaired individuals, Thewissen and colleagues (2005) showed that $\mathrm{HI}$ originating early in life constituted an independent risk factor for the development of psychotic experiences later in life in this population-based sample. More recently, these results were replicated and extended to the age range of late adolescence (Stefanis et al., 2006). The evidence to date suggests that particularly long-standing $\mathrm{HI}$ in the young will predispose to psychotic symptoms later in life. In line with this is the report by David et al. (1995), who investigated the association between $\mathrm{HI}$ and schizophrenia in a large cohort $(\mathrm{N}=50,000)$ of 18 -year-old male Swedish conscripts and found that schizophrenia was 1.8 times more prevalent among the hard of hearing.

A question remains with regard to the mechanism by which $\mathrm{HI}$ may increase the risk for psychosis, in particular with regard to possible underlying mediation by other variables. For example, $\mathrm{HI}$ may also increase the risk for other domains of psychopathology, in particular depression. Indeed, acquired $\mathrm{HI}$ has been considered a risk factor for depression (Heine and Browning, 2002; Tsuruoka et al., 2001), possibly because sensory loss is often followed by a period in which adaptation to the loss occurs, resulting in feelings of grief and depression. Given the fact that the pathogenesis of psychosis is thought to involve, among others, an emotional pathway (Garety et al., 2001; Hanssen et al., 2005; Krabbendam and van Os, 2005; Krabbendam et al., 2005; Myin-Germeys and Os, 2007), one hypothesis is that emotional dysfunction arising in the context of $\mathrm{HI}$ may contribute to the onset of psychotic experiences.

The aims of the study were threefold. The first aim was to replicate the association between $\mathrm{HI}$ and psychotic experiences in a non-clinical general population sample. The second was to examine the hypothesis of possible mediation by emotional dysfunction. The final aim was to examine possible 


\section{Chapter 4}

interaction of $\mathrm{HI}$ with age. It was hypothesised that (1) hearing-impaired individuals would have higher levels of psychotic symptoms and paranoid delusions, (2) this effect could be explained in part by the mediating effect of depressive feelings, (3) the association between $\mathrm{HI}$ and psychosis would be more prominent in younger individuals.

\section{METHODS}

\section{Participants}

Subjects were participants in the Maastricht Aging Study (MAAS) (Jolles et al., 1995), a longitudinal study devoted to the age-related decline of memory and other cognitive functions in the normal aging population (Jolles et al., 1995; van Boxtel et al., 1998). Participants were recruited from a patient register of family practices (Registration Network Family Practices, RNH; Metsemakers et al., 1992). Medical exclusion criteria were previous coma, cerebrovascular pathology, tumors or congenital malformations of the nervous system, multiple sclerosis, Parkinsonism, epilepsy, dementia, organic psychosis, schizophrenia, affective psychosis or mental retardation. Data were collected at four points in time; at baseline (F0), and at 3 (F1), 6 (F2) and 9 years (F3) after baseline assessment. The reference measurement for the present study, $F 2$, consisted of more male participants $(z=2.73, p<0.001)$, was younger $(\mathrm{t}=4.95, \mathrm{p}<0.001)$ and had higher SES $(\mathrm{t}=-4.99, \mathrm{p}<0.001)$ as compared to the group at baseline. Since only data collected at F2 and F3 were used, these will be referred to as TO (or baseline) and T1 (3 years after baseline), respectively. The group at T0 consisted of 1031 individuals. Over the 3-year follow-up period, 210 subjects were lost to follow-up due to various reasons: no contact $(n=54)$, deceased $(n=51)$, too old or illness $(n=30)$ and loss of interest $(n=75)$. Socioeconomic status (SES) was defined as monthly level of income, divided into twelve categories which were collapsed into three main groups for the final analyses ('low' <1361€, 'medium' 1362-2268€ and 'high' $>2269 €)$. 


\section{Measurement of hearing impairment}

Objective assessment of hearing function was done at T0 using pure tone audiometry at four different frequencies (500, 1000, 2000 and $4000 \mathrm{~Hz}$ ) which are relevant for speech comprehension. Detection thresholds were determined for each ear separately in steps of $5 \mathrm{~dB}$ (Jolles et al., 1995; van Boxtel et al., 2000). Objective hearing function was divided into ' 0 ', nonimpaired, and ' 1 ', impaired, when a loss of more than $35 \mathrm{~dB}$ at the best ear was present (Davis, 1995). Subjective evaluation of hearing function was assessed at $\mathrm{Tl}$ by asking each participant to judge his or her own auditory function (hereafter: subjective $\mathrm{HI}$ ), in addition to a question about whether one experienced problems in following conversations in groups of four to five people (hereafter: conversational $\mathrm{HI}$ ), with value labels ' 0 ' no and ' 1 ' yes. These questions have been shown to be effective in identifying hearing loss in different age groups and were found to be insensitive to language or culture (Nondahl et al., 1998; Torre et al., 2006; van Boxtel et al., 2000). Information on the use of hearing aids was added to create dummy variables; "1" impairment without hearing aid and "2" impairment with hearing aid, with "0" no impairment set as reference group. This was done as the additional presence of hearing aids confers a greater level of validation to the exposure (Thewissen et al., 2005).

\section{Measurements of psychotic experiences and paranoid ideation}

The Psychoticism (SCL-psy) and Paranoid ideation (SCL-par) subscales of the $S C L-90-R$ were used to assess level of psychotic experiences and paranoid ideation at $\mathrm{T} 1$. The $\mathrm{SCL}-90-\mathrm{R}$ is a multidimensional self-report inventory consisting of 90 items (Arrindell and Ettema, 1986, 2003; Derogatis, 1983). The instrument has been designed to measure psychopathology as a continuous dimension of human experiences and enables screening of nine dimensions of psychopathology. The two scales consisted of ten and six questions respectively. The SCL-psy subscale included questions such as: "Do you ever have the feeling that other people can control your thoughts?" The 


\section{Chapter 4}

SCL-par subscale included questions such as "Do you ever have the feeling that you are watched or talked about by others?" Participants were asked to rate these questions on a 5 -point Likert scale, with ' 1 ' representing 'not at all' and ' 5 ' representing 'very much'. Sum scores were calculated and a previously described (Henquet et al., 2005; Spauwen et al., 2006) single outcome measure was created by combining the two subscales in a single psychosis dimension reflecting psychotic experiences (hereafter: PS; range: 16-80). The SCL-90-R depression subscale was used to measure the presence of depressive symptoms (hereafter: DS; range: 15-75).

\section{Statistical analyses}

All analyses were performed using STATA version 9.0 (StataCorp, 2005). Associations between $\mathrm{HI}$ as exposure and $\mathrm{PS}$ as response variable were assessed using multiple regression analyses. The sample size was considered sufficiently large to use regression analysis on the expected skewed distribution of the SCL-90-R subscales outcome (Ross, 1976). A priori defined confounding factors were adjusted for: age, sex and SES. Mediation by emotional dysfunction was investigated by adjusting for DS. Effect sizes of the association between $\mathrm{HI}$ and PS on the one hand, and between $\mathrm{HI}$ and DS on the other were compared using the MVREG routine in STATA. Effect modification by age was examined by including the Age $\times \mathrm{HI}$ interaction term. Associations at the two-sided $p \leq 0.05$ level were considered statistically significant.

\section{RESULTS}

\section{Descriptive statistics}

Included in the analysis were 848 individuals with non-missing data on $\mathrm{HI}$ and PS (Table 1). There was a small but significant association between age and PS (Pearson $r=0.093, p=0.007$ ). T0 prevalence of objective $\mathrm{HI}$ was $9.4 \%$. At $\mathrm{Tl}$, $11.0 \%$ reported having hearing problems (subjective $\mathrm{HI}$ ) and $10.8 \%$ had problems in following conversations in groups consisting of more than four 
people (conversational $\mathrm{HI}$ ). Of the total sample $8.2 \%$ used a hearing aid. T0 objective and T1 conversational HI (OR 9.44, 95\% Cl 5.57, 16.00, $\mathrm{p}<0.001$ ), T0 objective and T1 subjective HI (OR 9.93, 95\% Cl 5.83, 16.92, p<0.001) and T1 subjective and $\mathrm{Tl}$ conversational $\mathrm{HI}(\mathrm{OR} 14.29,95 \% \mathrm{Cl} 8.55,23.89$, $\mathrm{P}<0.001)$ were all strongly associated with each other. Mean score on the PS scale was 22.71 ( $S D=8.13$, range: 16-64). The distribution of paranoid and psychotic experiences in the sample resembled a reversed J-shape indicating that most people had none or very few symptoms with a continuous halfnormal distribution of psychotic experiences in the remainder. Mean score on the DS scale was 26.53 ( $S D=10.24$, range: 17-73).

Table 1 Characteristics of the sample at T1 $(n=848)$

\begin{tabular}{|c|c|}
\hline Variable & \\
\hline Mean age in years (SD) & $57.2(14.3)$ \\
\hline Age distribution, $\mathrm{n}(\%)$ & \\
\hline Young $(<50$ year $)$ & $315(37.2)$ \\
\hline Middle-aged (50-70 year) & $359(42.3)$ \\
\hline Old (>69 year) & $174(20.5)$ \\
\hline Male gender, $\mathrm{n}(\%)$ & $437(51.5)$ \\
\hline Mean psychotic experiences (SD) & \\
\hline Young $(<50$ year $)$ & $21.77(7.82)$ \\
\hline Middle-aged (50-70 year) & $22.85(7.87)$ \\
\hline Old (>70 year) & $23.80(8.87)$ \\
\hline Total & $22.71(8.13)$ \\
\hline Monthly income, $n$ (\%) & \\
\hline Low $(<1361 €)$ & $133(15.7)$ \\
\hline Medium (1362-2268€) & $451(53.2)$ \\
\hline High $(>2269 €)$ & $264(31.1)$ \\
\hline
\end{tabular}

\section{Hearing impairment and psychotic experiences at $\mathrm{T} 1$}

Logistic regression with age as predictor revealed that objective $\mathrm{HI}$ (OR 1.16, $95 \% \mathrm{Cl}: 1.12,1.19, \mathrm{p}<0.001)$ at $\mathrm{T0}$, and subjective (OR $1.06,95 \% \mathrm{Cl}: 1.04$, $1.08, \mathrm{p}<0.001)$ and conversational $\mathrm{HI}(\mathrm{OR} 1.06,95 \% \mathrm{Cl}: 1.04,1.08, \mathrm{p}<0.001)$ at $\mathrm{T} 1$ were all positively associated with age. Table 2 presents zero-order correlations between predictors and outcome variables. Regression analysis showed significant associations between $\mathrm{Tl}$ conversational $\mathrm{HI}$ and $\mathrm{Tl}$ PS ( $\beta=0.080,95 \% \mathrm{Cl}: 0.23,7.90, \mathrm{p}=0.038$ ) and between $\mathrm{Tl}$ subjective $\mathrm{HI}$ and $\mathrm{Tl}$ 


\section{Chapter 4}

PS ( $\beta=0.087,95 \% \mathrm{Cl}: 0.70,10.30, p=0.025)$. Both associations were only present if self-reported hearing problems persisted in spite of the use of hearing aids. The same pattern was present for the association between $\mathrm{Tl}$ conversational $\mathrm{HI}$ and $\mathrm{Tl}$ DS $(\beta=0.079,95 \% \mathrm{Cl}: 0.24,9.73, \mathrm{p}=0.040)$, and $\mathrm{Tl}$ subjective $\mathrm{HI}$ and T1 DS $(\beta=0.084,95 \% \mathrm{Cl}: 0.59,12.55, p=0.031)$. The presented associations were more prominent for DS than for PS $(F=4.27$, $\mathrm{p}=0.04)$ and disappeared after testing for possible mediation in the model (Table 3). A negative interaction was found between age and conversational $\mathrm{HI}$ in the model of PS which was solely present in the group without hearing aids $(\beta=-0.745,95 \% \mathrm{Cl}:-0.49,-0.13, p=0.001)$.

Table 2. Zero-order correlations (Pearson) between variables that were included in the regression model ( $\mathrm{N}=848$; numbers available for pairwise correlations may be smaller).

\begin{tabular}{|c|c|c|c|c|c|c|c|c|}
\hline Variable & 1 & 2 & 3 & 4 & 5 & 6 & 7 & 8 \\
\hline 1. Age & -- & & & & & & & \\
\hline 2. Sex & .017 & -- & & & & & & \\
\hline 3. Income & $-.271^{* *}$ & $-.136^{* * *}$ & -- & & & & & \\
\hline 4. Psy_symptoms & $.085^{*}$ & .009 & $-.216^{\text {k* }}$ & -- & & & & \\
\hline 5. Dep_symptoms & $.079^{*}$ & $.116^{*}$ & $-.209^{\text {k*t }}$ & $.850^{* *}$ & -- & & & \\
\hline 6. Hearing aid & $.127^{* * *}$ & -.069 & $-.116^{*}$ & $.094^{*}$ & $.099^{*}$ & -- & & \\
\hline 7. Conversational HI & $.250^{* *}$ & -.021 & $-.186^{* * *}$ & .065 & $.104^{*}$ & $.394^{* * *}$ & -- & \\
\hline 8. Subjective HI & $.246^{* *}$ & -.068 & $-.099^{*}$ & .023 & .055 & $.370^{* * *}$ & $.508^{*}$ & -- \\
\hline 9. Objective $\mathrm{HI}$ & $.365^{* * *}$ & $-.078^{*}$ & $-.116^{*}$ & .025 & .016 & $.453^{\text {w*t }}$ & $.390^{* * *}$ & $.404^{* *}$ \\
\hline
\end{tabular}


Table 3. Overview of the multiple regression analyses with PS and DS as dependent variables $(\mathrm{N}=848)$. Reported are standardised regression coefficients (beta), 95\% confidence interval and level of significance $(* \mathrm{p}<.05$ and $* * \mathrm{p}<.01)$.

\begin{tabular}{|c|c|c|c|c|}
\hline & \multicolumn{2}{|c|}{ DS } & \multicolumn{2}{|c|}{ PS } \\
\hline & $\beta$ & $95 \% \mathrm{Cl}$ & $\beta$ & $95 \% \mathrm{Cl}$ \\
\hline \multicolumn{5}{|l|}{ Model 1.} \\
\hline \multirow{2}{*}{\multicolumn{5}{|c|}{$\begin{array}{c}\text { conversational HI } \\
\text { without HA }\end{array}$}} \\
\hline & .064 & $-0.41,5.02$ & .037 & $-1.13,3.26$ \\
\hline with HA & .079 & $0.24,9.73^{*}$ & .080 & $0.23,7.90^{*}$ \\
\hline \multicolumn{5}{|l|}{ subjective HI } \\
\hline without HA & .031 & $-1.50,3.53$ & .022 & $-1.44,2.60$ \\
\hline with HA & .084 & $0.59,12.55^{*}$ & .087 & $0.70,10.30 *$ \\
\hline \multicolumn{5}{|l|}{ objective HI } \\
\hline without HA & -.035 & $-4.41,1.62$ & -.040 & $-3.73,1.13$ \\
\hline with $\mathrm{HA}$ & .029 & $-2.35,5.32$ & .028 & $-1.92,4.25$ \\
\hline \multicolumn{5}{|l|}{ Model 2.} \\
\hline \multicolumn{5}{|c|}{ conversational HI } \\
\hline without HA & .032 & $-0.18,2.49$ & -.019 & $-1.64,0.52$ \\
\hline with HA & .010 & $-1.74,2.94$ & .011 & $-1.33,2.45$ \\
\hline \multicolumn{5}{|l|}{ subjective HI } \\
\hline without HA & .032 & $-0.18,2.49$ & -.019 & $-1.64,0.52$ \\
\hline with HA & .008 & $-2.34,3.52$ & .014 & $-1.50,3.25$ \\
\hline \multicolumn{5}{|l|}{ objective HI } \\
\hline without HA & .000 & $-1.44,1.48$ & -.010 & $-1.49,0.86$ \\
\hline with HA & .004 & $-1.64,2.07$ & .003 & $-1.38,1.62$ \\
\hline \multicolumn{5}{|c|}{$\begin{array}{l}\text { Model } 3 . \\
\text { conversational HI }\end{array}$} \\
\hline without HA & .036 & $-0.05,2.63$ & -.029 & $-1.92,0.26$ \\
\hline with HA & .021 & $-0.99,3.65$ & -.004 & $-2.10,1.66$ \\
\hline \multicolumn{5}{|l|}{ subjective $\mathrm{HI}$} \\
\hline without HA & .022 & $-0.49,1.97$ & -.017 & $-1.44,0.5$ \\
\hline with $\mathrm{HA}$ & .019 & $-1.42,4.40$ & -.002 & $-2.50,2.19$ \\
\hline \multicolumn{5}{|l|}{ objective HI } \\
\hline without HA & .018 & $-0.82,2.26$ & -.029 & $-2.20,0.28$ \\
\hline with $\mathrm{HA}$ & .018 & $-0.94,2.81$ & -.015 & $-2.13,0.90$ \\
\hline
\end{tabular}

Note $\mathrm{HA}=$ hearing aid; $\mathrm{PS}=$ psychotic symptoms; $\mathrm{DS}=$ depressive symptoms 1 = unadjusted effect sizes, 2 = effect sizes adjusted for DS as possible mediator for PS outcome and adjusted for PS as possible mediator for DS outcome, 3 = as in 2 and additionally adjusted for age, sex and SES 


\section{DISCUSSION}

As expected, $\mathrm{HI}$ was more prevalent among the elderly in this normal aging population sample. Not only did older people complain more about hearing loss, the prevalence of objective $\mathrm{HI}$ was also much higher. Participants with self-reported hearing loss (subjective and conversational $\mathrm{HI}$ ) scored higher on the PS subscale than those participants without complaints. However, this association with psychotic experiences was only present if the self-reported hearing problems persisted in spite of the use of a hearing aid. On the contrary, objective $\mathrm{HI}$ was not associated with higher scores on the PS subscale. This suggests that not the objective impairment, but the perception of impairment contributed to the development of psychotic experiences in this population sample. Although all $\mathrm{HI}$ variables used in this study were strongly interrelated, self-reported $\mathrm{HI}$ assessment probably indexes a different aspect of hearing loss than objective HI. Self-reported hearing difficulties are an accepted indicator of true hearing loss, but additionally have also been found to measure the psychosocial problems associated with HI (Hashimoto et al., 2004). And likewise, conversational problems will often be the presenting complaint in individuals with $\mathrm{HI}$, but may not yet be consciously appraised as evidence of sensory impairment.

Although numerous studies have reported evidence for a contributory role of emotional processes in symptom formation, pathogenesis and maintenance of psychosis (Hanssen et al., 2005; Krabbendam and van Os, 2005; Krabbendam et al., 2005), no evidence for a mediating role of depressive feelings in the association between self-reported hearing problems and psychotic experiences was found. Although individuals with conversational and subjective $\mathrm{HI}$ had stronger evidence of depressive feelings than psychotic experiences, these were unlikely to mediate the presented associations. The strong association between $\mathrm{HI}$ and depressive feelings is in accordance with earlier research in which acquired $\mathrm{HI}$ has been considered a 
risk factor for depression. Sensory loss often results in feelings of grief and depression (Heine and Browning, 2002; Tsuruoka et al., 2001). However, in our data this association also disappeared after testing for possible mediation by psychotic experiences.

A negative interaction was found between age and conversational $\mathrm{HI}$ in the association with psychotic experiences at Tl. Younger age increased the susceptibility of developing psychotic experiences in the presence of conversational HI. However, no evidence was found for a risk-increasing effect of conversational $\mathrm{HI}$ on psychosis outcome in older participants. These results are in agreement with previous research, even though different age categories were used to define "young" and "old". The association between $\mathrm{HI}$ and psychotic experiences is probably an age-dependent one which tends to be absent in older persons. Cooper (1976) postulated that especially $\mathrm{HI}$ with early onset and long duration and severity would be of etiological significance. More recently, it was shown that individuals with long-standing $\mathrm{HI}$ were more likely to develop psychotic symptoms and paranoid ideation (Stefanis et al., 2006).

Interpretation of the results should be made with some caution given the fact that not all variables could be measured at the same period in time. Conditions may have changed in 3 years, which could have attenuated associations between the variables that were measured, leading to a potential underestimation of the observed associations. Furthermore, bias may have occurred if participants who remained in the study differed systematically from those individuals who were lost to follow-up with respect to key exposures and outcomes. The possibility that those individuals who were lost to follow-up had low rates of $\mathrm{HI}$ and more experiences of psychopathology, thus biasing the results, cannot be ruled out by the present data set. It must also be kept in mind that the study design does not allow us to draw any conclusions about causality since information on level of psychotic experiences at baseline is absent. As such, conversational $\mathrm{HI}$ might be a consequence rather than a cause of psychotic symptoms. Although reverse 


\section{Chapter 4}

causality cannot be excluded, empirical evidence to date suggests that this may not be a very likely mechanism (Cooper and Curry, 1976; Stefanis et al., 2006; Thewissen et al., 2005). Another limitation concerns the assumption of the multidimensionality of the SCL-90-R. The SCL-90-R is developed as an instrument to measure distinct multidimensional subcategories of psychopathology (Arrindell and Ettema, 1986). This multidimensionality has recently been questioned. In a review (Hafkenscheid, 2004) it was argued that the SCL-90-R should be seen as a unidimensional screening instrument for general psychopathology, since all SCL subscales of the SCL-90-R were highly intercorrelated. Most of the variance of SCL psychotic experiences was explained by level of depression, and other predictors, such as income and sex, only showed minor contributions. Furthermore, symptoms of paranoia and psychotic experiences are much more attenuated in non-clinical samples, which could make it more difficult to measure this dimension of psychopathology in a sensitive fashion. Apart from these disadvantages, it has been shown that the SCL-90-R has good power to discriminate between patients and the community and many subscales show good convergent and divergent validity. It can be used very well in research settings to assess psychological functioning and distress (Kamphuis and Geurts, 2006; Schmitz et al., 2000). It could be argued that auditory impairment and vulnerability to psychosis both share common precursors. Although we cannot exclude this based on our results, there is no evidence available to date to support this notion. Finally, it has been argued that especially early onset, long-standing and severe hearing deficits (e.g. due to middle-ear infections in children) are of aetiological importance in the pathogenesis of psychotic experiences, rather than the quality of hearing loss. This suggests that the mode of action of deafness in paranoid psychosis is probably one in which changes in psychological functioning and social adaptation take place slowly and progressively over a prolonged period (Cooper, 1976; Cooper and Curry, 1976; Stefanis et al., 2006). Given this time frame, presbyacusia may not be as important in the etiology of psychosis in the elderly (Cooper, 1976). In the 
Risk for Psychosis: A Life Span Perspective

MAAS study, no distinction was made between different causes of hearing loss and age of onset. Variability in $\mathrm{HI}$ was even restricted at baseline, because $\mathrm{HI}$ that was incompatible with cognitive testing was used as an exclusion criterion. This might have weakened any existing association, in particular if exposure to $\mathrm{HI}$ over certain developmental periods is critical in relation to the development of psychosis. 
Arrindell, W.A., Ettema, J.H.M., 1986. SCL-90. Een multidimensionale psychopathologie indicator (SCL-90. A Multidimensional Psychopathology Indicator). Swets Test Publisher, Lisse.

Arrindell, W.A., Ettema, J.H.M. (Eds.), 2003. Scl-90. Handleiding bij een multidimensionale psychopathologie indicator. (Scl-90. Manual of a Multidimensional Indicator of Psychopathology). Swets Test Publisher, Lisse.

Cooper, A.F., 1976. Deafness and psychiatric illness. Br. J. Psychiatry 129, 216-226.

Cooper, A. F., Curry, A.R., 1976. The pathology of deafness in the paranoid and affective psychoses of later life. J. Psychosom. Res. 20 (2), 97-105.

Corbin, S.L., Eastwood, M.R., 1986. Sensory deficits and mental disorders of old age: causal or coincidental associations? Psychol. Med. 16 (2), 251-256.

David, A., Malmberg, A., Lewis, G., Brandt, L., Allebeck, P., 1995. Are there neurological and sensory risk factors for schizophrenia? Schizophr. Res. 14 (3), 247-251.

Davis, A., 1995. Hearing in Adults. Whurr Publishers, Nottingham.

Derogatis, L.R., 1983. SCL-90-R administration, scoring and procedures manual II. Towson, MD.

Garety, P.A., Kuipers, E., Fowler, D., Freeman, D., Bebbington, P.E., 2001. A cognitive model of the positive symptoms of psychosis. Psychol. Med. 31 (2), 189-195.

Hafkenscheid, A., 2004. Hoe multidimensionaal is de scl-90 nu eigenlijk? (How multidimensional is the SCL-90-R really?) De Psycholoog. 4, 191-194.

Hanssen, M., Krabbendam, L., de Graaf, R., Vollebergh, W., van Os, J., 2005. Role of distress in delusion formation. Br. J. Psychiatr., Suppl. 48, s55-s58.

Hashimoto, H., Nomura, K., Yano, E., 2004. Psychosomatic status affects the relationship between subjective hearing difficulties and the results of audiometry. J. Clin. Epidemiol. 57 (4), 381-385.

Heine, C., Browning, C.J., 2002. Communication and psychosocial consequences of sensory loss in older adults: overview and rehabilitation directions. Disabil. Rehabil. 24 (15), 763-773.

Henquet, C., Krabbendam, L., Spauwen, J., Kaplan, C., Lieb, R., Wittchen, H.U., van Os, J., 2005.

Prospective cohort study of cannabis use, predisposition for psychosis, and psychotic symptoms in young people. BMJ 330 (7481), 11.

Howard, R., Almeida, O., Levy, R., 1994. Phenomenology, demography and diagnosis in late paraphrenia. Psychol. Med. 24 (2), 397-410.

Johns, L.C., van Os, J., 2001. The continuity of psychotic experiences in the general population. Clin. Psychol. Rev. 21 (8), 1125-1141.

Jolles, J., Houx, P.J., van Boxtel., M.P.J., Ponds, R.W.H.M., 1995. Neuropsych Publishers, Maastricht. Kamphuis, J.H., Geurts, H.M., 2006. Gestandaardiseerde psychodiagnostische methoden (Standardised psychodiagnostic methods). In: Van der Eycken, H., Emmelkamp (Eds.), Handboek Psychopathologie deel 2.

Krabbendam, L., van Os, J., 2005. Affective processes in the onset and persistence of psychosis. Eur. Arch. Psychiatry Clin. Neurosci. 255 (3), 185-189.

Krabbendam, L., Myin-Germeys, I., De Graaf, R., Vollebergh, W., Nolen, W.A., ledema, J., Van Os, J., 2004. Dimensions of depression, mania and psychosis in the general population. Psychol. Med. 34 (7), $1177-$ 1186.

Krabbendam, L., Myin-Germeys, I., Hanssen, M., de Graaf, R., Vollebergh, W., Bak, M., van Os, J., 2005. Development of depressed mood predicts onset of psychotic disorder in individuals who report hallucinatory experiences. Br. J. Clin. Psychol. 44 (Pt 1), 113-125.

Laroi, F., Van der Linden, M., DeFruyt, F., van Os, J., Aleman, A., 2006. Associations between delusion proneness and personality structure in non-clinical participants: comparison between young and elderly samples. Psychopathology 39 (5), 21 8-226.

Livingston, G., Kitchen, G., Manela, M., Katona, C., Copeland, J., 2001. Persecutory symptoms and perceptual disturbance in a community sample of older people: the Islington study. Int. J. Geriatr. Psychiatry 16 (5), 462-468. 


\section{Risk for Psychosis: A Life Span Perspective}

Metsemakers, J.F., Hoppener, P., Knottnerus, J.A., Kocken, R.J., Limonard, C.B., 1992. Computerized health information in The Netherlands: a registration network of family practices. Br. J. Gen. Pract. 42 (356), 102106.

Myin-Germeys, I., Os, J., 2007. Stress-reactivity in psychosis: evidence for an affective pathway to psychosis. Clin. Psychol. Rev. 27 (4), 409-424.

Nondahl, D.M., Cruickshanks, K.J., Wiley, T.L., Tweed, T.S., Klein, R., Klein, B.E., 1998. Accuracy of selfreported hearing loss. Audiology 37 (5), 295-301.

Peters, E., Day, S., McKenna, J., Orbach, G., 1999. Delusional ideation in religious and psychotic populations. Br. J. Clin. Psychol. 38 (Pt 1), 83-96.

Poulton, R., Caspi, A., Moffitt, T.E., Cannon, M., Murray, R., Harrington, H., 2000. Children's self-reported psychotic symptoms and adult schizophreniform disorder: a 15-year longitudinal study. Arch. Gen. Psychiatry 57 (11), 1053-1058.

Rodriguez-Ferrera, S., Vassilas, C.A., Haque, S., 2004. Older people with schizophrenia: a community study in a rural catchment area. Int. J. Geriatr. Psychiatry 19 (12), 1181-1187.

Ross, S., 1976. A First Course in Probability. Macmillan, New York. Sadock, B.J., Sadock, V.A., 2000. Lippincott Williams \& Wilkins. Philadelphia.

Schmitz, N., Hartkamp, N., Kiuse, J., Franke, G.H., Reister, G., Tress, W., 2000. The Symptom Check-List90-R (SCL-90-R): a German validation study. Qual. Life Res. 9 (2), 185-193.

Spauwen, J., Krabbendam, L., Lieb, R., Wittchen, H.U., van Os, J., 2006. Evidence that the outcome of developmental expression of psychosis is worse for adolescents growing up in an urban environment. Psychol. Med. 36 (3), 407-415.

StataCorp., 2005. STATA Statistical Software: Release 9.0. College Station, Texas.

Stefanis, N., Thewissen, V., Bakoula, C., van Os, J., Myin-Germeys, I., 2006. Hearing impairment and psychosis: a replication in a cohort of young adults. Schizophr. Res. 85 (1-3), 266-272.

Stein, L.M., Bienenfeld, D., 1992. Hearing impairment and its impact on elderly patients with cognitive, behavioural, or psychiatric disorders: a literature review. J. Geriatr. Psychiatry 25, 145-155.

Thewissen, V., Myin-Germeys, I., Bentall, R., de Graaf, R., Vollebergh, W., van Os, J., 2005. Hearing impairment and psychosis revisited. Schizophr. Res. 76 (1), 99-103.

Tien, A.Y., 1991. Distributions of hallucinations in the population. Soc. Psychiatry Psychiatr. Epidemiol. 26 (6), 287-292.

Torre, P., Moyer, C.J., Haro, N.R., 2006. The accuracy of self-reported hearing loss in older LatinoAmerican adults. Int. J. Audiol. 45 (10), 559-562.

Tsuruoka, H., Masuda, S., Ukai, K., Sakakura, Y., Harada, T., Majima, Y., 2001. Hearing impairment and quality of life for the elderly in nursing homes. Auris, Nasus, Larynx 28 (1), 45-54.

van Boxtel, M.P., Buntinx, F., Houx, P.J., Metsemakers, J.F., Knottnerus, A., Jolles, J., 1998. The relation between morbidity and cognitive performance in a normal aging population. J. Gerontol., Ser. A, Biol. Sci. Med. Sci. 53 (2), M147-M154.

van Boxtel, M.P., van Beijsterveldt, C.E., Houx, P.J., Anteunis, L.J., Metsemakers, J.F., Jolles, J., 2000. Mild hearing impairment can reduce verbal memory performance in a healthy adult population. J. Clin. Exp. Neuropsychol. 22 (1), 147-154.

van Os, J., 2003. Is there a continuum of psychotic experiences in the general population? Epidemiol. Psichiatr. Soc. 12 (4), 242-252. 

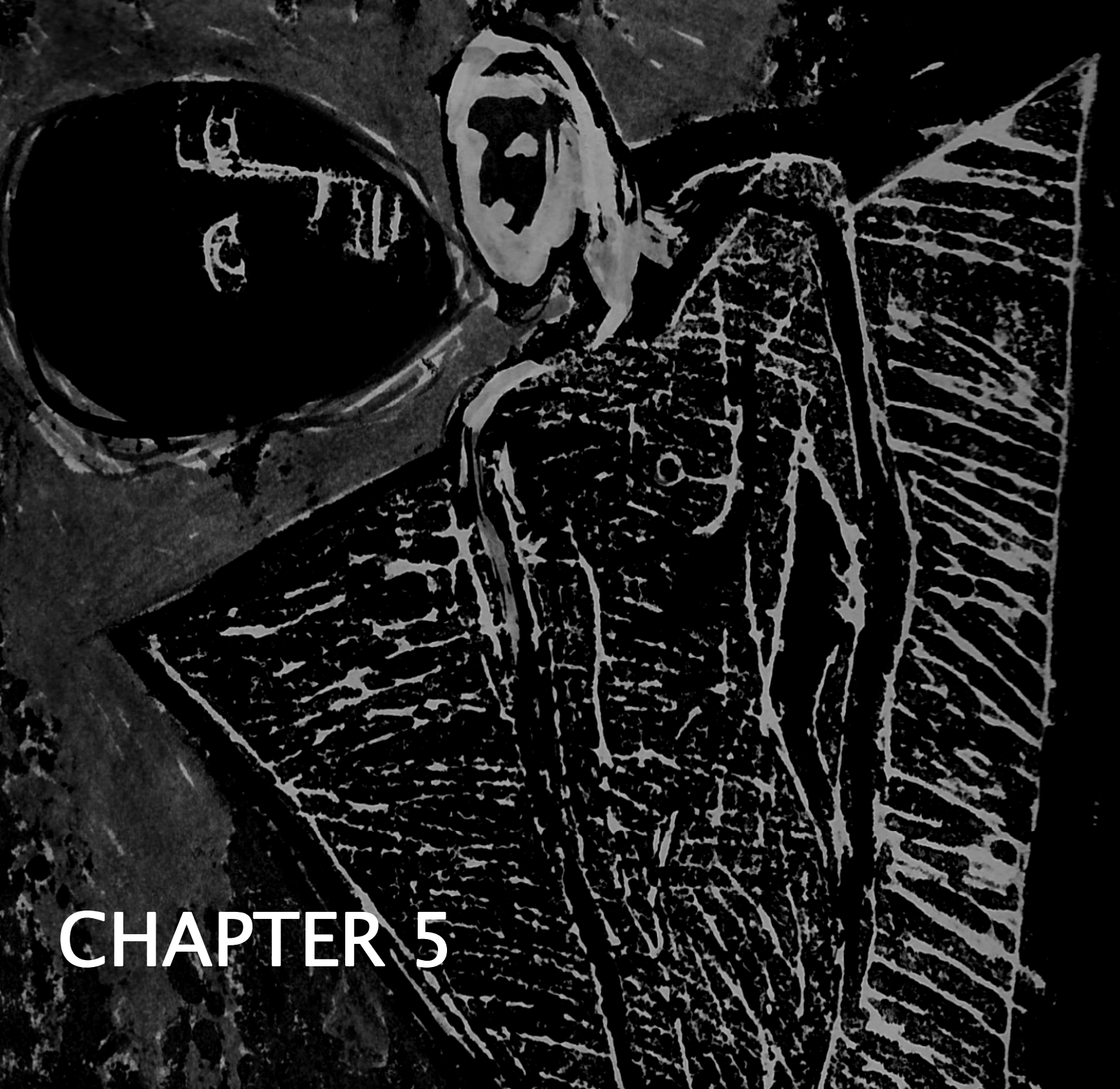

ADOLESCENT DEVELOPMENT OFPSYGHOSIS AS AN OUTCOME OF HEARING IMPAIRMEN A IO YEAR

\section{LONGITUDINAL STUDY}

Margriet van der Werf, Viviane Thewissen, Maria de anacial Polninguez Roselind Lieb, Hans'Wittchen and Jim van Os

\section{2. $\quad 40$}

Psychologicâl Medicine (2011), 41 (03), pp. $477-485$.

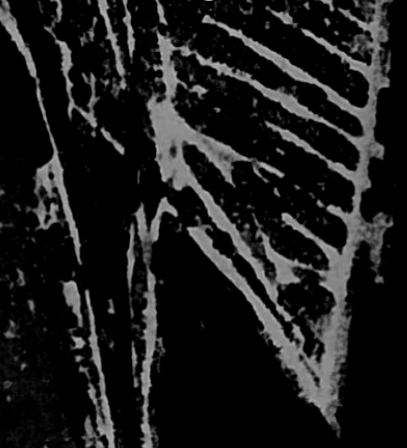




\section{ABSTRACT}

Background - It has long been acknowledged that hearing impairment may increase the risk for psychotic experiences. Recent work suggests young people in particular may be at risk, indicating a possible developmental mechanism.

Method - The hypothesis that individuals exposed to hearing impairment in early adolescence would display the highest risk for psychotic symptoms was examined in a prospective cohort study of a population sample of originally 3021 adolescents and young adults aged 14-24 years at baseline, in Munich, Germany (Early Developmental Stages of Psychopathology Study). The expression of psychosis was assessed at multiple time points over a period of up to ten years, using a diagnostic interview (Munich Composite International Diagnostic Interview- CIDI) administered by clinical psychologists.

Results - Hearing impairment was associated with CIDI psychotic symptoms $(\mathrm{OR}=2.04,95 \% \mathrm{Cl}=1.10-3.81)$, particularly more severe psychotic symptoms $(\mathrm{OR}=5.66,95 \% \mathrm{Cl}=1.64,19.49)$. The association between hearing impairment and CIDI psychotic symptoms was much stronger in the youngest group aged 14-17 years at baseline $(\mathrm{OR}=3.28,95 \% \mathrm{Cl}=1.54-7.01)$ than in the older group aged $18-24$ years at baseline $(\mathrm{OR}=0.82,95 \% \mathrm{Cl}=0.24-2.84)$.

Conclusion - The finding of an age-specific association between hearing impairment and psychotic experiences suggests that disruption of development at a critical adolescent phase, in interaction with other personal and social vulnerabilities, may increase the risk for psychotic symptoms. 


\section{INTRODUCTION}

Recent meta-analyses of general population surveys suggest that psychometric liability for psychosis in the form of subclinical psychotic experiences, such as paranoid delusional thinking and fleeting auditory hallucinations, is present in 5-10\% of healthy people (Linscott and van Os, 2010, van Os et al., 2009). There is consistent evidence that the highest rates are observed in adolecents and young adults (Lataster et al., 2009, Peters et al., 1999, Rossler et al., 2007, Verdoux et al., 1998). Follow-up studies indicate that the majority of low-grade psychotic phenomena are benign and transitory (Cougnard et al., 2007, Hanssen et al., 2005). However, there is evidence from two birth cohorts (Poulton et al., 2000, Welham et al., 2009), three representative general population cohorts (Dominguez et al., 2009, Hanssen et al., 2005, Weiser et al., 2009) and other longitudinal work (Chapman et al., 1994) that low grade psychotic experiences such as delusional thinking and mild hallucinatory experiences may precede the diagnosis of psychotic disorder and hospital admission for schizophrenia by many years. It has been suggested that environmental risk factors operating in early adolescence may interact with background genetic risk (van Os et al., 2008) in producing low-grade delusional ideation and hallucinatory experiences that in some cases, if persistent, may progress to full-blown clinical psychotic states (Dominguez et al., 2009, Kaymaz and van Os, 2010).

There is evidence suggesting that hearing impairment increases the risk for psychosis (Stefanis et al., 2006, van der Werf et al., 2007), particularly in young people (David et al., 1995, Thewissen et al., 2005). Although the mechanism by which hearing impairment may increase risk for psychosis in young people remains elusive, a number of hypotheses have been put forward. First, hearing impairment and psychosis may be the consequence of a common underlying cause. For example, exposure to perinatal infections 
affecting the central nervous system, such as rubella and meningitis (Brown et al., 2000, Dalman et al., 2008, Leask et al., 2002), may explain the association between early hearing impairment and later psychosis. Second, psychotic experiences may be a direct or indirect consequence of processes triggered by hearing loss. For example, experimental studies have demonstrated psychotomimetic effects induced by sensory deprivation (Leff, 1968, Mason and Brady, 2009). In addition, it has been proposed that hearing loss may indirectly increase psychosis risk through social defeat stress (Selten and Cantor-Graae, 2007). Finally, hearing impairment originating early in life may impact on risk for psychosis by interfering with critical developmental phases for language, cognition and social skills (Bess et al., 1998).

The current investigation focused on the expression of psychosis in adolescents with hearing impairment. It was hypothesised that adolescent hearing impairment, particularly in the phase of early adolescence, would be associated with an increased risk for psychotic symptoms. We relied on assessments of psychotic experiences by trained and experienced clinical psychologists in order to reduce the risk of false positive ratings. In addition, the longitudinal design allowed for examination of possible alterations in exposure assessment induced by high levels of psychosis proneness at baseline.

\section{METHODS}

\section{Sample and Study Design}

The Early Developmental Stages of Psychopathology (EDSP) study is a prospective longitudinal cohort community study which collected data on the prevalence, incidence, risk factors and course of mental disorders. Following ethics committee approval, the sample was randomly drawn from the 1994 government population registers. The sample consisted of adolescent and young adults living in the Munich area (Germany), aged 14 to 24 years at 


\section{Chapter 5}

baseline. Participants completed a baseline investigation (TO) and three follow-up investigations (T1, T2, T3). At baseline, 3021 interviews were completed (response rate: $71 \%$ ). Because the study primarily intended to examine the incidence and developmental risk factors for psychopathology, the younger group (14-15 years) was sampled at twice the rate of persons aged 16-21 years, and the oldest group (22-24 years) was sampled at half this rate. Furthermore, participants aged 14-17 years were assessed three times $(T 1, T 2, T 3)$ and participants aged 18-24 years were assessed only two times $(\mathrm{T} 2, \mathrm{~T} 3)$ after baseline. The follow-up periods had mean durations of approximately 1.6 years $(\mathrm{T} 0-\mathrm{T} 1, \mathrm{SD}=0.2), 3.4$ years $(\mathrm{T} 0-\mathrm{T} 2, \mathrm{SD}=0.3)$ and 8.6 years (T0-T3, range $7.4-10.6$ years, $S D=0.7$ ). The risk set consisted of the 3021 individuals at baseline and their $\mathrm{T1}(\mathrm{n}=1228$; response rate=88\%), T2 $(n=2548 ; 84 \%)$ and T3 $(n=2210 ; 73 \%)$ follow-up measurements. Figure 1 shows an overview of the study design and lists the measurements conducted at the different time points. Written informed consent was obtained from all participants. More detailed information about the EDSP study can be found elsewhere (Lieb et al., 2000, Wittchen et al., 1998b). 


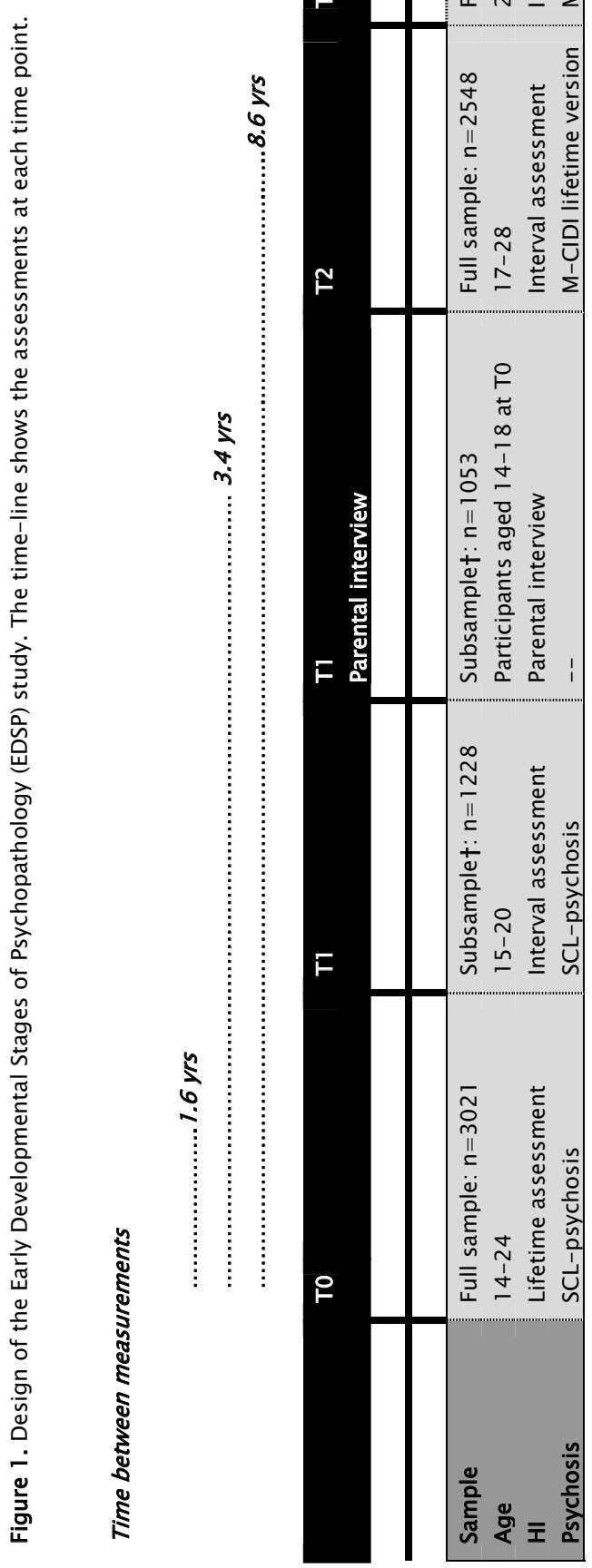




\section{Instruments}

Assessment of Psychotic Experiences - Psychotic experiences were assessed using the computer-assisted version of the Munich Composite International Diagnostic Interview (DIA-X/M-CIDI) (Wittchen and Pfister, 1997), an updated version of the World Health Organization's CIDI version 1.2 (WHO, 1990). The DIA-X/M-CIDI is a comprehensive, fully standardised computer-assisted diagnostic interview for the assessment of symptoms, syndromes and diagnoses of various mental disorders in accordance with the DSM-IV criteria, along with information about psychosocial impairment as well as the onset, duration and severity of symptoms. The DIA-X/M-CIDI was developed specifically for use in adolescents and young adults. High validity (Reed et al., 1998) and high interrater and test-retest reliability of the CIDI have previously been shown (Wittchen, 1994, Wittchen et al., 1998a). Fully trained and experienced clinical psychologists, who were allowed to probe with clinical follow-up questions, conducted the interviews to ensure validity and reliability of assessments. The lifetime version of the DIA-X/M-CIDI was used at baseline and the interval version was applied at each of the follow-ups, covering the respective time periods between interviews.

The presence of psychotic experiences was assessed using the 20 core psychosis items of the DIA-X/M-CIDI-G section (G1, G2a, G3-5, G7-G13, $\mathrm{G} 13 \mathrm{~b}, \mathrm{G} 14, \mathrm{G} 17, \mathrm{G} 18, \mathrm{G} 20, \mathrm{G} 20 \mathrm{c}, \mathrm{G} 21$ and G22a) including symptoms of delusions, hallucinations and passivity phenomena. Participants first read a list of all the psychotic experiences and were then asked whether they ever experienced these symptoms (list and phrasing available upon request). All items could be rated as absent or present, without intermediate levels. Data on the DIA-X/M-CIDI-psychosis section were collected at T2 (lifetime version) and T3 (interval version) only. The mean interval between T2 and T3 measurements was 4.9 years. Two different outcome measures were created: (i) a dichotomous variable indicating the presence or absence of at least one positive rating on the 20 core psychotic items (hereafter: CIDI-psychosis) and 
(ii) in order to examine dose-response in the association between $\mathrm{HI}$ and psychotic experiences at increasing levels of psychosis severity, four progressively stricter psychosis subcategories were constructed (hereafter: CIDI-psychosis severity) with: no symptoms (0), 1 or 2 symptoms (1), 3 or 4 symptoms (2) and at least 5 symptoms (3).

In addition, participants completed the self-report Symptom Checklist-90Revised at T0 (SCL-90-R; Derogatis, 1983). The SCL-90-R is a multidimensional self-report symptom inventory that assesses psychopathology as a continuous dimension of human experiences and enables screening of nine dimensions of psychopathology (Arrindell and Ettema, 2003, Derogatis, 1983). Reliability and validity have been established previously (Bonicatto et al., 1997). Baseline psychosis proneness was assessed using the Paranoid Ideation (6 items) and Psychoticism (10 items) subscales. These subscales include self-reports on psychotic experiences that can be regarded, if not as clear-cut psychotic symptoms, as an expression of psychosis proneness. In accordance with previous analyses in this sample (Henquet et al., 2005), the total scores of both subscales were combined into a single dimension reflecting psychotic experiences. In line with previous work (Henquet et al., 2005), and as validated recently (Dominguez et al., 2009), baseline psychosis proneness was defined dichotomously as the group of participants with the highest $10 \%$ of scores (hereafter: SCL-psychosis).

TO-T3 Assessment of Hearing Impairment - The presence of hearing impairment (HI) was based on self-report and assessed at T0 (lifetime assessment) and over the T0-T1, T1-T2 and T2-T3 intervals (interval assessments). The assessment was included in a questionnaire enquiring about a range of somatic complaints, including sensory deficits. At T0, participants were asked the following question: "Did you ever experience a period in which you were unable to hear anything at all?" yielding a binary exposure variable. At the T1, T2 and T3 follow-ups, HI was assessed using the same question, restricted to the interval since the last interview. Since 


\section{Chapter 5}

complete deafness was an exclusion criterion for EDSP study participation at baseline, the impairment assessed referred to a period of transient or permanent severe hearing impairment. The most common causes of severe hearing loss that may temporarily or permanently affect young people include syndromal or non-syndromal genetic disorders, prenatal and perinatal infections and noise exposure (reviews by: Olusanya and Newton, 2007, Tharpe and Sladen, 2008).

Childhood $\mathrm{HI}$ • Although previous work suggests that self-reported hearing impairment has adequate sensitivity and specificity (Sindhusake et al., 2001), an additional parental indicator of childhood hearing impairment (hereafter: Childhood $\mathrm{HI}$ ) was used to validate the exposure of $\mathrm{HI}$ in the current study. A parental investigation was conducted at $\mathrm{Tl}$ in the subsample of participants aged 14 to 17 years at baseline $(n=1053)$. Using a standardised checklist (Wittchen et al., 1999), information was gathered about family and early childhood variables, including sensory deficits. Parental reports of Childhood $\mathrm{HI}$, rated dichotomously, were available for 723 participants.

\section{Statistical analyses}

All analyses were conducted in STATA, version 10 (STATACORP, 2008). Prevalence estimates of $\mathrm{HI}$ and cumulative lifetime incidence of CIDI-psychosis were calculated. As data was acquired at multiple points in time, associations between exposure and outcome were analysed with data in the long format, i.e. each individual in the study contributed multiple observations (the variable "time" expressing the number of measurements for each person, with a maximum of four measurements at T0, T1, T2 and T3). Clustering of observations within subjects was controlled for by adjusting for the variable "time" in the model. Based on previous work, all analyses were adjusted for sex, age at baseline and education (low, medium, high). As young people may acquire hearing loss at a young age by attending pop concerts, during which exposure to illicit drugs may also occur, analyses were additionally adjusted 
for use of any illicit drugs at baseline (including cannabis, amphetamine, cocaine and other stimulants) at least five times lifetime (' 0 ' no, ' 1 ' yes).

\section{Association between $\mathrm{HI}$ and Psychotic Experiences at T2 and T3 - The} association between $\mathrm{HI}$ and $\mathrm{CIDI}-$ psychosis at $\mathrm{T} 2$ and T3 was examined by logistic regression analysis, with associations expressed as odds ratios (ORs) and their corresponding $95 \% \mathrm{Cls}$. In order to exclude the possibility that any association between $\mathrm{HI}$ and psychotic symptoms would be confounded by high levels of baseline psychosis proneness (given that this measure may possibly be associated with over-reporting of $\mathrm{HI}$ and, independent of that, with psychotic symptoms at follow-up), analyses of association between $\mathrm{HI}$ and T2-T3 CIDI-psychosis were repeated with additional adjustment for T0 SCL-psychosis. In addition, analyses were also repeated on a subsample from which participants with the 50\% highest baseline SCL-psychosis scores were excluded. Finally, as previous research has shown that the effect of certain predictors of psychosis (e.g. cannabis (Henquet et al., 2005) and childhood trauma (Spauwen et al., 2006)) is stronger in individuals already showing some degree of psychosis proneness at baseline, we examined whether the association between $\mathrm{HI}$ and T2-T3 CIDI-psychosis was stronger in those with higher levels of baseline psychosis proneness. To this end, a $\mathrm{HI} \times$ baseline SCL-psychosis interaction term was included in the model.

Associations at different levels of psychosis severity • The magnitude of the association between $\mathrm{HI}$ and different levels of psychosis severity was examined using multinomial logistic regression with the STATA MLOGIT routine, with the lowest psychosis-severity subcategory serving as the reference group.

Age-dependent association - The hypothesised age-dependent association between $\mathrm{HI}$ and psychosis was tested by splitting the baseline sample around the median age, creating a young (13-17 years) and an old (18-24 years) age 


\section{Chapter 5}

group. An age $\times \mathrm{HI}$ interaction term was fitted followed by calculation of agestratified effects from the model including the interaction by applying the appropriate linear combinations using the STATA LINCOM routine.

Childhood $\mathrm{HI}$ - In order to validate the self-report measure of $\mathrm{HI}$ used in the current study, the association between Childhood $\mathrm{HI}$ (based on parental report; see figure 1), and T0 $\mathrm{HI}$ (which should include any childhood experience of hearing impairment) was assessed by logistic regression analysis. In addition, the association between Childhood $\mathrm{HI}$ and baseline SCLpsychosis was examined using logistic regression analysis. Finally, the association between $\mathrm{HI}$ and CIDI-psychosis was examined after excluding all individuals with $\mathrm{HI}$ whose parents had not reported a similar impairment during childhood.

\section{RESULTS}

Mean age at baseline was 18.3 years $(S D=3.3)$ and $49.3 \%$ were male. The cumulative lifetime incidence of CIDI-psychosis at T3 was $17.9 \%(n=848)$. The prevalence of $\mathrm{HI}$ over time was: T0=92 (3.1\%), T1=8(0.7\%), T2=18(0.8\%) and T3=33 (1.6\%), yielding a total of 151 (1.8\%) observations of HI. Seven subjects reported $\mathrm{HI}$ at two time points and 1 subject at three time points. Neither CIDI-psychosis $(\mathrm{OR}=0.99,95 \% \mathrm{Cl}=0.97-1.01)$ nor $\mathrm{HI}(\mathrm{OR}=1.04,95 \% \mathrm{Cl}=0.99$ 1.09) were associated with age.

Association between $\mathrm{HI}$ and Psychotic Experiences at T2-T3 • There were 47 participants who reported $\mathrm{HI}$ at either $\mathrm{T} 2$ or $\mathrm{T} 3$, and two participants who reported $\mathrm{HI}$ at both $\mathrm{T} 2$ and $\mathrm{T} 3$, yielding a total of 51 observations of $\mathrm{HI}$ in the combined T2-T3 assessments. The association between $\mathrm{HI}$ and CIDIpsychosis was significant $(\mathrm{OR}=2.16,95 \% \mathrm{Cl}=1.17-4.01)$. Adjustment for age, sex, education and drug abuse $(\mathrm{OR}=2.04,95 \% \mathrm{Cl}=1.10-3.81)$ and baseline $\mathrm{SCL}-$ psychosis $(\mathrm{OR}=1.99,95 \% 1.06-3.73)$ did not attenuate the association. 
The magnitude of the association with $\mathrm{HI}$ increased with increasing levels of CIDI-psychosis severity (Table 7 ). A negative interaction between $\mathrm{HI}$ and age was apparent in the model of CIDI-psychosis $\left(X^{2}=5.86, p=.016\right)$. Stratified analyses indicated that the association was strong in young (age 13-17 years: $\mathrm{OR}=3.28,95 \% \mathrm{Cl}=1.54-7.01$ ), but not in older participants (age 18-24 years: $\mathrm{OR}=0.82,95 \% \mathrm{Cl}=0.24-2.84)$. There was no evidence for moderation by baseline $\mathrm{SCL}-$ psychosis $(\mathrm{X} 2=0.00, \mathrm{p}=0.99)$. Finally, the association remained large and significant after exclusion of participants with the $50 \%$ highest SCLpsychosis scores at baseline $(\mathrm{OR}=4.15,95 \% \mathrm{Cl}=1.25-13.82)$.

Table 1 Associations between cumulative lifetime incidence of hearing impairment (time points T0 to T3) and psychotic symptoms (CIDI-psychosis) at different levels of severity. Associations are presented as risk ratios (RR) and their $95 \%$ confidence intervals (Cl).

\begin{tabular}{|c|c|c|c|c|c|}
\hline CIDI-psychosis & Outcome level & $\begin{array}{l}\text { Hearing } \\
\text { Impairment } \\
\mathrm{n}^{*}(\%)\end{array}$ & $\begin{array}{l}\text { No Hearing } \\
\text { Impairment } \\
n^{*}(\%)\end{array}$ & $\begin{array}{l}\text { Unadjusted model } \\
\text { RR }(\mathrm{Cl})\end{array}$ & $\begin{array}{l}\text { Adjusted model } 1 \\
\text { RR }(\mathrm{Cl})\end{array}$ \\
\hline \multirow[t]{4}{*}{ Severity level } & No symptoms $₫$ & $36(70.6)$ & $3543(81.7)$ & - & - \\
\hline & $1-2$ symptoms & $8(15.7)$ & $623(14.4)$ & $1.46(0.67-3.18)$ & $1.41(0.65-3.08)$ \\
\hline & 3 - 4 symptoms & $4(7.8)$ & $116(2.7)$ & $4.14(1.43-11.98)$ & $3.82(1.31-11.17)$ \\
\hline & 5 or more symptoms & $3(5.9)$ & $56(1.3)$ & $6.33(1.87-21.41)$ & $5.66(1.64-19.49)$ \\
\hline
\end{tabular}

Note ${ }^{\prime}$ Adjusted for gender, education, drug abuse and time; * $\mathrm{n}$ refers to multiple observations clustered in individuals; $\$$ Reference category

Childhood $\mathrm{HI}$ - In the subsample with parental reports of childhood hearing impairment $(n=723), 36$ participants were rated positive for Childhood HI (5.0\%). Childhood $\mathrm{HI}$ was strongly associated with the T0 self-report of $\mathrm{HI}$ $(\mathrm{OR}=13.08,95 \% \mathrm{Cl}=4.79-35.67)$. In addition, childhood $\mathrm{HI}$ was strongly associated with the continuous baseline SCL-psychosis score (adjusted $b=2.15,95 \% \mathrm{Cl}=0.26-4.03)$. Finally, the adjusted odds ratio for the association between $\mathrm{HI}$ and $\mathrm{CIDI}-$ psychosis, excluding individuals with a selfreport of $\mathrm{HI}$ that was not matched by parental report of childhood $\mathrm{HI}$, was $5.61(95 \% \mathrm{Cl}=0.34-91.4)$. 


\section{DISCUSSION}

The finding of an association between hearing impairment and psychotic symptoms replicates earlier work (Stefanis et al., 2006, van der Werf et al., 2007). There was evidence for a dose-response relationship, as the association grew stronger with increasing levels of symptom severity. In a subsample with parental reports of childhood sensory deficits, childhood hearing impairment similarly predicted later psychotic experiences. Finally, the association was restricted to young adolescents, which is congruent with recent accounts of an age-dependent association between hearing impairment and psychosis (Stefanis et al., 2006, van der Werf et al., 2007). The age-dependent effect of hearing impairment suggests that disruption of development during a critical phase, in interaction with other social and personal vulnerabilities, may render an individual more susceptible to psychotic interpretations of internal and external stimuli (Kapur et al., 2005).

\section{Hearing impairment and psychosis: a shared cause?}

Numerous conditions in young people may affect hearing acuity, resulting in transient or permanent impairment (Reviewed in: Olusanya and Newton, 2007, Tharpe and Sladen, 2008). Causes of hearing impairment in young people that may also impact on the risk for psychotic experiences include birth trauma (Herrgard et al., 1995) and prenatal and postnatal exposure to infections (Dalman et al., 2008, Zammit et al., 2009). Rubella and meningitis may harm the developing central nervous system, and exposure has been associated with an increased risk for both hearing deficits (Fortnum and Davis, 1993) and psychosis (Brown et al., 2000, Dalman et al., 2008, Leask et al., 2002). Thus, hearing impairment and psychosis may be the result of a single underlying causative mechanism. This hypothesis is strengthened by a study reporting that rubella increased the risk for non-affective psychotic disorder independent of hearing impairment (Brown et al., 2000). 


\section{Hearing impairment and psychosis: causality?}

Not hearing what other people say may, directly or indirectly, trigger paranoid ideation and hallucinatory experiences. There is experimental evidence that sensory deprivation, mimicking profound hearing loss, induces feelings of paranoia and hallucinations (Leff, 1968, Mason and Brady, 2009). Sensory restriction may not only produce patterns of nerve impulses that give rise to hallucinatory experiences (Schultz and Melzack, 1991), it may also result in reality testing failures when the input from the outside world is significantly reduced. Failures of reality testing may cause a person to misattribute internal events to an external source. This mechanism may underlie the experience of hallucinations (Bentall, 1990, Leff, 1968). Second, social adversity has been shown to mould the risk for psychosis (Boydell et al., 2004, Veling et al., 2007). Hearing impairment, whether originating early in life, or acquired later in life, is associated with social isolation, low selfesteem and increased feelings of loneliness and stress (Bess et al., 1998, Kramer et al., 2002, Paykel et al., 2000, Romans-Clarkson et al., 1990). The adverse emotional and social consequences of hearing impairment may give rise to social defeat stress (Selten and Cantor-Graae, 2007). Prolonged exposure to social defeat stress may represent an intermediate mechanism linking multiple environmental exposures to an underlying biological mechanism of psychosis (Selten and Cantor-Graae, 2007, van Winkel et al., 2008). Thus, social defeat stress may mediate the link between hearing impairment and psychosis.

\section{Hearing impairment and psychosis: developmental impact?}

Finally, hearing impairment with onset early in life may compromise the development of language, cognition and social skills (Bess et al., 1998), giving rise to developmental alterations as observed in children destined to develop psychotic symptoms later in life (Cannon et al., 2002). Language and cognitive problems associated with hearing impairment may thus contribute 
to an increased risk in young people with a pre-existing vulnerability for psychosis. In addition, persecutory delusions and auditory hallucinations may develop as a result of delays in the acquisition of Theory of Mind (Frith, 1992, Janssen et al., 2003) in children with hearing impairment. Theory of Mind abilities normally emerge during preschool years (Peterson et al., 2005) and are highly dependent on day-to-day social interactions (Russell et al., 1998). Selective deprivation of access to these early conversations by hearing impairment during critical developmental phases may interfere with Theory of Mind acquisition. Evidence to support this notion comes from studies showing significant delays in the mastery of Theory of Mind in hard-ofhearing children (Marschark, 1993, Peterson and Siegal, 1995, 1998). Thus, hearing impairment originating early in life may impact, during critical developmental phases, on language, cognition and social skills, increasing the risk for psychosis.

\section{Hearing impairment and psychosis: towards a multifactorial model}

The association between hearing impairment and psychosis shows variation with age. Although the evidence to date suggests an increased risk in young people (David et al., 1995, Stefanis et al., 2006), the association has also been found in older people (Cooper and Curry, 1976, Stein and Thienhaus, 1993). This latter implies the operation of multiple mechanisms contributing to the increase in psychosis risk, with differential impact across the age span. Hearing impairment with onset during critical developmental phases may impact on risk by delaying the development of social reasoning skills, language and cognition, whilst other mechanisms may be operating in people who acquire hearing impairment later in life. Considering the negative impact of hearing impairment on perceived quality of life, as expressed by increased feelings of loneliness and a tendency for social isolation, social defeat stress may represent a more general mechanism mediating the link between hearing impairment and psychosis, regardless of age. Therefore, to 
the degree that hearing impairment moulds risk for psychosis, it is likely to do so in combination with a range of other factors.

\section{Limitations}

Several limitations should be considered when interpreting these results. First, the study used a measure of hearing impairment that was based on self report and consisted of a single question. Although this may not seem a very reliable measure, self-reports of hearing impairment have been found to yield reasonable sensitivity and specificity (Sindhusake et al., 2001). Also, EDSP interviewers were allowed to follow-through with follow-up questions to clarify if participants had understood the question. Finally, parental reports of Childhood $\mathrm{HI}$ were strongly associated with $\mathrm{TO} \mathrm{HI}$, suggesting validity in the sense that adolescent $\mathrm{HI}$ was continuous with earlier permanent or recurrent hearing impairment. In addition, the validity of the findings was supported by the fact that if exposure status was restricted to those participants with hearing impairment who also had evidence of childhood hearing impairment according to parental report, the odds ratio was also very high, albeit statistically inconclusive due to the small number of participants. Furthermore, to the degree that misclassification may have arisen, it is difficult to see how this could have been differential with regard to the psychosis outcome. Second, the assessment of psychotic experiences confers the risk of false positive answers, increasing random error. However, not only was the DIA-X/M-CIDI specifically developed for use in young and adolescent populations, there is also a substantial literature on the validity of self-reported psychotic experiences (van Os et al., 2009). In addition, the assessment of psychotic experiences in the current study was based on both self-report and diagnostic interview by trained and experienced clinical psychologists, lowering the risk for false positive ratings. Finally, although observational studies cannot provide evidence for causality in the association between hearing impairment and psychotic symptoms, no evidence to date exists to support reverse causality (psychosis provoking spurious reports of 


\section{Chapter 5}

having impaired hearing). Furthermore, the association remained highly significant after exclusion of those people at baseline with high psychosis scores, rendering reverse causality as an explanation for the findings less likely. 
Arrindell, WA \& Ettema, JHM eds. (2003). Scl-90. Handleiding bij een multidimensionale psychopathologie indicator [scl-90. Manual of a multidimensional indicator of psychopathology]. Swets Test Publisher: Lisse. Bentall, RP (1990). The illusion of reality: a review and integration of psychological research on hallucinations. Psychological Bulletin 107, 82-95.

Bess, FH, Dodd-Murphy, J \& Parker, RA (1998). Children with minimal sensorineural hearing loss: prevalence, educational performance, and functional status. Ear Hear 19, 339-54.

Bonicatto, S, Dew, MA, Soria, J \& Seghezzo, ME (1997). Validity and reliability of Symptom Checklist '90 (SCL90) in an Argentine population sample. Social Psychiatry and Psychiatric Epidemiology 32, 332-8.

Boydell, J, van Os, J, McKenzie, K \& Murray, RM (2004). The association of inequality with the incidence of schizophrenia--an ecological study. Social Psychiatry and Psychiatric Epidemiology 39, 597-9.

Brown, AS, Cohen, P, Greenwald, S \& Susser, E (2000). Nonaffective psychosis after prenatal exposure to rubella. American Journal of Psychiatry 157, 438-43.

Cannon, M, Caspi, A, Moffitt, TE, Harrington, H, Taylor, A, Murray, RM \& Poulton, R (2002). Evidence for early-childhood, pan-developmental impairment specific to schizophreniform disorder: results from a longitudinal birth cohort. Archives of General Psychiatry 59, 449-56.

Chapman, LJ, Chapman, JP, Kwapil, TR, Eckblad, M \& Zinser, MC (1994). Putatively psychosis-prone subjects 10 years later. Journal of Abnormal Psychology 103, 171-83.

Cooper, AF \& Curry, AR (1976). The pathology of deafness in the paranoid and affective psychoses of later life. Journal of Psychosomatic Research 20, 97-105.

Cougnard, A, Marcelis, M, Myin-Germeys, I, De Graaf, R, Vollebergh, W, Krabbendam, L, Lieb, R, Wittchen, HU, Henquet, C, Spauwen, J \& Van Os, J (2007). Does normal developmental expression of psychosis combine with environmental risk to cause persistence of psychosis? A psychosis proneness-persistence model. Psychological Medicine 37, 513-27.

Dalman, C, Allebeck, P, Gunnell, D, Harrison, G, Kristensson, K, Lewis, G, Lofving, S, Rasmussen, F, Wicks, $S$ \& Karlsson, H (2008). Infections in the CNS during childhood and the risk of subsequent psychotic illness: a cohort study of more than one million Swedish subjects. American Journal of Psychiatry 165, 5965.

David, A, Malmberg, A, Lewis, G, Brandt, L \& Allebeck, P (1995). Are there neurological and sensory risk factors for schizophrenia? Schizophrenia Research 14, 247-51.

Derogatis, LR (1983). SCL-90-R administration, scoring and procedures manual-II Clinical Psychometric Research: Towson.

Dominguez, MD, Wichers, M, Lieb, R, Wittchen, HU \& van Os, J (2009). Evidence That Onset of Clinical Psychosis Is an Outcome of Progressively More Persistent Subclinical Psychotic Experiences: An 8-Year Cohort Study. Schizophrenia Bulletin.

Fortnum, H \& Davis, A (1993). Hearing impairment in children after bacterial meningitis: incidence and resource implications. British Journal of Audiology 27, 43-52.

Frith, CD (1992). The Cognitive Neuropsychology of Schizophrenia. Lawrence Erlbaum Associates: Hove. Hanssen, M, Bak, M, Bijl, R, Vollebergh, W \& van Os, J (2005). The incidence and outcome of subclinical psychotic experiences in the general population. British Journal of Clinical Psychology 44, 181-91. Henquet, C, Krabbendam, L, Spauwen, J, Kaplan, C, Lieb, R, Wittchen, HU \& van Os, J (2005). Prospective cohort study of cannabis use, predisposition for psychosis, and psychotic symptoms in young people. British Medical Journal (Clinical Research Ed.) 330, 11.

Herrgard, E, Karjalainen, S, Martikainen, A \& Heinonen, K (1995). Hearing loss at the age of 5 years of children born preterm--a matter of definition. Acta Paediatrica 84, 1160-4.

Janssen, I, Krabbendam, L, Jolles, J \& van Os, J (2003). Alterations in theory of mind in patients with schizophrenia and non-psychotic relatives. Acta Psychiatrica Scandinavica 108, $110-7$.

Kapur, S, Mizrahi, R \& Li, M (2005). From dopamine to salience to psychosis--linking biology, pharmacology and phenomenology of psychosis. Schizophrenia Research 79, 59-68. 


\section{Chapter 5}

Kaymaz, N \& van Os, J (2010). Extended psychosis phenotype - yes: single continuum - unlikely. Psychological Medicine. Published online: 20 March 2010. doi: 10.1017/S0033291710000358.

Kramer, SE, Kapteyn, TS, Kuik, DJ \& Deeg, DJ (2002). The association of hearing impairment and chronic diseases with psychosocial health status in older age. Journal of Aging and Health 14, 122-37.

Lataster, T, Myin-Germeys, I, Derom, C, Thiery, E \& van Os, J (2009). Evidence that self-reported psychotic experiences represent the transitory developmental expression of genetic liability to psychosis in the general population. American Journal of Medical Genetics Part B 150B, 1078-84.

Leask, SJ, Done, DJ \& Crow, TJ (2002). Adult psychosis, common childhood infections and neurological soft signs in a national birth cohort. British Journal of Psychiatry 181, 387-92.

Leff, JP (1968). Perceptual phenomena and personality in sensory deprivation. British Journal of Psychiatry 114, 1499-508.

Lieb, R, Isensee, B, von Sydow, K \& Wittchen, HU (2000). The Early Developmental Stages of Psychopathology Study (EDSP): a methodological update. European Addiction Research 6, 170-82. Linscott, RJ \& van Os, J (2010). Systematic Reviews of Categorical versus Continuum Models in Psychosis: Evidence for Discontinuous Subpopulations Underlying a Psychometric Continuum. Implications for DSMV, DSM-VI, and DSM-VII. Annual Review Clinical Psychology 6. Published online: 4 January 2010. doi: 10.1146/annurev.clinpsy.032408.153506.

Marschark, M (1993). Psychological development of deaf children. Oxford University Press: New York. Mason, OJ \& Brady, F (2009). The psychotomimetic effects of short-term sensory deprivation. Journal of Nervous and Mental Disease 197, 783-5.

Olusanya, BO \& Newton, VE (2007). Global burden of childhood hearing impairment and disease control priorities for developing countries. Lancet 369, 1314-7.

Paykel, ES, Abbott, R, Jenkins, R, Brugha, TS \& Meltzer, H (2000). Urban-rural mental health differences in great Britain: findings from the national morbidity survey. Psychological Medicine 30, 269-80.

Peters, ER, Joseph, SA \& Garety, PA (1999). Measurement of delusional ideation in the normal population: introducing the PDI (Peters et al. Delusions Inventory). Schizophrenia Bulletin 25, 553-76.

Peterson, CC \& Siegal, M (1995). Deafness, conversation and theory of mind. Journal of Child Psychology and Psychiatry 36, 459-74.

Peterson, CC \& Siegal, M (1998). Changing focus on the representational mind: Deaf, autistic and normal children's concept of false photos, false drawings and false beliefs. British Journal of Developmental Psychology 16, 301-320.

Peterson, CC, Wellman, HM \& Liu, D (2005). Steps in theory-of-mind development for children with deafness or autism. Child Development 76, 502-17.

Poulton, R, Caspi, A, Moffitt, TE, Cannon, M, Murray, R \& Harrington, H (2000). Children's self-reported psychotic symptoms and adult schizophreniform disorder: a 15-year longitudinal study. Archives of General Psychiatry 57, 1053-8.

Reed, V, Gander, F, Pfister, H, Steiger, A, Sontagg, H, Trenkwalder, C, Hundt, W \& Wittchen, H (1998). To what degree does the Composite International Diagnostic Interview (CIDI) correctly identify DSM-IV disorders? Testing validity issues in a clinical sample. International Journal of Methods in Psychiatric Research 7, 619-627.

Romans-Clarkson, SE, Walton, VA, Herbison, GP \& Mullen, PE (1990). Psychiatric morbidity among women in urban and rural New Zealand: psycho-social correlates. British Journal of Psychiatry 156, 84-91.

Rossler, W, Riecher-Rossler, A, Angst, J, Murray, R, Gamma, A, Eich, D, van Os, J \& Gross, VA (2007). Psychotic experiences in the general population: a twenty-year prospective community study.

Schizophrenia Research 92, 1-14.

Russell, PA, Hosie, JA, Gray, CD, Scott, C, Hunter, N, Banks, JS \& Macaulay, MC (1998). The development of theory of mind in deaf children. Journal of Child Psychology and Psychiatry 39, 903-10.

Schultz, G \& Melzack, R (1991). The Charles Bonnet syndrome: 'phantom visual images'. Perception 20, 809-25.

Selten, JP \& Cantor-Graae, E (2007). Hypothesis: social defeat is a risk factor for schizophrenia? British Journal of Psychiatry (Suppl.) 51, s9-12. 


\section{Risk for Psychosis: A Life Span Perspective}

Sindhusake, D, Mitchell, P, Smith, W, Golding, M, Newall, P, Hartley, D \& Rubin, G (2001). Validation of self-reported hearing loss. The Blue Mountains Hearing Study. International Journal of Epidemiology 30 , 1371-8.

Spauwen, J, Krabbendam, L, Lieb, R, Wittchen, HU \& van Os, J (2006). Evidence that the outcome of developmental expression of psychosis is worse for adolescents growing up in an urban environment. Psychological Medicine 36, 407-15.

STATACORP (2008). Statistical software: release 10.0. TXS Stata corporation, college station TX.

Stefanis, N, Thewissen, V, Bakoula, C, van Os, J \& Myin-Germeys, I (2006). Hearing impairment and psychosis: a replication in a cohort of young adults. Schizophrenia Research 85, 266-72.

Stein, LM \& Thienhaus, OJ (1993). Hearing impairment and psychosis. International Psychogeriatrics 5, 4956.

Tharpe, AM \& Sladen, DP (2008). Causation of permanent unilateral and mild bilateral hearing loss in children. Trends in Amplification 12, 17-25.

Thewissen, V, Myin-Germeys, I, Bentall, R, de Graaf, R, Vollebergh, W \& van Os, J (2005). Hearing impairment and psychosis revisited. Schizophrenia Research 76, 99-103.

van der Werf, M, van Boxtel, M, Verhey, F, Jolles, J, Thewissen, V \& van Os, J (2007). Mild hearing impairment and psychotic experiences in a normal aging population. Schizophrenia Research 94, 180-6. van Os, J, Linscott, RJ, Myin-Germeys, I, Delespaul, P \& Krabbendam, L (2009). A systematic review and meta-analysis of the psychosis continuum: evidence for a psychosis proneness-persistence-impairment model of psychotic disorder. Psychological Medicine 39, 179-95.

van Os, J, Rutten, BP \& Poulton, R (2008). Gene-environment interactions in schizophrenia: review of epidemiological findings and future directions. Schizophrenia Bulletin 34, 1066-82.

van Winkel, R, Stefanis, NC \& Myin-Germeys, I (2008). Psychosocial stress and psychosis. A review of the neurobiological mechanisms and the evidence for gene-stress interaction. Schizophrenia Bulletin 34, 1095-105.

Veling, W, Selten, JP, Susser, E, Laan, W, Mackenbach, JP \& Hoek, HW (2007). Discrimination and the incidence of psychotic disorders among ethnic minorities in The Netherlands. International Journal of Epidemiology 36, 761-8.

Verdoux, H, Maurice-Tison, S, Gay, B, Van Os, J, Salamon, R \& Bourgeois, ML (1998). A survey of delusional ideation in primary-care patients. Psychological Medicine 28, 127-134.

Weiser, M, Werbeloff, N, Drukker, M, Van Os, J, Dohrenwend, BP, Yoffe, R, Levav, I \& Davidson, M (2009). Self-Reported Psychotic Symptoms in the Community, and Risk of Later Hospitalization for Non-Affective Psychotic Disorders. Schizophrenia Bulletin 35, 74-74.

Welham, J, Scott, J, Williams, G, Najman, J, Bor, W, O'Callaghan, M \& McGrath, J (2009). Emotional and behavioural antecedents of young adults who screen positive for non-affective psychosis: a 21 -year birth cohort study. Psychological Medicine 39, 625-34.

Wittchen, H-U, Lieb, R, Schuster, P \& Oldehinkel, T (1999). When is onset? Investigations into early developmental stages of anxiety and depressive disorders. In Childhood Onset of 'Adult' Psychopathology, Clinical and Research Advances. (ed. J. L. Rapoport), pp. 259-302. American Psychiatric Press:

Washington.

Wittchen, H \& Pfister, H eds. (1997). DIA-X-Interviews: Manual fur screening-verfahren und interview; interviewheft langsschnittuntersuchung (DIA-X-Lifetime); enganzungsheft (DIA-X-Lifetime); interviewheft Querschnittsuntersuchung (DIA-X-Monatsversion); erganzungsheft (DIA-X-12 Montasversion); PCprogramm zur durchfuhrung der interviews (Langsund Querschnittsuntersuchung). Ausertungsprogramm. Frankfurt, Germany.

Wittchen, HU (1994). Reliability and validity studies of the WHO--Composite International Diagnostic Interview (CIDI): a critical review. Journal of Psychiatric Research 28, 57-84.

Wittchen, HU, Lachner, G, Wunderlich, U \& Pfister, H (1998a). Test-retest reliability of the computerized DSM-IV version of the Munich-Composite International Diagnostic Interview (M-CIDI). Social Psychiatry and Psychiatric Epidemiology 33, 568-78.

Wittchen, HU, Perkonigg, A, Lachner, G \& Nelson, CB (1998b). Early developmental stages of 


\section{Chapter 5}

psychopathology study (EDSP): objectives and design. European Addiction Research 4, 18-27.

Zammit, S, Odd, D, Horwood, J, Thompson, A, Thomas, K, Menezes, P, Gunnell, D, Hollis, C, Wolke, D,

Lewis, G \& Harrison, G (2009). Investigating whether adverse prenatal and perinatal events are associated with non-clinical psychotic symptoms at age 12 years in the ALSPAC birth cohort. Psychological Medicine $39,1457-67$. 


\section{4}




\section{ABSTRACT}

Background - It has been suggested that part of the increased vulnerability for psychosis in individuals with hearing impairment $(\mathrm{HI})$ is the consequence of a decreased ability to form correct representations of the social world and attributions of intention of others. It was therefore hypothesized that associations between $\mathrm{HI}$ and psychosis risk would be sensitive to contextual variables representing higher level of social complexity, conceptualized as the population density of the social environment ('urbanicity').

Methods - Urbanicity and objective $\mathrm{HI}$ were assessed in the Maastricht Aging Study (MAAS), a longitudinal study of 1,823 participants from the general population in Maastricht, the Netherlands. Participants were tested at baseline (T0) and at 6-year (T2) and 12-year follow-up (T4). The degree to which the association between $\mathrm{HI}$ (T0-T2) and psychotic experiences at T4 was moderated by T0 urbanicity was examined.

Results - The association between $\mathrm{HI}$ and psychosis was conditional on level of urbanicity (interaction $\chi 2=7.51, p=.006$ ), with low effect size in non-urbanized areas $(b=-0.81,95 \% \mathrm{Cl}:-2.98,1.36)$ and high effect size in the most urbanized areas $(b=2.56,95 \% \mathrm{Cl}: 0.47,4.65)$. Although social isolation $(b=1.74, p=.022)$ and loneliness $(b=0.61, p<.001)$ were both associated with psychosis, they could not explain the observed interaction. Conclusion - The findings suggest that level of complexity of the social world, in interaction with the individual's ability to correctly process this information, may impact on risk for psychotic experiences. 


\section{INTRODUCTION}

It has become increasingly evident that genetic variation alone may not be sufficient to explain the population rate of psychosis. Environmental risk factors operating early and later in life have been shown to mould the risk for subclinical and clinical expressions of psychosis, possibly in interaction with genetic variation (van Os et al., 2008). Recent work has shown widespread variation in risk for psychosis related to urban upbringing and migrant status (McGrath et al., 2004, Cantor-Graae and Selten, 2005, Krabbendam and van Os, 2005). Other likely risk factors for psychosis that are at least partly non-genetic include cannabis use (Henquet et al., 2005), social stress (Wiles et al., 2006, van Winkel et al., 2008), childhood trauma (Read et al., 2005) and hearing impairment (David et al., 1995, Thewissen et al., 2005).

Although there is replicated evidence that hearing impairment $(\mathrm{HI})$ increases the risk for psychotic experiences (Thewissen et al., 2005, Stefanis et al., 2006, van der Werf et al., 2007), the underlying mechanisms remain elusive. Current models of psychosis acknowledge the importance of the social environment in the developmental pathway towards psychotic symptoms (Boydell et al., 2004, Veling et al., 2007). Alterations in the ability to understand the social world have recently been proposed as underlying mechanism explaining part of the increased risk of psychotic symptoms in people with $\mathrm{HI}$ (van der Werf et al., in press).

Successful adaptation to highly demanding and complex social environments can be difficult and relies, among others, on intact social cognition. $\mathrm{HI}$, by subtly altering perception of socially relevant information, may impact on the ability to correctly process social complexity. Furthermore, $\mathrm{HI}$ facilitates conversational ambiguity and decreases the capacity to adequately filter and appraise contextual stimuli. Deficient filtering capacities and increased social ambiguity may predispose an 
Risk for Psychosis: A Life Span Perspective

individual to the aberrant assignment of salience to stimuli in socially complex environments. This in turn may lead to the development of paranoid ideation and hallucinatory experiences (Kapur, 2003). Thus, risk for development of psychotic experiences may be increased when individuals with $\mathrm{HI}$ are exposed to high levels of social complexity. It has been suggested that people living in densely populated areas are exposed to more intense and more ambiguous social interactions (Weiser et al., 2007). Urban life therefore may represent a proxy of social complexity that is expected to mould psychosis risk in individuals with $\mathrm{HI}$.

The current investigation examined the hypothesis that the association between $\mathrm{HI}$ and psychosis would be conditional on level of urbanicity. This hypothesis was tested in the Maastricht Aging Study (MAAS), a longitudinal study devoted to non-pathological aging in a normal aging population of 1,823 healthy individuals (Jolles, 1995, van Boxtel et al., 1998).

\section{METHODS}

\section{Sample}

Participants were recruited from a register of collaborating representative family practices in Limburg (the Netherlands), stratified by age, sex and occupational status. Individuals with chronic neurological disorders, mental retardation, cerebrovascular disease and psychotropic drug use were excluded from baseline participation, since the study intended to study non-pathological aging. Those with severe psychiatric disorders, including psychotic disorder and major depression, were also not eligible for study participation. Participants completed a baseline investigation (T0) and four follow-up investigations (T1-T4). Participants aged 50 years and older at baseline were assessed every three years after baseline (T1, T2, T3 and T4), whereas participants under 50 years at baseline were assessed at six (T2) and twelve (T4) years follow-up. The current analyses were restricted to data obtained in the sample spanning the entire age range (T0, T2 and T4), 
with mean duration of follow-up of approximately six (T0-T2, range: 5.8 $6.9, \mathrm{SD}=0.18)$ and twelve years (T0-T4, range: $11.7-13.5$ years, $\mathrm{SD}=0.30$ ) respectively. At baseline, a total of 1,823 participants, aged 24-86 years, were included and underwent an extensive neuropsychological test battery. Medical information was obtained in a semi-structured interview and questionnaires were completed evaluating mood, general health and daily life functioning. The study was approved by the standing Ethics Committee and all participants provided written informed consent.

\section{Instruments}

Psychosis Expression at T4 - Participants completed the Symptom Checklist-90-Revised (SCL-90-R), a multidimensional self-report symptom inventory designed to measure psychopathology as continuous dimensions of human experience. The instrument provides scores on nine dimensions of psychopathology within the past two weeks (Derogatis, 1983, Arrindell and Ettema, 2003). All items are rated on a 5-point Likert scale of distress ranging from 1 (not at all) to 5 (very much). Expression of psychosis was assessed using the Paranoid Ideation (6 items) and Psychoticism (10 items) subscales which were administered for the first time at T3 and T4. Acceptable interrater reliability has been shown for both the Paranoid Ideation (Cronbachs alpha $=0.67$ ) and the Psychoticism (Cronbachs alpha $=0.62$ ) subscales (Bonicatto et al., 1997). Construct validity was good for the Psychoticism subscale and acceptable for the Paranoid Ideation subscale (Bonicatto et al., 1997). The Paranoid Ideation and Psychoticism subscales include self-reports on psychotic experiences that can be regarded, if not as clear-cut psychotic symptoms, as a subclinical expression of psychotic experiences. In line with previous work (Henquet et al., 2005), the total scores of both subscales were combined into a single dimension reflecting psychotic experiences (hereafter: psychosis, range: 16-80). The resulting continuous SCL-psychosis score displayed a half- 
normal distribution, typical for instruments assessing psychotic experiences dimensionally (van Os et al., 2009). Psychosis outcomes at T4 were used in the current analysis, allowing for temporal separation of assessment of exposure and outcome and for prospective assessment of exposure-outcome associations.

Hearing Impairment over T0-T2 - Objective assessment of $\mathrm{HI}$ was completed at four time points (T0, T1, T2 and T4) using pure tone audiometry at four different frequencies (500, 1000, 2000 and $4000 \mathrm{~Hz}$ ) which are considered relevant for speech comprehension. Detection thresholds were determined for each ear separately in steps of $5 \mathrm{~dB}$ (Jolles, 1995, van Boxtel et al., 2000). The maximum pure tone threshold in the better ear over the period T0-T2 was used to create two different exposure variables. In order to study associations at different levels of $\mathrm{HI}$ impairment severity, the sample was first divided into four quartile groups based on quartile point cut-offs of the underlying continuous score of $\mathrm{HI}$ (range Q1: 0-8.75dB; Q2:10-16.25dB; Q3:17.5-26.25dB; Q4:27.5-90dB) (hereafter: $\mathrm{HI}$-severity). Second, a dichotomous variable indicating the absence or presence of mild $\mathrm{HI}$ was defined by collapsing the lower two quartiles (mean $\mathrm{HI}=9.8 \mathrm{~dB}$, range: $0-16.25 \mathrm{~dB}$ ) and the upper two quartiles (mean $\mathrm{HI}=29.1 \mathrm{~dB}$, range: $17.5-90 \mathrm{~dB}$ ) of the $\mathrm{HI}$-severity score (hereafter: $\mathrm{HI}$ ).

Social complexity at T0 - Urbanicity was chosen as proxy for social complexity, with higher levels representing increasing complexity. In line with previous work (van Os et al., 2003), five levels of urbanicity were defined, following the standard classification of the Dutch Central Bureau of Statistics for the level of urbanization of place of residence. The classification is based on a measure of residential density consisting of the number of addresses per $\mathrm{km}^{2}$ within a circle with a radius of $1 \mathrm{~km}$ from a given place of residence as the center of the circle. For the present study, a categorical variable including the mean residential density of all the 
addresses within a geographical area was used, with levels 1-5 in the classification designating, respectively, <500, 500-999, 1000-1499, 15002499 , and $\geq 2500$ addresses per $\mathrm{km}^{2}$. Urbanicity was measured at baseline.

\section{Statistical analyses}

All analyses were conducted in STATA version 11 (StataCorp, 2009). Participants with Mini-Mental State Examination (MMSE; Folstein et al., 1975) scores below 24 at T4 were excluded from the final analyses $(n=18)$ in order to avoid possible organic causes of psychotic symptoms in the elderly. This yielded a risk set of 1,021 participants with complete SCLpsychosis data at T4. Associations between $\mathrm{HI}$ (over T0-T2), urbanicity (T0) and psychosis (T4) were examined using linear regression analyses, yielding unstandardized regression coefficients (b) and corresponding 95\% confidence intervals $(95 \% \mathrm{Cls})$. Additionally, associations between $\mathrm{HI}$ and psychosis were examined using the variable $\mathrm{HI}$-severity, in order to assess whether more severe $\mathrm{HI}$ conferred greater risk of psychosis expression. In order to examine whether the association between $\mathrm{HI}$ and psychosis was moderated by urbanicity, an $\mathrm{HI} \times$ urbanicity interaction term was added to the model. Stratified effects were calculated from the model including the interaction by applying the appropriate linear combinations using the STATA LINCOM routine.

All analyses were adjusted for age at baseline. Furthermore, since previous work has shown that the association between $\mathrm{HI}$ and psychosis is moderated by age (van der Werf et al., 2007), with higher effect sizes for younger people, an age $\times \mathrm{HI}$ interaction term was added to the model, followed by stratified analyses contrasting the youngest group aged 30 years and younger at baseline $(n=127)$ with the older group.

Urbanicity likely represents a set of environmental factors associated with psychosis that are more prevalent in the urban environment. Besides social complexity, feelings of social exclusion may increase psychosis risk (Romans-Clarkson et al., 1990, Paykel et al., 2000). Since people with HI 
report more feelings of loneliness and tend to be more socially isolated than individuals without impairment (Kramer et al., 2002), social isolation and loneliness may also explain part of the association between $\mathrm{HI}$ and psychosis. Therefore, in addition to age, all analyses were also adjusted for social isolation and loneliness. Social isolation, or the objective physical separation from people (Tomaka et al., 2006) was assessed over the period T0-T2 and was defined as either having no persons with whom to share intimate thoughts or having a contact frequency with friends of less then once a year. This yielded a binary exposure variable with value labels " 0 " no social isolation and " 1 " social isolation. Loneliness, or the discrepancy between actual and desired social contact (Hawkley and Cacioppo, 2003), was assessed at T2 using the Jong-Gierveld Loneliness Questionnaire (de Jong Gierveld and Kamphuis, 1985). This yielded a continuous variable ranging from 0 to 11 , with higher scores representing higher levels of loneliness.

\section{RESULTS}

Mean age of the participants at baseline was 46.3 years $(S D=13.9$, range 24-79 years); 127 participants (12.4\%) were younger than 30 years at baseline assessment. The proportion males was 50.2\%. Thirty-nine participants (3.8\%) were socially isolated. The mean score on the JongGierveld Loneliness Questionnaire was $2.5(\mathrm{SD}=2.7$, range $0-11$ ), with 43 (4.6\%) participants having scores of 9 and higher indicating moderate to severe loneliness. Mean score of psychosis at T4 was 19.5 ( $S D=4.7$, range 16-47). Mild to moderate $\mathrm{HI}$ (range: 17.5-90.0dB) was present in 394 (38.6\%) participants. The prevalence of $\mathrm{HI}$ showed a linear increase with age $(\mathrm{OR}=1.12,95 \% \mathrm{Cl}: 1.11,1.14, \mathrm{p}<.001)$, ranging from 7 participants $(5.3 \%)$ with $\mathrm{HI}$ in the youngest age group (30 years and younger) to 45 participants (83.3\%) in the oldest age group (70 years and older). Linear regression analysis showed a significant association between $\mathrm{HI}(b=0.66$, 
95\% Cl: $0.07,1.25, \mathrm{p}=.028)$ and psychosis, that was reduced after adjustment for age $(b=-0.02,95 \% \mathrm{Cl}:-0.74,0.70, p=.96)$. A similar pattern was seen for HI-severity (Table 1).

There was a negative interaction between age and $\mathrm{HI}$ in the model of psychosis, although this effect was not statistically significant $\left(X^{2}=1.80\right.$, $p=0.18)$. Stratified analyses yielded substantially larger effect sizes in younger (age $<30$ years: $b=1.78,95 \% \mathrm{Cl}:-1.78,5.34, p=.33$ ), than in older participants (age 30 years and older: $b=0.46,95 \% \mathrm{Cl}:-0.16,1.08, p=.15$ ).

Participants with $\mathrm{HI}$ were more socially isolated $(\mathrm{OR}=2.50,95 \% \mathrm{Cl}: 1.09$, $5.73, p=.031$ ), but did not experience more feelings of loneliness than those without $\mathrm{HI}(b=-0.19,95 \% \mathrm{Cl}:-0.63,0.25, \mathrm{p}=.39)$. Social isolation $(b=1.74,95 \% \mathrm{Cl}: 0.25,3.24, p=.022)$ and loneliness $(b=0.61,95 \% \mathrm{Cl}: 0.51$, $0.71, p<.001)$ were both associated with psychosis. Finally, participants living in more densely populated areas were not more often socially isolated $(\mathrm{OR}=0.92,95 \% \mathrm{Cl}: 0.69,1.22, \mathrm{p}=.56)$, nor did they display more feelings of loneliness $(b=0.12,95 \% \mathrm{Cl}:-.04,0.27, p=.14)$.

Effect modification by urbanicity - Eighty-five participants (8.7\%) were living in the most densily populated areas of which 9 participants (10.6\%) were younger than 30 years. Urbanicity alone was not associated with psychosis $(b=0.05,95 \% \mathrm{Cl}=-0.21 ; 0.31, p=.72)$. Limiting the analyses to the group of participants aged 30 years and younger at baseline yielded a trend towards an association between urbanicity and psychosis (mean psychosis score of 18.4 in non-urban versus 19.8 in urban areas; $b=1.36$, $95 \% \mathrm{Cl}:-1.77,4.48)$, not reaching significance due to the very small numbers of participants who were exposed to urban living. However, a strong positive interaction between objective $\mathrm{HI}$ and urbanicity on psychosis was apparent $(\chi 2=7.51, p=.006)$. Controlling for age, social isolation and loneliness did not reduce the $\mathrm{HIX}$ urbanicity interaction $(\chi 2=$ 8.95, $\mathrm{p}=.003$ ). The effect of $\mathrm{HI}$ was conditional on higher levels of urbanicity in a non-linear fashion, showing substantial effect size only in 
the most urbanised neighbourhoods $(b=2.56,95 \% \mathrm{Cl}=0.47 ; 4.65, p=.016$; Table 2).

Table 1. Psychosis expression as a function of hearing impairment (HI). Associations are expressed as unstandardized regression coefficients (b), representing the increase in the dependent variable with one unit change in the independent variable.

\begin{tabular}{|lllllll|}
\hline & & Psychosis & \multicolumn{2}{l|}{ Unadjusted Model } & \multicolumn{2}{l|}{ Age adjusted Model } \\
\hline HI over T0-T2 & No. (\%) & Mean $(S D)$ & $b$ & $95 \% \mathrm{Cl}$ & $b$ & $95 \% \mathrm{Cl}$ \\
\hline No $(0-8.8 \mathrm{~dB})$ & $295(28.9)$ & $18.88(4.32)$ & $1 \neq$ & & & \\
Little $(10-16.3 \mathrm{~dB})$ & $331(32.5)$ & $19.48(4.83)$ & $0.60 \mathrm{~ns}$ & $-0.13 ; 1.33$ & $0.19 \mathrm{~ns}$ & $-0.59 ; 0.96$ \\
Mild $(17.5-26.3 \mathrm{~dB})$ & $208(20.4)$ & $20.07(5.45)$ & $1.19^{*}$ & $0.36 ; 2.02$ & $0.42 \mathrm{~ns}$ & $-0.54 ; 1.37$ \\
Moderate $(27.5-90 \mathrm{~dB})$ & $186(18.2)$ & $19.62(3.88)$ & $0.74 \mathrm{~ns}$ & $-0.12 ; 1.59$ & $-0.39 \mathrm{~ns}$ & $-1.49 ; 0.72$ \\
\hline
\end{tabular}

Note: 1 ₹ Reference category; significance levels: * $\mathrm{p}<.05$; ** $\mathrm{p}<.001$; ns = not significant;

Psychosis $=$ mean score on $\mathrm{SCL}-90-\mathrm{R}$ psychosis scale at $\mathrm{T} 4$

Table 2. The interaction between hearing impairment $(\mathrm{HI})$ and urbanicity in the association with psychosis

\begin{tabular}{|c|c|c|c|c|c|c|c|}
\hline \multirow[b]{2}{*}{$\begin{array}{l}\text { Hl over } \\
\text { T0-T2 }\end{array}$} & \multirow[b]{2}{*}{$\begin{array}{l}\text { Urbanicity } \\
\text { (T0) }\end{array}$} & \multirow[b]{2}{*}{ No. (\%) } & \multirow{2}{*}{$\begin{array}{l}\text { Psychosis } \\
\text { Mean (SD) }\end{array}$} & \multicolumn{2}{|c|}{ Unadjusted Model } & \multicolumn{2}{|c|}{ Age adjusted Model } \\
\hline & & & & b & $95 \% \mathrm{Cl}$ & b & $95 \% \mathrm{Cl}$ \\
\hline \multirow[t]{5}{*}{ No } & $<499$ & $45(4.6)$ & $19.64(5.92)$ & $1 \neq$ & & & \\
\hline & 500-999 & $153(15.6)$ & $19.53(5.65)$ & $-0.12 \mathrm{~ns}$ & $-1.67 ; 1.44$ & $-0.12 \mathrm{~ns}$ & $-1.68 ; 1.42$ \\
\hline & $1000-1499$ & $114(11.7)$ & $19.16(4.24)$ & $-0.49 \mathrm{~ns}$ & $-2.10 ; 1.13$ & $-0.51 \mathrm{~ns}$ & $-2.12 ; 1.10$ \\
\hline & $1500-1999$ & $234(23.9)$ & $18.97(3.84)$ & $-0.67 \mathrm{~ns}$ & $-2.16 ; 0.82$ & $-0.67 \mathrm{~ns}$ & $-2.16 ; 0.81$ \\
\hline & $\geq 2500$ & $49(5.0)$ & $18.80(3.62)$ & -0.85 ns & $-2.74 ; 1.04$ & $-0.88^{\mathrm{ns}}$ & $-2.77 ; 1.00$ \\
\hline \multirow[t]{5}{*}{ Yes } & $<499$ & $31(3.2)$ & $19.36(4.08)$ & $-0.29 \mathrm{~ns}$ & $-2.43 ; 1.85$ & $-0.81 \mathrm{~ns}$ & $-2.98 ; 1.36$ \\
\hline & $500-999$ & $103(10.5)$ & $19.38(4.75)$ & $-0.15 \mathrm{~ns}$ & $-1.32 ; 1.02$ & $-0.60 \mathrm{~ns}$ & $-1.82 ; 0.62$ \\
\hline & $1000-1499$ & $82(8.4)$ & $19.34(4.36)$ & $0.18^{\mathrm{ns}}$ & $-1.14 ; 1.51$ & $-0.31 \mathrm{~ns}$ & $-1.69 ; 1.07$ \\
\hline & 1500-1999 & $131(13.4)$ & $20.18(4.45)$ & $1.21 *$ & $0.22 ; 2.21$ & $0.61 \mathrm{~ns}$ & $-0.50 ; 1.71$ \\
\hline & $\geq 2500$ & $36(3.7)$ & $22.11(6.87)$ & $3.32 * *$ & $1.31 ; 5.32$ & $2.56^{*}$ & $0.47 ; 4.65$ \\
\hline
\end{tabular}

Note 1 \# Reference category; significance levels: * $\mathrm{p}<.05$; ** $\mathrm{p}<.001$; ns = not significant Psychosis = mean score on SCL-90-R psychosis scale at $\mathrm{T} 4, \mathrm{Cl}=$ confidence interval $\mathrm{HI}$ over T0-T2 as defined in paragraph 2.2.2; Urbanicity refers to the area address density/km 


\section{DISCUSSION}

The findings suggest consistency with the notion that the social environment may play a role in the developmental pathway leading to expression of psychosis, and possibly shed light on at least part of the mechanism by which urban environments may contribute to higher rates of psychotic disorder. The results suggest that the expression of psychosis may be sensitive to the converging effects of increasing levels of urbanicity and HI. Whereas urban living did not affect the risk for psychotic experiences in people without $\mathrm{HI}$, people with $\mathrm{HI}$ were more prone to develop psychotic experiences when living in more densely populated neighbourhoods. Social isolation and loneliness, although associated with psychosis, did not reduce the $\mathrm{HI} \mathrm{X}$ urbanicity interaction.

Urban life confronts people to relatively intense and ambiguous social interactions (Weiser et al., 2007), requiring adequately developed social cognitive skills to adapt and interact. $\mathrm{HI}$ may get in the way of correct perception and ease of processing of socially relevant information, particularly in circumstances of high social complexity that may induce biased information processing and increase the risk of psychotic experiences (Garety et al., 2001). The findings suggest that level of complexity of the social world, in interaction with the individual's ability to correctly process this information, may impact on risk for psychotic experiences.This latter is in agreement with theories of psychosis as a syndrome of aberrant attribution of salience (Kapur, 2003, Kapur et al., 2005, van Os and Kapur, 2009) associated with biased information processing (Garety et al., 2001).

'Urbanicity' appears to explain an important part of the increased risk for psychotic experiences in people with $\mathrm{HI}$, possibly because of exposure to higher levels of social complexity. However, since the exact nature of the urban exposure remains unclear, it is likely that other factors may be 
involved as well. Although social isolation was more prevalent among people with $\mathrm{HI}$ in our sample, no evidence was found that social isolation or loneliness mediated the interaction between $\mathrm{HI}$ and the urban environment, which is in line with previous work (Stefanis et al., 2004). Nevertheless, the data suggest that social exclusion may represent a second intermediate construct of social risk for psychosis. Social isolation may induce feelings of social exclusion, which may constitute social defeat stress (Selten and Cantor-Graae, 2005). Prolonged exposure to social defeat stress has been implied as an intermediate mechanism linking multiple environmental exposures to an underlying biological mechanism of psychosis (van Winkel et al., 2008). Both social complexity and social exclusion may thus operate simultaneously in the urban environment to facilitate psychosis risk, although the effects of social complexity may be more specific to hearing impaired individuals. The findings suggest that interaction between different environmental factors over time, a process that may be referred to as 'sensitization', may shape risk for psychosis as suggested previously (Collip et al., 2008).

\section{Limitations}

Several limitations should be considered when interpreting these results. First, causality cannot be inferred from the presented observational data, especially since baseline measurements of psychotic symptoms were unavailable. Second, self-report of psychotic experiences may increase the likelihood of inaccurately identifying people as psychotic (false-positives), increasing random error. Nevertheless, there is a substantial literature showing validity of self-reported psychotic experiences in the general population (Polanczyk et al., 2009, van Os et al., 2009).

Since previous work suggests that especially young age and longer periods of $\mathrm{HI}$ over adolescent development are associated with risk for psychotic symptoms (van der Werf et al., Stefanis et al., 2006), it could be argued that this normal ageing population, in combination with assessment 


\section{Chapter 6}

of psychotic experiences over the last two weeks rather than lifetime, is not ideal to assess the impact of the social environment in the pathway linking $\mathrm{HI}$ to psychosis. However, significant effects of the social environment were nevertheless shown, suggesting that even larger effect sizes may be present in younger populations.

The older age of the sample, in combination with the low temporal sensitivity of the psychosis assessment, may also explain the absence of a main effect of urbanicity and the non-replication of the previously demonstrated negative interaction between age and $\mathrm{HI}$ in the risk for psychosis (van der Werf et al., in press, van der Werf et al., 2007). Most participants in this normal ageing population sample were past the age of common expression of psychosis (Verdoux et al., 1998). This is in agreement with previous work showing decreasing effects of urbanicity on psychosis risk in older age groups (Marcelis et al., 1998) and absence of an effect of urbanicity on psychotic symptoms in a sample with a relatively high proportion of older people (Wiles et al., 2006). However, there was a trend towards an association between urbanicity and psychosis when limiting the analyses to the group of young participants, not reaching significance owing to the very small number of participants in the young age group who were exposed to urban living.

Finally, most of the previous studies examining the effect of age in the association between $\mathrm{HI}$ and psychosis have relied on self-report assessments of $\mathrm{HI}$ (e.g. Thewissen et al., 2005, Stefanis et al., 2006, van der Werf et al., 2007) instead of objective measures. The prevalence of $\mathrm{HI}$ based on self-report in young people likely exceeds the prevalence of objective $\mathrm{HI}$, thus increasing -assuming self-report exposure assessment is valid- the power to detect significant associations. The current study included only very few young participants with HI. For this reason, the age $\mathrm{x} \mathrm{HI}$ interaction in the model of psychosis was inconclusive. Nevertheless, the direction of the interaction was in line with previous research showing greater effect sizes for $\mathrm{HI}$ in younger people. Thus, the observation of a 
Risk for Psychosis: A Life Span Perspective

greatly reduced association between $\mathrm{HI}$ and psychosis after adjustment for age should be interpreted in relation to the fact that the model with the age interaction (i.e. with age as a moderator rather than a confounder) is probably the correct one. Despite these limitations, the present results are consistent with the hypothesis that higher levels of social complexity may contribute to increased risk of psychosis in people with $\mathrm{HI}$. 


\section{Chapter 6}

\section{REFERENCES}

Arrindell, WA \& Ettema, JHM (2003). Scl-90. Handleiding bij een multidimensionale psychopathologie indicator [scl-90. Manual of a multidimensional indicator of psychopathology].

Bonicatto, S, Dew, MA, Soria, JJ \& Seghezzo, ME (1997). Validity and reliability of Symptom Checklist '90 (SCL90) in an Argentine population sample. Social Psychiatry and Psychiatric Epidemiology 32, 332-8.

Boydell, J, van Os, J, McKenzie, K \& Murray, RM (2004). The association of inequality with the incidence of schizophrenia--an ecological study. Soc Psychiatry Psychiatr Epidemiol 39, 597-9.

Cantor-Graae, E \& Selten, JP (2005). Schizophrenia and migration: a meta-analysis and review. Am J Psychiatry 162, 12-24.

Collip, D, Myin-Germeys, I \& Van Os, J (2008). Does the concept of "sensitization" provide a plausible mechanism for the putative link between the environment and schizophrenia? Schizophrenia Bulletin 34, 220-5.

David, A, Malmberg, A, Lewis, G, Brandt, L \& Allebeck, P (1995). Are there neurological and sensory risk factors for schizophrenia? Schizophr Res 14, 247-51.

de Jong Gierveld, J \& Kamphuis, FH (1985). The development of a Rasch-type loneliness scale. Applied Psychological Measurement 9, 289-299.

Derogatis, LR (1983). SCL-90-R administration, scoring and procedures manual-I/Clinical Psychometric Research: Towson.

Folstein, MF, Folstein, SE \& McHugh, PR (1975). "Mini-mental state". A practical method for grading the cognitive state of patients for the clinician. J Psychiatr Res 12, 189-98.

Garety, PA, Kuipers, E, Fowler, D, Freeman, D \& Bebbington, PE (2001). A cognitive model of the positive symptoms of psychosis. Psychol Med 31, 189-95.

Hawkley, LC \& Cacioppo, JT (2003). Loneliness and pathways to disease. Brain Behav Immun 17 Suppl 1, S98-105.

Henquet, C, Krabbendam, L, Spauwen, J, Kaplan, C, Lieb, R, Wittchen, HU \& van Os, J (2005). Prospective cohort study of cannabis use, predisposition for psychosis, and psychotic symptoms in young people. Bmj 330, 11.

Jolles, J, Houx, P.J., van Boxtel., M.P.J., and Ponds, R.W.H.M. (1995). The Maastricht Aging Study. Determinants of cognitive aging. Neuropsych publishers: Maastricht.

Kapur, S (2003). Psychosis as a state of aberrant salience: a framework linking biology, phenomenology, and pharmacology in schizophrenia. Am J Psychiatry 160, 13-23.

Kapur, S, Mizrahi, R \& Li, M (2005). From dopamine to salience to psychosis--linking biology, pharmacology and phenomenology of psychosis. Schizophrenia Research 79, 5968.

Krabbendam, L\& van Os, J (2005). Schizophrenia and urbanicity: a major environmental influence--conditional on genetic risk. Schizophr Bull 31, 795-9.

Kramer, SE, Kapteyn, TS, Kuik, DJ \& Deeg, DJ (2002). The association of hearing impairment and chronic diseases with psychosocial health status in older age. J Aging Health 14, 122-37. 
Marcelis, M, Navarro-Mateu, F, Murray, R, Selten, JP \& Van Os, J (1998). Urbanization and psychosis: a study of 1942-1978 birth cohorts in The Netherlands. Psychological Medicine 28, 871-9.

McGrath, J, Saha, S, Welham, J, El Saadi, O, MacCauley, C \& Chant, D (2004). A systematic review of the incidence of schizophrenia: the distribution of rates and the influence of sex, urbanicity, migrant status and methodology. BMC Med 2, 13.

Paykel, ES, Abbott, R, Jenkins, R, Brugha, TS \& Meltzer, H (2000). Urban-rural mental health differences in great Britain: findings from the national morbidity survey. Psychol Med 30, 269-80.

Polanczyk, G, Moffitt, TE, Arseneault, L, Cannon, M, Ambler, A, Keefe, RSE, Houts, R, Odgers, CL \& Caspi, A (2009). Childhood psychotic symptoms share etiological and clinical features with

adult schizophrenia: Results from a representative birth cohort. Archives of General Psychiatry in press.

Read, J, van Os, J, Morrison, AP \& Ross, CA (2005). Childhood trauma, psychosis and schizophrenia: a literature review with theoretical and clinical implications. Acta Psychiatr Scand 112, 330-50.

Romans-Clarkson, SE, Walton, VA, Herbison, GP \& Mullen, PE (1990). Psychiatric morbidity among women in urban and rural New Zealand: psycho-social correlates. BrJ Psychiatry 156, 84-91.

Selten, JP \& Cantor-Graae, E (2005). Social defeat: risk factor for schizophrenia? Br J Psychiatry 187, 101-2.

StataCorp (2009). Stata Statistical Software. (ed. T. College Station): Texas.

Stefanis, NC, Delespaul, P, Smyrnis, N, Lembesi, A, Avramopoulos, DA, Evdokimidis, IK, Stefanis, CN \& van Os, J (2004). Is the excess risk of psychosis-like experiences in urban areas attributable to altered cognitive development? Soc Psychiatry Psychiatr Epidemio/39, 364-8.

Stefanis, NC, Thewissen, V, Bakoula, C, van Os, J \& Myin-Germeys, I (2006). Hearing impairment and psychosis: a replication in a cohort of young adults. Schizophrenia Research 85, 266-72.

Thewissen, V, Myin-Germeys, I, Bentall, R, de Graaf, R, Vollebergh, W \& van Os, J (2005). Hearing impairment and psychosis revisited. Schizophrenia Research 76, 99-103. Tomaka, J, Thompson, S \& Palacios, R (2006). The relation of social isolation, loneliness, and social support to disease outcomes among the elderly. J Aging Health 18, 359-84. van Boxtel, MP, Buntinx, F, Houx, PJ, Metsemakers, JF, Knottnerus, A \& Jolles, J (1998). The relation between morbidity and cognitive performance in a normal aging population. $J$ Gerontol A Biol Sci Med Sci 53, M147-54.

van Boxtel, MP, van Beijsterveldt, CE, Houx, PJ, Anteunis, LJ, Metsemakers, JF \& Jolles, J (2000). Mild hearing impairment can reduce verbal memory performance in a healthy adult population. J Clin Exp Neuropsycho/ 22, 147-54.

van der Werf, M, Thewissen, V, Dominguez, MD, Lieb, R, Wittchen, H \& van Os, J

Adolescent development of psychosis as an outcome of hearing impairment: a 10-year longitudinal study. Psychological Medicine; in press.

van der Werf, M, van Boxtel, M, Verhey, F, Jolles, J, Thewissen, V \& van Os, J (2007). Mild hearing impairment and psychotic experiences in a normal aging population.

Schizophrenia Research 94, 180-6. 


\section{Chapter 6}

van Os, J, Hanssen, M, Bak, M, Bijl, RV \& Vollebergh, W (2003). Do urbanicity and familial liability coparticipate in causing psychosis? Am J Psychiatry 160, 477-82.

van Os, J \& Kapur, S (2009). Schizophrenia. Lancet 374, 635-45.

van Os, J, Linscott, RJ, Myin-Germeys, I, Delespaul, P \& Krabbendam, L (2009). A

systematic review and meta-analysis of the psychosis continuum: evidence for a psychosis proneness-persistence-impairment model of psychotic disorder. Psychological Medicine 39, 179-95.

van Os, J, Rutten, BP \& Poulton, R (2008). Gene-environment interactions in schizophrenia: review of epidemiological findings and future directions. Schizophr Bul/ 34, 1066-82.

van Winkel, R, Stefanis, NC \& Myin-Germeys, I (2008). Psychosocial stress and psychosis. A review of the neurobiological mechanisms and the evidence for gene-stress interaction.

Schizophrenia Bulletin 34, 1095-105.

Veling, W, Selten, JP, Susser, E, Laan, W, Mackenbach, JP \& Hoek, HW (2007). Discrimination and the incidence of psychotic disorders among ethnic minorities in The Netherlands. Int J Epidemio/ 36, 761-8.

Verdoux, H, van Os, J, Maurice-Tison, S, Gay, B, Salamon, R \& Bourgeois, M (1998). Is early adulthood a critical developmental stage for psychosis proneness? A survey of delusional ideation in normal subjects. Schizophrenia Research 29, 247-54.

Weiser, M, van Os, J, Reichenberg, A, Rabinowitz, J, Nahon, D, Kravitz, E, Lubin, G, Shmushkevitz, M, Knobler, HY, Noy, S \& Davidson, M (2007). Social and cognitive functioning, urbanicity and risk for schizophrenia. Br J Psychiatry 191, 320-4.

Wiles, NJ, Zammit, S, Bebbington, P, Singleton, N, Meltzer, H \& Lewis, G (2006). Selfreported psychotic symptoms in the general population: results from the longitudinal study of the British National Psychiatric Morbidity Survey. BrJ Psychiatry 188, 519-26. 


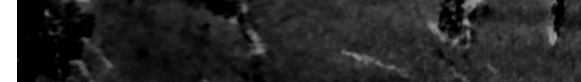

(4) II) $(5),-1$,
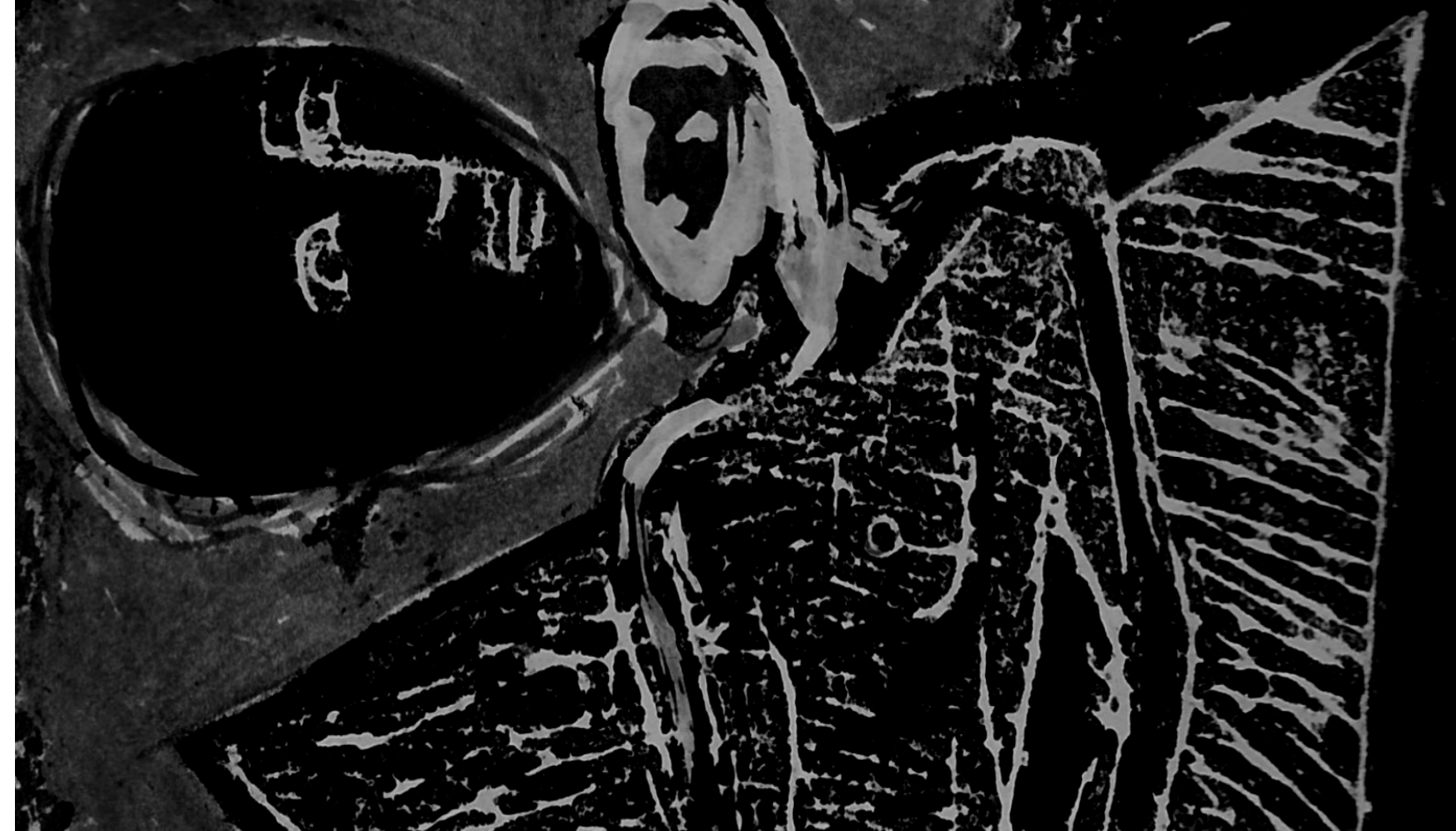

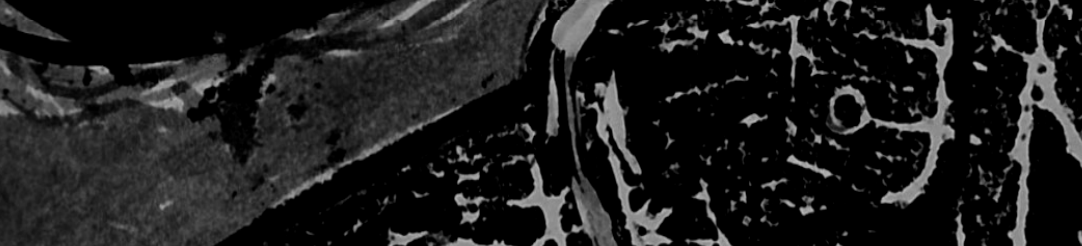
$\left(1-\frac{-}{2}\right)$

$x$ s. $3 x=$

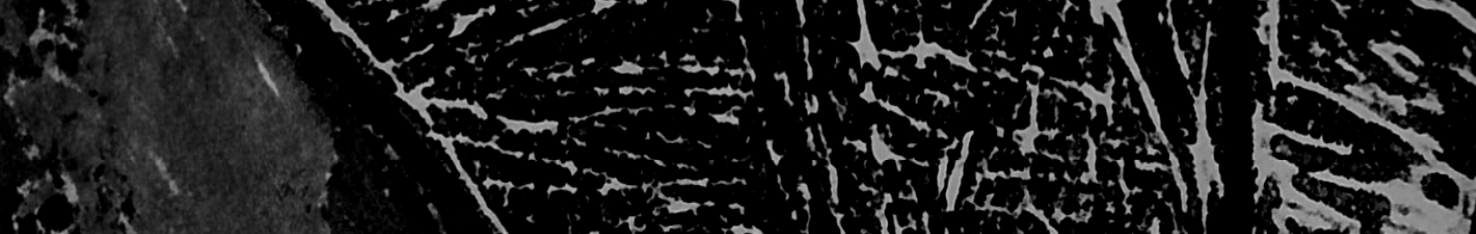

A

cts.

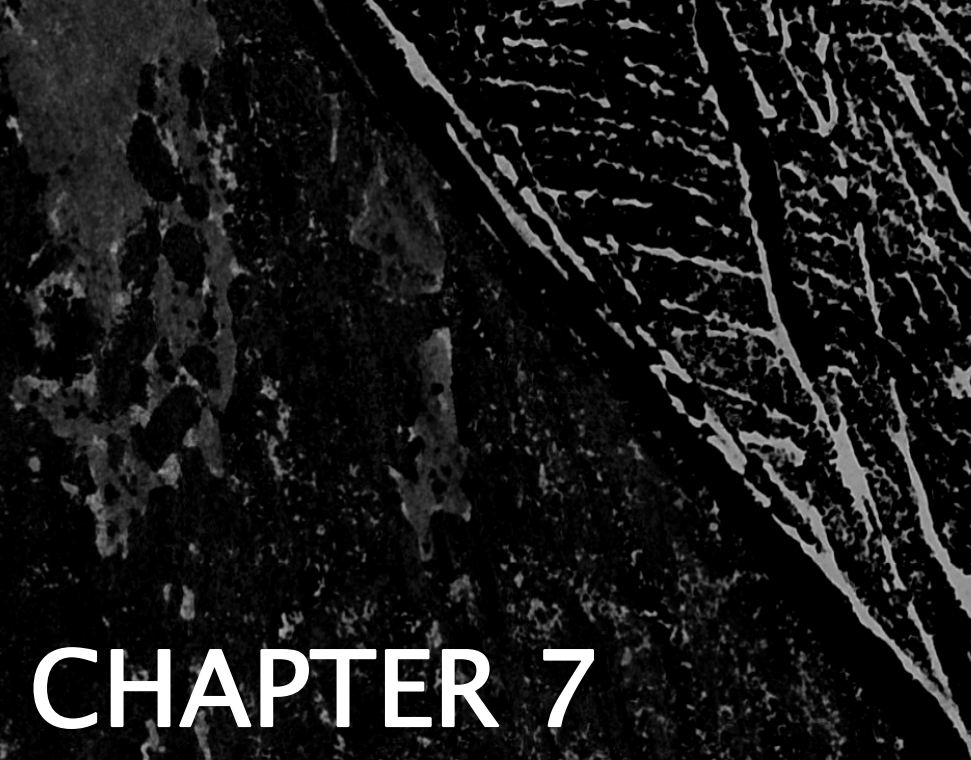

\section{CHAPTER 7} tis

Concluding Remarks 
Age is considered by far the most influential and powerful variable in epidemiology (Bhopal, 2002). Understanding the developmental window of psychosis yields important clues about the underlying mechanisms involved in disease expression. Although the importance of this type of knowledge is well-acknowledged, very few studies have examined this throughout the whole life span. Hence, the main objective of this thesis, Risk for Psychosis: A Life Span Perspective, was therefore to examine risk and its contributing factors for psychosis across the whole age span.

\section{THE RICH EPIDEMIOLOGICAL LANDSCAPE OF SCHIZOPHRENIA}

The evidence points to the singular conclusion that contrary to almost any other common condition, the incidence of schizophrenia is independent of the environment and a characteristic of human populations (Crow, 2000 pp 119).

It has long believed that schizophrenia affects all individuals equally strong. This firm belief in the homogeneity of schizophrenia incidence is nicely illustrated by the above quote. Variations in the population distribution are however inherent to most human diseases, including schizophrenia. Moreover, heterogeneity in the risk expression may well be the most reliable hallmark of schizophrenia.

Why are findings of variation important? - Understanding variability in disease expression may help to elucidate causes of schizophrenia. Whereas an apparent lack of variation points to major impact of genetic factors, heterogeneity emphasizes the importance of environmental influences. The population pattern of disease is not entirely defined by the biological or genetic characteristics of the individual. Instead most variation originates from the environment in which people live and from the interactions they have with each other (Bhopal, 2002). Variations in risk may therefore guide us towards the possible environmental influences on disease expression. Prominent variations in incidence rates for schizophrenia are apparent 


\section{Chapter 7}

across sites, over time, according to level of urbanicity and migrant status. (McGrath, 2007) However, age and sex are undoubtedly the most important sources of variation in schizophrenia. Risk typically peaks in early adulthood (Hafner et al., 1993a), but is not confined to this early period of vulnerability. The age-incidence pattern further varies strongly between men and women (Angermeyer and Kuhn, 1988). Variations by age seldom yield easy explanations due to the complex mixture of social, environmental and biological factors underlying these variations. Yet, age is by far the most influential and powerful variable in epidemiology (Bhopal, 2002). Along the same line, examining sex differences in risk of schizophrenia may yield valuable, unidirectional and uncontaminated clues about its pathogenesis (Pokorny and Overall, 1970, Aleman et al., 2003). Hence, understanding the timing and the window of sex disparity in illness onset may help pinpoint the underlying process of vulnerability (Goel and Bale, 2009).

Sketching the timing of onset and its window of sex disparity - The individual participant meta-analysis described in Chapter 2 was set up to establish age- and sex-specific incidence rates for schizophrenia covering the whole age span. Using data from 43 independent samples (and more than 100.000 patients), the overall median incidence rate was 18.3 per 100.000 person-years. This estimated risk was slightly higher than the 15.3 per 100.000 person-years estimated in an earlier effort to systematically examine and pool schizophrenia incidence rates (McGrath et al., 2004). Men had a 1.2 greater morbid risk for schizophrenia than women, which was rather similar to a previous meta-analytical estimate (Aleman et al., 2003). Figure 1 shows the pattern of risk by age and sex. 


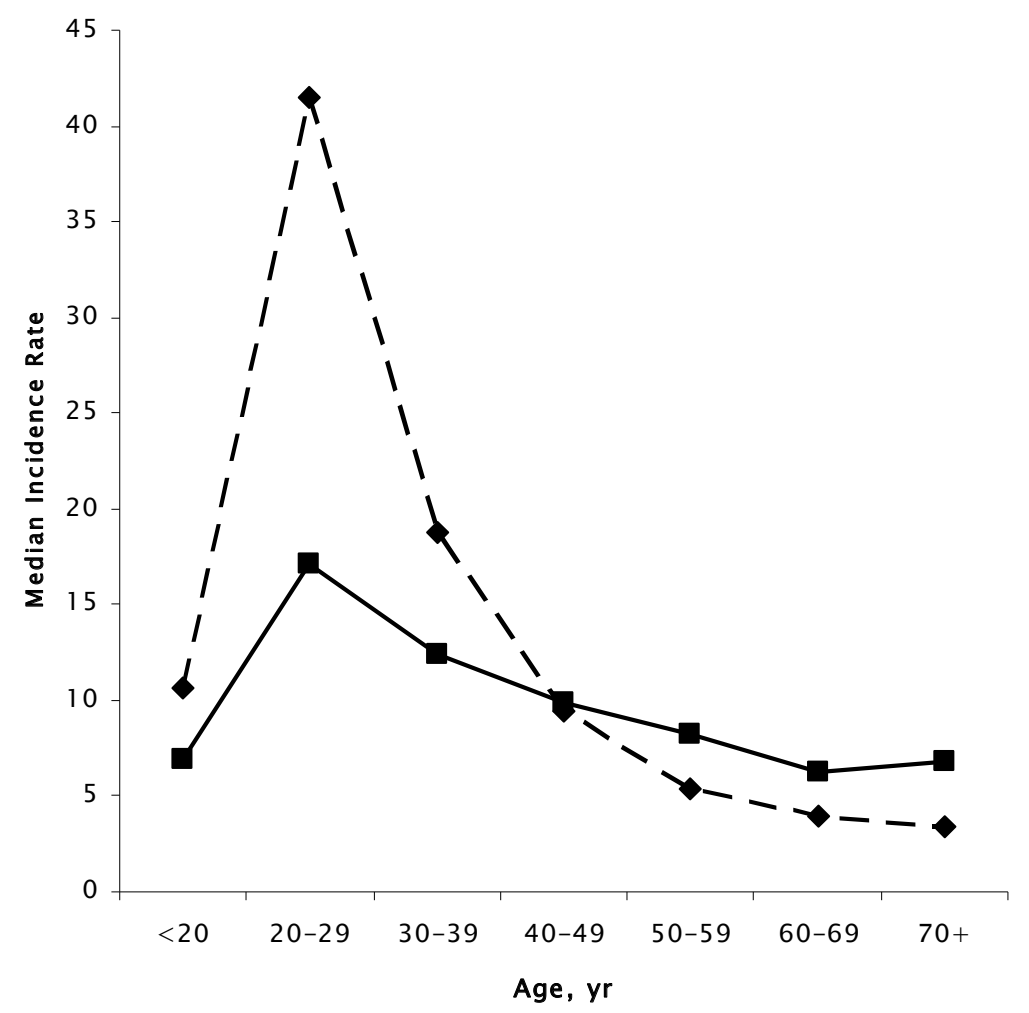

Figure 1 Median age- and sex-specific incidence rates for schizophrenia (-- women; - - men)

Both men and women show a steep rise in risk from adolescence to young adulthood. However, marked sex differences were evident in the ageincidence distribution. Schizophrenia risk in early adulthood was approximately twofold greater in men than in women. Further, whereas this high peak in men was followed by an immediate and dramatic age-related decline, this decline started later and was more modest in women. This different developmental window of illness onset resulted in a clear excess of men at younger ages and a relative overrepresentation of women in middle and older age. Contrasting previous work, the meta-analysis could not confirm the presence of a second peak in illness onset in women during the mid-to-late 40s (Hafner et al., 1993b). Instead, incidence rates 


\section{Chapter 7}

continued to decline after the initial peak up to age 60 where risk stabilized. The distribution of schizophrenia is thus characterized by three different phenomena, namely a (1) dramatic increase in risk of schizophrenia in early adulthood, (2) much rarer, but far from absent risk in middle and old age, and (3) marked sex-differences in risk across the age span. Each of these phenomena may yield clues about the etiology of schizophrenia.

Early adulthood as critical period of vulnerability - The meta-analytic results confirmed the common conception that schizophrenia is primarily a disorder of early adulthood that is more common in men (Kirkbride et al., 2006). Schizophrenia is by many considered a neurodevelopmental disorder (Murray et al., 1992). In its most simple form, this model posits that schizophrenia is the behavioral outcome of alterations in neurodevelopmental processes that begin long before the formal onset of clinical psychosis (Rapoport et al., 2005). Genetic factors, inherited or acquired, and early environmental perturbations may together confer risk for schizophrenia by derailing normal developmental processes resulting in pathologic alterations of specific neurons and their brain circuits. This latent vulnerability may 'lie silent' until biological and/or environmental factors trigger the onset of the illness. Adolescence and early adulthood may constitute a particular vulnerable period for illness onset due to extensive brain maturational processes and marked developmental changes in hormonal and neurotransmitter levels that take place (Walker et al., 2010). The dramatic functional rearrangements that characterise adolescence represent a turning point in how the brain deals with exogenous stimulation. Whereas the mature brain functionally adapts to the changing environment, the adolescent immature brain incorporates these environmental influences into the adult topography which results in long-lasting effects of early environmental exposures. Furthermore early exposure to environmental risks may make the individual more sensitive to 
later exposures ('sensitization') due to underlying increases in mesolimbic dopamine reactivity (Lieberman et al., 1997). The process of sensitization may be the final common pathway by which early environmental exposures augment a pre-existing neurodevelopmental vulnerability and set the stage for the formal onset of psychosis in early adulthood (Van Os et al., 2010). Thus, early brain alterations and normal maturational processes interacting with early/additive environmental exposures may explain why early adulthood is a critical period to develop schizophrenia.

An extended period of vulnerability - The meta-analytic findings have shown that, although risk declines rapidly with age, still a significant proportion of individuals develop schizophrenia after age 40 , or even age 60. Schizophrenia is therefore a disorder of all ages. Although there is little doubt about the importance of neurodevelopmental factors in the diathesis from which schizophrenia arises, the application of this model to schizophrenia with onset later in life has appeals less. It is generally believed that schizophrenia in late life reflect neurodegenerative processes (Murray et al., 1992). However, it is not unlikely that the aetiopathology of late-onset schizophrenia also encompasses a neurodevelopmental component (Palmer and Jeste, 1996). While the role of neurodevelopmental deficits may be substantial, a second developmentally and/or environmentally driven "hit" is needed to trigger and determine the timing of illness onset. The onset of illness in later life may unfold when normal or pathological age-related processes interact with underlying vulnerability. Hence, differentiating between pure neurodevelopmental and neurodegenerative causes of schizophrenia may be futile. Both neurodevelopmental and neurodegenerative processes will, albeit to a different extent, shape the vulnerability over the age span. Exposure to environmental risk or protective influences may further determine the point of illness onset. The onset of schizophrenia may be postponed in the absence of environmental risk factors that are capable of precipitating an 


\section{Chapter 7}

early age at onset (i.e. cannabis abuse (Veen et al., 2004)). Risk factors that are more prevalent among the elderly, including sensory deprivation and social isolation, are hypothesized to specially affect risk in later life. Finally, protective factors, such as marriage (Jablensky and Cole, 1997) or estrogen (Seeman, 1996) and an extensive social network may act to delay the onset until protection wanes. Thus, there appears to be an extended period of psychosis vulnerability that stems from socio-environmental, hormonal and age-related brain changes interacting with different levels of neurodevelopmentally defined vulnerability.

Sex-disparity in window of onset - Risk differences in the expression of schizophrenia by age and sex have often been interpreted as inherent biological characteristics of the disorder. However, alternative explanations are ready available. Sex-differences in age at onset may reflect (methodological or statistical) artifact or to sex-related mechanisms. Artifact: The strength of sex differences may depend on the applied methodology, such as stringency of the applied diagnostic classification systems and age cutoffs (Castle et al., 1993). In Chapter 2 it was examined whether sex differences in age at onset reflected methodological artifact. Variations in risk by age and sex persisted after taking into account methodological differences and age bias, rendering methodological artifact less likely. Hence, sex differences in schizophrenia appear to be systematic. Sex-related mechanism: Sex in itself may not explain differences in age at onset. Differences may be an epiphenomenon of the protective effects of marital status (Jablensky and Cole, 1997) and harmful effects of older paternal age (Rosenfield et al., 2010) and a positive family history of schizophrenia (Esterberg et al., 2010) in women. The lack of sex differences in age at onset in patients with a positive family history of schizophrenia (or other psychiatric disorder) suggest that sporadic forms of schizophrenia represent nonhereditary etiologic factors that may differentially affect men and women (Esterberg et al., 2010). Women with 
older fathers also do not show the typical later age at onset (Rosenfield et al., 2010). Age at onset difference may further be less evident in developing than in developed countries (Gangadhar et al., 2002, Venkatesh et al., 2008). Although our meta-analytic results failed to confirm this last finding, the possibility of cultural influences on age- and sex-differences in schizophrenia cannot be refuted due to the small number of incidence studies conducted in developing countries. Male/female differences in age at onset may thus not entirely originate from fixed biological characteristics inherent to the disorder. Instead, differences in biological and socio-environmental processes differentially affecting sex, but not necessarily linked to sex, may modulate the timing of onset. Sexdependent mechanism: Notwithstanding the considerable influence of these 'sex-related' factors, men and women may to a certain degree have a true differential sensitivity to develop schizophrenia at different stages of life. The most important proposed sex-linked mechanisms include hormonal modulation and a differential susceptibility to schizophrenia subtypes. The estrogen hypothesis postulates that structural and functional effects of estrogen underlie sex-differences in age at onset (Seeman, 1996). A relative lack of estrogen during early critical phases causes the male brain to mature and develop later than the female brain, resulting in greater vulnerability to early brain insults and a consequent higher risk to develop schizophrenia earlier in life (Seeman, 1996). The effect of estrogen in women is further reinforced in adolescence through their neuromodulatory and dopaminergic blocking effects on dopamine $D_{2-}$ receptors that buffer the expression of psychosis (McEwen, 1981). These structural and functional effects may together contribute to the typical later onset in women. Menopausal waning of estrogen levels is thought to account for the often observed second period of increased risk in middleaged women. However, our meta-analysis could not confirm the existence of such a peak in middle-aged women, which questions the dominating role of estrogen in shaping sex-differences in later life. Different 


\section{Chapter 7}

susceptibilities in men and women to either a neurodevelopmental or affective pathway to psychosis has also been proposed (Castle and Murray, 1991). It is believed that men have greater vulnerability for neurodevelopmental perturbations, resulting in an earlier age at onset and a more severe form of the illness (Murray et al., 1992). This greater male vulnerability for neurodevelopmental impairment is best understood within the context of a slower pace of normal developmental and maturational processes, a worse response to early environmental insults and differential exposure to sex hormones (Raz et al., 1994). The faster developing female brain is more resistant to early environmental insults. However, women may show greater affinity for affective dysregulation, resulting in a later onset and a milder affective-colored phenotype. Altered stress-sensitivity may be one of the contributing factors leading to this more episodic, good-outcome type of psychosis seen more frequently in women (MyinGermeys and van Os, 2007).

\section{UNRAVELING THE ORIGINS OF COGNITIVE IMPAIRMENT IN PSYCHOSIS}

Characterising the relationship between age at onset and cognitive deficits will illuminate from a cognitive perspective the unravelling of the disease process at different levels of severity (Rajji et al, 2009, pp 186).

Patients with schizophrenia show cognitive impairments in a wide range of cognitive domains, including verbal and working memory, attention and executive functioning (Goldberg and Gold, 1995, Heinrichs and Zakzanis, 1998, Dollfus et al., 2002). Impairments are often present before illness onset (Davidson et al., 1999), persist despite remission of psychotic symptoms (Bilder et al., 2000) and can be found in non-affected relatives (Sitskoorn et al., 2004). As such, cognitive impairment is considered a core feature of schizophrenia reflective of the pathophysiology of the illness (Heinrichs and Zakzanis, 1998, Elvevag and Goldberg, 2000). However, the overall degree and pattern of impairment varies considerably across 
patients (Joyce et al., 2005). Whereas some patients show widespread and severe deficits, others have cognitive functioning that is relatively unimpaired (Goldstein, 1990, Palmer et al., 1997). Examining variation in cognitive functioning may help to unravel the origins of the impairment in psychosis and shed light on its pathophysiology. Given that age at onset is considered to reflect the severity of the illness process (DeLisi, 1992), the degree and pattern of affected cognitive functions may well vary according to the age at onset of psychosis.

Age at onset and cognitive functioning - The study described in Chapter 3 examined the effect of age at onset on cognitive functioning across the entire age at onset range (age range 7-86) years using a sample of 1053 patients with non-affective psychotic disorder and 631 healthy controls. In this sample an earlier age at onset was associated with more severe impairments on memory recall and sustained attention, but not with IQ, processing speed and executive functioning. These findings are consistent with previous work showing that patients with early-onset schizophrenia are more compromised on learning and memory (Tuulio-Henriksson et al., 2004, Vahia et al., 2010) and sustained attention (Hoff et al., 1996, Bellino et al., 2004). Rather than impacting on global cognitive functioning, age at onset appears to relate to specific cognitive deficits. This suggests that neurobiological substrates subserving memory recall and sustained attention may be especially vulnerable to early neurodevelopmental aberrations assumed to underlie the onset of schizophrenia early in life (Tuulio-Henriksson et al., 2004).

Characterising the nature of the relationship - Despite the converging evidence that cognitive functions are more affected in patients with earlyonset schizophrenia, characterising the nature of the observed relationship remains challenging. Most of the clinical and demographic characteristics associated with earlier age at onset also relate to poor cognitive 


\section{Chapter 7}

functioning (Goldstein et al., 1998). Hence, age at onset may contribute to cognitive functioning through its associations with illness severity features. The results in Chapter 3 show that an earlier age at onset of psychosis is also associated with male gender, fewer positive and more negative symptoms, a higher dose of antipsychotics and a diagnosis of schizophrenia. These findings lend support to the prevailing idea that early-onset schizophrenia represents a more severe form of the illness (DeLisi, 1992). Moreover, the pattern of features relating to early onset in our study are generally believed to be characteristic for neurodevelopmental alterations underlying the illness process (Murray et al., 1992). After taking into account the different distributions of these neurodevelopmental markers, variation in cognitive functioning initially attributed to age at onset was removed. Instead, the association between age at onset and sustained attention was mediated by the presence of more negative symptoms in patients with early onset. Further, male gender, more negative symptoms and higher dose of antipsychotics explained the more compromised functioning on immediate recall. Overall, these results suggest that the severity of cognitive impairment reflects the severity of the underlying neurodevelopmental alterations.

A lifespan perspective - The present findings are contingent with the neurodevelopmental vulnerability model (Murray et al., 1992). There is evidence suggesting that especially early-onset schizophrenia is characterised by more severe neurodevelopmental alterations (Hollis, 1995) (Verdoux et al., 1997). Given that the degree of impairment is shaped by age at onset, the degree of underlying neurodevelopmental alterations likely affect the severity of the observed cognitive impairment. Although age at onset and cognitive functioning may be separate features of the same illness, they appear to derive from the same underlying latent vulnerability. Memory recall and sustained attention may be especially vulnerable to early neurodevelopmental processes, suggesting that they 
Risk for Psychosis: A Life Span Perspective

should be considered as trait markers for the underlying neurobiological vulnerability. As such, we propose a model in which cognitive functioning and age at onset are separate features of the illness relating to shared underlying factors that reflect neurodevelopmental alterations (Figure 2).

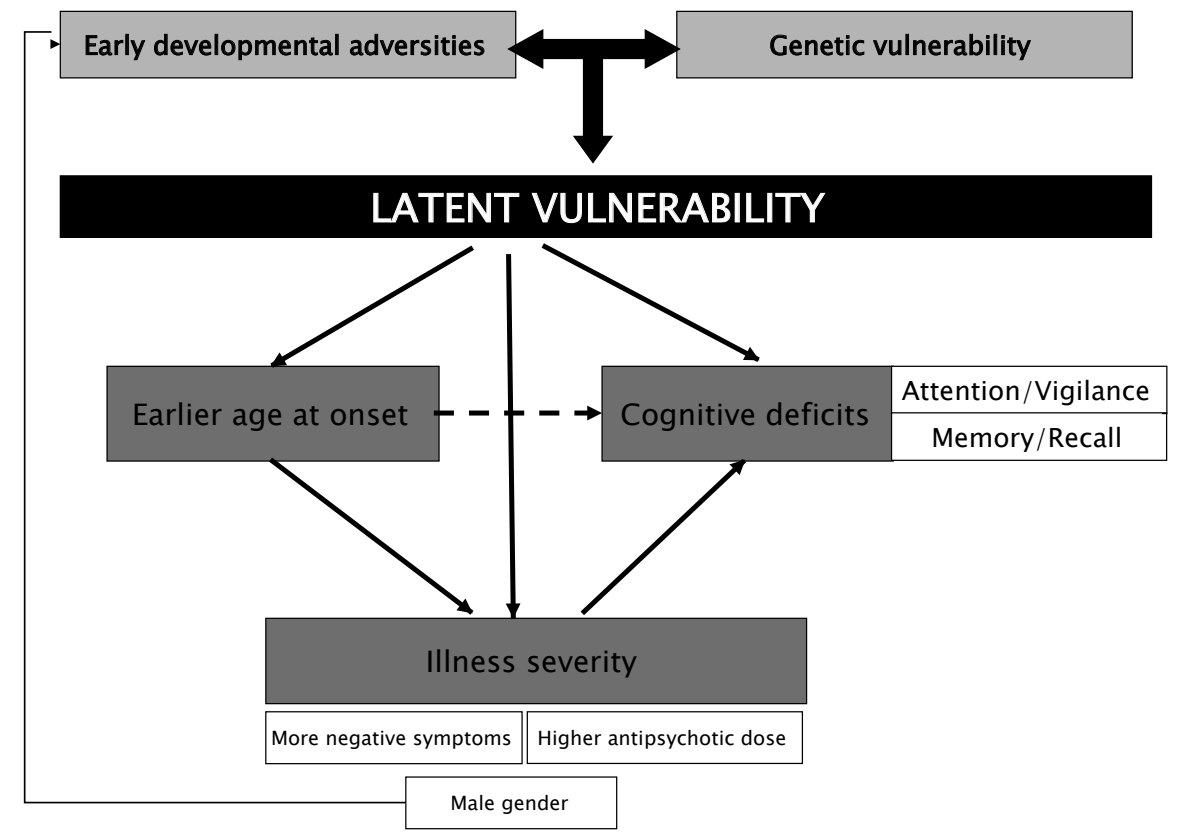

Figure 2. A proposed model of cognitive vulnerability in relation to age at onset

Beyond early adulthood - As mentioned before, late-onset schizophrenia is thought to reflect neurodegenerative processes emerging close to the time of illness. The non-progressive nature of the cognitive alterations (Sachdev et al., 1999, Palmer et al., 2003) and the absence of brain abnormalities suggestive of neurodegenerative processes (Pearlson et al., 1993, Rivkin et al., 2000) suggest otherwise. However, long-term follow-up of people with late-onset schizophrenia often yields a picture of progressive cognitive decline. As such, it has been argued that late-onset schizophrenia 


\section{Chapter 7}

is a prelude to dementia (Brodaty et al., 2003). Although the results presented in Chapter 4 suggested milder cognitive impairment in patients with late-onset psychotic disorder, these were based on a sample from which patients with dementia at follow-up were excluded. Preliminary results within the total sample of patients with late-onset schizophrenia showed that seven out of fifty-three patients (13.2\%) with a baseline diagnosis of schizophrenia received a diagnosis of probable dementia over a mean follow-up period of approximately 1.5 years. These apparently contrasting findings emphasizes that late-onset schizophrenia is a heterogeneous syndrome consisting of different groups of patients with different etiology. The first group may develop schizophrenia in the context of a mild or absent neurodevelopmental diathesis with little impact on the development of cognitive functions. The second group may show schizophrenia-like psychosis in the context of mild underlying neurodegenerative alterations that predispose to further cognitive deterioration and later dementia over time. Thus, the cognitive alterations in patients with a late-onset psychosis appear to represent two final pathways, namely (i) one in which the severity of cognitive alterations is shaped by declining levels of neurobiological vulnerability with increasing age at onset, and (ii) one in which underling neurodegeneration determines cognitive functioning.

\section{RISK FACTORS FOR PSYCHOSIS - CLUES FROM HEARING IMPAIRMENT}

Faith comes by hearing (Romans 10:17).

As outlined above, vulnerability for psychosis encompasses multiple neurobiological, genetic and socio-environmental mechanisms that act together to modulate the timing of onset. It has been argued that a second "hit" might be necessary to unmask the underlying liability for psychosis. Among the key environmental factors that may trigger its onset and shape 
the window of illness onset are exposure to drugs, stress, urban upgrowing, minority position and possibly also hearing impairment (Van Os et al., 2010).

Sketching the problem - Affecting approximately 279 million people across the world, hearing loss is one of the most common health problems worldwide (WHO, 2010). Hearing loss may seriously hamper speech comprehension with consequent difficulties in the exchange of information with others and has been linked to multiple negatives outcomes, including depression, low self-esteem, lower quality of life, loneliness and social isolation (Wallhagen et al., 2001, Dalton et al., 2003, Tambs, 2004). People with moderate hearing loss experience more difficulties in paying attention, tend not to feel close to others and feel left out in groups (Strawbridge et al., 2000, Wallhagen et al., 2001). Finally, hearing loss preceding the acquisition of language can have long-lasting effects by affecting the development of speech, language and (social) cognition (Bess et al., 1998). Together these findings emphasize the major impact of hearing impairment on mental health. Most work on hearing impairment and mental health has focused on the negative impact on domains of general well-being and depression. However, considering the profound psychosocial, emotional and possibly developmental consequences of hearing impairment, hearing loss may also constitute a vulnerability factor to develop psychosis.

Hearing impairment and psychosis - There is increasing evidence that hearing impairment increases the risk for psychosis (David et al., 1995, Thewissen et al., 2005). Older work has mainly focused on hearing impairment as risk factor for psychosis in the elderly (Cooper, 1976, Cooper and Curry, 1976), yet evidence is converging that younger and older people may be differentially sensitive to the negative impact of hearing impairment (Stefanis et al., 2006). Using two different general 


\section{Chapter 7}

population samples, the studies described in Chapter 4 and Chapter 5 were set up to (i) establish hearing impairment as risk factor for psychosis and to (ii) narrow down its period of vulnerability. People with selfperceived hearing problems were found to be more likely to report psychotic phenomena, such as paranoid ideation or hallucinatory experiences, than people without hearing problems. The association was stronger at the more severe end of the psychosis continuum, adding to the notion that hearing impairment confers risk for subclinical (Stefanis et al., 2006) and clinical expressions of psychosis (David et al., 1995). Moreover, the latter suggests that self-reported psychotic experiences in the general population share commonly reported risk factors for clinical psychosis (Johns et al., 2004, Wiles et al., 2006). Contrasting older work (Cooper and Curry, 1976), but confirming the more recent studies (Stefanis et al., 2006), the association between hearing impairment and psychosis was confined to young adolescents. Despite the apparent robust associations between hearing impairment and psychosis in young people, the underlying mechanism remains largely unknown. Considering the adverse social and emotional consequences of hearing impairment, it has been suggested that affective symptoms and social exclusion (loneliness and social isolation) might represent the intermediate constructs by which hearing impairment confer risk for psychosis. However, these possibilities were refuted in Chapter 4 and Chapter 6 . Although depressive symptoms and social isolation were important determinants of risk for psychosis, they did not explain the association between hearing impairment and psychosis. Finally, in Chapter 6 it was demonstrated that people with hearing impairment who were living in densely populated areas (urban areas) were most prone to develop psychotic experiences. Hence, difficulties in the ability to process relative intense and ambiguous stimuli in the social environment may be one of the driving forces behind psychosis risk. The findings have established hearing impairment as risk factor for psychosis and have narrowed its window of vulnerability to adolescence. Additionally, they add 
to a growing body of literature that emphasizes the importance of the wider social environment in the pathway to psychosis (Van Os et al., 2010).

A lifespan perspective - As detailed previously, adolescence is an extremely vulnerable period to develop psychopathology, not only because of the extensive maturational rearrangements that take place in the yet immature brain, but also because early environmental influences may become incorporated in the structure and function of the mature brain (Andersen, 2003). Hence, childhood and adolescent hearing impairment may have longer-lasting consequences for psychosis vulnerability than hearing problems originating later in life. Hearing impairment, in combination with exposure to other risks, may trigger the onset in adolescents with a preexisting vulnerability. In addition, childhood hearing impairment may compromise effective learning of language, cognitive and social skills (Bess et al., 1998) which may set the stage to develop psychosis later in life. Alternatively, that the link between childhood/adolescent hearing impairment and psychosis may reflect shared causation cannot be refuted yet. Infections such as rubella and meningitis are potentially harmful for the developing brain and may predispose the child to both hearing impairment and vulnerability for psychosis (Brown et al., 2000, Leask et al., 2002).

Beyond adolescence - While hearing impairment shows strongest impact in young people, risk may not be confined to young people only (Cooper and Curry, 1976) (Stein and Thienhaus, 1993). Other mechanisms should therefore be considered when trying to explain how hearing impairments shapes risk for psychosis throughout life. Instead of influencing risk through its effects on the developing and maturing brain, hearing impairment may directly trigger paranoia and hallucinatory experiences when sensory deprivation produces patterns of nerve impulses that bring forward hallucinatory experiences (Mason and Brady, 2009). The onset of 


\section{Chapter 7}

positive symptoms in persons with hearing impairment can further be understood in terms of psychological models which focus on social cognitive biases (Thewissen et al., 2005). Hallucinatory experiences may result from reality-testing failures. These may cause a person to misattribute internal stimuli to an external source (Bentall, 1990). Finally, considering its associations with stress, social isolation and loneliness, hearing impairment is considered to constitute social defeat (RomansClarkson et al., 1990, Bess et al., 1998, Kramer et al., 2002). Social defeat may represent the general mechanism linking multiple environmental exposure, including hearing impairment, to the underlying biological mechanism of psychosis (van Winkel et al., 2008). Hearing impairment thus encompasses multiple mechanisms that may mould the risk for psychosis throughout life, some of them specific to young age and others acting regardless of age.

\section{INTEGRATIVE MODEL OF PSYCHOSIS RISK ACROSS THE LIFE SPAN}

Genetic or environmental, the seeds of schizophrenia seem to be sown during early life (Jones et al, 1994).

The ultimate goal of schizophrenia research is to find its origins in order to better treat or prevent this often debilitating disorder. Although we are currently far from being able to answer the most pressing questions, small pieces of the complex puzzle are starting to fall into place. The results from this thesis may contribute to a better understanding of the 'seeds' of schizophrenia by extending knowledge about the developmental timing of schizophrenia onset and its window of sex disparity. Figure 3 aims to model these results into a lifespan perspective of risk for psychosis. 


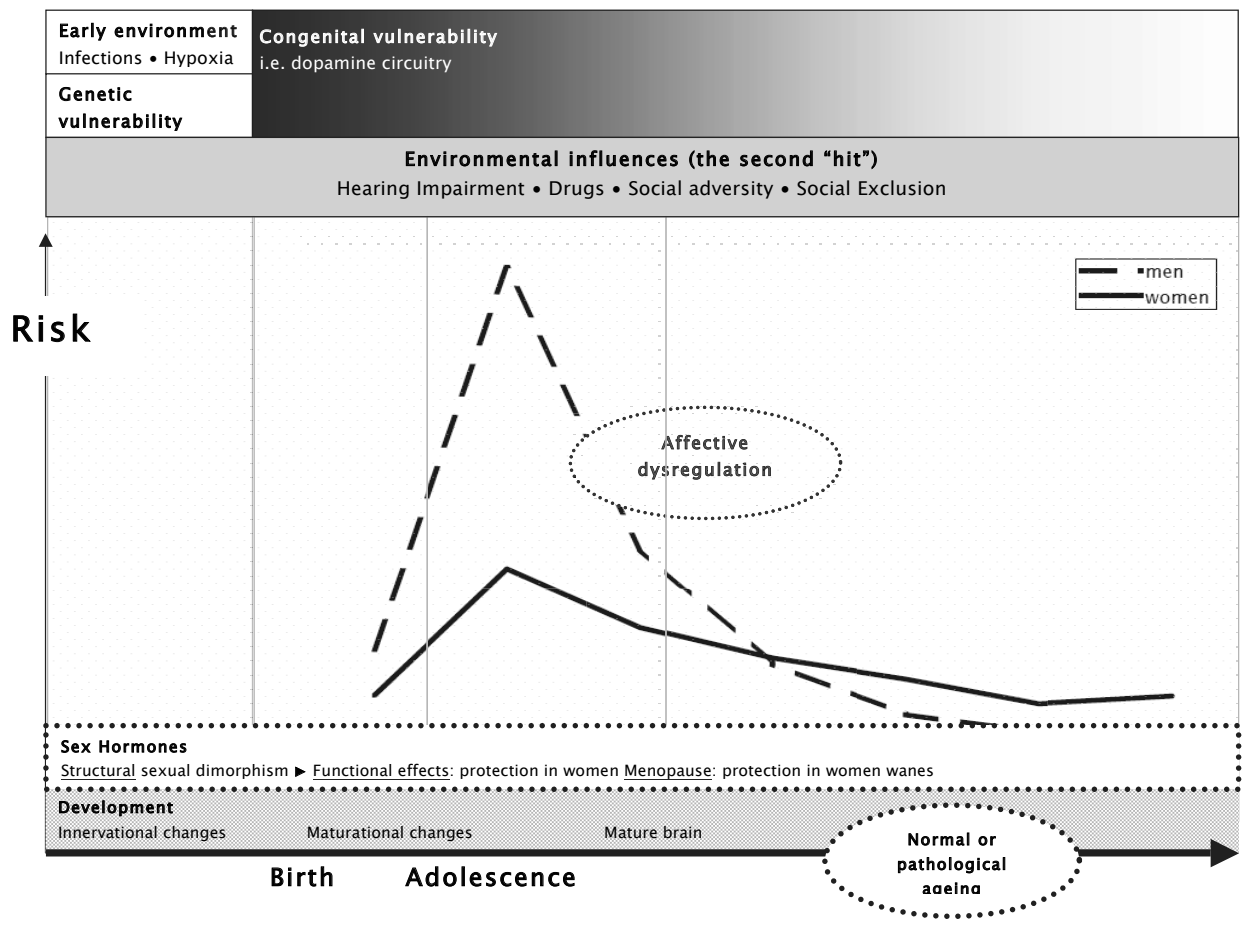

Figure 3. A life span perspective of risk for psychosis

What determines the timing of onset? - The seeds of schizophrenia are most likely sown during early life (Jones et al., 1994). Inherited or acquired genetic factors and early environmental adversities may together set the stage for psychosis vulnerability. During this same critical period, sexlinked genes and sex-hormones exert organizational and activational effects on the developing brain which results in sexual differentiation of the brain (Davies and Wilkinson, 2006). The determination of neurobiological vulnerability and sexual differentiation during a same critical period may explain the heightened vulnerability for neurodevelopmental alterations in men, and may thereby contribute to sex differences in age at onset of schizophrenia. Although schizophrenia vulnerability is founded early in life, formal onset of schizophrenia is thought to be delayed until brain maturational changes and environmental 


\section{Chapter 7}

influences unmask underlying liability (McGlashan and Hoffman, 2000). While early-onset schizophrenia may reflect the negative outcome of severe neurodevelopmental alterations interacting with normal maturational processes(Andersen, 2003), later onset may be the result of a milder neurodevelopmental diathesis in combination with normal or pathological age-related processes (Vahia et al., 2010). The age at first onset may further be brought forward when the underlying vulnerability is triggered by the early or repeated exposure to environmental factors that impact on the immature brain during critical developmental phases. Substance abuse (Veen et al., 2004), urban upbringing (Pedersen and Mortensen, 2001), minority position (Bourque et al., 2010) and hearing impairment (van der Werf et al., 2010) are among the key risk factors that may precipitate an early onset. Other, more general environmental influences such as social stress or social defeat may represent the mechanism by which risk is enhanced regardless of age (Bebbington et al., 1993, Selten and Cantor-Graae, 2007). Finally, the age at onset of schizophrenia in women may be delayed by the neuromodulatory antidopaminergic effects of estrogen in the pubertal brain. These different processes are far from mutually exclusive in determining the point of illness onset. Instead, they most likely interact with each other, and contribute to different degrees to mould risk across the age span. Thus, the window of illness onset appears to be shaped by the extent to which an individual is subjected to early developmental vulnerability, early or additive environmental influences and underlying hormonal and agerelated brain changes.

\section{WHERE TO GO FROM HERE?}

CLINICAL IMPLICATIONS AND FUTURE DIRECTIONS

Screening for preschizophrenia in the general population with the aim of preventing transition to full-blown illness is an epidemiological impossibility because a rare disease cannot be predicted (van Os \& Delespaul, 2005). 
The findings of this thesis contribute to the fundamental knowledge about the window of schizophrenia onset and its contributing factors. Recognizing different risk periods may reveal the window of opportunity for early detection and possibly prevention strategies, which makes this type of information important for policy makers, mental health service development and service planning. Early detection and prevention $\downarrow$ Early detection and prevention strategies may delay formal onset (Morrison et al., 2007) and have long-term beneficial outcomes (Larsen et al., 2007). However, setting up early detection and screening programmes for the whole community is infeasible due to the low incidence of schizophrenia. Since schizophrenia risk increases steeply from adolescence to reach its summit in early adulthood, these programmes should therefore target on the (pre) adolescent population. Identification of risk factors and risk markers that define adolescents at ultra high risk for schizophrenia should further guide prevention programmes. Never too late for prevention $\downarrow$ The results from thesis further highlight the widespread window of illness onset for schizophrenia, with a small but not negligible proportion of individuals developing schizophrenia or schizophrenia-like psychotic disorder after age 65 years. The first of this post-war "baby boom" generation will reach the age of 65 years by the end of 2010, and the number of elderly persons is anticipated to rise exponentially from then on (Jeste et al., 1999). Hence, the number of individuals in the community with late-onset psychotic disorder is expected to rise as well. As noted previously, late-onset psychotic disorders likely encompass multiple etiologies and should be treated accordingly. Thus, whereas some patients show a disease trajectory that is most compatible with those seen in early-onset psychotic disorders, a significant proportion of patients will have psychotic disorder as a prelude to dementia (Brodaty et al., 2003). Primary health care and mental health care professionals should acknowledge and recognize these potential different outcomes and their underlying etiological heterogeneity 


\section{Chapter 7}

in patients who present with psychosis in late life. To ameliorate adequate service planning and possible early interventions in late-onset psychotic disorder, research efforts should be aimed at identifying early markers that define these different groups. The concept of prevention should therefore not be restricted to adolescents only and should be applied to elderly persons as well (Lebowitz and Pearson, 2000). Risk factor prevention - A prevention-oriented goal for schizophrenia researchers is to identify and influence malleable causal risk factors to delay and ideally to prevent the disorder. The findings of this thesis imply that some risk factors may have greatest impact in young people, whereas others may operate independent of age. Identifying the window of vulnerability of these risk factors of schizophrenia vulnerability may help to narrow down and to optimize the focus of prevention strategies. For example, especially early cannabis abuse appears to be associated with psychosis (McGrath et al., 2010). Along the same line, whereas childhood/adolescent hearing impairment confers risk for psychosis, the onset of hearing impairment in life does much less so. Hence, appropriate prevention and intervention strategies should aim at preventing or treating hearing impairment in young people at risk for psychosis. Finally, future research must go beyond identifying risk factors for schizophrenia, but should instead target at finding possible biological and psychosocial protective factors that delay onset. 


\section{REFERENCES}

Aleman, A, Kahn, RS \& Selten, JP (2003). Sex differences in the risk of schizophrenia: evidence from meta-analysis. Arch Gen Psychiatry 60, 565-71.

Andersen, SL (2003). Trajectories of brain development: point of vulnerability or window of opportunity? Neurosci Biobehav Rev 27, 3-18.

Angermeyer, MC \& Kuhn, L (1988). Gender differences in age at onset of schizophrenia. An overview. Eur Arch Psychiatry Neurol Sci 237, 351-64.

Bebbington, P, Wilkins, S, Jones, P, Foerster, A, Murray, R, Toone, B \& Lewis, S (1993). Life events and psychosis. Initial results from the Camberwell Collaborative Psychosis Study. British Journal of Psychiatry. Supplement 162, 72-79.

Bellino, S, Rocca, P, Patria, L, Marchiaro, L, Rasetti, R, Di Lorenzo, R, Paradiso, E \& Bogetto, $F$ (2004). Relationships of age at onset with clinical features and cognitive functions in a sample of schizophrenia patients. J Clin Psychiatry 65, 908-14.

Bentall, RP (1990). The illusion of reality: a review and integration of psychological research on hallucinations. Psychological Bulletin 107, 82-95.

Bess, FH, Dodd-Murphy, J \& Parker, RA (1998). Children with minimal sensorineural hearing loss: prevalence, educational performance, and functional status. Ear Hear 19, 339-54.

Bhopal, RS (2002a). Concepts of Epidemiology: an integrated introduction to the ideas, theories, principles and methods of epidemiology. Oxford University Press: Oxford. Bhopal, RS (2002b). What is epidemiology? In Concepts of Epidemiology. An integrated introduction to the ideas, theories, principles and methods of epidemiology. (ed. R. S. Bhopal), pp. 1-16. Oxford University Press: Oxford, New York.

Bilder, RM, Goldman, RS, Robinson, D, Reiter, G, Bell, L, Bates, JA, Pappadopulos, E, Willson, DF, Alvir, JM, Woerner, MG, Geisler, S, Kane, JM \& Lieberman, JA (2000). Neuropsychology of first-episode schizophrenia: initial characterization and clinical correlates. Am J Psychiatry 157, 549-59.

Bourque, F, van der Ven, E \& Malla, A (2010). A meta-analysis of the risk for psychotic disorders among first- and second-generation immigrants. Psychol Med, 1-14.

Brodaty, H, Sachdev, P, Koschera, A, Monk, D \& Cullen, B (2003). Long-term outcome of late-onset schizophrenia: 5-year follow-up study. British Journal of Psychiatry.

Supplement 183, 213-219.

Brown, AS, Cohen, P, Greenwald, S \& Susser, E (2000). Nonaffective psychosis after prenatal exposure to rubella. American Journal of Psychiatry 157, 438-43.

Castle, DJ \& Murray, RM (1991). The neurodevelopmental basis of sex differences in schizophrenia. Psychological Medicine 21, 565-575.

Castle, DJ, Wessely, S \& Murray, RM (1993). Sex and schizophrenia: effects of diagnostic stringency, and associations with and premorbid variables. BrJ Psychiatry 162, 658-64. Cooper, AF (1976). Deafness and psychiatric illness. BrJ Psychiatry 129, 216-26.

Cooper, AF \& Curry, AR (1976). The pathology of deafness in the paranoid and affective psychoses of later life. Journal of Psychosomatic Research 20, 97-105.

Dalton, DS, Cruickshanks, KJ, Klein, BE, Klein, R, Wiley, TL \& Nondahl, DM (2003). The impact of hearing loss on quality of life in older adults. Gerontologist 43, 661-8. 


\section{Chapter 7}

David, A, Malmberg, A, Lewis, G, Brandt, L \& Allebeck, P (1995). Are there neurological and sensory risk factors for schizophrenia? Schizophrenia Research 14, 247-51.

Davidson, M, Reichenberg, A, Rabinowitz, J, Weiser, M, Kaplan, Z \& Mark, M (1999).

Behavioral and intellectual markers for schizophrenia in apparently healthy male adolescents. Am J Psychiatry 156, 1328-35.

Davies, W \& Wilkinson, LS (2006). It is not all hormones: Alternative explanations for sexual differentiation of the brain. Brain Research 1126, 36-45.

DeLisi, LE (1992). The significance of age of onset for schizophrenia. Schiz Bull 18, 20915.

Dollfus, S, Lombardo, C, Benali, K, Halbecq, I, Abadie, P, Marie, RM \& Brazo, P (2002).

Executive/attentional cognitive functions in schizophrenic patients and their parents: a preliminary study. Schizophr Res 53, 93-9.

Elvevag, B \& Goldberg, TE (2000). Cognitive impairment in schizophrenia is the core of the disorder. Crit Rev Neurobiol 14, 1-21.

Esterberg, ML, Trotman, HD, Holtzman, C, Compton, MT \& Walker, EF (2010). The impact of a family history of psychosis on age-at-onset and positive and negative symptoms of schizophrenia: A meta-analysis. Schizophr Res In Press, Corrected Proof.

Gangadhar, BN, Selvan, CP, Subbakrishna, DK \& Janakiramaiah, N (2002). Age-at-onset and schizophrenia: reversed gender effect. Acta Psychiatr Scand 105, 317-319.

Goel, N \& Bale, TL (2009). Examining the intersection of sex and stress in modelling neuropsychiatric disorders. J Neuroendocrino/ 21, 415-20.

Goldberg, TE \& Gold, JM (1995). Neurocognitive deficits in schizophrenia. In Schizophrenia (ed. S. R. Hirsch and D. R. Weinberger), pp. 146-162. Blackwell: Oxford.

Goldstein, $\mathrm{G}$ (1990). Neuropsychological heterogeneity in schizophrenia: a consideration of abstraction and problem-solving abilities. Arch Clin Neuropsycho/ 5, 251-64.

Goldstein, JM, Seidman, LJ, Goodman, JM, Koren, D, Lee, H, Weintraub, S \& Tsuang, MT (1998). Are there sex differences in neuropsychological functions among patients with schizophrenia? Am J Psychiatry 155, 1358-64.

Hafner, H, Maurer, K, Loffler, W \& Riecher-Rossler, A (1993a). The influence of age and sex on the onset and early course of schizophrenia. Br J Psychiatry 162, 80-6.

Hafner, H, Riecher-Rossler, A, An Der Heiden, W, Maurer, K, Fatkenheuer, B \& Loffler, W (1993b). Generating and testing a causal explanation of the gender difference in age at first onset of schizophrenia. Psychol Med 23, 925-40.

Heinrichs, RW \& Zakzanis, KK (1998). Neurocognitive deficit in schizophrenia: a quantitative review of the evidence. Neuropsychology 12, 426-45.

Hoff, AL, Harris, D, Faustman, WO, Beal, M, DeVilliers, D, Mone, RD, Moses, JA \& Csernansky, JG (1996). A neuropsychological study of early onset schizophrenia. Schizophr Res 20, 21-28.

Hollis, C (1995). Child and adolescent (juvenile onset) schizophrenia. A case control study of premorbid developmental impairments. BrJ Psychiatry 166, 489-495.

Jablensky, A \& Cole, SW (1997). Is the earlier age at onset of schizophrenia in males a confounded finding? Results from a cross-cultural investigation. BrJ Psychiatry 170, 23440. 
Jeste, DV, Alexopoulos, GS, Bartels, SJ, Cummings, JL, Gallo, JJ, Gottlieb, GL, Halpain, MC, Palmer, BW, Patterson, TL, Reynolds, CF, 3rd \& Lebowitz, BD (1999). Consensus statement on the upcoming crisis in geriatric mental health: research agenda for the next 2 decades. Arch Gen Psychiatry 56, 848-53.

Johns, LC, Cannon, M, Singleton, N, Murray, RM, Farrell, M, Brugha, T, Bebbington, P, Jenkins, R \& Meltzer, H (2004). Prevalence and correlates of self-reported psychotic symptoms in the British population. Br J Psychiatry 185, 298-305.

Jones, P, Rodgers, B, Murray, R \& Marmot, M (1994). Child development risk factors for adult schizophrenia in the British 1946 birth cohort. Lancet 344, 1398-402.

Joyce, EM, Hutton, SB, Mutsatsa, SH \& Barnes, TRE (2005). Cognitive heterogeneity in firstepisode schizophrenia. British Journal of Psychiatry. Supplement 187, 516-522.

Kirkbride, JB, Fearon, P, Morgan, C, Dazzan, P, Morgan, K, Tarrant, J, Lloyd, T, Holloway, J, Hutchinson, G, Leff, JP, Mallett, RM, Harrison, GL, Murray, RM \& Jones, PB (2006).

Heterogeneity in incidence rates of schizophrenia and other psychotic syndromes: findings from the 3-center AeSOP study. Arch Gen Psychiatry 63, 250-8.

Kramer, SE, Kapteyn, TS, Kuik, DJ \& Deeg, DJ (2002). The association of hearing impairment and chronic diseases with psychosocial health status in older age. Journal of Aging and Health 14, 122-37.

Larsen, TK, Melle, I, Friis, S, Joa, I, Johannessen, JO, Opjordsmoen, S, Simonsen, E, Vaglum, P \& McGlashan, TH (2007). One-year effect of changing duration of untreated psychosis in a single catchment area. BrJ Psychiatry Supp/ 51, s128-32.

Leask, SJ, Done, DJ \& Crow, TJ (2002). Adult psychosis, common childhood infections and neurological soft signs in a national birth cohort. British Journal of Psychiatry 181, 387-92. Lebowitz, BD \& Pearson, JL (2000). Intervention research in psychosis: prevention trials. Schizophr Bul/ 26, 543-9.

Lieberman, JA, Sheitman, BB \& Kinon, BJ (1997). Neurochemical sensitization in the pathophysiology of schizophrenia: deficits and dysfunction in neuronal regulation and plasticity. Neuropsychopharmacology 17, 205-29.

Mason, OJ \& Brady, F (2009). The psychotomimetic effects of short-term sensory deprivation. Journal of Nervous and Mental Disease 197, 783-5.

McEwen, BS (1981). Neural gonadal steroid actions. Science 211, 1303-11.

McGlashan, TH \& Hoffman, RE (2000). Schizophrenia as a Disorder of Developmentally Reduced Synaptic Connectivity. Arch Gen Psychiatry 57, 637-648.

McGrath, J, Saha, S, Welham, J, El Saadi, O, MacCauley, C \& Chant, D (2004). A systematic review of the incidence of schizophrenia: the distribution of rates and the influence of sex, urbanicity, migrant status and methodology. BMC Med 2, 13.

McGrath, J, Welham, J, Scott, J, Varghese, D, Degenhardt, L, Hayatbakhsh, MR, Alati, R, Williams, GM, Bor, W \& Najman, JM (2010). Association Between Cannabis Use and Psychosis-Related Outcomes Using Sibling Pair Analysis in a Cohort of Young Adults. Arch Gen Psychiatry 67, 440-447.

McGrath, JJ (2007). The surprisingly rich contours of schizophrenia epidemiology. Arch Gen Psychiatry 64, 14-6.

Morrison, AP, French, P, Parker, S, Roberts, M, Stevens, H, Bentall, RP \& Lewis, SW (2007). Three-year follow-up of a randomized controlled trial of cognitive therapy for the prevention of psychosis in people at ultrahigh risk. Schizophr Bul/33, 682-7. 


\section{Chapter 7}

Murray, RM, O'Callaghan, E, Castle, DJ \& Lewis, SW (1992). A neurodevelopmental approach to the classification of schizophrenia. Schizophr Bull 18, 319-32.

Myin-Germeys, I \& van Os, J (2007). Stress-reactivity in psychosis: evidence for an affective pathway to psychosis. Clinical Psychological Review 27, 409-24.

Palmer, BW, Bondi, MW, Twamley, EW, Thal, L, Golshan, S \& Jeste, DV (2003). Are lateonset schizophrenia spectrum disorders neurodegenerative conditions? Annual rates of change on two dementia measures. J Neuropsychiatry Clin Neurosci 15, 45-52.

Palmer, BW, Heaton, RK, Paulsen, JS, Kuck, J, Braff, D, Harris, MJ, Zisook, S \& Jeste, DV (1997). Is it possible to be schizophrenic yet neuropsychologically normal?

Neuropsychology 11, 437-46.

Palmer, BW \& Jeste, DV (1996). Neurodevelopmental theories of schizophrenia: application to late-onset schizophrenia. . Indian Journal of Psychiatry 38.

Pearlson, GD, Tune, LE, Wong, DF, Aylward, EH, Barta, PE, Powers, RE, Tien, AY, Chase, GA, Harris, GJ \& Rabins, PV (1993). Quantitative D2 dopamine receptor PET and structural MRI changes in late-onset schizophrenia. Schizophr Bull 19, 783-95.

Pedersen, CB \& Mortensen, PB (2001). Evidence of a dose-response relationship between urbanicity during upbringing and schizophrenia risk. Arch Gen Psychiatry 58, 1039-46.

Pokorny, AD \& Overall, JE (1970). Relationships of psychopathology to age, sex, ethnicity, education and marital status in state hospital patients. J Psychiatr Res 7, 143-52.

Rajji, TK, Ismail, Z \& Mulsant, BH (2009). Age at onset and cognition in schizophrenia: meta-analysis. BrJ Psychiatry 195, 286-93.

Rapoport, JL, Addington, AM, Frangou, S \& Psych, MRC (2005). The neurodevelopmental model of schizophrenia: update 2005. Mol Psychiatry 10, 434-449.

Raz, S, Goldstein, R, Hopkins, TL, Lauterbach, MD, Shah, F \& Porter, CL (1994). Sex differences in early vulnerability to cerebral injury and their neurodevelopmental implications. Psychobiology 22, 244-253.

Rivkin, P, Kraut, M, Barta, P, Anthony, J, Arria, AM \& Pearlson, G (2000). White matter hyperintensity volume in late-onset and early-onset schizophrenia. pp. 1085-1089. John Wiley \& Sons, Ltd.

Romans-Clarkson, SE, Walton, VA, Herbison, GP \& Mullen, PE (1990). Psychiatric morbidity among women in urban and rural New Zealand: psycho-social correlates. British Journal of Psychiatry 156, 84-91.

Rosenfield, PJ, Kleinhaus, K, Opler, M, Perrin, M, Learned, N, Goetz, R, Stanford, A, Messinger, J, Harkavy-Friedman, J \& Malaspina, D (2010). Later paternal age and sex differences in schizophrenia symptoms. Schizophr Res 116, 191-5.

Sachdev, P, Brodaty, H, Rose, N \& Cathcart, S (1999). Schizophrenia with onset after age 50 years. 2: Neurological, neuropsychological and MRI investigation. Br J Psychiatry 175, 416 21.

Seeman, MV (1996). The role of estrogen in schizophrenia. J Psychiatry Neurosci 21, 1237.

Selten, JP \& Cantor-Graae, E (2007). Hypothesis: social defeat is a risk factor for schizophrenia? British Journal of Psychiatry (Suppl.) 51, s9-12.

Sitskoorn, MM, Aleman, A, Ebisch, SJ, Appels, MC \& Kahn, RS (2004). Cognitive deficits in relatives of patients with schizophrenia: a meta-analysis. Schizophr Res 71, 285-95. 
Stefanis, NC, Thewissen, V, Bakoula, C, van Os, J \& Myin-Germeys, I (2006). Hearing impairment and psychosis: a replication in a cohort of young adults. Schizophrenia Research 85, 266-72.

Stein, LM \& Thienhaus, OJ (1993). Hearing impairment and psychosis. International Psychogeriatrics 5, 49-56.

Strawbridge, WJ, Wallhagen, MI, Shema, SJ \& Kaplan, GA (2000). Negative consequences of hearing impairment in old age: a longitudinal analysis. Gerontologist 40, 320-6.

Tambs, K (2004). Moderate effects of hearing loss on mental health and subjective wellbeing: results from the Nord-Trondelag Hearing Loss Study. Psychosom Med 66, 776-82. Thewissen, V, Myin-Germeys, I, Bentall, R, de Graaf, R, Vollebergh, W \& van Os, J (2005). Hearing impairment and psychosis revisited. Schizophrenia Research 76, 99-103.

Tuulio-Henriksson, A, Partonen, T, Suvisaari, J, Haukka, J \& Lonnqvist, J (2004). Age at onset and cognitive functioning in schizophrenia. BrJ Psychiatry 185, 215-9.

Vahia, IV, Palmer, BW, Depp, C, Fellows, I, Golshan, S, Kraemer, HC \& Jeste, DV (2010). Is late-onset schizophrenia a subtype of schizophrenia? Acta Psychiatr Scand van der Werf, M, Thewissen, V, Dominguez, MD, Lieb, R, Wittchen, H \& van Os, J (2010). Adolescent development of psychosis as an outcome of hearing impairment: a 10-year longitudinal study. Psychological Medicine, 1-9.

Van Os, J, Kenis, G \& Rutten, PF (2010). The Environment and schizophrenia. Nature In press.

van Winkel, R, Stefanis, NC \& Myin-Germeys, I (2008). Psychosocial stress and psychosis. A review of the neurobiological mechanisms and the evidence for gene-stress interaction.

Schizophrenia Bulletin 34, 1095-105.

Veen, ND, Selten, JP, van der Tweel, I, Feller, WG, Hoek, HW \& Kahn, RS (2004). Cannabis use and age at onset of schizophrenia. Am J Psychiatry 161, 501-6.

Venkatesh, BK, Thirthalli, J, Naveen, MN, Kishorekumar, KV, Arunachala, U, Venkatasubramanian, G, Subbakrishna, DK \& Gangadhar, BN (2008). Sex difference in age of onset of schizophrenia: findings from a community-based study in India. World Psychiatry 7, 173-6.

Verdoux, H, Geddes, J, Takei, N, Lawrie, S, Bovet, P, Eagles, J, Heun, R, McCreadie, R, McNeil, T, O'Callaghan, E, Stober, G, Willinger, M, Wright, P \& Murray, R (1997). Obstetric complications and age at onset in schizophrenia: an international collaborative metaanalysis of individual patient data. Am J Psychiatry 154, 1220-1227.

Walker, E, Shapiro, D, Esterberg, M \& Trotman, H (2010). Neurodevelopment and Schizophrenia. Current Directions in Psychological Science 19, 204-208.

Wallhagen, MI, Strawbridge, WJ, Shema, SJ, Kurata, J \& Kaplan, GA (2001). Comparative impact of hearing and vision impairment on subsequent functioning. J Am Geriatr Soc 49, $1086-92$.

WHO (2010). Deafness and hearing impairment. Fact sheet $\mathrm{N}^{\circ} 300$. World Health Organization.

Wiles, NJ, Zammit, S, Bebbington, P, Singleton, N, Meltzer, H \& Lewis, G (2006). Selfreported psychotic symptoms in the general population: results from the longitudinal study of the British National Psychiatric Morbidity Survey. BrJ Psychiatry 188, 519-26. 


\section{SUMMARY}

The aim of this thesis - Risk for psychosis: A Life Span Perspective - was to increase the understanding the developmental window of schizophrenia onset and its conributing factors across the whole age span.

Chapter 1 starts by emphasizing the importance of examining variation in risk of schizophrenia by age. Possible etiological mechanisms subserving the onset of psychosis throughout life are introduced. First, the neurodevelopmental model is introduced as one of the most influential models explaining risk for schizophrenia with early-onset. It is further proposed that variability in timing of onset among individuals arises in the context of interactions between neurobiological vulnerability and exposure to environmental risks. Finally, although neurodegeneration may sometimes precipitate the onset of psychosis in late life, arguments are brought forward against a pure neurodegenerative diathesis of late-onset psychosis. Instead it is proposed that other risk factors, or lack of risk factors, should be considered. In this context, the role of gonodal hormones and hearing impairment are discussed. Despite the firm conviction that examining variability in schizophrenia risk by age of onset yields important clues about the etiological underpinnings of schizophrenia, very few studies have specifically addressed this issue by systematically examining the age of onset distribution in samples covering the whole age span. Hence, this thesis was set out to study risk and its correlates for psychosis across the life span.

In Chapter 2 we investigated the distribution of schizophrenia risk by age and sex. Data from 43 non-overlapping samples, encompassing more than 100,000 cases of schizophrenia, was gathered through a comprehensive systematic review and individual participant meta-analysis of schizophrenia 
incidence studies. The results showed a sharp incidence peak at age 20-29 years. This peak was followed by a continuous risk decline up to age 60 where incidence rates leveled off to a non-significant risk difference. Although overall risk of developing schizophrenia was 1.2-fold greater in men than in women, marked sex differences were apparent in risk over the age span. Risk of schizophrenia was approximately two times greater in young men than in young women. On the contrary, due to a slower drop in risk after the initial risk peak in early adulthood, women showed a greater relative risk of schizophrenia from middle age. Differences in risk by age and sex could not be attributed to differences in methodology or population characteristics. Based on these results it was concluded that robust sex-differences exist in the distribution of risk for schizophrenia across the age span, suggestive of sex-linked differences in susceptibility to schizophrenia at different stages of life.

In Chapter 3 we examined the nature of the effect of age at onset on the pattern and severity of cognitive impairments in patients with schizophrenia spectrum disorder. Independent contributions of age at onset and related demographic and clinical characteristics to cognitive functioning were examined using data from 1053 patients with nonaffective psychotic disorder across the entire age at onset range. Participants aged 50 years and younger were recruited in the Genetic Risk and Outcome in Psychosis (GROUP) study, and participants aged 45 years and older were recruited for the parallel Psychosis in the Elderly (PSITE) study. Earlier onset of psychosis was associated with greater impairment in memory and sustained attention. Instead, male sex, negative symptoms and higher antipsychotic dose contributed to the more profound impairments in immediate recall in patients with earlier onset of psychosis, and differences in sustained attention by age at onset were explained by negative symptoms. The results suggest that greater impairment in memory and sustained attention in patients with early-onset psychotic 
Risk for Psychosis: A Life Span Perspective

disorder can be explained by features indicative of underlying neurodevelopmental vulnerability. Hence, it is argued that early age at onset, greater illness severity and the more profound impairments in memory and sustained attention may be the outcome of a shared underlying vulnerability of neurodevelopmental origin.

The aim of the study described in Chapter 4 was to replicate the association between hearing impairment and psychosis and to examine the effect of age on this association. For this, data was used from 848 individuals (aged 33 to 89 years) recruited within the first two waves of the Maastricht Aging Study (MAAS), a longitudinal general population study conducted in Maastricht, the Netherlands. Participants with self-perceived hearing problems (and not those whose hearing impairment was objectively determined) had more paranoid ideation and hallucinatory experiences than participants without hearing complaints. In addition, this association was much stronger in younger than in older individuals. Finally, there was no evidence for a mediating effect of depressive feelings in the association between hearing impairment and psychotic experiences. It was concluded that self-perceived hearing impairment, rather than the true and objective measured hearing impairment, contributes to the development of psychotic experiences in young rather than in older individuals. The association between hearing impairment and psychosis may thus be age-dependent one.

Further evidence for an age-specific association between hearing impairment and psychotic symptoms was supplied in Chapter 5. The hypothesis that adolescent hearing impairment would be associated with an increased risk of psychotic symptoms was examined in the Early Developmental Stages of Psychopathology Study (EDSP), a population sample of originally 3021 adolescents and young adults in Munich. Selfreported hearing impairment was associated with psychotic symptoms that 
were assessed using a diagnostic interview administered by clinical psychologists. In addition, the effect of hearing impairment was confined to adolescents (aged 14-17). These results suggest that disruption of development at a critical adolescent phase, possibly in interaction with other personal and social vulnerabilities, may increase the risk for psychotic symptoms.

Building on the previous results, the aim of Chapter 6 was to examine underlying mechanisms of the link between hearing impairment and psychosis. Considering the importance of the social environment in risk for psychotic symptoms, it was postulated that difficulties in processing complex stimuli in the social environment would contribute to risk for psychosis in hearing-impaired individuals. The hypothesis that higher levels of social complexity, conceptualized as 'urbanicity', would moderate psychosis risk in individuals with objective hearing impairment was examined using data from 1823 participants in the MAAS study. The association between hearing impairment and psychosis was conditional on level of urbanicity, i.e. the effect of hearing impairment was confined to individuals living in highly urbanized areas. Higher levels of social isolation and loneliness could not explain the association. These results suggest that complexities of the social world, in interaction with the individual's ability to correctly process this information, may be one of the driving forces behind psychosis risk.

Finally, Chapter 7 rounds off by discussing the results of the studies described in this thesis, and by integrating the most striking findings into a lifespan perspective on risk for psychosis. It is postulated that the window of illness onset is shaped by the convergence of early developmental vulnerability, later maturational and environmental influences and underlying hormonal and age-related brain changes. 
SAMENVATTING

Het doel van dit proefschrift - Risk for psychosis: A Life Span Perspective - was het verhogen van het begrip ten aanzien van het ontstaan van psychose over de gehele levenspanne heen en de factoren die aan dit risco bijdragen.

Hoofdstuk $l$ begint met het benadrukken van het belang van het bestuderen van variatie in risico voor schizofrenie met leeftijd. Verschillende etiologische mechanismsen die ten grondslag liggen kunnen liggen aan het ontstaan van psychose gedurende het leven worden besproken. Als eerste wordt het neuro-ontwikkelingsmodel geïntroduceerd als een van de meest gezaghebbende modellen voor het verklaren van het ontstaan van schizofrenie vroeg in het leven. Individuele variabiliteit in timing van ontstaan van psychose ontstaat dan mogelijk als gevolg van interacties tussen neurobiologische kwetsbaarheid en blootstelling aan risicos in de omgeving. Ondanks dat neurodegeneratieve processen soms het ontstaan van psychose kunnen uitlokken op latere leeftijd, wordt er afsluitend beargumenteerd dat een puur neurodegeneratieve oorsprong van laat-ontstane psychose onwaarschijnlijk is. In plaats daarvan zullen andere risicofactoren, of juist een gebrek aan deze risicofactoren, in overweging genomen moeten worden bij het ontstaan van psychose op latere leeftijd. Sex hormonen en slechthorendheid worden aangehaald als mogelijke moderators van variabiliteit in risico over de levenspanne heen. Ondanks de sterke overtuiging dat het bestuderen van leeftijdspecifieke variatie in het risico voor schizofrenie belangrijke aanwijzingen levert voor haar etiologische fundering, zijn er nog maar zeer weinig studies die dit systematisch hebben bestudeerd over de gehele levenspanne heen. Dit proefschrift is daarom opgezet om het risico voor psychose te bestuderen over de gehele levenspanne heen. 
Summary

In Hoofdstuk 2 onderzochten we de verdeling van het risico op schizofrenie over leeftijd en geslacht heen. Data van totaal 170.000 patienten met schizofrenie, verzameld binnen 43 onafhankelijke samples, werd verzameld door middel van een uitgebreide systematische review en individuele participant meta-analyse van schizofrenie incidentie studies. De resultaten lieten een scherpe incidentie piek zien tussen 20-29 jaar. Deze piek werd gevolgd door een continue afname in risico tot aan het $60^{\mathrm{e}}$ jaar waar verdere afname stagneerde. Hoewel het totale risico voor schizofrenie 1,2 keer zo groot was in mannen dan in vrouwen waren er duidelijke sexe verschillen aanwezig in het risico voor schizofrenie over de levenspanne heen. Op jonge leeftijd was het risico voor schizofrenie ongeveer twee keer zo groot in mannen dan in vrouwen. Echter, door een tragere afname in risico na de initiele piek op jongvolwassen leeftijd in vrouwen, hadden vrouwen een groter risico voor schizofrenie op middelbare en oudere leeftijd dan mannen. Tegen de verwachtingen in, werd er geen bewijs gevonden voor de vaak gerapporteerde tweede incidentie piek in vrouwen van middelbare leeftijd. De verschillen in risico over leeftijd en geslacht konden niet toegeschreven worden aan verschillen in methodologie of bevolkingskarakteristieken. Er blijken dus robuuste sexe verschillen te bestaan in de verdeling van het risico voor schizofrenie over de levenspanne heen. Deze bevindingen doen vermoeden dat aan sexgekoppelde (of aan sex-gerelateerde) mechanismen een rol spelen bij het ontstaan van kwetsbaarheid voor schizofrenie gedurende verschillende fasen van het leven.

In Hoofdstuk 3 onderzochten we de aard van het effect van leeftijd van ontstaan van psychose op het patroon en de ernst van de cognitieve beperkingen in patienten met een niet-affectieve psychotische stoornis. Onafhankelijke bijdragen van leeftijd van ontstaan, demografische en klinische eigenschappen aan het cognitieve functioneren werd onderzocht in een sample van 1053 patienten met een niet-affectieve psychotische 
stoornis over de gehele range van leeftijd van ontstaan. Deelnemers van 50 jaar en jonger werden geworven binnen de Genetic Risk and Outcome in Psychosis (GROUP) studie, en deelnemers van 45 jaar en ouder binnen de parallelle Psychosis in the Elderly (PSITE) studie. Een vroeger ontstaan van psychose was geassocieerd met grotere beperkingen op geheugen en volgehouden aandacht. Echter, mannelijk geslacht, negatieve symptomen en hoger antipsychotica gebruik droegen volledig bij aan de ernstigere geheugenproblemen in patienten met een vroeg-ontstane psychose. Verschillen in ernst van problemen of volgehouden aandacht tussen patienten werden verder geheel verklaard door negatieve symptomen. Deze klinische en demografische eigenschappen worden beschouwd als markers voor een onderliggend probleem tijdens de vroege neuro-ontwikkeling. De resultaten laten daarom zien dat een vroeg ontstaan van psychose en ernstige cognitieve beperkingen waarschijnlijk voortkomen uit een gedeelde onderliggende kwetsbaarheid tijdens de vroege ontwikkeling.

Het doel van de in Hoofdstuk 4 beschreven studie was om enerzijds de associatie tussen slechthorendheid en psychose te repliceren en anderzijds om het effect van leeftijd binnen deze associatie te bestuderen. Data van 848 deelnemers (leeftijd 33-89 jaar), geworven voor de eerste twee meetmomenten van een longitudinale bevolkingsstudie in Maastricht (de Maastricht Aging Study; MAAS), werd gebruikt. Deelnemers met subjectief ervaren gehoorsproblemen hadden meer paranoide ideeen en hallucinatoire ervaringen dan deelnemers zonder klachten van het gehoor. De associatie was veel sterker in jongeren dan in ouderen. Als laatse bleken depressieve gevoelens de associatie tussen slechthorendheid en psychotische ervaringen niet te kunnen verklaren. Deze bevindingen laten zien dat de subjectieve ervaring van slechthorendheid, en niet de objectief gemeten slechthorendheid, bijdraagt aan het ontwikkelen van psychotische ervaringen in jongeren en niet in ouderen. De associatie tussen slechthorendheid en psychose is dus waarschijnlijk leeftijdsafhankelijk. 
Aanvullend bewijs voor een leeftijdsspecifieke associatie tussen gehoorsproblemen en psychotische symptomen werd geleverd in Hoofdstuk 5. De hypothese dat met name slechthorendheid tijdens de adolescentie geassocieerd zou zijn met een verhoogd risico op psychotische symptomen werd onderzocht binnen een algemene bevolkingstudie van 3021 adolescenten en jongvolwassen in München, Duitsland (Early Developmental Stages of Psychopathology Study; EDSP). Zelf-gerapporteerde slechthorendheid was geassocieerd met psychotische symptomen zoals gemeten middeld een diagnostisch interview door klinisch psychologen. Het effect van slechthorendheid op psychose was beperkt tot adolescenten (leeftijd 14-17). Deze resultaten geven aan dat verstoringen tijdens de kritische ontwikkelingsfase in adolescentie, in interactie met andere persoonlijke en sociale kwetsbaarheden, het risico verhoogt op psychotische symptomen.

Voortbouwend op de vorige resultaten was het doel van Hoofdstuk 6 om de onderliggende mechanismen van het verband tussen gehoorsproblemen en psychose te onderzoeken. Gezien de belangrijke bijdrage van de sociale omgeving in het ontstaan van psychose werd er verondersteld dat problemen bij het verwerken van complexe stimuli in de sociale omgeving zouden kunnen bijdragen aan het verhoogde risico op psychose in slechthorenden. De hypothese dat een hoger niveau van sociale complexiteit (geconceptualiseerd als verstedelijking) het risico op psychose bij mensen met een gehoorsprobleem zou modereren werd onderzocht binnen 1823 deelnemers aan de MAAS studie. Zoals verwacht was de associatie tussen slechthorendheid en psychose afhankelijk van het niveau van verstedelijking; het effect van slechthorendheid op psychose was beperkt tot personen die in sterk verstedelijkte gebieden woonden. De resultaten tonen aan dat de complexiteit van de sociale wereld in combinatie met de persoonlijke mogelijkheden om deze informatie correct 
Risk for Psychosis: A Life Span Perspective

te verwerken een van de stuwende krachten is achter het risico op psychose.

Hoofdstuk 7 sluit af met een discussie over de beschreven studies binnen dit proefschrift. De belangrijkste bevindingen worden geïntegreerd tot een levenspan perspectief op het risico op psychose. Er wordt beargumenteerd dat verschillen in timing van het ontstaan van psychose hun oorsprong hebben in verschillen in kwetsbaarheid tijdens de vroege ontwikkeling, de latere rijping van het brein, omgevingsinvloeden en onderliggende hormonale en leeftijdsgerelateerde hersenveranderingen. 


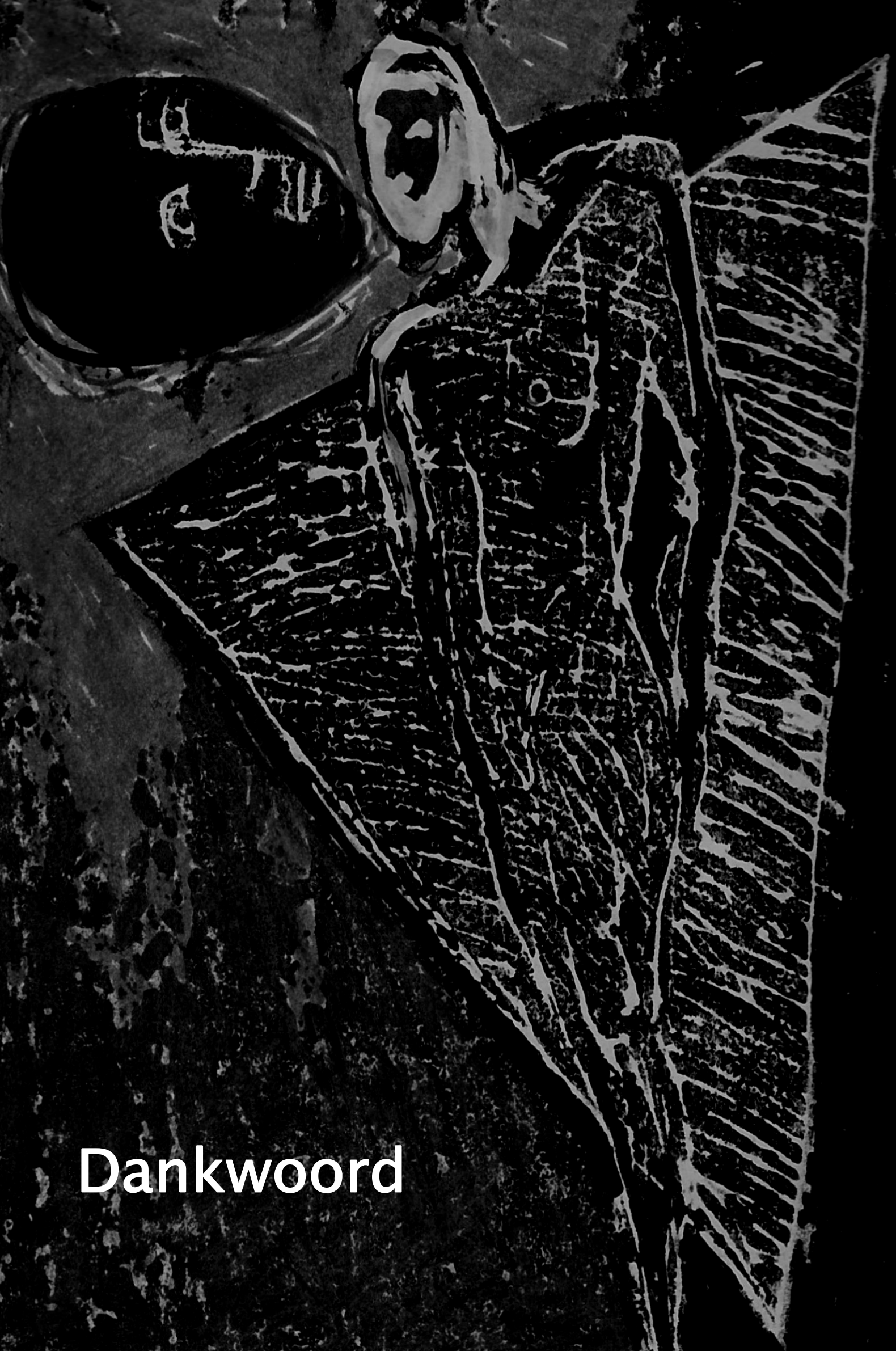




\section{BEDANKT}

Promoveren was vooral veel wachten. Op plekken als Brussel-Noord, het fietscafé in Gastel, Heerenveen in de regen, met of zonder volle tassen bij bushaltes terwijl schapen mekkerden en de zon gaten in mijn hoofd scheen. Voordat ik iedereen bedank, gaat dan als eerste ook mijn dank uit naar meneer Yorke, meneer Young en Waits en vele anderen zonder wie dit wachten minder draaglijk zou zijn geweest.

Mijn dank gaat uit naar mijn eerste promotor Prof. Dr. Jim van Os. Jim bedankt voor la grande vitesse, je gedrevenheid en besmettelijk enthousiasme om de wetenschap 'sexier' te maken. Ik heb ontzettend veel van je geleerd. Ook wil ik mijn tweede promotor Prof. Dr. Frans Verhey bedanken. Beste Frans bedankt voor de tweewekelijkse bijeenkomsten met koffie en raad, voor je rust en je klinische blik. Ruud merci voor je humor, je geduld en de kostbare vrije tijd die je hebt vrij gemaakt tussen kinderen en verbouwingen door. En Sebastian natuurlijk. Voor alle weloverwogen enthousiaste en statistische puntjes op de $i$, voor je rustige persoonlijkheid en vooral voor je geduld om te blijven luisteren naar de stroom van mijn soms chaotische brein. De ritjes van her naar der in de auto heb ik zeer gewaardeerd. Judith thank you so much for being so tediously, cautiously, hilariously, Scottishly and humorously helpful! Cheers! Martin van Boxtel bedankt voor het vertrouwen dat je me hebt gegeven om destijds te gaan promoveren. Ron bedankt voor het terugvinden van alle kwijtgemaakte en per ongeluk verwijderde bestanden en voor het reanimeren van mijn door groene thee gedoopte laptop.

Bedankt Petra voor je tegen beter weten in niet aflatende zelfvertrouwen dat je me hebt gegeven tijdens al die jaren dat we samenwerkten- van het kamertje zonder ramen op de drTans tot het kamertje met de loeiende grote PC schermen. Ik mis je nu al. En Nele, ach Nele, eigenlijk zou ik je 


\section{Dankwoord}

twee keer moeten bedanken. Voor de gezelligheid, de kaasplankjes, terrasjes, de goede gesprekken en voor de kennismaking met een bepaald persoon. Daarom, Nele, ach Nele, eigenlijk zou ik je twee keer moeten bedanken. Voor de gezelligheid, de kaasplankjes, terrasjes, de goede gesprekken en voor de kennismaking met een bepaald persoon.

Collega's van Divisie 1 en Divisie 2 bedankt voor de logeeraanbiedingen, kattenopvang, biertjes in de kroeg, muziektips, dansjes op de vloer, steeds later wordende terrasjes, sinterklaas met dobbelstenen, nachtelijke opvang voor enge bovenbuurmannen en al het andere dat binnen of buiten werktijd werd gedaan.

Zonder vrienden, familie en vooruit huisdieren geen rust en vertrouwen om dit boekje te schrijven. Dus ... lieve Elke, Anouk, Onno, Eva, Irene, Imme, Daan, Claar, Dor, Esther, LL en Marie (en iedereen die ik vergeten bent) bedankt voor dat beetje extra hilariteit in mijn leven, voor de tijgervrouwen in de dierentuin, wandelingen van station naar station, hutspot, tennisrackets, opgewonden gesprekken in de Edd's, late snacks \& rode wijn, het ongegeneerd dansen en meezingen op nostalgische muziek en het gevoel van geborgenheid dat ik van jullie krijg. Lieve Mart wanneer gaan we weer eens zingend door de keiharde regen fietsen om daarna weer iets met mais te eten en rode wijn te drinken? Lieve Jan, ik ben zo blij dat we elkaar nog steeds kennen, iets ouder en soms wijzer, maar gelukkig nooit minder dan vroeger. Lieve Marieke. Op een verlaten station in Brussel terwijl we alle treinen missen, in de regen in Schotland, in de regen in lerland, of zwoegend en zwetend in Italie: Ik wil zingen voor wie ik liefheb. Waar dan ook. En dat zullen we altijd blijven doen.

Opgewonden brommend, spinnend, bijtend, klauwend in blote voeten, klagend miauwend door lege gangen en springend tegen muren. Ach Henk, een leven met jou is zelden saai. En ach Bettie wat ben ik blij dat jij er bent 
Risk for Psychosis: A Life Span Perspective

om Henk te temmen zodat het boekje daadwerkelijk ook afgerond kon worden.

Lieve Marius. Nog bedankt voor het vroege ophalen van het vliegveld toen, voor je geduld met mij, en met Henk en Bettie hangend aan je blote benen. Bedankt voor je soms onuitstaanbare en onnavolgbare verbale woordenbrei. Zonder jou was ik niet half zo ontspannen. Zus, lieve sterke zus, moeder van mijn favoriete neefje, maar boven alles mijn liefste luisterend oor, tegen de klippen op tegen de keer. Lieve mama. Bedankt voor de enveloppen vol met uitgescheurde stukjes wetenschap, muziek en vertrouwen. Voor alles dat je blijft geven. Lieve papa. Zonder jou had ik geen hoofd vol met verhalen en teksten gehad. Zonder jou had ik nooit leren kijken, had ik nooit gezien hoe mooi de lelijkheid kan zijn. Zonder jou had ik nooit beseft hoe verwarrend de wereld en de tijd kan zijn. Papa, lieve papa, zonder jou was ik niet geworden wie ik nu ben. 


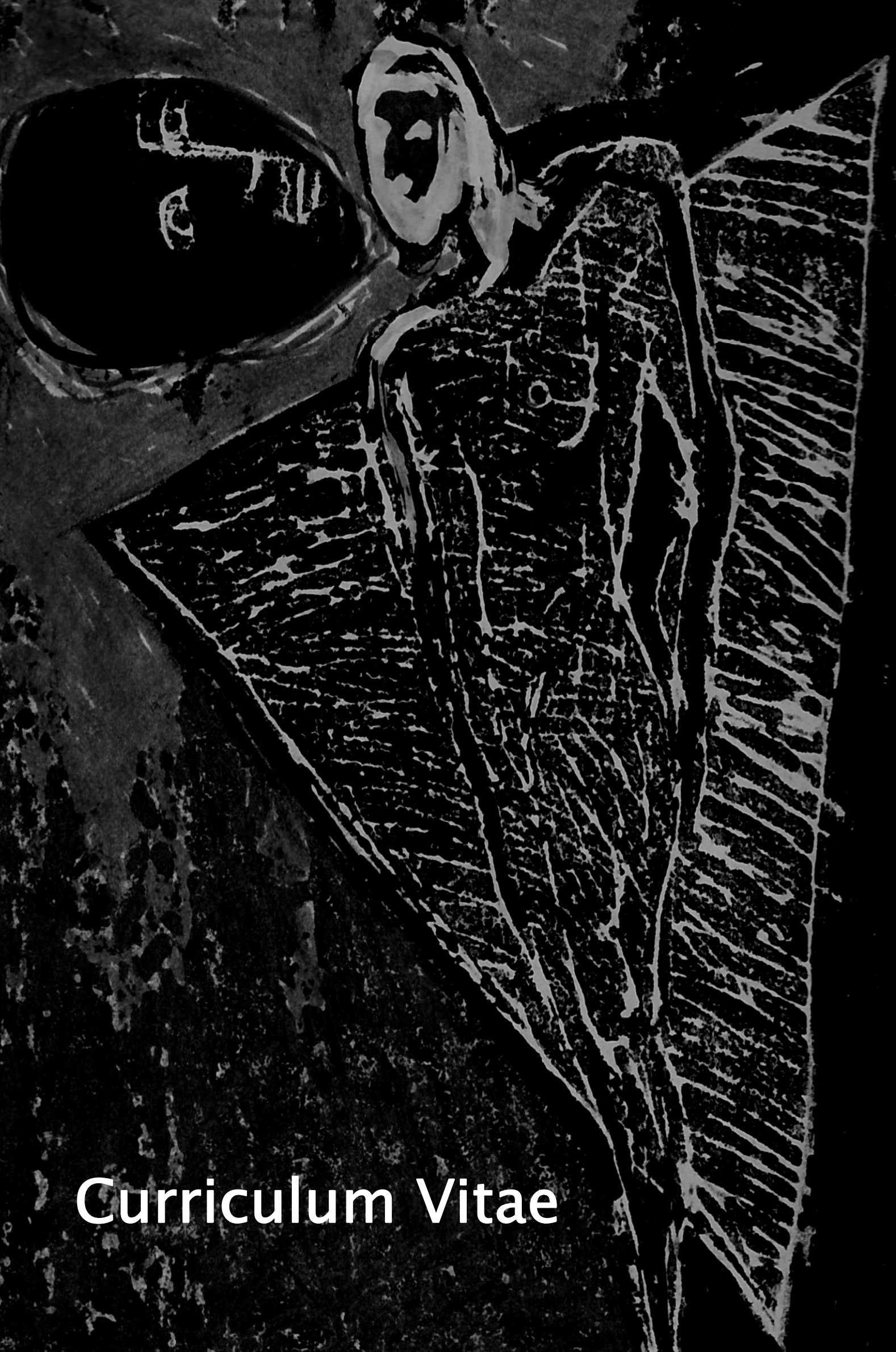


Margriet van der Werf werd op 6 mei 1981 geboren in Arnhem. Na het behalen van haar VWO diploma op het (voormalige) Van Lingen College te Arnhem startte ze in 1999 met de opleiding Geneeskunde aan de Universiteit Maastricht waar zij in 2006 haar diploma behaalde. Tevens startte ze in 2000 met de opleiding Psychologie, waar zij in 2004 haar diploma haalde binnen de afstudeerrichting neuropsychologie. Haar gecombineerde wetenschapsstage voor Geneeskunde en Psychologie volgde zij bij de vakgroep Psychiatrie en Neuropsychologie van de Universiteit Maastricht. In oktober 2006 begon zij als promovendus op het promotietraject 'Psychose bij Ouderen' bij de vakgroep Psychiatrie en Neuropsychologie, School for Mental Health and Neurosciences. Sinds december 2010 werkt ze als revalidatiearts in opleiding bij het VU Medisch Centrum te Amsterdam en woont ze samen met Marius (en Henk en Bettie) in Utrecht. 


\section{PUBLICATIONS AND PRESENTATIONS}

\section{Publications}

van der Werf, M., van Winkel, R. van Boxtel, M. and van Os., J. (2010) Evidence that the impact of hearing impairment on psychosis risk is moderated by the level of complexity of the social environment. Schizophrenia Research. 2010;122(1):193-198.

van der Werf, M., Thewissen, V., Gracia-de Dominguez, M., Lieb, R., Wittchen, H and van Os, J. (2010) Adolescent psychosis as an outcome of hearing impairment in a 10-year longitudinal study. Psychological Medicine, doi:10.1017/ S0033291710000978

Kohler, S., van der Werf, M., Hart, B., Morrison, G., Kirkpatrick, B., Verkaaik, M., Krabbendam, L., Verhey, F., van Os, J. and Allardyce, J. (2009). Evidence that better outcome of psychosis in women is reversed with increasing age of onset: a populationbased 5-year follow-up study. Schizophrenia Research, 113 (2-3), 226-232.

van der Werf, M., van Boxtel, M., Verhey, F., Jolles, J., Thewissen, V., \& van Os, J. (2007). Mild hearing impairment and psychotic experiences in a normal aging population. Schizophrenia Research, 94(1-3), 180-186

\section{Submitted papers}

van der Werf M, Köhler S, Verkaaik M, Verhey, F., van Winkel, R., van Os, J. And GROUPinvestigators. Cognitive functioning and age at onset in non-affective psychotic disorder. Submitted.

\section{In preparation}

van der Werf, M., Hanssen, M., Köhler, S., Verkaaik, M., Verhey, F., RISE-investigators, van Winkel, R., van Os, J. and Allardyce, J. Sex differences in schizophrenia risk across the age span: an individual participant meta-analysis of 117,000 incident cases. 


\section{List of Publications}

\section{Oral presentations}

van der Werf, M. (2011). Kwetsbaarheid voor psychose: een levensloop-benadering. 39e Voorjaarscongres van de Nederlandse Vereniging voor Psychiatrie (NVVP), Maart, Amsterdam, Nederland.

van der Werf, M., Köhler, S., Verhey, F. and van Os, J. (2011). Het effect van leeftijd van ontstaan op het cognitieve profiel van patienten met een schizofrenie spectrum stoornis. 39e Voorjaarscongres van de Nederlandse Vereniging voor Psychiatrie (NVVP), April, Amsterdam, Nederland.

van der Werf, M., Köhler, S., Verkaaik., M., Verhey, F. and van Os, J. (2010). Age of onset and neurocognitive functioning in psychosis. Federation of European Neuropsychological Federation, September $22^{\text {nd }}$ Amsterdam, the Netherlands.

van der Werf, M., Hanssen, M, Köhler, S., Verkaaik, M., Verhey, F., van Os, J. en Allardyce, J. (2010). Schizofrenie bij ouderen zeldzaam? Een systematische review en meta-analyse van incidentie naar laat-ontstane schizofrenie. 38 e Voorjaarscongres van de Nederlandse Vereniging voor Psychiatrie (NVVP), April, Maastricht, Nederland.

van der Werf, M., Hanssen, M, Köhler, S., Verkaaik, M., Verhey, F., van Os, J. and Allardyce, J. (2009). A systematic review and standardized recalculation of incidence rates for late onset schizophrenia. 14th Congress of the International Psychogeriatric Association (IPA), September 1st-5th 2009, Montreal, Canada.

van der Werf, M., Thewissen, V., Lieb, R., Wittchen, H.U. and van Os, J. (2009). Deafness as a predictor of psychosis outcome in a young population sample. 12th International Congress of the International Federation of Psychiatric Epidemiology (IFPE), April 16th - 19th, Vienna, Austria.

van der Werf, M., Köhler, S., Krabbendam, L., Verhey, F., Driessen, G., Allardyce, J. and van Os, J. (2008). Battle of the sexes: is het latere ontstaan van schizofrenie bij vrouwen onafhankelijk van burgerlijke staat? 36e Voorjaarscongres van de Nederlandse Vereniging voor Psychiatrie (NVVP), April, Amsterdam, Nederland.

van der Werf, M., van Boxtel, M. Verhey, F., Thewissen, V. en van Os, J. (2007) Gehoorsbeperking en de relatie met het ontstaan van psychose in een normal verouderende populatie. 35e Voorjaarscongres van de Nederlandse Vereniging voor Psychiatrie (NVVP), April, Maastricht, Nederland. 
